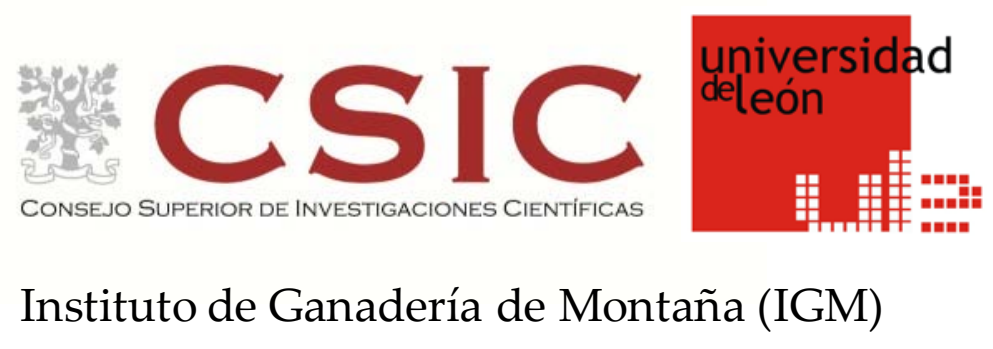

\author{
EFECTO DE LA ADICIÓN DE LÍPIDOS A LA DIETA DE \\ OVEJAS LECHERAS SOBRE LOS MICROORGANISMOS \\ IMPLICADOS EN EL METABOLISMO RUMINAL DE LOS \\ ÁCIDOS GRASOS Y LA REGULACIÓN NUTRICIONAL DE \\ LA LIPOGÉNESIS MAMARIA
}



EFECTO DE LA ADICIÓN DE LÍPIDOS A LA DIETA DE OVEJAS LECHERAS SOBRE LOS MICROORGANISMOS IMPLICADOS EN EL METABOLISMO RUMINAL DE LOS ÁCIDOS GRASOS Y LA REGULACIÓN NUTRICIONAL DE LA LIPOGÉNESIS MAMARIA

EFFECT OF THE ADDITION OF LIPIDS TO THE DIET OF DAIRY EWES ON THE MICROORGANISMS INVOLVED IN RUMEN FATTY ACID METABOLISM AND THE NUTRITIONAL REGULATION OF MAMMARY LIPOGENESIS

Memoria de Tesis Doctoral presentada por Tamara Castro Carrera dirigida por Dr. Álvaro Belenguer Ferrando y Dr. Pablo Gutiérrez Toral para acceder al grado de Doctor, dentro del programa de Doctorado "Medicina, Sanidad y Producción Animal y Ciencia de los Alimentos" de la Universidad de León. León, diciembre de 2014 

La autora de esta memoria ha disfrutado de una ayuda del Programa JAE Predoc para la formación de personal investigador del Consejo Superior de Investigaciones Científicas (CSIC) cofinanciada por el Fondo Social Europeo.

El Ministerio de Economía y Competitividad (MINECO), a través del Proyecto AGL2011-23700, ha aportado la mayor parte de la financiación necesaria para llevar a cabo los trabajos que componen esta memoria. La Junta de Castilla y León también ha contribuido gracias al Proyecto CSI023U13. 

Deseo expresar mi agradecimiento a todas las personas e instituciones que han puesto a nuestra disposición sus conocimientos y los medios necesarios para la realización de este trabajo. 

CONTENIDOS 



\section{ÍNDICE}

Página

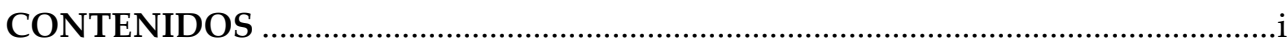

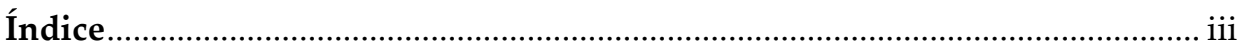

Índice en inglés ............................................................................................... vii

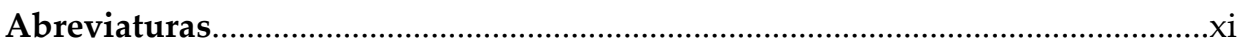

Abreviaturas en inglés ......................................................................................

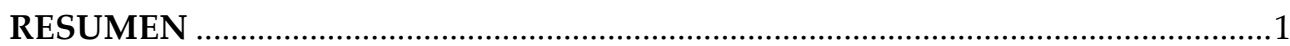

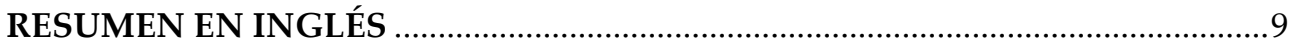

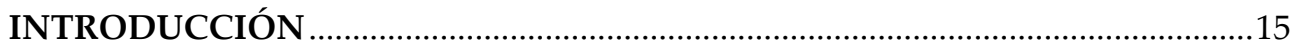

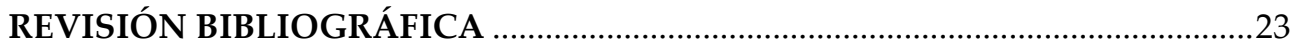

1. Mecanismos responsables de la composición de ácidos grasos de la

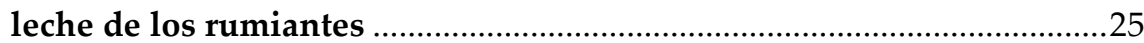

1.1. Origen metabólico de los lípidos de la leche ................................................25

1.2. Efecto de la alimentación sobre el perfil de ácidos grasos de la leche........27

2. Microbiología del metabolismo de los lípidos en el rumen ...........................29

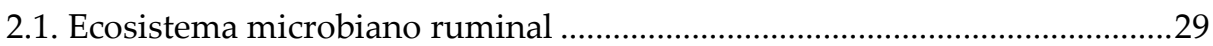

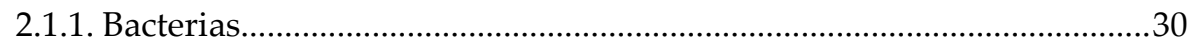

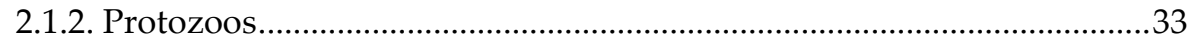

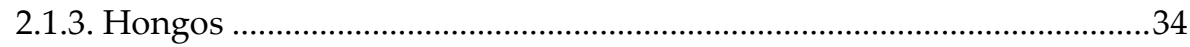

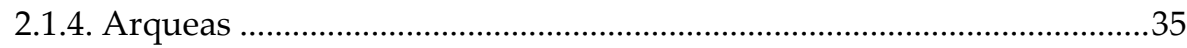

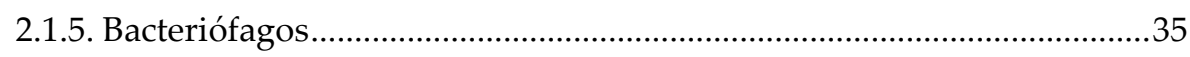

2.2. Procesos metabólicos y microorganismos implicados .................................36

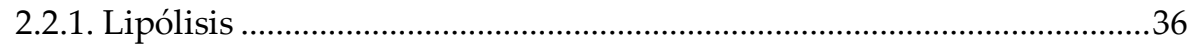

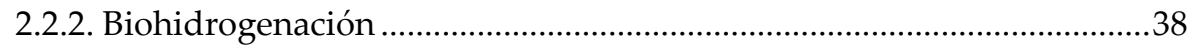

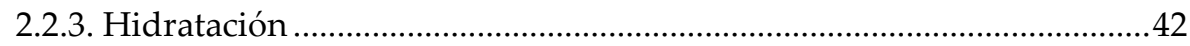

2.2.4. Efecto de la alimentación .....................................................................4

2.3. Técnicas de estudio de la comunidad microbiana ruminal ..........................46

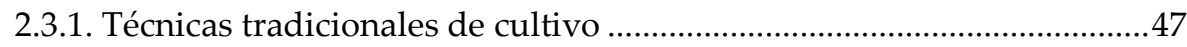

2.3.2. Técnicas basadas en biología molecular ....................................................4 48

2.3.2.1. Técnicas de identificación de la huella genética ...............................50

2.3.2.2. Técnicas basadas en la secuenciación ...............................................53

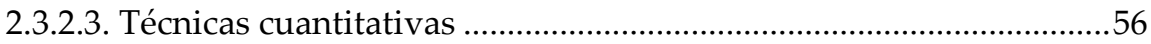


3. Metabolismo de los lípidos en los tejidos del animal en lactación 60

3.1. Tejido secretor mamario 60

3.1.1. Síntesis de ácidos grasos de novo. .61

3.1.2. Captación de los ácidos grasos circulantes en el plasma ....................... 63

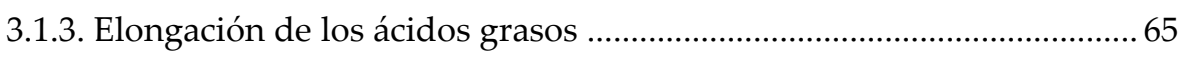

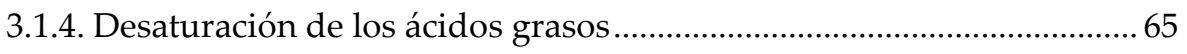

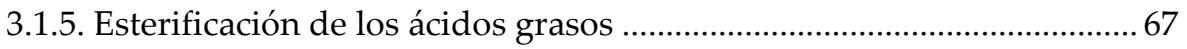

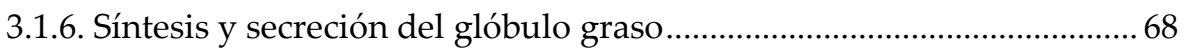

3.1.7. Factores de transcripción implicados en la regulación nutricional de

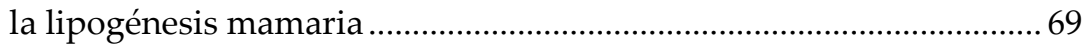

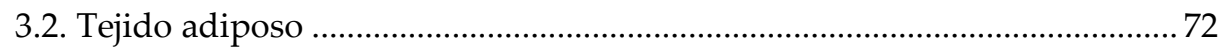

3.3. Técnicas de estudio de la expresión de los genes ......................................... 74

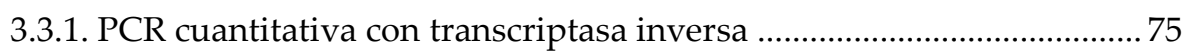

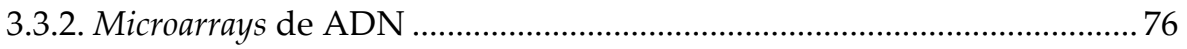

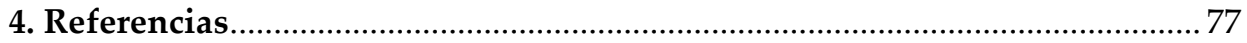

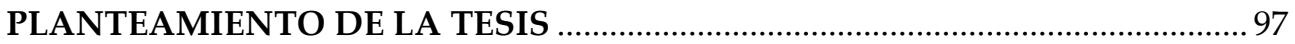

PRUEBA I - Cambios en la población ruminal de Butyrivibrio en ovejas lecheras alimentadas con una dieta suplementada con aceite de girasol y

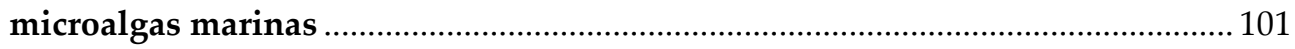

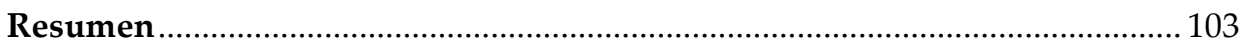

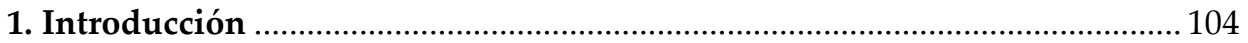

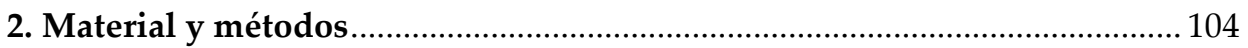

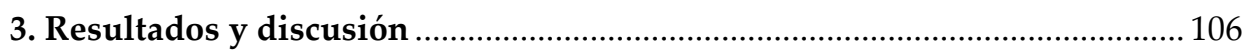

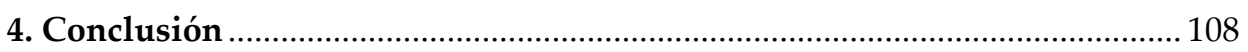

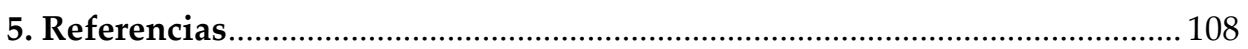

PRUEBA II - Utilización de la pirosecuenciación 454 y el polimorfismo de la longitud de los fragmentos terminales de restricción para evaluar la comunidad bacteriana ruminal en ovejas lecheras alimentadas con

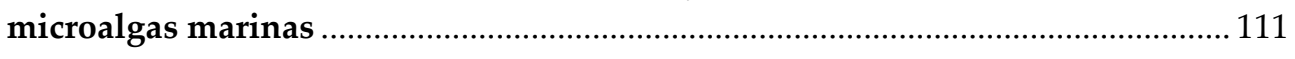

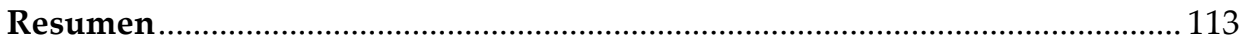

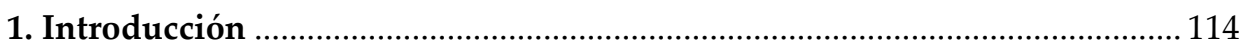

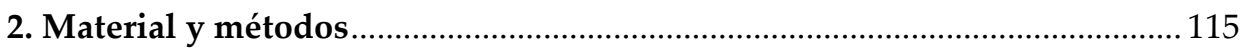

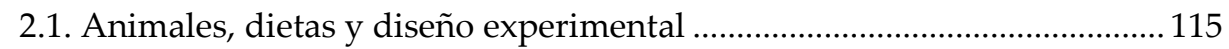

2.2. Medidas, recogida de muestras y análisis .................................................. 116

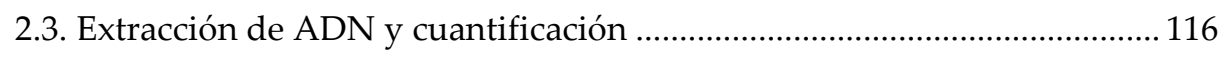

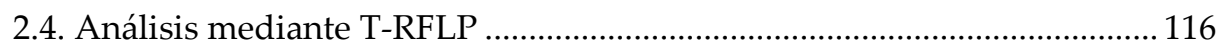


2.5. Pirosecuenciación y análisis de secuencias 117

2.6. Análisis estadísticos .118

3. Resultados 119

3.1. Análisis de la comunidad bacteriana mediante T-RFLP . 119

3.2. Análisis de la comunidad bacteriana mediante pirosecuenciación 123

4. Discusión. 127

5. Conclusiones .131

6. Referencias 131

7. Material suplementario 134

PRUEBA III - Enriquecimiento en Quinella ovalis de suspensiones de microorganismos ruminales y su cultivo in vitro. 139

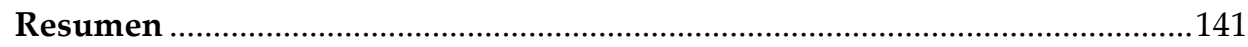

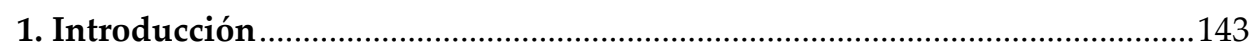

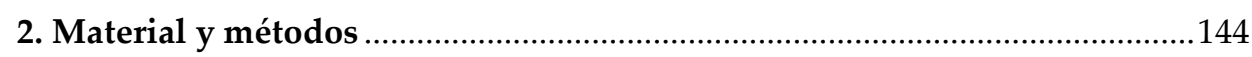

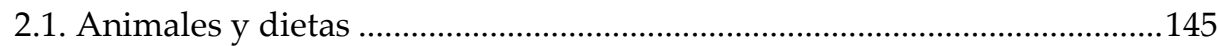

2.2. Obtención de la fracción enriquecida en QO ............................................145

2.3. Cultivos discontinuos de microorganismos ruminales...............................147

2.4. Toma de muestras .......................................................................................149

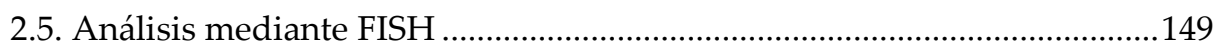

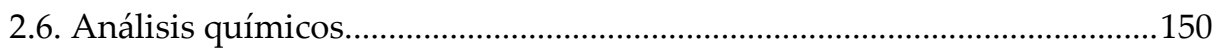

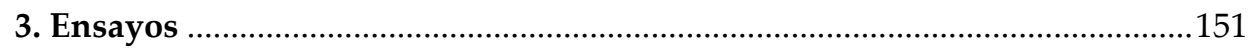

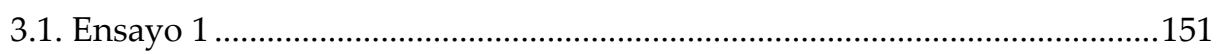

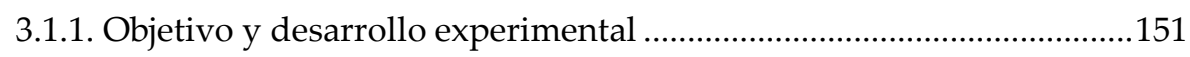

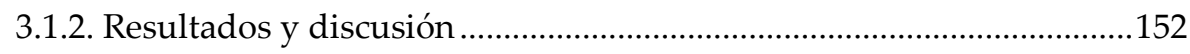

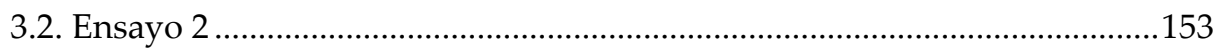

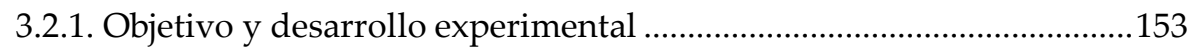

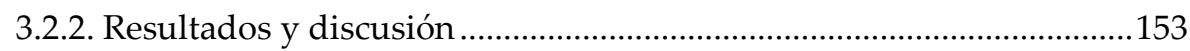

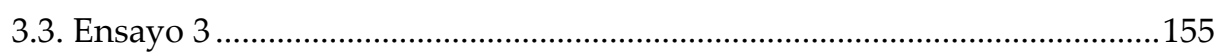

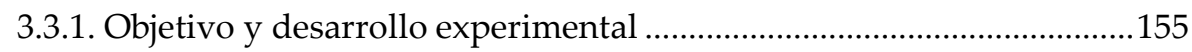

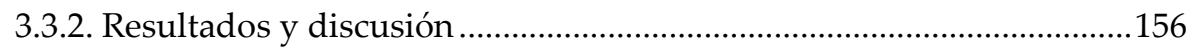

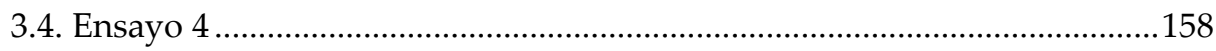

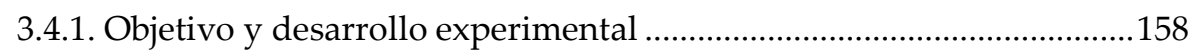

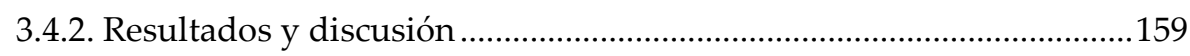

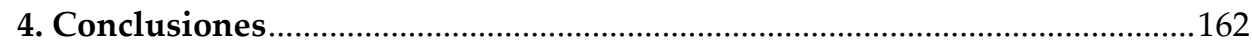

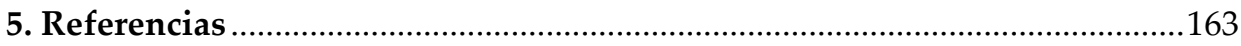


PRUEBA IV - La suplementación de la dieta de ovejas con aceite de girasol modula la composición de ácidos grasos de la leche sin cambios importantes en el perfil de ácidos grasos de los tejidos mamario y adiposo o en la abundancia del ARNm de los genes relacionados.

Resumen

1. Introducción 168

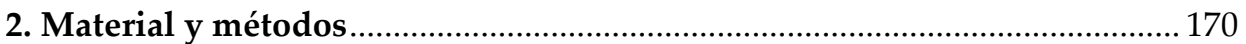

2.1. Animales, diseño experimental y manejo ...................................................... 170

2.2. Medidas y recogida de muestras ................................................................... 170

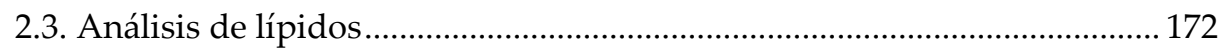

2.4. Aislamiento de ARN y PCR cuantitativa ...................................................... 172

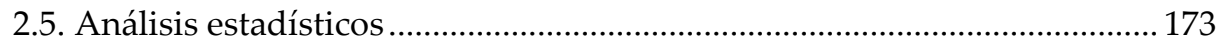

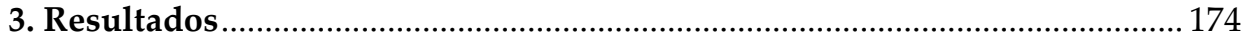

3.1. Rendimiento productivo y composición y secreción de ácidos grasos en la leche ........................................................................... 174

3.2. Composición de ácidos grasos de los tejidos mamario y adiposo.............. 178

3.3. Abundancias de ARNm de los genes candidatos en los tejidos mamario y adiposo ................................................................................ 178

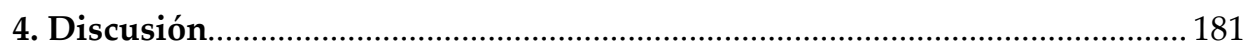

4.1. Rendimiento productivo y composición y secreción de ácidos grasos en la leche .................................................................................. 181

4.2. Metabolismo lipídico en la glándula mamaria............................................ 182

4.3. Metabolismo lipídico en el tejido adiposo .................................................... 184

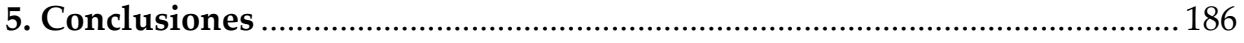

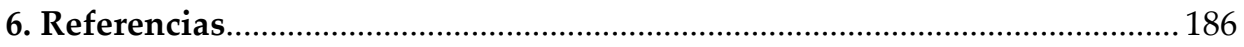

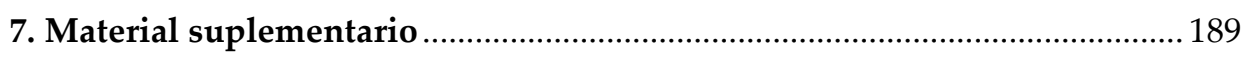

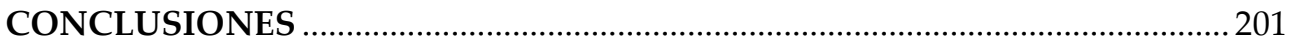

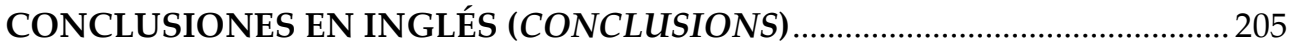




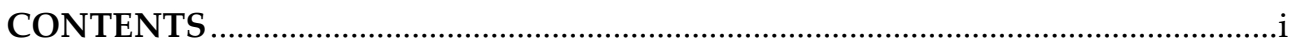

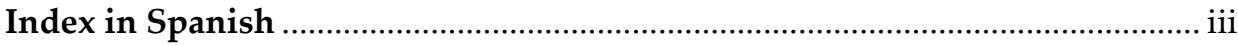

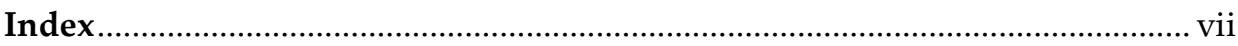

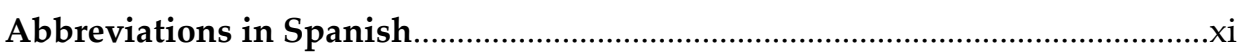

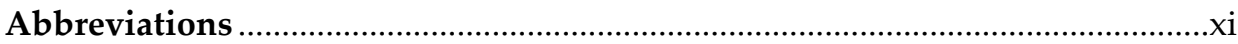

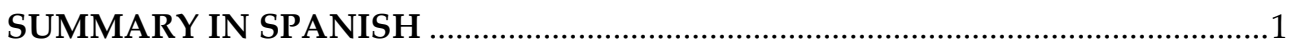

SUMMARY

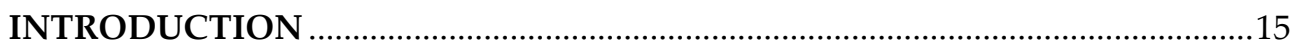

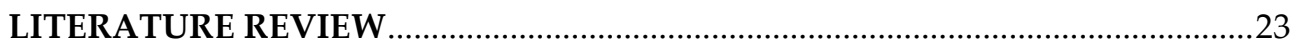

1. Mechanisms responsible for milk fatty acid composition in

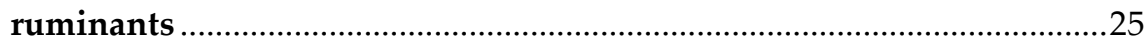

1.1. Metabolic origin of milk lipids ....................................................................25

1.2. Effect of feeding on milk fatty acid profile.....................................................2

2. Microbiology of rumen lipid metabolism.....................................................29

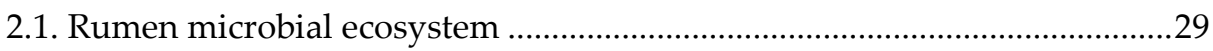

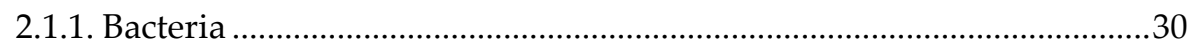

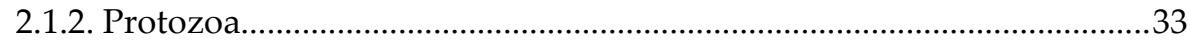

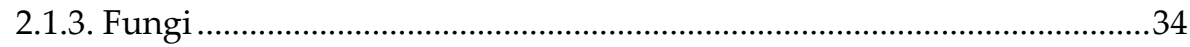

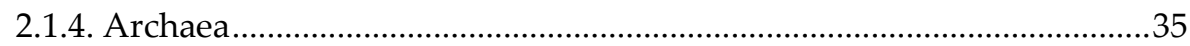

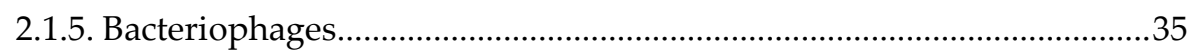

2.2. Metabolic processes and microorganisms involved ....................................36

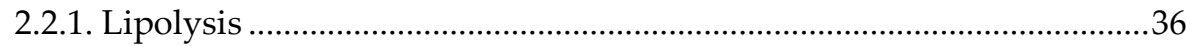

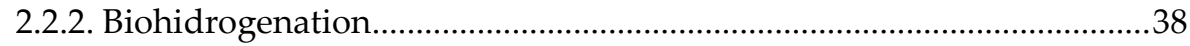

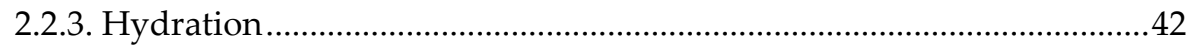

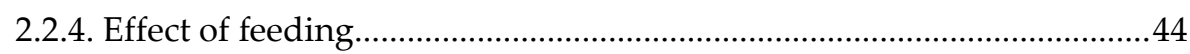

2.3. Methods for rumen microbial community studies ......................................46

2.3.1. Traditional culture-based techniques.......................................................47

2.3.2. Molecular biology techniques ................................................................4

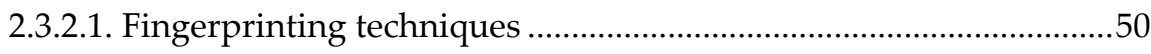

2.3.2.2. Sequencing techniques...................................................................53

2.3.2.3. Quantitative techniques....................................................................56 


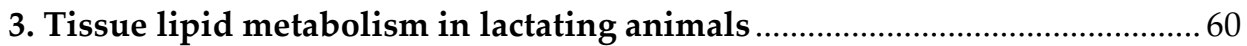

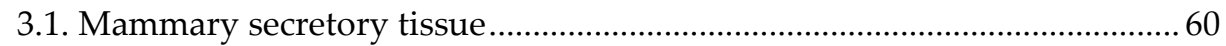

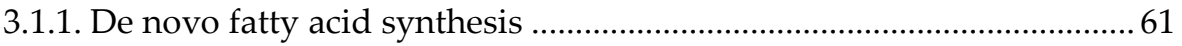

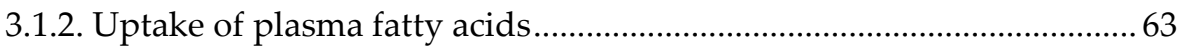

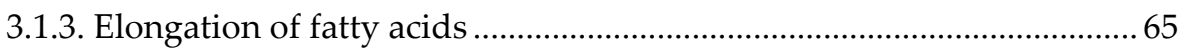

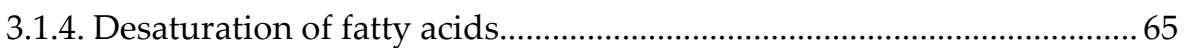

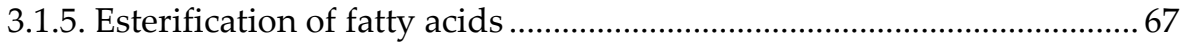

3.1.6. Synthesis and secretion of milk fat globules ........................................... 68

3.1.7. Transcription factors involved in the nutritional regulation of mammary lipogenesis............................................................................... 69

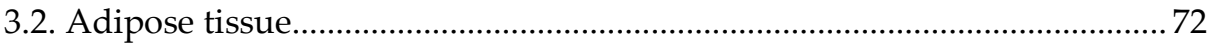

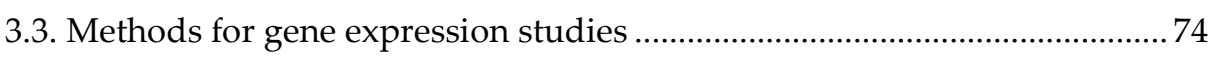

3.3.1. Reverse transcription quantitative PCR ................................................ 75

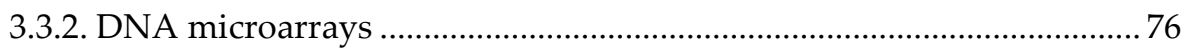

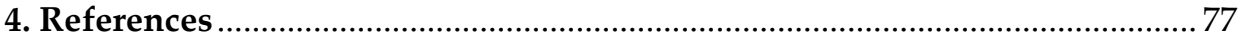

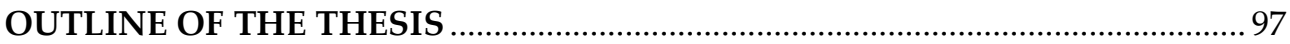

TRIAL I - Changes in the rumen Butyrivibrio group in lactating ewes fed a diet supplemented with sunflower oil with or without marine algae .................. 101

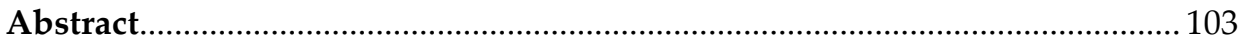

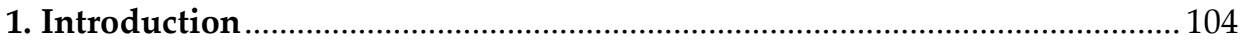

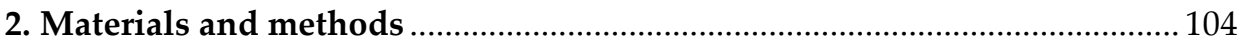

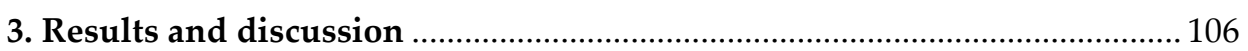

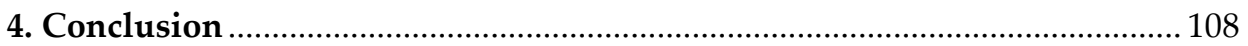

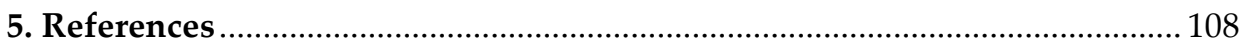

TRIAL II - Rumen bacterial community evaluated by 454 pyrosequencing and terminal restriction fragment length polymorphism analyses in dairy

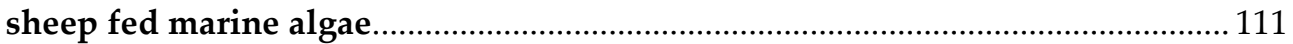

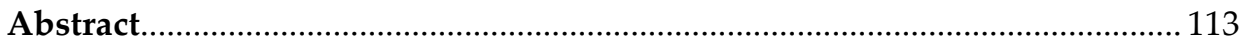

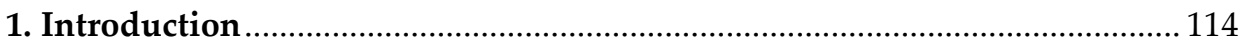

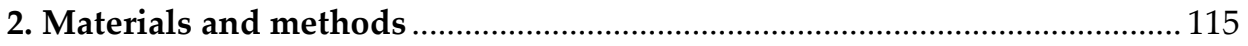

2.1. Animals, diets and experimental design....................................................... 115

2.2. Measurements, sampling procedures, and analyses................................. 116

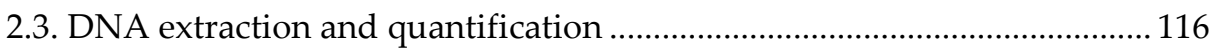

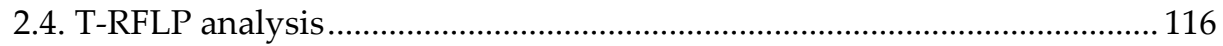

2.5. Pyrosequencing and sequence analysis ................................................... 117

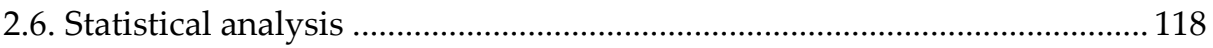


3. Results. 119

3.1. Bacterial community analysis by T-RFLP 119

3.2. Bacterial community analysis by pyrosequencing 123

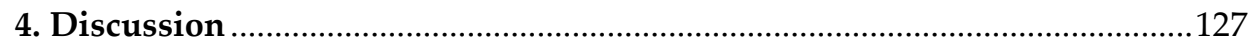

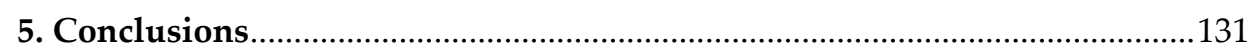

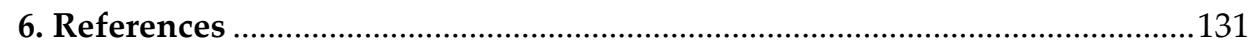

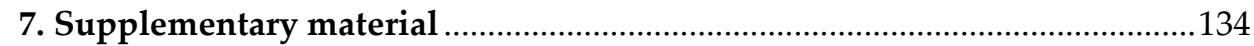

TRIAL III - Enrichment of suspensions of ruminal microorganisms in

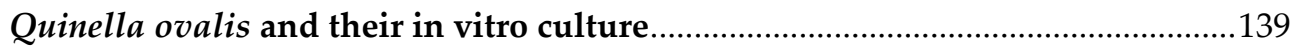

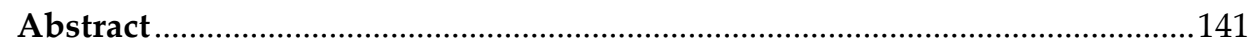

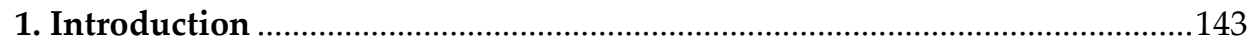

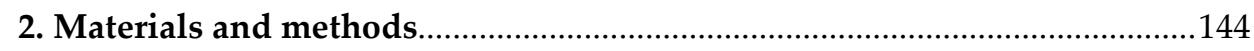

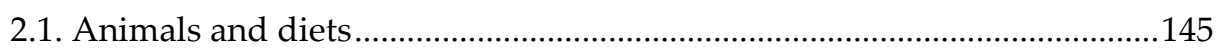

2.2. Preparation of QO-enriched cell suspension ............................................145

2.3. Batch cultures of rumen microorganisms ...............................................147

2.4. Sampling procedures ……...........................................................................149

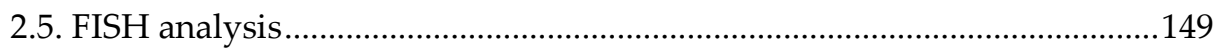

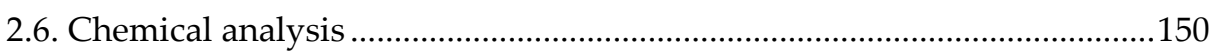

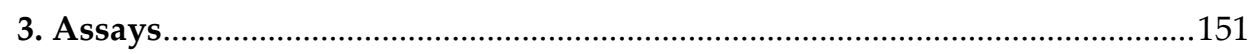

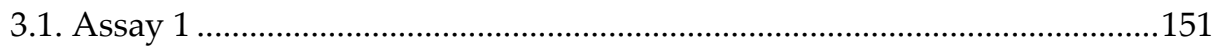

3.1.1. Objective and experimental development...........................................151

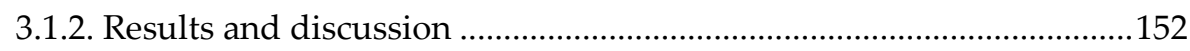

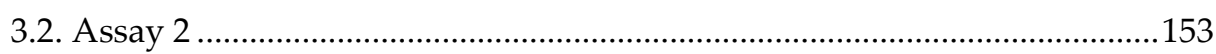

3.2.1. Objective and experimental development..........................................153

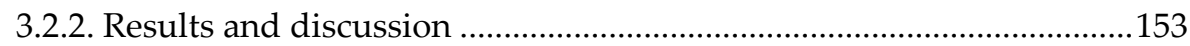

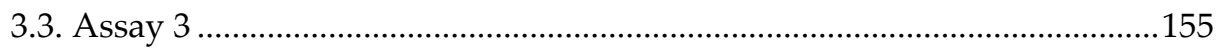

3.3.1. Objective and experimental development..........................................155

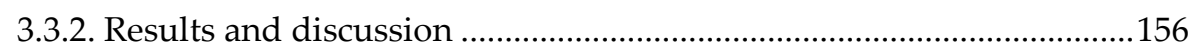

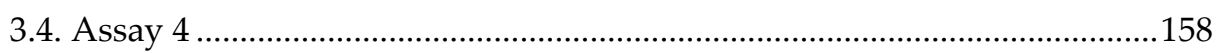

3.4.1. Objective and experimental development..........................................158

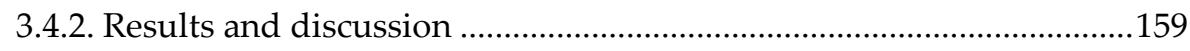

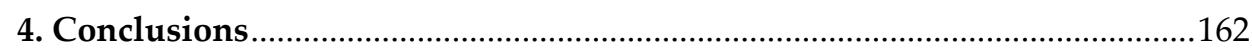

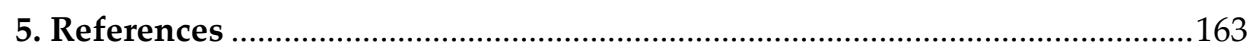


TRIAL IV - Dietary sunflower oil modulates milk fatty acid composition without major changes in adipose and mammary tissue fatty acid profile or related gene mRNA abundance in sheep............................................................. 165

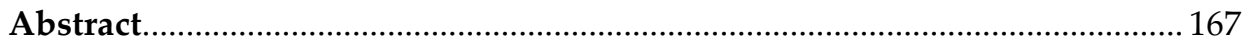

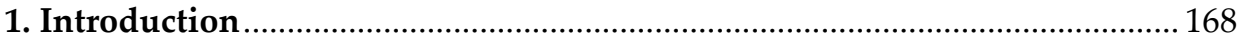

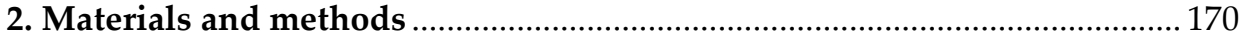

2.1. Animals, experimental diets and management ......................................... 170

2.2. Measurements and sampling procedures.................................................... 170

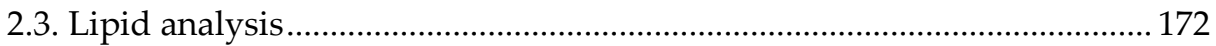

2.4. RNA isolation and quantitative PCR.......................................................... 172

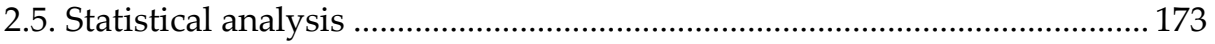

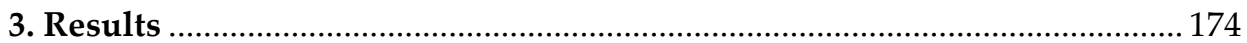

3.1. Animal performance and milk fatty acid composition and secretion...... 174

3.2. Mammary and adipose tissue fatty acid composition ................................ 178

3.3. mRNA abundances of candidate genes in mammary and adipose

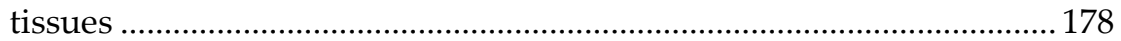

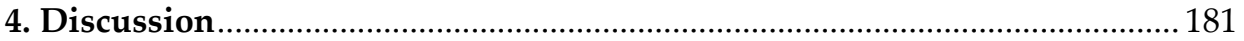

4.1. Animal performance and milk fatty acid composition and secretion...... 181

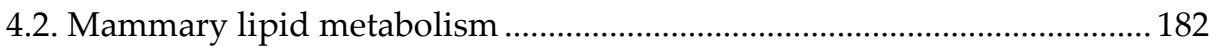

4.3. Adipose tissue lipid metabolism.................................................................. 184

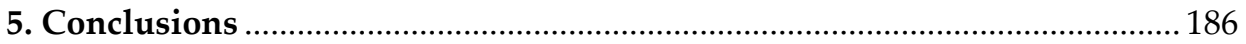

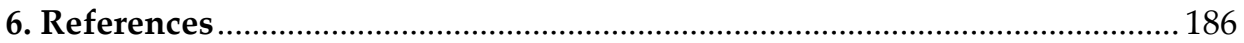

7. Supplementary material ................................................................................ 189

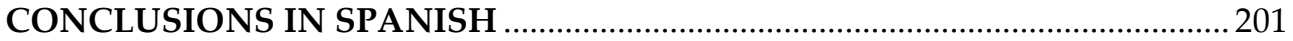

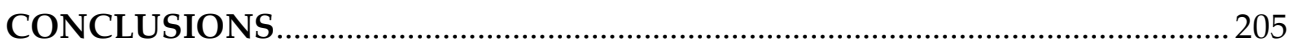




\section{ABREVIATURAS}

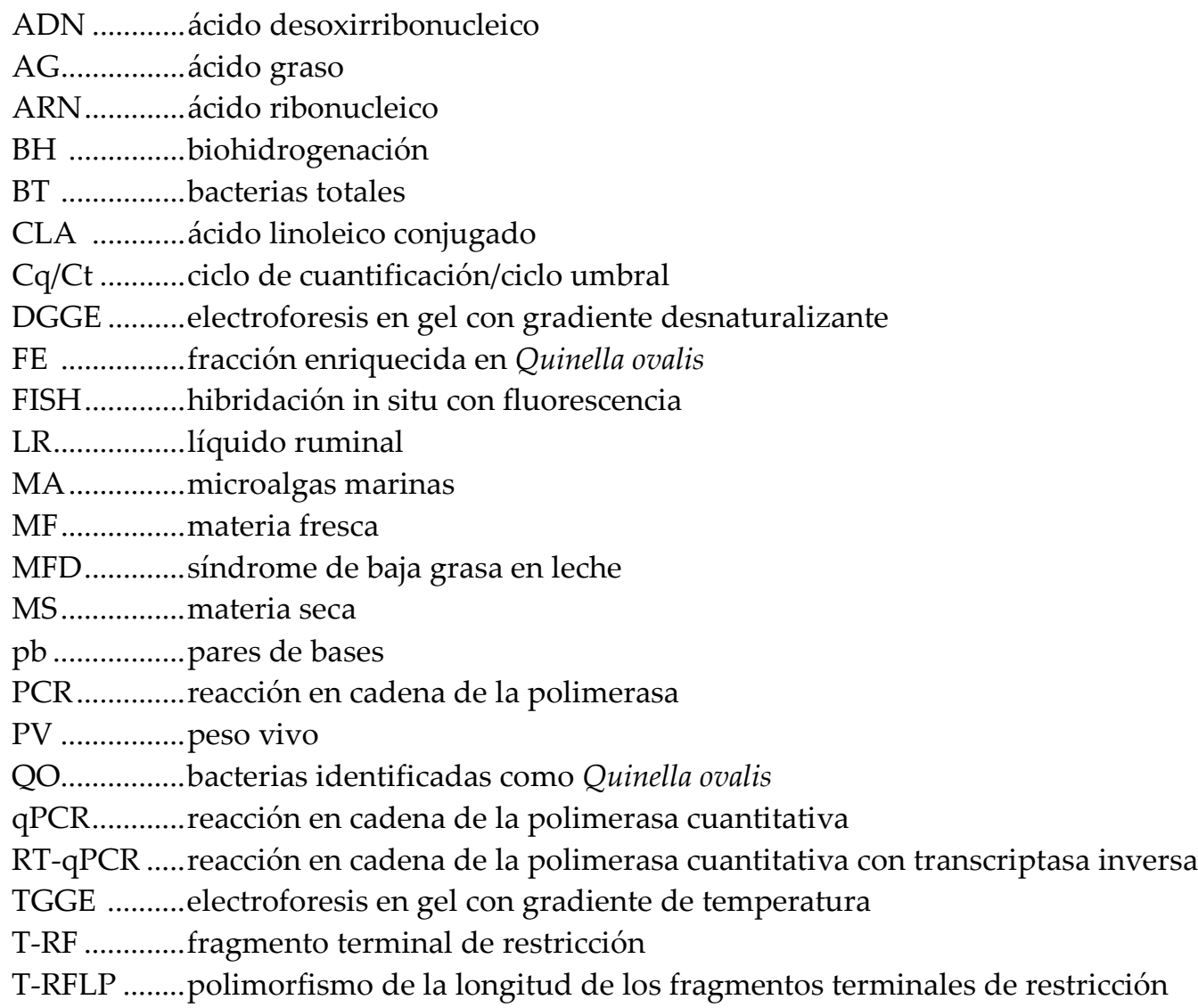

\section{ABBREVIATIONS}

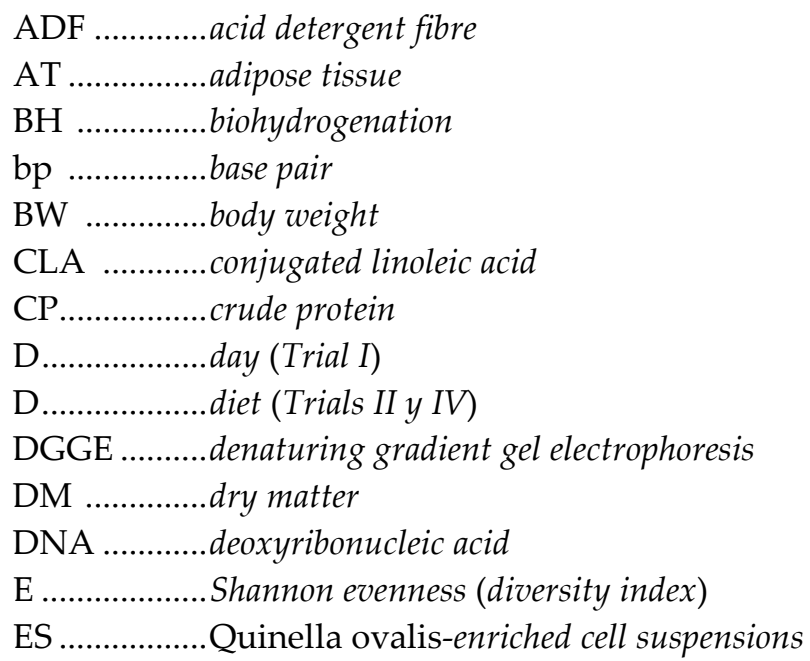


F .................. rumen fraction (Trial II)

FA ............... fatty acid

FAME .........fatty acid methyl ester

FISH .............fluorescence in situ hybridization

FO ...............fish oil

GC-MS ........ gas chromatography-mass spectrometry

H ................. Shannon-Wiener (diversity index)

MA .............. marine algae

MFD ............ milk fat depression

NDF ............neutral detergent fibre

ns .................non-significant

OS .................observed species

OTU............. operational taxonomic units

P.................. probability

PCR.............. polymerase chain reaction

PUFA........... polyunsaturated fatty acid

QO ............... Quinella ovalis-like bacteria

qPCR ........... quantitative polymerase chain reaction

$\mathrm{R}$.................. richness (diversity index)

$\mathrm{RC}$................ rumen content

RF................. rumen fluid

RNA ............ ribonucleic acid

RT-qPCR..... reverse transcription quantitative polymerase chain reaction

SED ............ standard error of the difference

SO ................ sunflower oil

SOMA ......... sunflower oil plus marine algae

T................... treatment (Trial I)

T.................. tissue (Trial IV)

TMR ............ total mixed ration

T-RF............. terminal restriction fragment

T-RFLP ........ terminal restriction fragment length polymorphism 
RESUMEN 

El aumento de la incidencia de enfermedades crónicas relacionadas con la dieta y la preocupación de los consumidores por los alimentos de origen animal han supuesto un estímulo para el desarrollo de productos más saludables, entre los que destacan la leche y sus derivados.

La suplementación de la dieta de los rumiantes con aceites vegetales y lípidos de origen marino permite modificar la composición de los ácidos grasos (AG) de la leche y obtener un perfil potencialmente más saludable, reduciendo el contenido de AG saturados y aumentando el de algunos compuestos con propiedades bioactivas. Aunque los mecanismos que intervienen en esta respuesta parecen estar mediados por alteraciones en el metabolismo lipídico en el rumen y en la glándula mamaria, la información disponible al respecto es muy limitada, especialmente en las ovejas lecheras. Así, persiste un gran desconocimiento sobre los microorganismos responsables de la biohidrogenación ruminal de los AG y el efecto de los lípidos de la dieta sobre la estructura de la comunidad bacteriana, siendo esta información aún más escasa en lo referente a la regulación nutricional de la lipogénesis mamaria. En este sentido, la aplicación de herramientas de biología molecular podría contribuir a esclarecer el efecto de la alimentación sobre la composición de AG de la leche, lo que sería de gran ayuda en el desarrollo de estrategias de alimentación que permitan modular de forma eficiente la plasticidad de la grasa láctea.

Por ello, en esta tesis se llevaron a cabo cuatro pruebas experimentales en ovino con el objetivo de profundizar en el conocimiento de los microorganismos implicados en el metabolismo ruminal de los AG, así como los mecanismos que intervienen en la regulación nutricional de la síntesis de grasa en la glándula mamaria.

La primera prueba se realizó con ovejas en lactación para investigar el efecto de la adición de lípidos sobre la población ruminal de Butyrivibrio, incluyendo las variaciones temporales durante un periodo de tiempo prolongado. Aunque las cepas cultivadas de Butyrivibrio no parecen tener un papel dominante en la biohidrogenación ruminal in vivo, es posible que especies filogenéticamente 
próximas pero que aún no han sido aisladas en cultivo pudieran verse estimuladas por la suplementación lipídica y ser más relevantes. Treinta y seis ovejas en lactación se distribuyeron en 6 lotes y recibieron una dieta rica en aceite de girasol (2,5\% MS) suplementada con 0 o $0,8 \%$ de microalgas marinas (MA). Tras 0,26 y 52 días de tratamiento, se recogieron muestras individuales de fluido ruminal mediante el uso de sonda esofágica y, tras mezclarse para cada lote, se analizaron mediante la técnica molecular del polimorfismo de la longitud de los fragmentos terminales de restricción (T-RFLP). Ni la dieta ni el tiempo causaron cambios significativos en los perfiles de la población de Butyrivibrio o en las abundancias relativas de los principales fragmentos terminales de restricción, lo que concuerda con la baja relevancia de estas bacterias en el metabolismo ruminal de los AG en ovejas lecheras. Sin embargo, el efecto observado sobre algunas subpoblaciones poco abundantes de este grupo (e. g., sobre un fragmento compatible con bacterias productoras de 18:0) no permite descartar su implicación en el proceso de biohidrogenación.

A partir de los resultados del primer experimento, la segunda prueba experimental se centró en la aplicación de una tecnología de alto rendimiento que permitiera abarcar una mayor diversidad microbiana en el rumen. Así, se empleó la técnica de pirosecuenciación 454, de forma simultánea a la T-RFLP, para evaluar el efecto de la suplementación de la dieta con MA sobre la comunidad bacteriana del rumen en ovino lechero. Además, como la canulación ruminal es poco factible en ovejas en lactación y se suele recurrir a la recogida de muestras de fluido mediante sonda esofágica, un segundo objetivo fue investigar si las muestras de fluido ruminal podrían ser una alternativa válida a las de contenido total para estudiar el impacto de la suplementación lipídica sobre la microbiota del rumen. Para ello, se utilizaron 11 ovejas en lactación procedentes del primer estudio, que se sacrificaron mediante eutanasia tras 54 días de tratamiento con la dieta suplementada o no con MA, tomándose muestras independientes de contenido y fluido ruminal para los análisis de microbiología. Como cabía esperar, la pirosecuenciación permitió una mayor cobertura de la diversidad bacteriana que 
la T-RFLP y la identificación de poblaciones minoritarias. No obstante, ambas técnicas moleculares detectaron de forma similar las diferencias debidas a la adición de las MA, que se observaron principalmente en los filos mayoritarios del rumen (i. e., Bacteroidetes, Firmicutes y Proteobacteria). Los descensos en la abundancia de bacterias no clasificadas de Bacteroidales, Porphyromonadaceae y Ruminococcaceae, y los aumentos en especies no cultivadas de Succinivibrionaceae, podrían estar relacionados con un papel activo en diferentes rutas del metabolismo ruminal de los AG. Sin embargo, la suplementación con MA no alteró la abundancia relativa de los géneros Butyrivibrio y Pseudobutyrivibrio, lo que coincide con lo observado en la primera prueba. Además, los resultados de pirosecuenciación 454 y T-RFLP indican que, a pesar de las diferencias en la composición bacteriana del contenido y el fluido ruminal, el impacto de las MA es similar en ambas fracciones, lo que sugiere que las muestras obtenidas mediante sonda esofágica podrían ser una alternativa válida para inferir el efecto de los suplementos lipídicos sobre la estructura y diversidad bacterianas.

La tercera prueba experimental se planteó para diseñar una estrategia que permitiera examinar la implicación de bacterias grandes y ovaladas identificadas como Quinella ovalis (QO) en el metabolismo ruminal de los AG insaturados, hipótesis esta (la de la implicación) que había sido sugerida en estudios previos con ovejas alimentadas con lípidos marinos. Se realizaron 4 ensayos in vitro utilizando ovejas canuladas que recibieron una dieta suplementada con un $1,8 \%$ de aceite de pescado para favorecer la presencia de QO en el fluido ruminal, el cual se empleó para obtener suspensiones celulares enriquecidas en QO mediante centrifugación diferencial. Los recuentos de bacterias totales y QO se realizaron mediante hibridación in situ con fluorescencia (FISH). En el primer ensayo, el protocolo de enriquecimiento incrementó la proporción de QO respecto al total de bacterias desde el 2,6\% en el fluido ruminal hasta el 12,6\% en la suspensión enriquecida, lo que parecía insuficiente para un estudio de metabolismo. Por lo tanto, el segundo y tercer ensayo se plantearon para mejorar la efectividad del protocolo de enriquecimiento e incrementar aún más el porcentaje de $\mathrm{QO}$ a través 
de la incubación in vitro de las suspensiones celulares enriquecidas. Se realizaron cultivos selectivos con manitol como único sustrato para estimular el crecimiento de QO, pero su abundancia alcanzó valores de hasta el $42 \%$ de las bacterias totales tras 6 h de incubación y cayó de forma drástica a continuación. En el cuarto ensayo se planteó una estrategia alternativa que consistía en la comparación de dos suspensiones celulares con una estructura microbiana similar, pero una rica en QO y otra libre de esta bacteria, obtenidas mediante cultivo selectivo con sustratos que pudieran favorecer (manitol) o minimizar (celobiosa y almidón) su crecimiento. Sin embargo, este planteamiento tampoco fue satisfactorio. En conjunto, los resultados de esta prueba sobre QO ponen de manifiesto la complejidad para desarrollar un método basado en su cultivo que permita estudiar sus características metabólicas.

Además de estos estudios de microbiología, se llevó a cabo una última prueba experimental de nutrigenómica. Su principal objetivo fue investigar la respuesta de la glándula mamaria, en términos de composición de AG y abundancia del ARNm de genes implicados en el metabolismo lipídico, a una dieta que modifica el perfil de AG de la leche. Un segundo objetivo consistió en estudiar la posible contribución de los tejidos adiposos a la regulación de la lipogénesis mamaria. Se utilizaron 10 ovejas en lactación que fueron distribuidas en 2 grupos y alimentadas con una dieta suplementada con 0 o 2,5\% de aceite de girasol. Tras 48 días de tratamiento, se analizó la composición de la leche, incluyendo su perfil lipídico. El día 49, los animales se sacrificaron mediante eutanasia y se recogieron muestras de tejidos mamario y adiposo (subcutáneo y perirrenal) para examinar su perfil de AG y la abundancia del ARNm de 16 genes candidatos. La suplementación de la dieta con aceite de girasol modificó la composición lipídica de la leche, disminuyendo la concentración de AG derivados de la síntesis de novo (e. g., 12:0, 14:0 y 16:0) y aumentando la de AG de cadena larga (e. g., 18:0, cis-9 18:1, isómeros trans-18:1 y cis-9, trans-11 CLA). Sin embargo, esta respuesta no se vio acompañada ni de cambios significativos en la abundancia del ARNm de los genes de la lipogénesis (i. e., ACACA, FASN, LPL, CD36, FABP3, 
SCD1 y SCD5) o de los factores de transcripción (SREBF1 y PPARG) que se estudiaron, ni de diferencias en los AG constituyentes del tejido mamario. Respecto a los tejidos adiposos, la escasa influencia del aceite de girasol sobre su perfil lipídico no pareció estar relacionada con variaciones en la abundancia del ARNm (i. e., descensos de GPAM y SREBF1 en ambos depósitos y de PPARG en el subcutáneo). De forma similar, las grandes diferencias en la composición de AG entre ambos tejidos adiposos no se asociaron a cambios en la abundancia del ARNm de los genes analizados. En conjunto, estos resultados sugieren que la expresión génica podría tener una contribución marginal a la regulación nutricional del metabolismo lipídico en estos tejidos, al menos con las dietas examinadas y tras 7 semanas de tratamiento. Sin embargo, no se puede descartar que los efectos del aceite de girasol estén mediados por cambios en otros genes o por mecanismos postranscripcionales. 

SUMMARY 

The growing incidence of diet-related chronic diseases and consumers' concerns about food of animal origin has led to an increasing interest in developing healthier foods, much of it relating to milk and dairy products.

Supplementation of ruminants' diet with plant oils and marine lipids enables modulation of milk fatty acid (FA) composition towards a potentially healthier profile, lowering saturated FA content and increasing the concentration of some bioactive lipids. Although the mechanisms underlying this response seem to be mediated by alterations in ruminal and mammary lipid metabolism, the information available is very scant, in particular in dairy sheep. Thus, the relevance of specific microorganisms in ruminal FA metabolism and the effect of dietary lipids on the bacterial community structure remain largely unknown, and even less data are available on the nutritional regulation of mammary lipogenesis. In this regard, it could be hypothesized that the application of molecular biology techniques would allow a better understanding of the effects of nutrition on milk FA profile, which may be of great help in developing nutritional strategies to better control milk fat plasticity.

A series of four studies was therefore conducted in sheep with the aim of providing further insight into the microorganisms related to the metabolism of unsaturated FA in the rumen, as well as the mechanisms involved in the nutritional regulation of milk fat synthesis in the mammary gland.

The first trial was carried out with lactating ewes to examine the effect of lipid addition on the rumen Butyrivibrio population, as well as time-dependent variations over an extended period. Although Butyrivibrio strains do not seem to have a dominant role in ruminal biohydrogenation in vivo, some yet-uncultured species within this group might be stimulated by lipid supplementation and be more relevant in this process. Thirty-six lactating ewes were divided in 6 lots and offered a diet rich in sunflower oil $(2.5 \% \mathrm{DM})$ supplemented with 0 or $0.8 \%$ of marine algae (MA). After 0, 26 and 52 days on treatments, individual samples of rumen fluid were collected through a stomach tube, composited for each lot, and analysed using the terminal restriction fragment length polymorphism (T-RFLP) 
molecular technique. Results showed no significant variations, due to either diet or time, in the Butyrivibrio profiles or in the relative abundances of the major terminal restriction fragments detected, which supports a low relevance of these bacteria in the ruminal FA metabolism in dairy sheep. However, the effect on some small subpopulations within this group (e. g., a fragment compatible with 18:0-producing bacteria) would not allow ruling out their involvement in the biohydrogenation process.

Based on the results of the first experiment, the second trial was focused on the application of a high-throughput technology that may allow for a great coverage of rumen microbial diversity. Thus, in this experiment, 454 pyrosequencing was used, concurrently with T-RFLP, to assess the effect of diet supplementation with MA on the rumen bacterial community of dairy sheep. In addition, since ruminal cannulation is not really feasible in lactating sheep and stomach probe is often used to collect rumen fluid, a second objective was to investigate if samples of rumen fluid may be an alternative to those of whole rumen content to examine the effect of lipid supplementation on the bacterial community. Eleven lactating ewes from the first study were then euthanized after 54 days on treatments (i. e., on diets supplemented or not with MA) and samples of rumen content and fluid were collected separately for microbial analysis. Pyrosequencing yielded a greater coverage of bacterial diversity than T-RFLP and allowed the identification of low abundant populations. Nevertheless, both molecular approaches pointed to similar conclusions and showed that relevant changes due to MA addition were observed within the major ruminal phyla, namely Bacteroidetes, Firmicutes and Proteobacteria. Decreases in the abundance of unclassified Bacteroidales, Porphyromonadaceae and Ruminococcaceae, and increases in as yet-uncultured species of the family Succinivibrionaceae, might be related to a potential role of these groups in different pathways of rumen FA metabolism. Diet supplementation with MA had, however, no effect on the relative abundance of Butyrivibrio and Pseudobutyrivibrio genera, in line with findings from the first trial. In addition, results from both 454 pyrosequencing and T-RFLP indicate that the 
impact of MA was rather consistent in rumen content or fluid samples, despite inherent differences between these fractions in their bacterial composition, which suggests that fluid samples may be a valid alternative to infer the effect of dietary lipids on bacterial structure and diversity.

The third study was aimed at designing a strategy to examine the ability of large oval bacteria identified as Quinella ovalis (QO) to metabolize unsaturated FA, which had been suggested in previous studies in ewes fed marine lipids. Four in vitro assays were conducted using cannulated sheep as rumen fluid donors. Animals received a diet supplemented with $1.8 \%$ of fish oil to favour the presence of QO, and rumen fluid was employed to obtain QO-enriched cell suspensions by differential centrifugation. Total bacteria and QO were counted by fluorescence in situ hybridization (FISH). In the first assay, the protocol of purification increased the proportion of QO over total bacteria from $2.6 \%$ in the rumen fluid to only $12.6 \%$ in the enriched suspension, which seemed unsufficient for a metabolic study. Thus, the objectives of the second and third assays were to improve the enrichment protocol and increase the percentage of QO through in vitro cultivation of the enriched cell suspensions. Selective cultures with mannitol as the sole substrate were conducted to stimulate growth of QO, but its abundance reached values of up to $42 \%$ of total bacteria after $6 \mathrm{~h}$ of incubation and dramatically decreased afterwards. In the fourth assay, an alternative strategy was proposed, consisting of the comparison of two cell suspensions with similar microbial structure but rich or depleted in QO through selective cultures with substrates that might favour (mannitol) or minimize (cellobiose and starch) its growth. However, this approach was not successful either. Overall, these results emphasize the great difficulty of designing culture-based strategies to study the metabolic features of QO.

Once these studies of microbiology were completed, a last experiment was conducted in order to investigate the response of the mammary gland, in terms of FA profile and mRNA abundance of genes involved in lipid metabolism, to a diet known to modify milk FA composition, as well as the possible contribution of 
adipose tissues to the regulation of mammary lipogenesis. Ten lactating ewes were randomly divided in two groups and fed a diet supplemented with 0 or $2.5 \%$ of sunflower oil. After 48 days on treatments, milk composition, including FA profile, was analysed. On day 49 , the animals were euthanized and samples of the mammary and adipose (subcutaneous and perirenal) tissues were collected to analyse their FA profile and the mRNA abundance of 16 candidate genes. Feeding sunflower oil modified milk FA composition, with decreases in the concentration of FA derived from de novo synthesis (e. g., 12:0, 14:0 and 16:0) and increases in that of long chain FA (e. g., 18:0, cis-9 18:1, trans-18:1 isomers and cis-9, trans-11 CLA). However, these changes were not accompanied by significant variations in the mRNA abundance of studied lipogenic genes (i. e., ACACA, FASN, LPL, CD36, $F A B P 3, S C D 1$ and SCD5) and transcription factors (SREBF1 and PPARG), or in the constituent FA of mammary tissue. Regarding adipose tissues, the little influence of sunflower oil on their FA profile did not appear to be linked to observed changes in gene mRNA abundance (i. e., decreases of GPAM and SREBF1 in both tissues, and of PPARG in the subcutaneous depot). Similarly, the great variation between adipose depots in FA composition could not be related to variations in gene mRNA abundance due to tissue site. Overall, these results suggest a marginal contribution of gene expression to the nutritional regulation of lipid metabolism in these tissues, at least with the examined diets and after 7 weeks on treatments. Nevertheless, it cannot be ruled out that the response to linoleic-rich diets is mediated by other genes or post-transcriptional mechanisms. 
INTRODUCCIÓN 

En las últimas décadas se están produciendo importantes cambios en el estilo de vida y los hábitos alimentarios en las sociedades industrializadas, como resultado del desarrollo económico y urbano y la creciente globalización de los mercados (FAO, 2010). Aunque ello ha permitido una mejora general del estatus sanitario y nutricional de la población, también se han producido aumentos en la prevalencia de enfermedades crónicas relacionadas con la dieta tales como obesidad, diabetes, cardiopatías coronarias, cáncer y osteoporosis (OMS, 2003; FAO, 2010). En consecuencia, la nutrición ha ganado peso en los programas de salud pública y los consumidores son cada día más conscientes de la interacción entre alimentación y bienestar. En este sentido, destaca la preocupación por los alimentos de origen animal, lo que ha supuesto un estímulo para el desarrollo de productos más saludables (Givens, 2010; Doreau et al., 2011). Entre ellos, se ha prestado especial atención a la leche y los derivados lácteos, que cuentan con un mercado muy dinámico en los países desarrollados (Siró et al., 2008; Bigliardi y Galati, 2013).

La leche constituye una fuente importante de energía, proteína de alta calidad, vitaminas y minerales (Recio et al., 2009; Givens, 2010), aunque existe la percepción generalizada de que su grasa, al ser rica en lípidos saturados, aumenta el riesgo de sufrir enfermedades cardiovasculares. Sin embargo, numerosos estudios han mostrado una relación positiva entre el consumo de lácteos y la salud (Parodi, 2004; Elwood et al., 2008), lo que concuerda con el hecho de que una parte importante de los ácidos grasos (AG) saturados de la leche no son perjudiciales (e. g., 4:0-10:0 y 18:0; Shingfield et al., 2008; Parodi, 2009). Del mismo modo, una revisión sistemática de la literatura científica (Gayet-Boyer et al., 2014) parece mostrar que no existe relación entre el consumo de AG trans derivados de los rumiantes y el riesgo de enfermedad cardiovascular, al contrario de lo que sucede con las grasas trans de origen industrial (Chardigny et al., 2008; FAO, 2010). Esta ausencia de efectos negativos, sobre la que, no obstante, aún persiste una importante controversia, se asocia a la diferente distribución de los isómeros trans18:1, en la cual parece radicar la clave de sus efectos biológicos, así como a la presencia en la leche de otros nutrientes con carácter netamente saludable 
(Shingfield et al., 2008; Recio et al., 2009). Así, se sabe que la grasa láctea contiene un buen número de lípidos con propiedades bioactivas, como el ácido linoleico conjugado (CLA, por las siglas en inglés de conjugated linoleic acid), el ácido butírico (4:0), algunos AG ramificados, el ácido vaccénico (trans-11 18:1) o la esfingomielina (Shingfield et al., 2008). Entre ellos, el isómero cis-9, trans-11 del CLA (ácido ruménico) es quizás el que ha recibido mayor atención en el campo de la investigación, tanto por sus potentes efectos antiproliferativos y apoptóticos en cultivos de células tumorales (Pariza et al., 2001) como por la efectividad de las estrategias dirigidas a aumentar su contenido en la leche mediante cambios en la alimentación del ganado (e. g., mediante la utilización de suplementos lipídicos; Lock y Bauman, 2004; Chilliard et al., 2007). Sin embargo, aún se sabe relativamente poco de los mecanismos mediante los cuales la dieta modifica la composición de la leche, a pesar de las implicaciones que ello tiene en el marco general de la mejora de sus propiedades saludables.

Numerosos estudios en vacuno, ovino y caprino han demostrado que la suplementación de la dieta con cantidades moderadas de aceites vegetales insaturados (2-3\%) es muy eficaz para aumentar el contenido de cis-9, trans-11 CLA en la leche (e. g., Chilliard et al., 2007; Hervás et al., 2008). Aunque esto se explicaría por la acción de los microorganismos ruminales sobre los AG insaturados de los aceites (principalmente, 18:2n-6 y 18:3n-3), persiste un gran desconocimiento sobre las poblaciones responsables de dicho proceso (Jenkins et al., 2008; Shingfield y Wallace, 2014). Así, a pesar de la información aportada por numerosos estudios in vitro con cepas bacterianas capaces de metabolizar los AG (e. g., Butyrivibrio fibrisolvens y B. proteoclasticus; Paillard et al., 2007; Maia et al., 2010; McKain et al., 2010), la aplicación de técnicas de biología molecular para el estudio de la microbiota sugiere que serían otras bacterias ruminales aún no cultivadas las que jugarían un papel dominante en el proceso in vivo (Boeckaert et al., 2008; Belenguer et al., 2010; Huws et al., 2011). Del mismo modo, se sabe que la enorme capacidad de los lípidos de origen marino para modular el perfil de AG de la leche (incluso a dosis menores del 1\% de la dieta) está mediada por su efecto 
sobre el metabolismo microbiano de los AG, pero se ha avanzado muy poco en la caracterización de las poblaciones ruminales que estarían específicamente implicadas en esta respuesta (Kim et al., 2008; Huws et al., 2010; Toral et al., 2012). Por otra parte, aunque la mayor parte de esta información procede de los estudios en ganado vacuno, la comparación con los escasos trabajos llevados a cabo en ovino sugiere la existencia de importantes diferencias interespecíficas entre rumiantes (e. g., Belenguer et al., 2010; Toral et al., 2012).

Para entender los efectos de la alimentación sobre el perfil de AG de la leche, además de los mencionados mecanismos ruminales se deben considerar los relacionados con la síntesis de grasa en la glándula mamaria. La reciente aplicación de herramientas de biología molecular también ha permitido avanzar en este campo (Loor y Cohick, 2009) y, así, se ha observado que el impacto de la nutrición sobre la lipogénesis podría estar mediado por cambios en la expresión de los genes, principalmente a nivel de la transcripción (Bauman et al., 2011; Shingfield et al., 2013). Sin embargo, los estudios de nutrigenómica en rumiantes aún son muy escasos e inconsistentes y, por ejemplo, aunque se sabe que los aceites vegetales reducen el contenido de AG saturados de cadena media en la leche (12:0, 14:0 y 16:0, con efecto potencialmente perjudicial para la salud; Parodi, 2009), la importancia de la regulación transcripcional en esta respuesta parece diferir entre vacas y cabras (Shingfield et al., 2013). En el ovino, por su parte, la información al respecto es aún más limitada y persisten numerosos interrogantes sobre los mecanismos mamarios responsables de los cambios en el perfil de AG de la leche inducidos por la dieta (Bichi et al., 2013).

Por lo tanto, en función de todo lo expuesto, la aplicación de herramientas de biología molecular al estudio de la regulación nutricional del metabolismo lipídico en los rumiantes (tanto a nivel del rumen como de la glándula mamaria) podría contribuir a esclarecer el efecto de la alimentación sobre la composición de AG de la leche. Además, cabe destacar que a pesar de la creciente importancia económica de la producción de leche de oveja en España (que representó 509 millones de euros en el año 2013, un 64\% más que hace una década; MAGRAMA, 2014), se 
sigue prestando muy poca atención a la investigación en el área de la nutrición del ovino lechero.

Por todo ello, el presente trabajo de tesis doctoral se enmarcó dentro de una línea de investigación que pretende mejorar las propiedades saludables de la leche de oveja, mediante la modulación de su perfil de AG, y se llevó a cabo con el objetivo general de profundizar en el conocimiento de los microorganismos implicados en el metabolismo ruminal de los AG y en los mecanismos que intervienen en la regulación nutricional de la lipogénesis mamaria en las ovejas lecheras.

\section{REFERENCIAS}

Bauman DE, Harvatine KJ and Lock AL 2011. Nutrigenomics, rumen-derived bioactive fatty acids, and the regulation of milk fat synthesis. Pages 299-319 in Annual Review of Nutrition, Vol 31, Cousins RJ, Bier DM and Bowman BA, eds. Palo Alto, CA, USA.

Belenguer A, Toral PG, Frutos P and Hervás G 2010. Changes in the rumen bacterial community in response to sunflower oil and fish oil supplements in the diet of dairy sheep. J. Dairy Sci. 93, 3275-3286.

Bichi E, Frutos P, Toral PG, Keisler D, Hervás G and Loor JJ 2013. Dietary marine algae and its influence on tissue gene network expression during milk fat depression in dairy ewes. Anim. Feed Sci. Technol. 186, 36-44.

Bigliardi B and Galati F 2013. Innovation trends in the food industry: The case of functional foods. Trends Food Sci. Tech. 31, 118-129.

Boeckaert C, Vlaeminck B, Fievez V, Maignien L, Dijkstra J and Boon N 2008. Accumulation of trans C-18:1 fatty acids in the rumen after dietary algal supplementation is associated with changes in the Butyrivibrio community. Appl. Environ. Microbiol. 74, 6923-6930.

Chardigny JM, Destaillats F, Malpuech-Brugère C, Moulin J, Bauman DE, Lock AL, Barbano DM, Mensink RP, Bezelgues JB, Chaumont P, Combe N, Cristiani I, Joffre F, German JB, Dionisi F, Boirie $\mathrm{Y}$ and Sébédio JL 2008. Do trans fatty acids from industrially produced sources and from natural sources have the same effect on cardiovascular disease risk factors in healthy subjects? Results of the trans Fatty Acids Collaboration (TRANSFACT) study. Am. J. Clin. Nutr. 87, 558-566.

Chilliard Y, Glasser F, Ferlay A, Bernard L, Rouel J and Doreau M 2007. Diet, rumen biohydrogenation and nutritional quality of cow and goat milk fat. Eur. J. Lipid Sci. Technol. $109,828-855$.

Doreau M, Bauchart D and Chilliard Y 2011. Enhancing fatty acid composition of milk and meat through animal feeding. Anim. Prod. Sci. 51, 19-29.

Elwood PC, Givens DI, Beswick AD, Fehily AM, Pickering JE and Gallacher J 2008. The survival advantage of milk and dairy consumption: an overview of evidence from cohort studies of vascular diseases, diabetes and cancer. J. Am. Coll. Nutr. 27, 723-734. 
FAO 2010. Fats and fatty acids in human nutrition. Report of an expert consultation. Food and Nutrition paper 91. Food and Agriculture Organisation, United Nations, Rome, Italy.

Gayet-Boyer C, Tenenhaus-Aziza F, Prunet C, Marmonier C, Malpuech-Brugère C, Lamarche B and Chardigny JM 2014. Is there a linear relationship between the dose of ruminant transfatty acids and cardiovascular risk markers in healthy subjects: results from a systematic review and meta-regression of randomised clinical trials. Brit. J. Nutr. 112, 1914-1922.

Givens DI 2010. Milk and meat in our diet: good or bad for health? Animal 4, 1941-1952.

Hervás G, Luna P, Mantecón AR, Castañares N, de la Fuente MA, Juárez M and Frutos P 2008. Effect of diet supplementation with sunflower oil on milk production, fatty acid profile and ruminal fermentation in lactating dairy ewes. J. Dairy Res. 75, 399-405.

Huws SA, Lee MRF, Muetzel SM, Scott TW, Wallace RJ and Scollan ND 2010. Forage type and fish oil cause shifts in rumen bacterial diversity. FEMS Microbiol. Ecol. 73, 396-407.

Huws SA, Kim EJ, Lee MRF, Scott MB, Tweed JKS, Pinloche E, Wallace RJ and Scollan ND 2011. As yet uncultured bacteria phylogenetically classified as Prevotella, Lachnospiraceae incertae sedis and unclassified Bacteroidales, Clostridiales and Ruminococcaceae may play a predominant role in ruminal biohydrogenation. Environ. Microbiol. 13, 1500-1512.

Jenkins TC, Wallace RJ, Moate PJ and Mosley EE 2008. Recent advances in biohydrogenation of unsaturated fatty acids within the rumen microbial ecosystem. J. Anim. Sci. 86, 397-412.

Kim EJ, Huws SA, Lee MRF, Wood JD, Muetzel SM, Wallace RJ and Scollan ND 2008. Fish oil increases the duodenal flow of long chain polyunsaturated fatty acids and trans-11 18:1 and decreases 18:0 in steers via changes in the rumen bacterial community. J. Nutr. 138, 889-896.

Lock AL and Bauman DE 2004. Modifying milk fat composition of dairy cows to enhance fatty acids beneficial to human health. Lipids 39, 1197-1206.

Loor JJ and Cohick WS 2009. ASAS Centennial Paper: Lactation biology for the twenty-first century. J. Anim. Sci. 87, 813-824.

MAGRAMA 2014. Encuestas lácteas 2014. Ministerio de Agricultura, Alimentación y Medio Ambiente de España. http://www.magrama.gob.es/es/estadistica/temas/estadisticasagrarias/ganaderia/estadistica-industrias-lacteas/estadistica-lactea-anual/. Acceso el 6 de diciembre de 2014.

Maia MRG, Chaudhary LC, Bestwick CS, Richardson AJ, McKain N, Larson TR, Graham IA and Wallace RJ 2010. Toxicity of unsaturated fatty acids to the biohydrogenating ruminal bacterium, Butyrivibrio fibrisolvens. BMC Microbiol. 10, 52-61

McKain N, Shingfield KJ and Wallace RJ 2010. Metabolism of conjugated linoleic acids and 18:1 fatty acids by ruminal bacteria: products and mechanisms. Microbiol-SGM 156, 579-588.

OMS. 2003. Diet, nutrition, and the prevention of chronic diseases. Report of a joint WHO/FAO expert consultation. World Health Organization technical reports series 916. World Health Organization, Geneva, Switzerland.

Paillard D, McKain N, Chaudhary LC, Walker ND, Pizette F, Koppova I, McEwan NR, Kopecny J, Vercoe PE, Louis P and Wallace RJ 2007. Relation between phylogenetic position, lipid metabolism and butyrate production by different Butyrivibrio-like bacteria from the rumen. Anton. Leeuw. Int. J. G. 91, 417-422.

Pariza MW, Park Y and Cook ME 2001. The biologically active isomers of conjugated linoleic acid. Prog. Lipid Res. 40, 283-298.

Parodi PW 2004 Milk fat in human nutrition. Aust. J. Dairy Technol. 59, 3-59. 
Parodi PW 2009. Has the association between saturated fatty acids, serum cholesterol and coronary heart disease been over emphasized? Int. Dairy J. 19, 345-361.

Recio I, de la Fuente MA, Juárez M and Ramos M 2009. Bioactive components in sheep milk. Pages 83-104 in Bioactive components in milk and dairy products, Park YW, WileyBlackwell, ed. Ames, IA, USA.

Shingfield KJ, Chilliard Y, Toivonen V, Kairenius P and Givens DI 2008. Trans fatty acids and bioactive lipids in ruminant milk. Adv. Exp. Med. Biol. 606, 3-65.

Shingfield KJ, Bonnet M and Scollan ND 2013. Recent developments in altering the fatty acid composition of ruminant-derived foods. Animal 7, 132-162.

Shingfield KJ and Wallace RJ 2014. Synthesis of conjugated linoleic acid in ruminants and humans. Pages 1-65 in Conjugated linoleic acids and conjugated vegetable oils, Sels B and Philippaerts A, eds. The Royal Society of Chemistry, Oxford, UK.

Siró I, Kápolna E, Kápolna B and Lugasi A 2008. Functional food. Product development, marketing and consumer acceptance-A review. Appetite 51, 456-467.

Toral PG, Belenguer A, Shingfield KJ, Hervás G, Toivonen V and Frutos P 2012. Fatty acid composition and bacterial community changes in the rumen fluid of lactating sheep fed sunflower oil plus incremental levels of marine algae. J. Dairy Sci. 95, 794-806. 
REVISIÓN BIBLIOGRÁFICA 



\section{MECANISMOS RESPONSABLES DE LA COMPOSICIÓN DE ÁCIDOS GRASOS DE LA LECHE DE LOS RUMIANTES}

\subsection{ORIGEN METABÓLICO DE LOS LÍPIDOS DE LA LECHE}

Los ácidos grasos de la leche de los rumiantes tienen un origen doble. Por una parte, pueden derivar de la captación de los que son transportados en el plasma, procedentes mayoritariamente de los lípidos de la dieta y de los metabolitos de su biohidrogenación (BH) ruminal (Jenkins et al., 2008; Shingfield et al., 2010). Por otra parte, pueden ser sintetizados de forma endógena en la glándula mamaria, a partir fundamentalmente de acetato y 3-hidroxibutirato (Barber et al., 1997; Palmquist, 2006).

Los lípidos que entran en el rumen son principalmente insaturados (e. g., 18:2n-6 y 18:3n-3), pero debido al extenso metabolismo microbiano que sufren en esta cámara (Harfoot y Hazlewood, 1997; Lourenço et al., 2010), los AG que se absorben en el intestino son en su mayor parte saturados (e. g., 18:0; Jenkins et al., 2008; Shingfield et al., 2012). Por lo tanto, la composición de los AG disponibles para la captación mamaria depende en gran medida de las transformaciones de los

lípidos de la dieta en el rumen, lo que repercute de forma notable sobre la calidad nutricional de la grasa láctea (Lock y Bauman, 2004; Chilliard et al., 2007). Dicha repercusión justifica el interés en el estudio de la microbiología del metabolismo lipídico ruminal, para intentar conocer las principales poblaciones bacterianas implicadas en la composición lipídica de la leche (Jenkins et al., 2008, Lourenço et al., 2010; Shingfield y Wallace, 2014).

En los últimos años, se ha avanzado notablemente en el conocimiento del metabolismo de los AG insaturados en el rumen. Así, se ha pasado de asumir que era un proceso relativamente sencillo, con un número muy limitado de reacciones enzimáticas (Harfoot y Hazlewood, 1997), a saber que existe un elevado número de rutas metabólicas alternativas (McKain et al., 2010; Toral et al., 2010a; Honkanen et al., 2012), lo que conlleva la formación de una gran variedad de metabolitos intermedios que pueden pasar a la leche y tener efectos biológicos 
relevantes (Shingfield et al., 2008a). Sin embargo, los avances en la identificación de los microorganismos potencialmente implicados en estos procesos han sido más limitados. De hecho, aunque la aplicación de técnicas de biología molecular ha permitido observar que las bacterias más estudiadas in vitro podrían tener un papel poco relevante en la biohidrogenación ruminal in vivo (Kim et al., 2008; Belenguer et al., 2010; Huws et al., 2011), se desconocen aún las poblaciones específicamente implicadas en cada ruta metabólica.

Los AG derivados del metabolismo ruminal que son captados por la glándula mamaria representan la práctica totalidad de los AG de cadena larga (i. e., con 18 o más átomos de carbono) y en torno al 50\% de los de 16 carbonos que aparecen en la leche (Van Soest, 1994; Palmquist, 2006). No obstante, en determinadas circunstancias, como periodos de balance energético negativo, una parte de los AG circulantes en el plasma y disponibles para la captación mamaria puede proceder de la movilización de las reservas corporales (Chilliard et al., 2000). Por el contrario, los AG de cadena corta y media de la leche (i. e., la gran mayoría de los de menos de 16 átomos de carbono y aproximadamente la mitad de los de 16) derivan de la síntesis de novo en la glándula mamaria (Barber et al., 1997; Palmquist et al., 2006). En el interior de las células secretoras de la mama, los AG procedentes de ambos orígenes son utilizados para ensamblar los triglicéridos que serán posteriormente secretados en los glóbulos grasos de la leche, en un proceso metabólico muy complejo (Barber et al., 1997; Jensen, 2002; Palmquist, 2006). La lipogénesis mamaria supone la acción coordinada de numerosas enzimas, como por ejemplo carboxilasas, desaturasas, translocasas y aciltransferasas, cuya actividad está determinada por factores genéticos y fisiológicos (e. g., el momento de la lactación), pero puede ser fuertemente regulada por otros de tipo ambiental, en especial por la nutrición (Loor et al., 2013). Por lo tanto, mediante cambios en la alimentación del ganado se podría alterar el proceso de síntesis de grasa en la glándula mamaria y, de forma indirecta, el perfil de AG de la leche (Bauman et al., 2011a; Shingfield et al., 2013). 


\subsection{EFECTO DE LA ALIMENTACIÓN SOBRE EL PERFIL DE ÁCIDOS}

\section{GRASOS DE LA LECHE}

Tal y como se ha mencionado previamente, entre los factores que determinan el perfil lipídico de la leche de los rumiantes (e. g., especie, genotipo, estado fisiológico), el más importante es la nutrición (Chilliard et al., 2007; Lourenço et al., 2010; Shingfield et al., 2013). Los cambios en la alimentación constituyen una estrategia efectiva para modular la composición de la grasa láctea en respuesta a la demanda de los consumidores.

Una de las estrategias más comúnmente utilizadas para mejorar el valor nutricional de la grasa de la leche es la suplementación de la dieta con lípidos ricos en AG insaturados (Chilliard et al., 2007; Li et al., 2012a; Bichi et al., 2013a). Algunos aceites vegetales, como por ejemplo el de girasol o el de lino, contienen una gran cantidad de AG poliinsaturados de 18 carbonos y su adición a la dieta de los rumiantes permite aumentar la concentración en la leche de AG con efectos potencialmente saludables, como el trans-11 18:1, el cis-9, trans-11 CLA o el 18:3n-3, y disminuir la de AG saturados de cadena corta y media (Hervás et al., 2008; Bernard et al., 2009a; Halmemies-Beauchet-Filleau et al., 2011). Por otro lado, los

lípidos de origen marino, como por ejemplo el aceite de pescado o las microalgas marinas, son ricos en AG poliinsaturados de cadena muy larga (20 y 22 carbonos) y pueden incrementar la concentración láctea de estos últimos y de los isómeros 18:1 (Boeckaert et al., 2008; Toral et al., 2010a; Chilliard et al., 2014).

Los efectos de la alimentación del ganado sobre el perfil lipídico de su leche vienen determinados fundamentalmente por dos mecanismos diferentes, los que ocurren en el rumen y los que ocurren en la glándula mamaria (Barber et al., 1997; Bauman et al., 2011b). Así, habría un mecanismo que podría considerarse relativamente directo y que se refiere a la transferencia de los lípidos que se aportan en la dieta y de los productos intermedios de su metabolismo ruminal (Jenkins et al., 2008). Esto explicaría por ejemplo el mayor contenido de cis-9, trans11 CLA, metabolito de la BH del principal AG del aceite de girasol (i. e., el 18:2n6), en la leche de animales alimentados con dicho aceite (Hervás et al., 2008; Toral 
et al., 2010b; Martínez Marín et al., 2011) o de 18:3n-3 y 22:6n-3 en rumiantes alimentados con aceite de lino (Glasser et al., 2008) o lípidos de origen marino (Papadopoulos et al., 2002; Toral et al., 2010a), respectivamente. Además, la mayor concentración láctea de los isómeros trans-18:1 con estos últimos suplementos es consecuencia de la inhibición que causan sobre el paso final de la $\mathrm{BH}$ (saturación de los isómeros trans-18:1 a 18:0), la cual está mediada por su efecto sobre los microorganismos (Wasowska et al., 2006; Maia et al., 2010). Sin embargo, como ya se ha indicado en diversas ocasiones, todavía persiste un elevado desconocimiento sobre las poblaciones bacterianas realmente implicadas en las diferentes rutas del metabolismo de los lípidos en el rumen (Shingfield y Wallace, 2014).

Por otra parte, existe otro mecanismo de tipo indirecto, que estaría relacionado con la regulación nutricional de la lipogénesis en la glándula mamaria, especialmente con las modificaciones provocadas por la alimentación en la expresión de determinados genes que intervienen en la síntesis de lípidos (Bauman et al., 2011a; Shingfield et al., 2013). Así, por ejemplo, el descenso de la secreción en la leche de AG de cadena corta y media cuando se añade aceite de girasol a la dieta, podría explicarse en ganado vacuno por una represión de la expresión de determinados genes implicados en la síntesis de novo (Piperova et al., 2000; Shingfield et al., 2013). No obstante, se desconocen aún los mecanismos moleculares de este tipo de respuesta, debido a que los estudios de nutrigenómica son todavía escasos (Bauman et al., 2011b; Loor et al., 2013). Tal y como se ha señalado previamente, esta información es particularmente limitada en el ganado ovino (Dervishi et al., 2012; Bichi et al., 2013b), a pesar de las importantes diferencias interespecíficas entre rumiantes en la regulación nutricional del metabolismo lipídico (Shingfield et al., 2013; Chilliard et al., 2014). 


\section{MICROBIOLOGÍA DEL METABOLISMO DE LOS LÍPIDOS EN EL RUMEN}

\subsection{ECOSISTEMA MICROBIANO RUMINAL}

Los animales rumiantes se caracterizan por poseer un estómago dividido en 4 compartimentos bien diferenciados funcional y anatómicamente: 3 preestómagos (i. e., rumen, retículo y omaso) y un estómago glandular (i. e., abomaso). El rumen es el de mayor tamaño ( $80 \%$ del volumen total) y funciona como una cámara de fermentación con un flujo continuo, en la que reside una comunidad microbiana simbiótica de la que solo ahora, con la aplicación de técnicas de estudio independientes de cultivo, se ha empezado a conocer su diversidad y complejidad reales (McSweeney y Mackie, 2012). Estos microorganismos ruminales permiten que el hospedador pueda aprovechar parte de los carbohidratos estructurales que contiene la pared de la célula vegetal (e. g., celulosa, hemicelulosa y pectinas; Van Soest, 1994), transformándolos en otros productos como los AG volátiles que constituyen su principal fuente de energía (Bergman, 1990). Además, gracias a la localización del rumen anterior a los lugares de digestión enzimática, la proteína microbiana (de elevado valor biológico) puede ser utilizada por el propio animal, siendo uno de sus principales aportes proteicos (Van Soest, 1994).

El rumen posee unas condiciones apropiadas y estables para el mantenimiento de su microbiota: temperatura (aprox. $\left.39^{\circ} \mathrm{C}\right), \mathrm{pH}(5,7-7,3)$, potencial redox (de -250 a $-400 \mathrm{mv}$ ) y osmolaridad (250-350 miliosmoles). Su comunidad microbiana contiene representantes de los 3 dominios en que Woese et al. (1990) distribuyeron a los organismos celulares, es decir, de Bacteria, Archaea y Eucarya (hongos y protozoos), además de presentar virus bacteriófagos (Mackie et al., 2002; Deng et al., 2008). Estos microorganismos se encuentran ecológicamente integrados con el animal hospedador bajo un constante equilibrio dinámico en el que se establecen relaciones beneficiosas, perjudiciales o competitivas entre ellos. Existe un considerable grado de interdependencia entre las diferentes especies, ya que comúnmente unas utilizan los productos de desecho del metabolismo de otras (Dehority, 2003). Además, los diferentes individuos ocupan distintos nichos y 
poseen diferentes estrategias de utilización de los recursos, lo que hace posible la conservación de la diversidad de la comunidad (Czerkawski, 1986).

\subsubsection{Bacterias}

Las bacterias son los microorganismos más importantes y abundantes del rumen, al encontrarse en una concentración de hasta $10^{11}$ células/mL y suponer entre el 50 y el 60\% del total de la masa microbiana (Stewart et al., 1997; Mackie et al., 2002). Constituyen una comunidad heterogénea en morfología y tamaño (Ogimoto e Imai, 1981) y la mayoría son anaerobias estrictas, aunque algunas pueden vivir en presencia de oxígeno e incluso utilizarlo (Van Soest, 1994).

Tradicionalmente, las bacterias del rumen se clasificaban en función de sus características morfológicas y bioquímicas (Hobson y Stewart, 1997), determinadas principalmente mediante estudios basados en el cultivo. Estos métodos han permitido identificar unas 200 especies cultivables, que se agrupaban en función de su actividad metabólica en, por ejemplo, celulolíticas, hemicelulolíticas, pectinolíticas, amilolíticas o proteolíticas (Dehority, 2003). Sin embargo, el empleo de metodologías basadas en el análisis de la secuencia del gen del ARNr 16S ha demostrado la existencia de un número mucho mayor. Así, la técnica de secuenciación enzimática de Sanger ha permitido estimar la presencia de entre 300 y 400 especies diferentes en el rumen (Edwards et al., 2004) y otras estrategias de secuenciación masiva más modernas, como la pirosecuenciación 454, han llegado a diferenciar hasta aproximadamente 2400 (Fouts et al., 2012) e incluso más de 12000 en algunos individuos (de Menezes et al., 2011). El uso de este tipo de herramientas de biología molecular ha permitido también establecer una clasificación filogenética de los microorganismos (Woese et al., 1990). En la Tabla 1 se muestra como ejemplo la de algunas de las principales bacterias ruminales.

De acuerdo con dicha clasificación filogenética, la mayoría de las especies bacterianas del rumen en animales domésticos pertenecen habitualmente a los filos Bacteroidetes y Firmicutes, que juntos pueden suponer más del 90\% del total de bacterias (Jami y Mizrahi, 2012; Lee et al., 2012; Wu et al., 2012). El filo 
Tabla 1. Clasificación filogenética de algunos de los principales géneros y especies bacterianas descritas en el rumen ${ }^{1}$.

\begin{tabular}{|c|c|c|c|c|}
\hline Filo & Familia & Género & Especie representativa & Actividad metabólica \\
\hline \multirow{5}{*}{ Bacteroidetes } & Prevotellaceae & Prevotella & P. ruminicola & Hemicelulolítica y proteolítica \\
\hline & & & P. bryantii & Xilanolítica \\
\hline & Bacteroidaceae & Bacteroides & B. amylophilus & Amilolítica \\
\hline & Porphyromonadaceae & Paludibacter & P. propionicigenes & Sacarolítica \\
\hline & Paraprevotellaceae & Paraprevotella & P. clara & Sacarolítica \\
\hline \multirow[t]{18}{*}{ Firmicutes } & Lachnospiraceae & Butyrivibrio & B. fibrisolvens & Celulolítica y hemicelulolítica \\
\hline & & & B. proteoclasticus & Pectinolítica \\
\hline & & Pseudobutyrivibrio & P. ruminis & Sacarolítica \\
\hline & & Blautia & B. hydrogenotrophica & Sacarolítica \\
\hline & & Lachnospira & L. multiparus & Pectinolítica \\
\hline & & Coprococcus & C. spp.Pe 15 & Utiliza floroglucinol \\
\hline & & Moryella & M. indoligenes & Sacarolítica \\
\hline & Ruminococcaceae & Ruminococcus & R. flavefaciens y albus & Celulolíticas \\
\hline & & Oscillibacter & O. ruminantium & Utiliza ácidos orgánicos \\
\hline & Veillonellaceae & Anaerovibrio & A. lipolyticus & Lipolítica \\
\hline & & Mitsuokella & M. multiacidus & Amilolítica \\
\hline & & Selenomonas & S. ruminantium & Utiliza lactato \\
\hline & & Megasphaera & M. elsdenii & Utiliza lactato \\
\hline & & Quinella & Q. ovalis & Utiliza manitol \\
\hline & Streptococcaceae & Streptococcus & S. bovis & Pectinolítica y amilolítica \\
\hline & Eubacteriaceae & Eubacterium & E. ruminantium & Hemicelulolítica \\
\hline & Clostridiaceae & Clostridium & C. aminophilum & Utiliza aminoácidos \\
\hline & Acidaminococcaceae & Succiniclasticum & S. ruminis & Utiliza succinato \\
\hline
\end{tabular}


Tabla 1. (continuación)

\begin{tabular}{|c|c|c|c|c|}
\hline Filo & Familia & Género & Especie representativa & Actividad metabólica \\
\hline \multirow[t]{4}{*}{ Proteobacteria } & Succinivibrionaceae & Succinomonas & S. amylolytica & Amilolítica \\
\hline & & Succinivibrio & S. dextrinosolvens & Amilolítica y dextrinolítica \\
\hline & & Ruminobacter & R. amylophilus & Proteolítica \\
\hline & Desulfovibrionaceae & Desulfovibrio & D. desulfuricans & Metaboliza sulfatos \\
\hline \multirow[t]{2}{*}{ Actinobacteria } & Bifidobacteriaceae & Bifidobacterium & B. ruminantium & Utiliza ribosa y manitol \\
\hline & Coriobacteriaceae & Atopobium & A. minutum & Utiliza péptidos y aminoácidos \\
\hline Spirochaetes & Spirochaetaceae & Treponema & T. bryantii & Pectinolítica \\
\hline Fibrobacteres & Fibrobacteraceae & Fibrobacter & F. succinogenes & Celulolítica \\
\hline
\end{tabular}

${ }^{1}$ Información extraída de: Patel et al., 1981; Biavati y Mattarelli, 1991; van Gylswyk , 1995; Stewart et al., 1997; Eschenlauer et al., 2002; Dehority., 2003; Piknova et al., 2006; Morotomi et al., 2009; Gronow et al., 2011; Kim y Yu, 2012; Li et al., 2013. 
Proteobacteria suele ser el tercero más abundante (hasta el 20\% del total; Tajima et al., 1999; Jami y Mizhari, 2012), mientras que el resto de filos (e. g., Spirochaetes, Fibrobacteres, Actinobacteria, Verrucomicrobia, Synergistetes, Tenericutes, Cyanobacteria, TM7, Elusimicrobia, SR1, Fusobacteria y Chloroflexi) se encuentran normalmente en porcentajes menores al 1,5\% (Jami y Mizhari, 2012; Lee et al., 2012; Wu et al., 2012). A nivel de género, aunque las abundancias son muy variables, Prevotella (filo Bacteroidetes) es normalmente el más abundante y puede representar más del $50 \%$ del total de bacterias (Jami y Mizrahi, 2012; Lee et al., 2012; Wu et al., 2012), mientras que del resto son pocos los géneros que alcanzan abundancias relativas superiores a 0,5\%, como es el caso de Butyrivibrio, Fibrobacter, Ruminococcus, Succinivibrio, Selenomonas y Treponema (Stevenson y Weimer 2007; Jami y Mizhari, 2012; Wu et al., 2012). Así, la composición de la comunidad bacteriana es variable y depende de factores como el estado fisiológico del animal, el tiempo tras la ingesta y especialmente la dieta consumida (Dehority, 2003; Jami y Mizhari, 2012; Wu et al., 2012). En este sentido, la importancia de la alimentación en relación a las bacterias implicadas en el metabolismo lipídico se describirá más adelante.

\subsubsection{Protozoos}

El rumen alberga una comunidad protozoaria que, aunque contiene un número de células inferior a la bacteriana, puede representar hasta la mitad de la masa microbiana debido al mayor tamaño de los protozoos (Williams y Coleman, 1997). Tradicionalmente, estos organismos se dividen en dos grandes grupos en función de su morfología, ciliados y flagelados (Dehority, 1993). En el rumen el grupo predominante es el de los ciliados (104-106 células/mL; Williams y Coleman 1997), formado a su vez por 2 subgrupos denominados comúnmente entodiniomorfos y holotricos, que pertenecen a las familias Orphyroscolecidae e Isotrichidae, respectivamente. Los primeros son los más abundantes e incluyen al género principal, Entodinium, que engloba aproximadamente el $80 \%$ del total de protozoos del rumen (Shin et al., 2004). La segunda familia más importante incluye principalmente los géneros Isotricha y Dasytricha (Ricard et al., 2006). 
Aunque la identificación de estos microorganismos continúa realizándose mediante el uso del microscopio, las técnicas moleculares son cada vez más utilizadas para su estudio (McSweeney y Mackie, 2012).

Los protozoos aparecen frecuentemente asociados a otros microorganismos ruminales, principalmente a las arqueas metanogénicas (Mackie et al., 2002). Aunque su presencia en el rumen no es necesaria, pueden ayudar a mantener la estabilidad del ecosistema, por ejemplo mediante el almacenamiento y degradación gradual del almidón (Williams y Coleman, 1997), y juegan un papel importante en el reciclaje de nitrógeno (Koenig et al., 2000) debido a su actividad predatoria de bacterias (Newbold et al., 1996). Sin embargo, no parecen ser capaces de metabolizar los lípidos (Lourenço et al., 2010), tal y como se detalla posteriormente.

\subsubsection{Hongos}

En el rumen, los hongos pueden suponer hasta el 8\% del total de la biomasa microbiana (103-106 células/mL; Orpin y Joblin, 1997). Recientemente, mediante la aplicación de técnicas moleculares, los hongos ruminales se han asignado a un nuevo filo (Neocallimastigomycota; McSweeney y Mackie, 2012) y los principales géneros descritos son Neocallismatix, Piromyces, Caecomyces, Orpinomyces, Anaeromyces y Cyllamyces; Ho y Barr, 1995; Liggenstoffer et al., 2010).

Aunque pueden encontrarse en forma de esporas móviles libres en el rumen (Krause et al., 2013), estos microorganismos están normalmente asociados a las partículas de fibra de las plantas. Así, contribuyen de manera significativa a la ruptura de la fibra mediante el desarrollo de un extenso rizoide en el interior de las partículas vegetales y la secreción de celulasas (Krause et al., 2013), lo que parece complementar y estimular la actividad fibrolítica bacteriana (Orpin y Joblin, 1997). Sin embargo, su contribución al metabolismo lipídico parece insignificante, tal y como se explica en el apartado 2.2 


\subsubsection{Arqueas}

Las arqueas representan entre el 0,3 y el 3,3\% de la biomasa ruminal (107-10 células/mL; Wright y Klieve, 2011; Leahy et al., 2013). Estudios moleculares han mostrado que la mayor parte de las arqueas ruminales pertenecen a los géneros Methanobrevibacter y Methanomicrobium y a un grupo de arqueas no cultivadas conocido como clúster $\mathrm{C}$ del rumen o Methanoplasmatales. Además, se han descrito otros géneros menos abundantes (Methanosphaera, Methanimicrococcus, Methanosarcina y Methanobacterium; Leahy et al., 2013).

Todas las arqueas ruminales son anaerobias estrictas y constituyen un grupo ecológica y fisiológicamente importante dentro del ecosistema ruminal, puesto que son las responsables de la producción de metano. Su actividad metanogénica es variable, siendo las especies Methanobrevibacter ruminantium y Methanosarcina spp. de las más activas en este sentido (Hook et al., 2010). Recientemente se ha comenzado a estudiar los genes funcionales de estos microorganismos (Leahy et al., 2010), aunque, en lo referente a los lípidos, hasta el momento no parece haber indicios de que estén implicadas en su metabolismo (Abecia et al., 2012).

\subsubsection{Bacteriófagos}

En el rumen también existe un buen número de virus bacteriófagos (107-109 fagos $/ \mathrm{mL}$ ) pertenecientes principalmente a 3 familias: Myoviridae, Siphoviridae y Podoviridae (Miller et al., 2012). Estos virus contribuyen a la evolución de los microorganismos del ecosistema ruminal y al mantenimiento de su equilibrio y diversidad (Miller et al., 2012) debido a su papel en la transferencia horizontal de genes y a la selección de bacterias resistentes a fagos (Rohwer y Thurber, 2009). Además, infectan y lisan bacterias ruminales, por lo que pueden afectar al reciclaje de la proteína microbiana y reducir la eficiencia de utilización del alimento (Swain et al., 1996). Al igual que en el caso de las arqueas, no existen evidencias de su implicación en el metabolismo lipídico. 


\subsection{PROCESOS METABÓLICOS Y MICROORGANISMOS IMPLICADOS}

El metabolismo de los lípidos de la dieta en el rumen, en contraste con el de otros compuestos como los polisacáridos, no es una actividad esencial para nutrir a los microorganismos que lo colonizan (Lourenço et al., 2010). Sin embargo, este proceso es extremadamente importante para el mantenimiento del ecosistema ruminal (Harfoot y Hazlewood, 1997), ya que permite la supervivencia de algunos microorganismos al prevenir el efecto tóxico de los AG insaturados sobre el crecimiento microbiano. Esto ocurre principalmente a través de la saturación de los dobles enlaces mediante la biohidrogenación (BH; Maia et al., 2007, 2010), aunque existen mecanismos alternativos como la hidratación (Jenkins et al., 2006). Como requisito imprescindible previo a estos procesos, los AG tienen que ser liberados al medio ruminal por medio de la lipólisis. Este conjunto de transformaciones, como ya se ha mencionado, es responsable de las grandes diferencias entre los AG que entran en el rumen, principalmente insaturados, y los que alcanzan el duodeno, mayoritariamente saturados (Jarvis y Moore, 2010; Lourenço et al., 2010; Shingfield et al., 2012).

\subsubsection{Lipólisis}

Tras la ingestión de los alimentos, los procesos de masticación y rumia rompen la matriz alimenticia y liberan los lípidos de su interior, que se encuentran principalmente en forma de fosfo- y glucolípidos (normalmente galactolípidos), con dietas basadas en forrajes, y de triglicéridos cuando las dietas son ricas en granos de cereal, semillas oleaginosas o están suplementadas con aceites (Harfoot y Hazlewood, 1997; Jenkins et al., 2008). Quedan así expuestos a la acción de las lipasas, que hidrolizan rápidamente los enlaces éster entre los AG y los alcoholes (lipólisis), liberando de esta manera los AG no esterificados al medio para que puedan ser posteriormente metabolizados (Jenkins et al., 2008).

Actualmente se sabe que las enzimas que llevan a cabo este proceso son fundamentalmente las lipasas microbianas, aunque existe cierta actividad 
lipolítica en el propio material vegetal (Shingfield y Wallace, 2014). Dentro de los microorganismos ruminales, las bacterias son las principales responsables de la lipólisis (Harfoot y Hazlewood, 1997; Jenkins et al., 2008; Lourenço et al., 2010) y, de todas ellas, Anaerovibrio lipolyticus (anteriormente A. lipolytica; Strömpl et al., 1999) y Butyrivibrio spp. se consideran las más activas (Lourenço et al., 2010). Aunque se han aislado otras bacterias con esta capacidad pertenecientes a los géneros Clostridium y Propionibacterium, aún se desconoce su importancia (Jarvis y Moore, 2010; Edwards et al., 2013), y es posible que haya otras especies no cultivadas que también estén implicadas en este proceso. Por otro lado, la actividad lipolítica de las bacterias sobre los diferentes tipos de lípidos es altamente específica (Edwards et al., 2013). Así, A. lipolyticus actúa sobre di- y triglicéridos (Privé et al., 2013), al igual que Propionibacterium y algunas cepas de Clostridium (Jarvis y Moore, 2010), mientras que Butyrivibrio spp. hidrolizan principalmente fosfo- y galactolípidos (Hazlewood y Dawson, 1979). Además, la tasa de lipólisis varía entre especies y depende de otros factores como la fase de crecimiento microbiano o la estructura y posición de los AG en la molécula (Edwards et al., 2013). En cuanto a los protozoos, aunque se sugirió que podrían contribuir a este proceso en el rumen (Wright, 1961), no ha sido posible discernir su actividad lipolítica de la de las bacterias asociadas (Harfoot y Hazlewood, 1997). Por otra parte, no existen evidencias de la participación de los hongos anaerobios en este proceso (Dehority, 2003).

No obstante, hay que considerar que la mayor parte del conocimiento sobre la microbiología de la lipólisis en el rumen se basa en resultados obtenidos a partir de cultivos bacterianos puros. Aunque el empleo de técnicas moleculares ha permitido observar variaciones simultáneas en la tasa de lipólisis y la abundancia de A. lipolyticus en fermentadores in vitro (Fuentes et al., 2009, 2011), esto no ha sido confirmado in vivo, ya que solo se conoce un estudio de este tipo en vacuno, en el que no se analizó la especie A. lipolyticus y no se pudo relacionar la actividad lipolítica con B. fibrisolvens (Halmemies-Beauchet-Filleau et al., 2013). Así, todavía se desconoce la contribución real de las bacterias mencionadas en la lipólisis 
ruminal. En este sentido, el análisis de genes funcionales que codifican para las enzimas lipasas podría contribuir significativamente a incrementar el conocimiento de las bacterias implicadas en el proceso in vivo (Privé et al., 2013).

\subsubsection{Biohidrogenación}

Tras la lipólisis, la mayoría de los AG insaturados son metabolizados por los microorganismos del rumen mediante el proceso de BH (Jenkins et al., 2008), que consiste en una serie de reacciones enzimáticas secuenciales, las cuales incluyen pasos de isomerización e hidrogenación y llevan a la saturación de los AG (Harfoot y Hazlewood, 1997). En un principio, se sugirió que los microorganismos llevaban a cabo la BH para eliminar el exceso de $\mathrm{H}_{2}$ en el medio (Lennarz, 1966), pero se ha confirmado que su contribución al respecto es mínima (Jenkins et al., 2008). Estudios más recientes han demostrado que, en el rumen, la $\mathrm{BH}$ actúa como un mecanismo de destoxificación que ha sido desarrollado por algunos microrganismos en respuesta al efecto inhibitorio que los AG insaturados ejercen sobre su crecimiento (Maia et al., 2007, 2010).

Los principales microorganismos implicados en la $\mathrm{BH}$ ruminal son las bacterias (Jenkins et al., 2008; Lourenço et al., 2010). Inicialmente se pensaba que los protozoos también llevaban a cabo este proceso (Wright, 1959) por su elevado contenido en AG insaturados (Keeney, 1970) y, particularmente, en cis-9, trans-11 CLA y trans-11 18:1 (Devillard et al., 2006), a cuyo flujo duodenal contribuyen de forma importante (Yáñez-Ruiz et al., 2006). Sin embargo, actualmente se considera que no participan (Lourenço et al., 2010) y que su elevado contenido en AG insaturados se debe, al menos en parte, a la ingesta de cloroplastos (Huws et al., 2009) y de bacterias con gran actividad biohidrogenadora (Devillard et al., 2006). Por otro lado, aunque algunos hongos ruminales (e. g., Neocallimastix frontalis) son capaces de formar cis-9, trans-11 CLA a partir del 18:2n-6 in vitro (Maia et al., 2007; Nam y Garnsworthy, 2007), su actividad es muy pequeña en comparación con las bacterias capaces de biohidrogenar en cultivo (Maia et al., 2007), por lo que su contribución al proceso in vivo parece ser insignificante (Jenkins et al., 2008). 
En cuanto a las bacterias implicadas, durante muchos años se clasificaron en dos grupos, A y B, considerando los productos que eran capaces de formar a partir del 18:2n-6 y el 18:3n-3 (Kemp y Lander, 1984), cuyas rutas son las más estudiadas puesto que son los AG más abundantes en las dietas habituales de los rumiantes (i. e., forrajes y alimentos concentrados). Así, aunque ambos grupos podían biohidrogenar el 18:2n-6 y el 18:3n-3 hasta trans-11 18:1, solo las bacterias del grupo B reducían los isómeros 18:1 hasta el producto final (18:0; Harfoot y Hazlewood, 1997; Figura 1). Las bacterias más representativas de los grupos A y B serían Butyrivibrio fibrisolvens y la que hoy se conoce como B. proteoclasticus (anteriormente Clostridium proteoclasticum; Wallace et al., 2006; Moon et al., 2008), respectivamente.

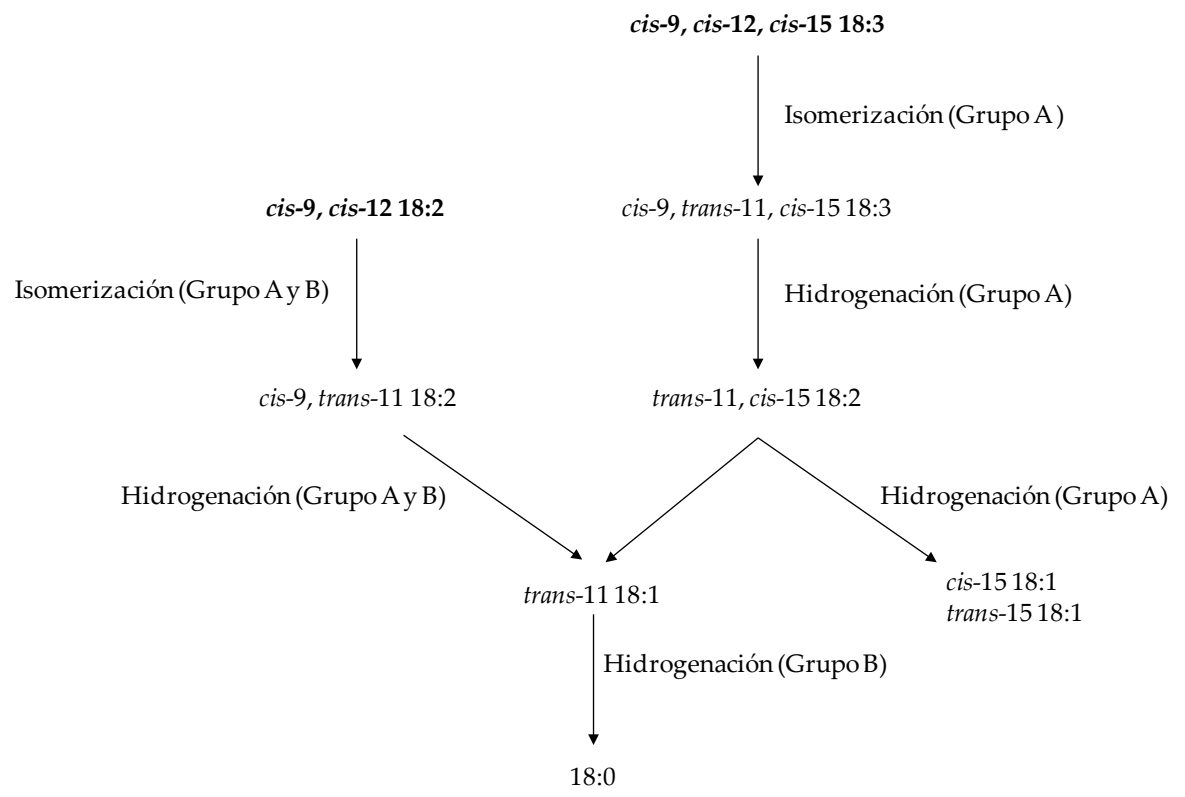

Figura 1. Rutas de biohidrogenación del ácido linoleico (18:2n-6) y del ácido linolénico (18:3n-3), según Harfoot y Hazlewood (1997).

Estudios in vitro mostraron que las bacterias del grupo Butyrivibrio, que incluye a especies de los géneros Butyrivibrio y Pseudobutyrivibrio, eran las más activas en el proceso de BH (Wallace et al., 2006; Maia et al., 2007). Mediante la 
utilización de técnicas moleculares, Paillard et al. (2007) propusieron clasificar a estas bacterias en función de su posición filogenética y establecieron tres grupos claramente diferenciados: VA1 y VA2, que comprenden diferentes especies de Butyrivibrio y Pseudobutyrivibrio, las cuales pueden hidrogenar hasta trans-11 18:1; y SA, que engloba a bacterias próximas a $B$. proteoclasticus, las únicas que producen 18:0.

Sin embargo, actualmente se sabe que las rutas metabólicas de la $\mathrm{BH}$ son mucho más complejas y que este proceso da lugar a la formación de numerosos metabolitos intermedios (Shingfield et al., 2010; Honkanen et al., 2012; Shingfield y Wallace, 2014; Figura 2). Además, la utilización de técnicas modernas de biología molecular ha demostrado que las bacterias que tradicionalmente se habían relacionado con la $\mathrm{BH}$ in vitro no parecen ejercer un papel clave en el proceso in vivo y que las realmente implicadas podrían no haber sido aún aisladas o no ser cultivables (Belenguer et al., 2010; Huws et al., 2011; Toral et al., 2012). Así, por ejemplo, estudios basados en el uso de técnicas moleculares no han encontrado correlación entre la abundancia de B. proteoclasticus, determinada a partir del ADNr o del ARNr 16S, y la cantidad de 18:0 en el contenido ruminal (Boeckaert et al., 2008; Huws et al., 2011; Shingfield et al., 2012; Toral et al., 2012). No obstante, se ha observado que existen otras bacterias capaces de llevar a cabo determinados pasos de la BH in vitro (Li et al., 2012b; Shingfield y Wallace, 2014) y aquellas que se han podido identificar a nivel de género o especie se incluyen en la Figura 2.

Además de las rutas de $\mathrm{BH}$ previamente mencionadas, en esta figura se muestran otras vías metabólicas del 18:2n-6, entre las que destaca la formación de trans-10, cis-12 CLA y trans-10 18:1, que son de gran interés por su posible impacto sobre el rendimiento productivo y la calidad nutricional de la leche en rumiantes, ya que son AG potencialmente inhibidores de la lipogénesis mamaria (Shingfield y Griinari, 2007; Shingfield et al., 2010; Hussein et al., 2013) y el trans-10 18:1 podría tener efectos potencialmente nocivos para la salud del consumidor (Shingfield et al., 2008a). En relación a las bacterias que podrían estar implicadas, aunque Kim et al. (2002) atribuyeron la formación de trans-10, cis-12 CLA a 


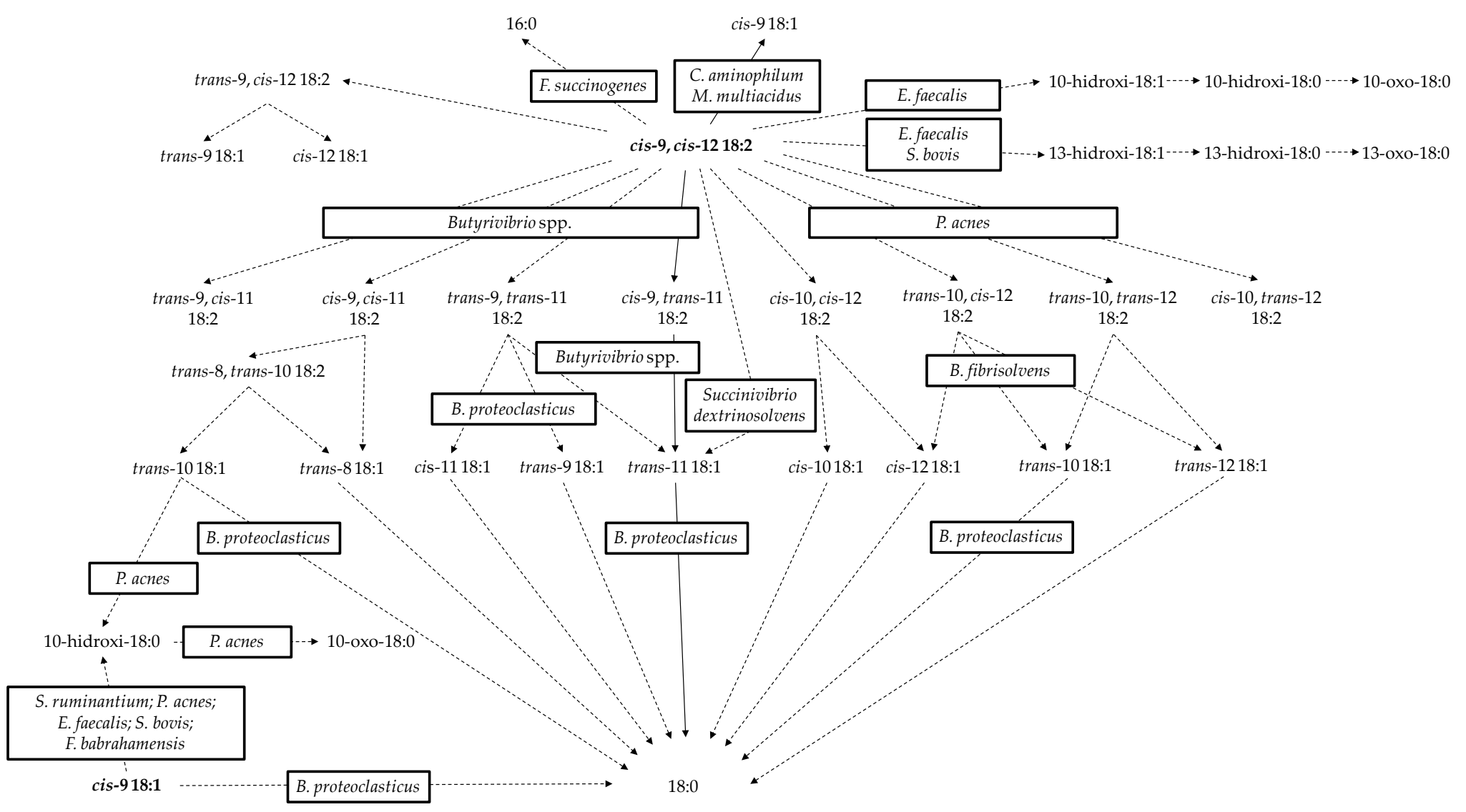

Figura 2. Principales rutas del metabolismo ruminal del cis-9 18:1 y 18.2n-6: bacterias cultivables capaces de llevar a cabo determinados pasos in vitro (datos extraídos de: Yokoyama y Davis, 1971; Kemp et al., 1975; Hudson et al., 1998; Ogawa et al., 2001; Maia et al., 2007; Shingfield y Wallace, 2014) 
Megasphaera elsdenii en un estudio in vitro, esta capacidad no ha podido confirmarse (Wallace et al., 2007; McKain et al., 2010). Sin embargo, la especie Propionibacterium acnes sí es capaz de llevar a cabo dicha isomerización en cultivo puro (McKain et al., 2010), aunque aún no hay información sobre su actividad específica (Liavonchanka et al., 2006). No obstante, P. acnes no puede hidrogenar el trans-10, cis-12 CLA a trans-10 18:1 y este paso podría implicar a algunas especies del grupo Butyrivibrio (McKain et al., 2010; Figura 2).

En cualquier caso, aún se desconoce la importancia real de todas las bacterias mencionadas en la BH ruminal (Jenkins et al., 2008; Lourenço et al., 2010; Shingfield y Walllace, 2014). En este sentido, se han llevado a cabo estudios in vivo que han sugerido que algunas poblaciones de bacterias no cultivadas pertenecientes a varios grupos taxonómicos como Clostridiales, Bacteroidales, Ruminococcaceae, Porphyromonadaceae, Lachnospiraceae, Prevotella y Anaerovorax (Boeckaert et al., 2008; Kim et al., 2008; Belenguer et al., 2010; Huws et al., 2011, 2015) podrían estar relacionadas con la BH y ejercer un papel importante en este proceso in vivo. Además, otros grupos bacterianos (e. g., Clostridium IV, Fibrobacter, Olsenella, Barnesiella, Eubacterium, Anaerophaga y Paludibacter) se han visto afectados por dietas que alteran la $\mathrm{BH}$ en el rumen y podrían participar también en este proceso (Petri et al., 2014).

En definitiva, aunque se han realizado numerosos estudios para elucidar la microbiología de la $\mathrm{BH}$ en el rumen, aún existen muchas incertidumbres al respecto (Lourenço et al., 2010; Shingfield y Wallace, 2014).

\subsubsection{Hidratación}

La hidratación de los AG insaturados en el rumen es un proceso metabólico del que aún se conoce poco y que podría ocurrir como alternativa a la $\mathrm{BH}$ para reducir el efecto tóxico de estos AG sobre el crecimiento microbiano (Maia et al., 2007; McKain et al., 2010). Como resultado se forman hidroxiácidos que a su vez pueden ser oxidados para dar lugar a cetoácidos como productos finales (Figura 2; Katz y Keeney, 1966; Jenkins et al., 2006; McKain et al., 2010). La formación de este tipo de 
metabolitos puede ser deseable, ya que los hidroxiácidos podrían tener actividad antitumoral (Abe y Sugiyama, 2005) y antiinflamatoria (Raphael et al., 2014), e incluso podrían existir microorganismos en el rumen capaces de convertir algunos isómeros (e. g., cis-12, 10-hidroxi-18:1) en cis-9, trans-11 CLA, tal y como se ha observado en especies del intestino humano (Devillard et al., 2007).

$\mathrm{Al}$ igual que en el caso de la $\mathrm{BH}$, todavía existe un elevado desconocimiento de las bacterias implicadas en este proceso en el rumen. En este sentido, se han realizado estudios in vitro que han permitido identificar especies ruminales capaces de hidratar algunos AG. Kemp et al. (1975) y Hazlewood et al. (1976) fueron los primeros en observar que una especie bacteriana ruminal, identificada entonces como Fusocillus babrahamensis, era capaz de hidratar el cis-9 18:1 a 10hidroxi-18:0 in vitro. Posteriormente, se demostró que Selenomonas ruminantium también era capaz de llevar a cabo ese proceso en cultivos puros (Hudson et al., 1995, 1996), al igual que Streptococcus bovis (Hudson et al., 1998, 2000; Maia et al., 2007) y Enterococcus faecalis (Hudson et al., 1995, 1996, 1998). Estas últimas pueden también formar el cis-9, 13-hidroxi-18:1 o el cis-12, 10-hidroxi-18:1 a partir del 18:2n-6. Por otro lado, P. acnes es la única bacteria cultivada capaz de formar 10hidroxi-18:0 y oxidarlo posteriormente a 10-oxo-18:0, tanto a partir de cis-9 18:1 como de trans-10 18:1 (McKain et al., 2010).

Toda la información descrita procede de estudios in vitro, aunque dos trabajos recientes in vivo en ovejas alimentadas con lípidos marinos (Belenguer et al., 2010; Toral et al., 2012) han mostrado cierta relación entre la concentración de 10-oxo-18:0 en el contenido ruminal y la abundancia de unas bacterias grandes y ovaladas identificadas presumiblemente como Quinella ovalis y por ello han sugerido cierta implicación de esta especie en el proceso de hidratación ruminal. Esta teoría está apoyada además por la proximidad filogenética y metabólica de $Q$. ovalis con S. ruminantium (Orpin, 1972; Krumholz et al., 1993), ya que ambas especies pertenecen al grupo IX de los Clostridiales (Selenomonas-MegasphaeraSporomusa). Sin embargo, serían necesarios más estudios para confirmar la relación entre estas bacterias grandes y ovaladas y la hidratación de AG en el rumen. 


\subsubsection{Efecto de la alimentación}

Como se ha mencionado previamente, el metabolismo de los lípidos en el rumen depende en gran medida de la nutrición. La composición de la dieta basal, la adición de lípidos ricos en AG insaturados y la interacción entre ambos factores ejercen un fuerte impacto sobre la comunidad microbiana ruminal y, por lo tanto, sobre el metabolismo lipídico (Lourenço et al., 2010).

En relación a la dieta basal, las variaciones en el tipo y proporción de forraje y concentrado pueden influir de forma considerable en la microbiota ruminal. Por ejemplo, respecto al tipo de forraje, Huws et al. (2010) observaron importantes cambios in vivo debidos al tipo de ensilado (de trébol rojo o de raigrás) en la abundancia ruminal de A. lipolyticus, así como en la de B. proteoclasticus, lo que podría implicar un efecto en la tasa de lipólisis (Jarvis y Moore, 2010; Edwards et al., 2013). No obstante, medidas simultáneas de los cambios en la BH y en la actividad lipolítica del rumen debidas al tipo de forraje no han podido confirmar in vivo su relación con la abundancia de poblaciones del grupo Butyrivibrio (Halmemies-Beauchet-Filleau et al., 2013). Conviene señalar aquí que a lo largo de este apartado se citan estudios de la abundancia de estos últimos microorganismos, a pesar de que actualmente se les atribuye una escasa importancia en la $\mathrm{BH}$ in vivo, como ejemplos del efecto de la nutrición, ya que hasta hace relativamente poco la mayor parte de los trabajos sobre microbiología del metabolismo lipídico analizaban principalmente estas poblaciones.

En referencia a los alimentos concentrados, el aumento de su proporción en la dieta basal de los rumiantes induce normalmente una disminución del pH ruminal (Bauman y Griinari, 2003; Fuentes et al., 2009), lo que inhibe el crecimiento de A. lipolyticus (Fuentes et al., 2009; Gudla et al., 2012). Esto podría conllevar una menor tasa de lipólisis y explicaría, por lo tanto, una mayor transferencia de los AG insaturados desde la dieta a la leche (Chilliard et al., 2007; Shingfield et al., 2008a). Por otra parte, la acidificación del medio también podría favorecer a bacterias potencialmente implicadas en la producción de trans-10, cis12 CLA (e. g., P. acnes; Therion et al., 1982), lo que justificaría parte de los cambios 
observados en las rutas del metabolismo lipídico en estos casos (Shingfield y Griinari, 2007). El descenso del pH, además, podría perjudicar a especies de Butyrivibrio formadoras de trans-11 18:1 (Fuentes et al., 2009, 2011).

Por otro lado, la inclusión de suplementos lipídicos ricos en AG insaturados en la dieta de los rumiantes conlleva un efecto tóxico sobre los microorganismos del rumen, cuya magnitud puede variar dependiendo del tipo de lípido (e. g., aceites de origen vegetal o lípidos de origen marino; Belenguer et al., 2010) y su grado de insaturación (podría ser mayor a medida que este aumenta; Maia et al., 2007), del nivel de inclusión (Kim et al., 2008; Toral et al., 2012) y también de la duración del periodo de suplementación (Boeckaert et al., 2008; Belenguer et al., 2010). Tanto los aceites de origen vegetal como los lípidos marinos podrían alterar la abundancia de bacterias potencialmente relacionadas con la $\mathrm{BH}$ en el rumen. Los primeros pueden causar in vivo un descenso de $B$. fibrisolvens y $R$. albus (aceites de lino y soja; Yang et al., 2009) o un incremento de bacterias no cultivadas de Lachnospiraceae (aceite de girasol; Toral et al., 2012), lo que podría contribuir a explicar una mayor concentración de determinados AG insaturados beneficiosos en la leche (e. g., cis-9, trans-11 CLA y trans-11 18:1; Hervás et al., 2008; Bernard et al., 2009b). Por otra parte, en comparación con los aceites vegetales, los lípidos marinos (i. e., aceite de pescado y microalgas marinas) provocan un efecto mayor sobre la estructura de la comunidad bacteriana del rumen (Belenguer et al., 2010; Huws et al., 2011; Toral et al., 2012), probablemente por su contenido en AG poliinsaturados de cadena larga (e. g., 20:5n-3 y 22:6n-3), que reducen la formación de 18:0 e incrementan la concentración de los isómeros 18:1 en el rumen (Boeckaert et al., 2008; Lee et al., 2008). Así, la administración de lípidos de origen marino en la dieta provoca variaciones en la estructura de la población de Butyrivibrio spp. (Boeckaert et al., 2008; Kim et al., 2008) y en la abundancia de especies no cultivadas y potencialmente implicadas en el metabolismo lipídico, tales como algunas de las familias Lachnospiraceae (Boeckaert et al., 2008; Toral et al., 2012) y Ruminococcaceae (Huws et al., 2011), o de los géneros Prevotella y Anaerovorax (Huws et al., 2011). Este tipo de lípidos también parecen favorecer a unas bacterias 
grandes y ovaladas identificadas presumiblemente como Q. ovalis que podrían ser las responsables de la acumulación de 10-oxo-18:0 en el rumen (Belenguer et al., 2010; Toral et al., 2012), como se ha explicado en la sección anterior. En relación a los estudios in vivo del efecto de la adición de estos lípidos a la dieta conviene indicar que hay pocos sobre las variaciones temporales que ocurren en la estructura de la comunidad bacteriana ruminal (Boeckaert et al., 2008; Belenguer et al., 2010). Además, estos cambios podrían ocurrir a más largo plazo del que se utiliza habitualmente (<30 días), como han sugerido las modificaciones observadas en el perfil de AG de la digesta ruminal y de la leche en ovejas que recibían una dieta suplementada con aceite de girasol y microalgas marinas (Toral et al., 2010a, 2012).

Habría que mencionar también que el efecto de los lípidos está influido por la composición de la dieta basal que recibe el animal (Chilliard y Ferlay, 2004; Gómez-Cortés et al., 2011; Gudla et al., 2012). Por ejemplo, la inclusión de aceite de girasol en la dieta indujo un incremento de bacterias del género Prevotella, potencialmente relacionadas con la BH (Huws et al., 2011) solo cuando esta contenía una elevada concentración de almidón (Zened et al., 2013). En este sentido, conviene señalar que las dietas ricas en forraje tienden a minimizar los efectos negativos de los AG insaturados, ya que promueven el funcionamiento normal del rumen para maximizar la BH (Palmquist, 1988).

\subsection{TÉCNICAS DE ESTUDIO DE LA COMUNIDAD MICROBIANA RUMINAL}

El estudio de los microorganismos que colonizan el rumen y su actividad funcional es necesario para comprender la ecología microbiana de este compartimento en general y la del metabolismo lipídico en particular. Estas cuestiones han sido estudiadas tradicionalmente mediante técnicas basadas en el cultivo. Sin embargo, el desarrollo de las técnicas modernas de biología molecular, que se apoyan en el análisis de los ácidos nucleicos, ha generado importantes avances en este campo. 


\subsubsection{Técnicas tradicionales de cultivo}

Hasta hace relativamente poco, la mayor parte de nuestro conocimiento sobre la comunidad microbiana del rumen ha derivado casi exclusivamente del empleo de técnicas basadas en el cultivo (i. e., aislamiento, enumeración y caracterización nutricional). Hungate (1944) fue el primero en conseguir establecer las condiciones apropiadas (i. e., anaerobiosis y potencial redox bajo) para cultivar microorganismos del rumen in vitro con medios de cultivo artificiales. Uno de los aspectos clave de su técnica, que ha sido mejorada posteriormente (Bryant y Robinson, 1961; Dehority, 1969; Bryant, 1972), es la composición del medio y los sustratos que se añaden, ya que determinan la especificidad del cultivo (i. e., permiten el crecimiento de unos $\mathrm{u}$ otros grupos microbianos en función de su metabolismo). Actualmente, la técnica "Hungate" continúa utilizándose en estudios ruminales (McSweeney y Mackie, 2012).

El aislamiento y cultivo de cepas puras mediante estos procedimientos anaeróbicos sigue siendo clave para estudiar su metabolismo y determinar importantes aspectos de su fisiología (McSweeney y Mackie, 2012). A pesar de ello, todas estas metodologías de cultivo presentan limitaciones debido a la complejidad de mimetizar exactamente las condiciones que los microorganismos encuentran en su hábitat natural. Factores como la existencia de requerimientos desconocidos para su crecimiento o la dificultad de reproducir las interacciones con otros microorganismos y con las células hospedadoras (Zoetendal et al., 2004) hacen que, hasta el momento, una gran parte de las bacterias ruminales no hayan podido ser cultivadas en medios artificiales (McSweeney y Mackie, 2012). No obstante, las constantes mejoras en las estrategias de aislamiento y los métodos de cultivo están permitiendo incrementar el número de especies cultivables (Kenters et al., 2011).

Estas técnicas basadas en el cultivo se han utilizado también para estimar la abundancia de determinadas poblaciones y estudiar la diversidad microbiana en el rumen. Entre las estrategias más comunes utilizadas para ello, además de los procedimientos de microbiología convencionales en cámaras de anaerobiosis, se 
encuentran la técnica de los tubos "Roll" (Hungate, 1969; Bryant, 1972), que se basa en el aislamiento y recuento de colonias en un medio sólido, y el método del número más probable (MPN por las siglas en inglés de most probable number; Dehority et al., 1989), que permite estimar la abundancia atendiendo a los cambios de $\mathrm{pH}$ durante el cultivo en tubos en medio líquido. Sin embargo, este tipo de metodologías ha llevado a subestimar de forma importante tanto la diversidad como la abundancia de los microorganismos del rumen (Orpin y Joblin, 1997; Williams y Coleman, 1997; McSweeney et al., 2007). Esto ha sido puesto de manifiesto por las nuevas técnicas moleculares, que se han desarrollado posteriormente y son las más utilizadas actualmente para estudiar la comunidad microbiana ruminal debido a sus numerosas ventajas frente a otros métodos de estudio independientes de cultivo (e. g., perfil de fosfolípidos y ácidos grasos; Ogimoto e Imai, 1981).

\subsubsection{Técnicas basadas en biología molecular}

Las técnicas moleculares basadas en el análisis de los ácidos nucleicos permiten identificar y enumerar poblaciones y caracterizar la microbiota ruminal de una forma mucho más precisa que las técnicas tradicionales, debido fundamentalmente a su capacidad de analizar la comunidad completa, incluyendo los microorganismos no cultivables (Deng et al., 2008). La mayoría de estos métodos requieren la extracción previa del material genético (ADN o ARN) de la comunidad microbiana y su amplificación mediante la técnica de la reacción en cadena de la polimerasa o PCR por las siglas de su nombre en inglés (polymerase chain reaction). Por eso es importante emplear un método de extracción adecuado $\mathrm{y}$, en el caso del ecosistema ruminal, el más extendido es el de Yu y Morrison (2004), que combina la disrupción mecánica de las células con una ruptura química y un paso final de extracción y purificación del ADN en columna.

La secuencia más utilizada para estudiar las comunidades microbianas es la del gen del ARN de la subunidad menor del ribosoma, que en los organismos procariotas se corresponde con el gen del ARNr 16S o ADNr 16S (Figura 3a). Su 
uso se ha extendido debido a una serie de características que convierten a esta molécula en un buen cronómetro evolutivo (Woese, 1987). En primer lugar, está presente en todas las células y la función universal del ARNr se traduce en una evolución genética muy lenta, por lo que la secuencia del gen correspondiente está muy conservada y su tasa de mutación proporciona información sobre la divergencia evolutiva de los organismos (Woese, 1987). Por otro lado, coexisten en su secuencia regiones altamente conservadas y otras variables o hipervariables (Figura 3b), lo que permite diseñar cebadores o sondas con mayor o menor grado de especificidad (Spiegelman et al., 2005). Este gen tiene un tamaño relativamente largo $(1500 \mathrm{pb})$ que, además de ser razonable para la amplificación y secuenciación, aporta una gran cantidad de información para la inferencia filogenética. Todo ello ha hecho posible que en la actualidad existan amplias bases de datos en continuo crecimiento, como GenBank (Bemson et al., 2004) o Ribosomal Database Project (RDP; http://cme.msu.edu; Cole et al., 2009, 2014), que recogen la secuencia del ADNr $16 \mathrm{~S}$ de numerosos microorganismos. Estas bases de datos, junto con la utilización de las herramientas bioinformáticas disponibles (e. g., QIIME, Caporaso et al., 2010), son importantes para analizar con éxito la información obtenida con la mayor parte de estas técnicas basadas en biología molecular, especialmente aquellas basadas en la secuenciación.

Así, en estudios de microbiología del rumen el ADNr 16S (o ARNr 16S) ha sido analizado de diferentes formas, por lo que las técnicas moleculares se pueden clasificar en cualitativas y cuantitativas. Las primeras se utilizan para estudiar la estructura, diversidad y dinamismo de un ecosistema (e. g., técnicas basadas en el análisis de la huella genética o en la secuenciación), mientras que las cuantitativas (e. g., PCR cuantitativa e hibridación in situ con fluorescencia) permiten determinar la abundancia de poblaciones microbianas específicas. 
a)

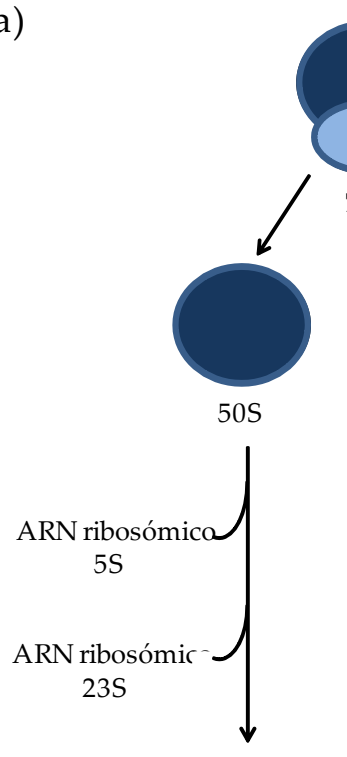

34 proteínas ribosómicas
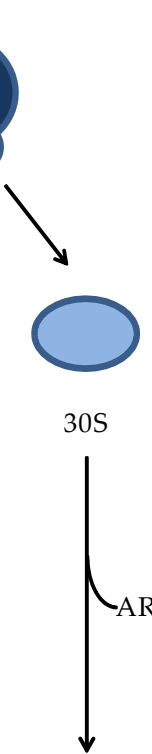

21 proteínas ribosómicas b)

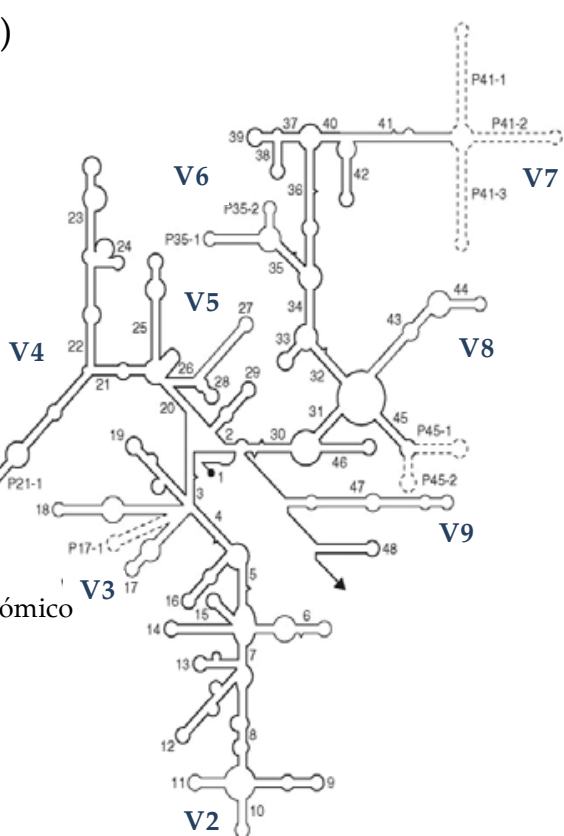

Figura 3. (a) Estructura del ribosoma procariota. (b) Disposición de las secuencias conservadas y las regiones variables (V1-V9) en la estructura secundaria del ARNr $16 S$ de las células procariotas. Adaptado de Neefs et al. (1990).

\subsubsection{Técnicas de identificación de la huella genética (fingerprinting)}

Estas técnicas permiten obtener de una manera rápida el perfil de una comunidad microbiana ("huella genética") considerando la existencia de polimorfismo en una secuencia génica (e. g., ADNr 16S; Deng et al., 2008). A continuación se describen las dos metodologías de este tipo más utilizadas en estudios de ecología microbiana del rumen, aunque existen otras menos empleadas como los microarrays o chips genéticos, el polimorfismo conformacional en la hebra sencilla (single strand conformation polymorphysm; SSCP) y el análisis de los espaciadores intergénicos ribosomales (automated ribosomal intergenic spacer analysis; ARISA).

Polimorfismo de la longitud de los fragmentos terminales de restricción (T-RFLP)

Esta técnica se basa en la utilización de enzimas de restricción, con las que se lleva a cabo la digestión de la secuencia del gen diana. Las variaciones en dicha 
secuencia determinan los puntos de corte de la enzima y, con ello, la longitud de los fragmentos obtenidos (Figura 4; Schütte et al., 2008).

La amplificación previa de un fragmento del gen diana se lleva a cabo con uno de los cebadores marcado con una molécula fluorescente en el extremo $5^{\prime}$ (Osborn et al., 2000; Schütte et al., 2008). De esta forma, tras la digestión de los productos de la PCR con una enzima de restricción (e. g., HhaI, MspI, HaeIII), solo el fragmento de ADN del extremo 5' estará marcado (fragmento terminal de restricción; T-RF). Los diferentes T-RF generados se separan en función de su tamaño por medio de electroforesis de alta resolución en un secuenciador automático de $\mathrm{ADN}$ con detector de fluorescencia. El registro de la intensidad de la fluorescencia da lugar a un perfil de picos de área y altura variables (electroferograma; Figura 4) que refleja la diversidad y abundancia de los T-RF obtenidos y que es característico de cada comunidad microbiana (Deng et al., 2008).

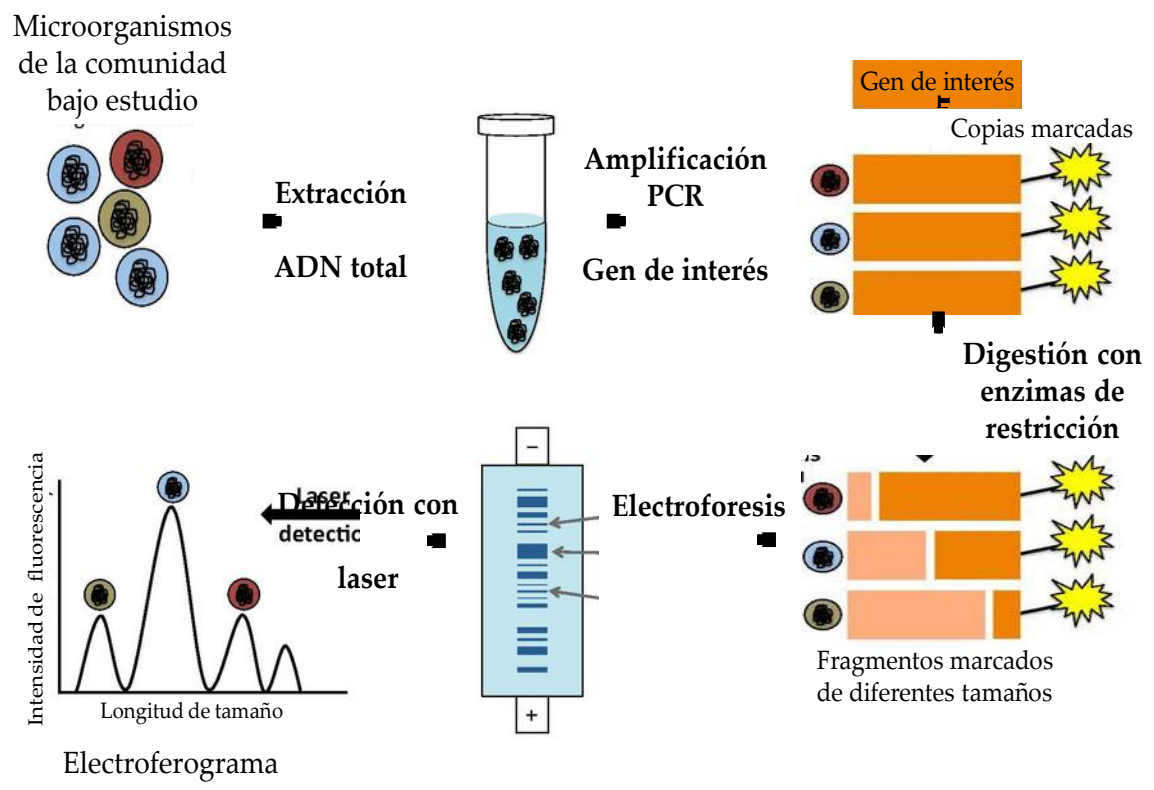

Figura 4. Esquema del desarrollo de la técnica T-RFLP. 
La asignación filogenética potencial de los T-RF es posible mediante la comparación de los resultados con los de una digestión in silico o simulada de las secuencias depositadas en las bases de datos (Dunbar et al., 2001; Kent et al., 2003). Aunque un mismo fragmento podría corresponder a diversas especies (Kent et al., 2003), el análisis de varias digestiones independientes, con diferentes enzimas de restricción, incrementa la especificidad de esta técnica, puesto que cada enzima genera un patrón de picos específico y el análisis combinado de los datos reduce el número de posibles especies bacterianas asignadas (Schütte et al., 2008). A pesar de su complejidad, la asignación filogenética potencial se ha simplificado gracias a la implementación de herramientas informáticas (Kent et al., 2003; Shyu et al., 2007).

Uno de los inconvenientes de esta técnica es que se requiere cierta información previa para una óptima elección de las enzimas de restricción. Además, solo puede detectar especies relativamente abundantes. Sin embargo, es una técnica rápida, sencilla y muy reproducible que permite comparar comunidades microbianas complejas (Deng et al., 2008), por lo que es una de las más utilizadas para el estudio de la microbiota ruminal (e. g., Yáñez-Ruiz et al., 2010; Huws et al., 2011), incluyendo trabajos sobre el efecto de la adición de lípidos a la dieta sobre la comunidad microbiana (Belenguer et al., 2010; Huws et al., 2011; Toral et al., 2012).

Electroforesis en gel con gradiente de desnaturalización (DGGE) o de temperatura (TGGE)

Estas técnicas se basan en el mismo principio, específicamente en el comportamiento de desnaturalización del $\mathrm{ADN}$, que viene determinado por su estabilidad intrínseca y esta, a su vez, por la secuencia de nucleótidos (Deng et al., 2008). En ambos casos (DGGE y TGGE) se amplifica un fragmento de entre $200 \mathrm{y}$ 700 pb (rango de tamaño óptimo; Yoon et al., 1991) del ADN de la comunidad microbiana y se une un extremo $5^{\prime}$ artificial con un alto contenido de guanina y citosina a todas las copias (Myers et al., 1985). La separación de los fragmentos resultantes se realiza en un gel de poliacrilamida con un gradiente 
desnaturalizante establecido con formamida y urea o con diferencias de temperatura (Muyzer, 1999). La migración de los fragmentos de ADN de doble cadena en el gel es cada vez más lenta conforme se alcanza el punto de desnaturalización y se van separando las hebras hasta quedar únicamente unidas por el extremo rico en guanina y citosina. Finalmente, se toma una imagen mediante un sistema de documentación de geles y se determina la intensidad de la señal de las bandas obtenidas (correspondientes a distintas secuencias) para realizar un análisis semicuantitativo de las mismas (Muyzer, 1999).

Uno de los problemas de estos métodos es que para obtener una reproducibilidad alta se requiere una estandarización minuciosa de todos los procedimientos. Además, son más laboriosas y menos sensibles que la T-RFLP. No obstante, es una técnica sencilla que no requiere elevadas inversiones y permite recoger $\mathrm{ADN}$ de las bandas de interés para secuenciarlo, aunque el tamaño del fragmento amplificado no siempre es adecuado para permitir su identificación taxonómica precisa (Ovreas, 2000). Aunque la DGGE es más común, ambos métodos han sido utilizados para estudiar la comunidad microbiana ruminal (Nicholson et al., 2007; Regensbogenova et al., 2004; Saro et al., 2014a), incluidos los microorganismos relacionados con el metabolismo lipídico (Boeckaert et al., 2008; Kim et al., 2008; Huws et al., 2011).

\subsubsection{Técnicas basadas en la secuenciación}

La secuenciación del $\mathrm{ADN}$ permite la identificación de los microorganismos con mayor o menor precisión en función del tamaño del fragmento a secuenciar y la información filogenética que contiene. La tradicional tecnología de secuenciación Sanger ha dado paso actualmente al desarrollo de nuevas plataformas que ya se aplican con éxito en el estudio del ecosistema ruminal (McCann et al., 2014).

No obstante, la construcción de bibliotecas de clones de marcadores filogenéticos y su secuenciación mediante la metodología de Sanger (Sanger et al., 1977) han sido estrategias extensamente utilizadas hasta hace poco para determinar la composición y diversidad de la microbiota ruminal. La creación de 
una biblioteca de clones consiste en insertar copias de un fragmento de ADN microbiano, normalmente del gen del ARNr 16S, previamente amplificado en un vector (generalmente plasmídico), el cual se introduce en el interior de células competentes de Escherichia coli, que se hacen crecer in vitro de tal manera que el material genético se mantendrá y replicará dentro de las mismas. Tras el cultivo de las bacterias clonadas, se extrae el ADN y se secuencia. La metodología de Sanger se basa en la interrupción controlada de la síntesis de la hebra complementaria mediante la incorporación de didesoxinucleótidos (ddNTP) terminadores de la cadena (Sanger et al., 1977). Esto genera un rango de fragmentos, cuyo tamaño se corresponde con la posición del terminador, el cual está marcado con fluorescencia. El uso de fluorocromos distintos ha permitido automatizar la separación de los fragmentos por electroforesis y la visualización para determinar su longitud (Metzker, 2005).

Se han obtenido bibliotecas de clones del ADNr $16 \mathrm{~S}$ a partir de muestras ruminales (Whitford et al., 1998; Tajima et al., 2000; Edwards et al., 2004), por lo que esta metodología ha contribuido a generar una parte importante de la información sobre secuencias de ácidos nucleicos depositadas en las bases de datos. Sin embargo, a pesar de las mejoras obtenidas y de una mayor resolución filogenética que los análisis de huella genética, estas técnicas presentan importantes limitaciones, entre ellas la laboriosidad del proceso de clonación.

Por otra parte, las técnicas de secuenciación masiva de nueva generación son capaces de secuenciar millones de fragmentos de ADN de forma paralela sin necesidad de clonación, por lo que evitan el sesgo inherente de este proceso. Además, el precio por base leída es menor que en las técnicas tradicionales, ya que se reduce la cantidad de reactivos, y su gran rendimiento las hace idóneas para el estudio de hábitats complejos como el ecosistema ruminal (Fouts et al., 2012). No obstante, el elevado coste de los aparatos y la necesidad de equipos de computación potentes y personal especializado suponen una limitación para su implantación (Mardis, 2008; Rothberg y Leamon, 2008). Actualmente los sistemas de nueva generación más utilizados son el método de pirosecuenciación 454 GS 
FLX de Roche (454 Life Science, Roche, Brandford, CT, EE.UU.), el de Illumina (San Diego, CA, EE.UU.) o el SOLiD de Applied Biosystems (Life Technologies Corporation, Carlsba, CA, EE.UU.), aunque existe otra plataforma desarrollada posteriormente, la secuenciación Ion Torrent PGM (Life Technologies). Todas estas metodologías requieren la generación de una biblioteca de fragmentos de ADN mediante amplificación por PCR, a diferencia de otras tecnologías de más reciente aparición (Pacific Biosciences, Helicos Biosciences, ZS Genetics) que, aunque ya se encuentran disponibles, no se han utilizado en los estudios de ecología ruminal publicados hasta el momento.

Para el desarrollo de la pirosecuenciación 454 GS FLX, tras la obtención de la biblioteca de fragmentos a secuenciar del gen del ARNr 16S, estos son desnaturalizados y las hebras se unen de forma individual a unas microesferas magnéticas. Cada una de estas esferas es aislada en una emulsión de agua y aceite, donde se vuelve a producir una amplificación de cada hebra (PCR en emulsión). Finalmente, cada esfera rodeada de muchas copias de un mismo fragmento se introduce en el secuenciador, donde se sintetiza la cadena complementaria. Los nucleótidos se liberan secuencialmente y cuando uno de ellos es incorporado por complementariedad, el pirofosfato liberado inicia una reacción enzimática en cadena que desemboca en la producción de luz, que es detectada por el equipo. La cantidad de luz emitida es proporcional al número de nucleótidos incorporados y se registra en forma de pirograma

Actualmente este método permite obtener secuencias de hasta $900 \mathrm{pb}$ en aproximadamente unas 24 h de duración, con una fidelidad del 99,9\% (Liu et al., 2012), lo que incrementa la cobertura y la posibilidad de detectar especies poco abundantes. Además, la incorporación de unas secuencias concretas (barcode) en los fragmentos amplificados de cada muestra permite secuenciar diferentes muestras en un único análisis e identificarlas posteriormente (Tringe y Hugenholtz, 2008), lo que incrementa el rendimiento y reduce los costes (Sogin et al., 2006). 
Presenta la limitación de producir errores en regiones homopoliméricas largas. No obstante, esta técnica permite comparar comunidades microbianas de una forma robusta, relativamente rápida y más barata que con la tecnología previa de clonación y secuenciación Sanger, por lo que ha sido utilizada en un buen número de estudios de ecología microbiana ruminal (Dowd et al., 2008; Callaway et al., 2010; de Menezes et al., 2011), aunque apenas se ha aplicado al estudio de la microbiología del metabolismo lipídico en el rumen (Zened et al., 2013).

Aunque la pirosecuenciación 454 es la más utilizada en estudios del rumen, las plataformas de secuenciación Illumina y SOLiD resuelven de forma más fiable las regiones homopoliméricas y son más baratas, especialmente la segunda. Sin embargo, son más lentas y hasta el momento la longitud de las lecturas es más limitada (hasta 400-500 pb de longitud para Illumina y 50-75 pb para SOLiD; Liu et al., 2012; Rücker et al., 2013).

Uno de los últimos métodos de secuenciación desarrollados es el Ion Torrent PGM. Es similar a la pirosecuenciación, pero la detección se realiza atendiendo a los protones liberados durante la polimerización del ADN, por cambios en el $\mathrm{pH}$. Sus principales ventajas son la velocidad de secuenciación y su menor coste, aunque la exactitud $(99,6 \%$ ) y el tamaño de las lecturas (hasta $400 \mathrm{pb}$ ) son hasta el momento menores que en la pirosecuenciación (Rücker et al., 2013).

\subsubsection{Técnicas cuantitativas}

Este tipo de técnicas permite la identificación y cuantificación de grupos microbianos concretos, siendo las que se describen a continuación las más empleadas en microbiología del rumen.

Hibridación in situ con fluorescencia (FISH)

Está basada en la detección in situ de secuencias específicas de ácidos nucleicos (e. g., ARNr 16S) mediante la hibridación selectiva de sondas de oligonucleótidos marcadas con fluorescencia (Amann, 1995). Así, además de identificar y cuantificar, este método permite la visualización directa de los microorganismos. 
A diferencia de otras técnicas moleculares no requiere la extracción del material genético, sino que las células bacterianas son fijadas directamente en la muestra y permeabilizadas para permitir la penetración de las sondas de oligonucleótidos y la posterior hibridación con la secuencia diana (Figura 5). Las sondas han de ser lo suficientemente pequeñas ( $<30$ nucleótidos) como para atravesar las membranas celulares sin afectar a su morfología o integridad (Vaughan et al., 1999). Como en otras técnicas descritas anteriormente, la secuencia diana es normalmente el ARNr 16S, debido a que, además, presenta un elevado número de copias en las células metabólicamente activas. La visualización se realiza con un microscopio de epifluorescencia y el recuento puede hacerse de forma manual o automatizada, con ayuda de un software de análisis de imagen que permita la digitalización y manipulación de las imágenes (Wagner et al., 2003).

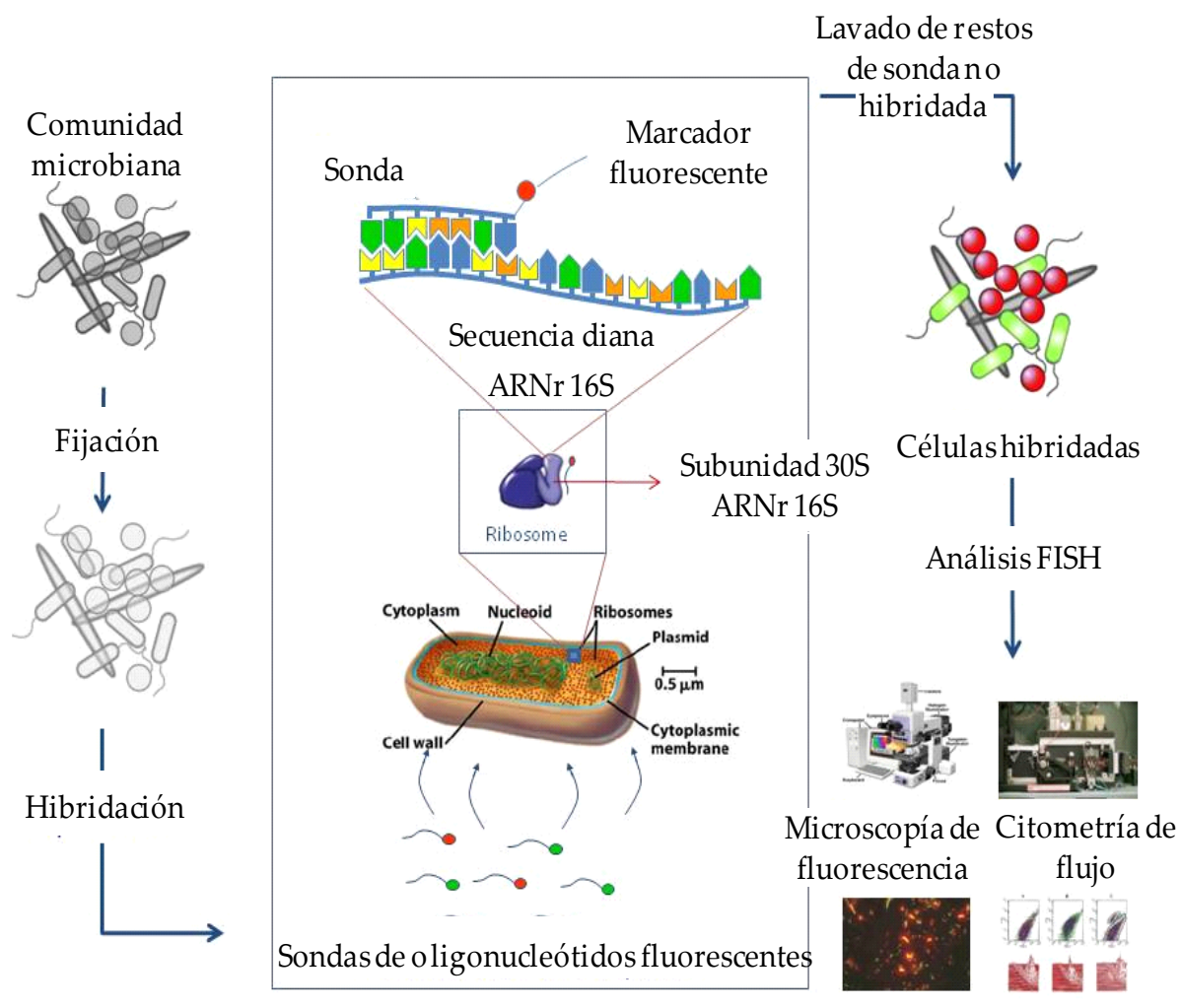

Figura 5. Esquema del proceso de marcado y visualización de células mediante FISH. 
Algunos de sus inconvenientes son que depende de la permeabilidad celular y la accesibilidad del ARNr y que presenta una baja sensibilidad (límite mínimo $10^{5}$ células $\left./ \mathrm{mL}\right)$. No obstante, además de identificar y enumerar células bacterianas, aporta información sobre su morfología y permite cuantificar el contenido celular de ARNr, lo cual sirve para estimar su actividad metabólica. Así, esta metodología ha sido utilizada con frecuencia para estudiar la microbiota digestiva (Castillo et al., 2007; Petersson et al., 2010; Belenguer et al., 2011), incluida la del rumen y los microorganismos potencialmente relacionados con el metabolismo lipídico (Belenguer et al., 2010; Kong et al., 2010).

\section{PCR cuantitativa o PCR a tiempo real ( $q P C R$ )}

Esta técnica permite determinar la abundancia de grupos microbianos mediante la combinación de la amplificación de una secuencia diana por PCR con la detección y cuantificación del producto específico. El funcionamiento es el mismo que el de la PCR convencional, aunque en este caso las copias generadas son detectadas y cuantificadas mediante la utilización de una molécula emisora de fluorescencia. La detección puede realizarse mediante agentes intercalantes como el SYBR Green, que se introduce en la doble hebra de ADN y emite fluorescencia (Wittwer et al., 1997), o mediante sondas de oligonucleótidos complementarias de una secuencia específica y marcadas con fluorocromos (Taqman y Molecular beacon; Heid et al., 1996). Estas sondas llevan unidos dos tipos de fluorocromos: un donador en el extremo $5^{\prime}$ y un aceptor en el extremo 3'. Las características de estas sondas permiten que el donador emita fluorescencia al ser excitado y que el aceptor absorba y anule la fluorescencia emitida cuando están próximos en el espacio (Wong y Medrano, 2005). Así, la fluorescencia solo será detectada en cada ciclo de PCR cuando la sonda se haya unido a la secuencia complementaria.

La cuantificación se realiza en función del número de ciclo a partir del cual la fluorescencia de la muestra es significativamente mayor a la fluorescencia basal, denominado ciclo de cuantificación $(\mathrm{Cq})$ o ciclo umbral $(\mathrm{Ct})$. Cuanto mayor sea la concentración inicial del ADN que se amplifica, antes se alcanzará este valor y 
menor será el número del Cq. Es posible cuantificar de forma relativa, expresando la abundancia del gen diana en función de la de otro gen que no varía, o absoluta, determinando el número de copias totales de la secuencia de ADN de interés a partir de una recta patrón realizada con diluciones seriadas de una muestra que contiene la secuencia de interés en una concentración conocida.

Esta técnica depende de la disponibilidad de cebadores y sondas específicas del grupo microbiano a estudiar y el coste es más elevado en comparación con otros métodos cuantitativos como FISH. No obstante, una de sus principales ventajas es la elevada sensibilidad, ya que es capaz de detectar secuencias presentes en concentraciones muy bajas. Además, permite obtener resultados de forma rápida y la cuantificación es fiable y precisa, por lo que ha sido empleada con frecuencia para cuantificar diferentes poblaciones microbianas del rumen (Tajima et al., 2001; Stevenson y Weimer, 2007; Saro et al., 2014b), incluidas aquellas capaces de biohidrogenar (Belenguer et al., 2010; Toral et al., 2012).

Una variable de esta técnica es la $q P C R$ con transcriptasa inversa (RT-PCR), que se diferencia de la qPCR en que el material genético de partida es ARN en lugar de ADN. Para su aplicación, el ARN de la muestra es transcrito a ADN complementario $(\mathrm{ADNc})$ por acción de la enzima transcriptasa inversa y es este ADNc el que se usa como molde para llevar a cabo la PCR cuantitativa (BéraMaillet et al., 2009). Esta estrategia permite cuantificar directamente el ARNr $16 \mathrm{~S}$ bacteriano, que se expresa solo en células metabólicamente activas, por lo que puede aportar información sobre la actividad metabólica de la población bacteriana de interés. De hecho, se ha utilizado en estudios de ecología ruminal para intentar relacionar determinados grupos bacterianos con algunas rutas de la BH (Huws et al., 2011). 


\section{METABOLISMO LIPÍDICO EN LOS TEJIDOS DEL ANIMAL EN LACTACIÓN}

\subsection{TEJIDO SECRETOR MAMARIO}

La glándula mamaria es el órgano responsable de la síntesis, secreción y almacenamiento de los componentes de la leche (Turner, 1952; Nickerson y Akers, 2011). Se trata de una glándula epitelial exocrina de tipo tubuloalveolar, cuyo parénquima está organizado en lóbulos constituidos por la unión de numerosos lobulillos y estos, a su vez, por la de alvéolos microscópicos que constituyen la unidad secretora funcional (Hurley, 2010; Nickerson y Akers, 2011). Los alvéolos son estructuras saculares que constan de una monocapa de células epiteliales secretoras, las cuales están en contacto con una red de capilares, responsables del aporte de nutrientes para la síntesis de los componentes de la leche, así como con células mioepiteliales, que al contraerse permiten la eyección de la leche desde la luz de los alvéolos al sistema de conductos que vierten a la cisterna mamaria (Akers, 2002; Hurley, 2010).

La grasa es uno de los componentes mayoritarios de la leche, aunque su contenido y composición pueden ser muy variables (Bauman et al., 2011b). Además de su relevancia como fuente de energía y de su influencia sobre las características físicas y organolépticas de la leche y sus derivados (Jensen, 2002; Park et al., 2007), la grasa es un determinante de su calidad nutricional por la presencia en ella de AG con propiedades bioactivas (Lock y Bauman, 2004; Shingfield et al., 2008b), tal y como se ha explicado anteriormente. Los lípidos de la leche están compuestos mayoritariamente por triglicéridos (más del 95\% del total), que contienen en torno a 400 AG diferentes (Jensen, 2002). De acuerdo con lo detallado en el apartado 1.1, su origen es doble, ya que pueden proceder tanto de la síntesis de novo en la glándula mamaria como de la captación de los AG circulantes en la sangre (Van Soest, 1994). Además, en el interior de la célula epitelial mamaria, los AG pueden ser desaturados (Bernard et al., 2013), antes de ser esterificados con el glicerol para dar lugar a los triglicéridos que serán 
secretados en los glóbulos grasos de la leche (Olivier-Bousquet, 2002; Bauman et al., 2011b).

Este proceso de lipogénesis mamaria implica la acción coordinada de una serie de enzimas cuya actividad está determinada tanto por factores genéticos o fisiológicos como ambientales, entre los cuales destaca la nutrición (Bernard et al., 2008; Bionaz y Loor, 2012). Sin embargo, aunque la aplicación de herramientas de biología molecular ha permitido avanzar en el conocimiento de los mecanismos implicados en la síntesis de grasa láctea y se ha caracterizado una buena parte de los genes que codifican las principales enzimas responsables de este proceso (Loor y Cohick, 2009; Bauman et al., 2011a; Shingfield et al., 2013), la información disponible respecto a su regulación nutricional sigue siendo muy limitada (Bauman et al., 2011a; Loor et al., 2013). Así, en las vacas se ha visto que los cambios en la composición de la leche en respuesta a la utilización de suplementos lipídicos podrían estar mediados por variaciones en la expresión de los genes de la lipogénesis (Bauman et al., 2011a; Shingfield et al., 2013), pero los escasos trabajos publicados en cabras (e. g., Ollier et al., 2009; Bernard et al., 2012; Toral et al., 2013) parecen sugerir que, en esta especie, la regulación transcripcional tendría poca relevancia en dicha respuesta. Aunque la información disponible en el ovino podría apuntar en la misma dirección que en el caprino, el número de estudios publicados hasta el momento es aún más escaso (Dervishi et al., 2012; Bichi et al., 2013b).

\subsubsection{Síntesis de ácidos grasos de novo}

En los rumiantes, las principales fuentes de carbono para la síntesis de AG son el acetato y el butirato derivados de la fermentación ruminal de los carbohidratos (Palmquist, 2006). En la célula mamaria, el acetato es activado a acetil-CoA y, mediante la acción de la acetil-CoA carboxilasa alfa (codificada por el gen $A C A C A)$, se forma malonil-CoA, a partir del cual se puede iniciar la síntesis de novo (Bernard et al., 2008; Bauman et al., 2011b). Por su parte, la activación del butirato (transformado previamente en 3-hidroxibutirato) con coenzima A permite 
su utilización directa como precursor en el proceso (Bauman et al., 2011b). A continuación, el complejo multienzimático ácido graso sintasa (codificado por el gen $F A S N$ ) cataliza ciclos sucesivos de condensación de las moléculas de acil-CoA en crecimiento con otras de malonil-CoA, extendiendo así la cadena hidrocarbonada con 2 átomos de carbono por cada ciclo, hasta un máximo de 16 (Barber et al., 1997; Bauman et al., 2011b). Esto da lugar a la síntesis de los AG pares de 4 a 16 átomos de carbono, aunque ocasionalmente se puede utilizar como precursor propionil-CoA (derivado del propionato producido en el rumen), dando lugar a la formación de AG de cadena impar (Dodds et al., 1981; Massart-Leën et al., 1983). En cualquier caso, la contribución de la síntesis de novo al porcentaje lácteo de estos últimos parece baja (Fievez et al., 2012).

En relación a la regulación de la síntesis de AG de novo, la alimentación que reciben los animales determina en buena parte su contribución al total de los AG secretados en la leche. Así, se sabe que la suplementación de la dieta con aceites vegetales insaturados inhibe la síntesis de AG de novo, reduciendo la concentración láctea de AG de cadena corta y media (Piperova et al., 2000; Bernard et al., 2005a; Toral et al., 2010a). Esta respuesta podría estar mediada por una represión de los genes ACACA y FASN (Shingfield et al., 2013) y, así, en vacas lecheras alimentadas con dietas ricas en alimentos concentrados y aceites insaturados, la inhibición en la síntesis de AG de novo se asoció a una menor abundancia del ARNm de ambos genes (Piperova et al., 2000; Ahnadi et al., 2002; Peterson et al., 2003; Angulo et al., 2012). No obstante, en estos trabajos se observó también una reducción específica en el porcentaje y secreción de grasa láctea, conocido como síndrome de baja grasa en la leche (MFD, por las siglas en inglés de milk fat depression; Bauman y Griinari, 2001). Por el contrario, en ausencia de MFD no se ha visto una relación clara entre el porcentaje de AG derivados de la síntesis de novo y la abundancia de los transcritos de ACACA y FASN en la glándula mamaria de vacas (Delbecchi et al., 2001; Murrieta et al., 2006). Así mismo, en caprino, donde no se observa MFD en respuesta a la inclusión de lípidos vegetales en la dieta, los cambios en la concentración de AG de cadena 
corta y media parecen ser independientes de la expresión de los genes implicados en su síntesis (Bernard et al., 2009a, 2009b; Ollier et al., 2009). En el ovino, por su parte, la información sobre los cambios moleculares implicados en dicha respuesta es muy limitada. Aunque los descensos en la abundancia del ARNm de ACACA y FASN parecieron explicar la menor secreción de AG de novo durante la MFD inducida por la administración del metabolito antilipogénico trans-10, cis-12 CLA en ovejas (Hussein et al., 2013), no hubo cambios en su expresión cuando este síndrome se asoció a la adición de lípidos marinos a la dieta (Bichi et al., 2013b). No obstante, en este último estudio, la dieta base estaba enriquecida con aceite de girasol, que al inhibir la síntesis de AG de novo (Hervás et al., 2008; Mele et al., 2008; Gómez-Cortés et al., 2011) podría estar enmascarando una respuesta a los lípidos marinos a este nivel.

\subsubsection{Captación de los ácidos grasos circulantes en el plasma}

Los AG que circulan por el torrente sanguíneo y están disponibles para la captación mamaria se originan a partir de los lípidos absorbidos en el tracto digestivo y de la movilización de las reservas corporales (Palmquist, 2006; Bauman et al., 2011b). En el primer caso, estos AG son transportados principalmente como triglicéridos en quilomicrones y lipoproteínas de muy baja densidad (VLDL), mientras que los segundos se encuentran en el plasma en forma de AG no esterificados (Bauman et al., 2011b). Dado que la célula epitelial mamaria solo puede captar los AG libres, la utilización de los triglicéridos plasmáticos requiere la intervención de la lipoproteinlipasa, codificada por el gen $L P L$ y localizada en la superficie luminal del endotelio capilar del tejido secretor mamario (Barber et al., 1997). Esta enzima rompe los enlaces éster y libera los AG, que alcanzan la superficie de las células secretoras mamarias y pueden atravesar su membrana mediante la acción de proteínas transportadoras o, en menor medida, difusión pasiva (Bernard et al., 2008; Bauman et al., 2011b). Aunque se desconocen aún muchos aspectos relacionados con los mecanismos de entrada de los AG en la célula mamaria y su posterior transporte intracelular, parece que la mediación de 
enzimas sería clave en ambos casos (Barber et al., 1997; Bernard et al., 2008). Entre las identificadas en el tejido mamario, las más destacables parecen ser la isoforma 3 de la proteína transportadora de ácidos grasos (codificada por el gen FAPB3) y la translocasa de AG (codificada por CD36; Doege y Stahl, 2006; Bionaz y Loor, 2008; Shingfield et al., 2010).

Tal y como se describió previamente para la síntesis de AG de novo, algunas de las estrategias nutricionales destinadas a modular el perfil lipídico de la leche también pueden alterar el proceso de captación de los AG. Así, además de inducir cambios en la composición de los AG absorbidos en el intestino y que estarían disponibles para ser utilizados por la célula epitelial mamaria, las dietas suplementadas con lípidos insaturados pueden reducir la secreción láctea de AG de cadena larga, lo que podría explicarse, en el vacuno, por descensos en la abundancia del ARNm de LPL (Ahnadi et al., 2002; Peterson et al., 2003; Harvatine y Bauman, 2006). En otros estudios, sin embargo, la inclusión de aceites o semillas de oleaginosas en la dieta de las vacas y, principalmente, de las cabras, produjeron aumentos en la proporción y secreción de AG de captación en la leche (Shingfield et al., 2008a; Chilliard et al., 2014), que en algunos casos también estuvieron asociados con cambios en la expresión de LPL (Murrieta et al., 2006; Li et al., 2012a). Otros trabajos en cabras mostraron, por el contrario, que el efecto positivo de los aceites vegetales insaturados sobre la proporción de AG de cadena larga en la leche puede producirse en ausencia de cambios en la abundancia de su ARNm (Bernard et al., 2005a, 2005b, 2009b), lo que sugiere que, en determinadas circunstancias, esta enzima podría no resultar un factor limitante para la captación de AG.

En relación a las proteínas transportadoras de AG FABP3 y CD36, existen aún muy pocos estudios disponibles acerca de la regulación nutricional de la expresión de los genes que las codifican (Peterson et al., 2003; Ollier et al., 2009; Toral et al., 2013), no habiéndose encontrado por el momento una relación clara entre esta y la proporción o secreción lácteas de AG procedentes de la captación mamaria. 
En el ovino, una vez más, la información disponible al respecto es sumamente limitada y, aunque la MFD inducida por trans-10, cis-12 CLA inhibió la expresión de LPL (Hussein et al., 2013), la suplementación de una dieta rica en aceite de girasol con microalgas marinas no indujo cambios en la abundancia del ARNm de este gen, ni tampoco de la de FABP3 (Bichi et al., 2013b).

\subsubsection{Elongación de los ácidos grasos}

En los mamíferos, las elongasas de ácidos grasos (codificadas por la familia de genes $E L O V L$ ) juegan un papel clave en la regulación de la homeostasis celular (Guillou et al., 2010). Por el momento, se han descrito 7 isoformas (ELOVL1-7) en los distintos tejidos corporales de diversas especies animales, contando con una especificidad más o menos marcada para los sustratos sobre los actúan (Jakobsson et al., 2006; Guillou et al., 2010). Sin embargo, la ausencia de una elongación del 16:0 en el tejido secretor mamario de los rumiantes, en la que estaría implicada ELOVL6, ha llevado a asumir que las células epiteliales mamarias carecen de elongasas de AG (Moore y Christie, 1981; Palmquist, 2006). Por ello, se ha prestado muy poca atención al estudio de otras isoformas de ELOVL. En este sentido, en un trabajo reciente se ha detectado la expresión de ELOVL5 en la glándula mamaria de cabras (Toral et al., 2013) y, a pesar de que la abundancia de su ARNm era considerablemente menor que la observada en los tejidos donde es más activa (e. g., tejido hepático o adiposo), parecía guardar relación con la proporción relativa de 22:5n-3, uno de sus principales productos (Jakobsson et al., 2006; Guillou et al., 2010). Sin embargo, esta abundancia no se veía modificada por la inclusión de aceite de pescado en la dieta (Toral et al., 2013).

\subsubsection{Desaturación de los ácidos grasos}

Tal y como se detalla en el apartado 2, el proceso de biohidrogenación ruminal (Jenkins et al., 2008) provoca que los AG absorbidos en el intestino de los rumiantes sean en su mayoría saturados, de ahí que la estearoil-CoA desaturasa o delta-9 desaturasa sea especialmente activa en estas especies (Bernard et al., 2013). 
Su papel en la conversión del 18:0 (punto de fusión: $69^{\circ} \mathrm{C}$ ) a cis-9 18:1 (punto de fusión: $14^{\circ} \mathrm{C}$ ) resulta, por lo tanto, clave en el mantenimiento de la fluidez de la grasa láctea (Timmen y Patton, 1988; Taylor y McGibbon, 2011).

Entre las dos isoformas del gen de la delta-9 desaturasa descritas en rumiantes (i. e., SCD1 y SCD5; Lengi y Corl, 2007), SCD1 se expresa en mayor medida que SCD5 en la glándula mamaria (Lengi y Corl, 2007; Gervais et al., 2009; Toral et al., 2013) y su estudio ha recibido gran interés debido a su impacto positivo sobre la calidad nutricional de la grasa de la leche (Griinari et al., 2000; Shingfield et al., 2008b; Bichi et al., 2012). Así, al ser su sustrato favorito el 18:0, esta enzima es responsable de la síntesis de una gran parte del cis-9 18:1 que aparece en la leche (Annison et al., 1974; Glasser et al., 2008; Frutos et al., 2014), aunque también puede introducir un doble enlace cis entre los carbonos 9 y 10 de otros AG (Bernard et al., 2013). Por ello, y dada su afinidad por el trans-11 18:1, sintetiza la mayoría del cis-9, trans-11 CLA secretado en la leche (i. e., 64-97\% en vacas, $63-73 \%$ en cabras y 51-89\% en ovejas; Glasser et al., 2008; Bernard et al., 2010; Toral et al., 2015). Además, cataliza la desaturación de otros isómeros 18:1 y 18:2 y de AG de cadena más corta, como los AG pares de 10 a 16 átomos de carbono, aunque podría haber importantes variaciones interespecíficas en la afinidad de la SCD por estos últimos (Mosley y McGuire, 2007; Bernard et al., 2013; Frutos et al., 2014). Así mismo, comparaciones indirectas han sugerido la existencia de diferencias en la regulación transcripcional de $S C D 1$ entre vacas y ovejas (Karlengen et al., 2012; Vilkki et al., 2012; Toral et al., 2015), aunque los efectos de la alimentación sobre la expresión de este gen son frecuentemente contradictorios, incluso dentro de la misma especie (Bernard et al., 2013).

Por ejemplo, algunos estudios han mostrado que la adición a la dieta de lípidos vegetales o de origen marino puede modificar la abundancia del ARNm de SCD1 en el tejido mamario de vacas (Ahnadi et al., 2002; Jacobs et al., 2011) y cabras (Bernard et al., 2005a; Li et al., 2012a). Por el contrario, otros estudios en las mismas especies observaron cambios en la concentración láctea de los sustratos y los productos de la delta-9 desaturasa, en respuesta a la suplementación lipídica, 
que no estaban ligados a variaciones en la expresión de SCD1 (Peterson et al., 2003; Harvatine y Bauman, 2006; Bernard et al., 2010). Estas diferencias han sido atribuidas a un elevado peso de la regulación de tipo postranscripcional en este gen (Bernard et al., 2013), que también podrían explicar la ausencia de modificaciones en la abundancia de su ARNm en ovejas que recibían microalgas marinas (Bichi et al., 2013b).

\subsubsection{Esterificación de los ácidos grasos}

Los triglicéridos de la leche de los rumiantes son sintetizados de forma que el glóbulo graso cuente con una adecuada fluidez a la temperatura corporal (Taylor y MacGibbon, 2011). Por lo tanto, la distribución de los AG en los tres puntos de unión al glicerol no tiene lugar de forma aleatoria (Bauman et al., 2011b). Así, se sabe que los AG de cadena corta (e. g., 4:0 y 6:0) se esterifican casi exclusivamente en el tercer carbono (sn-3; Jensen, 2002), lo que reduce la densidad del empaquetamiento y, con ello, el punto de fusión del triglicérido resultante (Hawke y Taylor, 1995; Taylor y McGibbon, 2011). Por su parte, los AG de 8 a 14 átomos de carbono se unen principalmente en la posición $s n-2$, mientras que el 18:0 suele encontrarse en sn-1 y el 16:0 se distribuye por igual entre estos dos carbonos (Jensen, 2002; Taylor y MacGibbon, 2011). Finalmente, el cis-9 18:1 muestra mayor preferencia por las posiciones sn-1 y sn-3 (Taylor y MacGibbon, 2011).

Este patrón de distribución es relativamente constante y resulta de un proceso secuencial de síntesis en el que participan varias enzimas. En primer lugar, se produce la unión de un AG en la posición sn-1 del glicerol, catalizada por la glicerol-3 fosfato aciltransferasa mitocondrial (codificada por los genes GPAT y GPAM; Bernard et al., 2008). Este paso va seguido de la esterificación de otro AG en el carbono sn-2, mediada por la 1-acilglicerol-3-fosfato O-aciltransferasa (codificada por $A G P A T$ ) y, finalmente, se ocupa la posición sn-3 por acción de la diacilglicerol O-aciltransferasa (gen DGAT; Bernard et al., 2008). Sin embargo, no se conocen bien los mecanismos implicados en la regulación nutricional de este proceso y los resultados de los pocos experimentos al respecto son inconsistentes. 
Por ejemplo, se han observado tanto reducciones como ausencia de cambios en la expresión de los genes que codifican estas enzimas durante la MFD inducida por la dieta en el vacuno (Peterson et al., 2003; Invernizzi et al., 2010), lo que podría estar ligado a los distintos suplementos lipídicos utilizados (vegetales o de origen marino). Así, mientras que la utilización de aceites vegetales aumenta la concentración de trans-10, cis-12 CLA en la leche, el aceite de pescado o las microalgas marinas no modifican significativamente el contenido lácteo de este metabolito antilipogénico (Peterson et al., 2003; Shingfield y Griinari, 2007; Bichi et al., 2013a) del cual se ha mostrado que inhibe la expresión de GPAM (Hussein et al., 2013).

\subsubsection{Síntesis y secreción del glóbulo graso}

Los triglicéridos recién formados se agrupan próximos al retículo endoplasmático, fusionándose para formar pequeñas gotas rodeadas de una membrana rica en proteínas y lípidos polares procedente de dicho orgánulo (Keenan y Mather, 2006). Estas gotitas migran por el citoplasma hasta alcanzar la superficie apical de la célula, al tiempo que se van fusionando para dar lugar a gotas de mayor tamaño (Heid y Keenan, 2005; Bauman et al., 2011b). Las gotas lipídicas se recubren entonces con una porción de la membrana plasmática de la propia célula secretora y, a continuación, son liberadas al lumen alveolar (Keenan y Mather, 2006; Bauman et al., 2011b).

La membrana del glóbulo graso resultante tiene una composición muy compleja e incluye algunas proteínas que podrían ser esenciales para la secreción de la grasa de la leche (Mather, 2000; Fong et al., 2007; Martini et al., 2010). En este sentido, la utilización de ratones como modelo de laboratorio ha demostrado que la represión total o parcial de la expresión de los genes que codifican la butirofilina $(B T N)$ y la xantina deshidrogenasa $(X D H)$, dos de las proteínas más abundantes en la membrana del glóbulo graso, provoca una acumulación de gotas de grasa en el interior de las células mamarias (Ogg et al., 2004). Además, se ha propuesto que la interacción entre estas proteínas y la perilipina 2 (codificada por el gen PLIN2) 
condiciona la unión de las gotas lipídicas intracelulares con la membrana apical de las células secretoras (McManaman et al., 2007). Otras proteínas presentes en la membrana del glóbulo graso son la lactoadherina (codificada por el factor EGF del glóbulo graso de la leche $8, M F G E 8)$ y la anteriormente mencionada CD36, que podría ejercer cierto papel en la señalización intracelular (Keenan y Mather, 2006). En cualquier caso, son muy escasos los estudios de nutrigenómica en rumiantes que cuantifican la expresión de los genes que codifican estas proteínas (Invernizzi et al., 2010; Bernard et al., 2012; Bichi et al., 2013b), por lo que aún se sabe poco acerca de su implicación real en la regulación nutricional de la lipogénesis mamaria en estas especies.

\subsubsection{Factores de transcripción implicados en la regulación nutricional de la lipogénesis} mamaria

Los factores de transcripción son proteínas con la capacidad de regular la transcripción del $\mathrm{ADN}$, por lo que, sin participar directamente en un paso específico de una ruta metabólica, pueden activar o inhibir la expresión de los genes que codifican las enzimas que intervienen en ella (Kadegowda et al., 2009; Ma y Corl, 2012; Shi et al., 2013). En relación con la lipogénesis mamaria en los rumiantes, los primeros estudios de nutrigenómica sugirieron que la represión coordinada de algunos genes durante la MFD inducida por dietas ricas en aceites insaturados (e. g., $A C A C A, F A S N, L P L, G P A T, A G P A T$ y SCD1) podría explicarse por la acción de un regulador central de la síntesis de lípidos, aunque estudios posteriores han demostrado la posible implicación de varios factores de transcripción en este proceso (ver la revisión de Bauman et al., 2011a). Los dos más importantes que han sido relacionados con la lipogénesis mamaria son el factor 1 de unión a elementos reguladores del esterol (SREBF1; Peterson et al., 2003; Ma y Corl, 2012) y el receptor gamma activado por el proliferador de peroxisomas (PPARG; Kadegowda et al., 2009; Schmitt et al., 2011; Shi et al., 2013).

El primer factor de transcripción al que se atribuyó un papel clave en la regulación de la lipogénesis mamaria fue SREBF1 (Harvatine y Bauman, 2006; Ma 
y Corl, 2012). Como otros factores de la familia $S R E B F$, la proteína codificada por esta isoforma se sintetiza en el retículo endoplasmático rugoso como un precursor inactivo, el cual permanece unido a su membrana y requiere una serie de escisiones proteolíticas y transformaciones para poder entrar en el núcleo celular, donde se une a la región promotora de los genes diana (Eberlé et al., 2004; Bernard et al., 2008). La activación de SREBF1, que resulta pues imprescindible para que ejerza su acción reguladora sobre la transcripción, podría estar mediada, a su vez, por la actuación de otros factores de transcripción (e. g., gen 1 inducido por insulina -INSIG1- y receptor hepático X alfa -LXR; Yang et al., 2002; McFadden y Corl, 2010).

Numerosos estudios in vitro e in vivo apoyan la implicación de SREBF1 en la respuesta mamaria a dietas que disminuyen el contenido y secreción de grasa láctea en los rumiantes (Peterson et al., 2004; Bauman et al., 2011a; Ma y Corl, 2012). Así, en vacas lecheras, se ha observado una relación directa entre la abundancia del ARNm de SREBF1, la concentración de grasa en la leche y la expresión de los genes de la lipogénesis que contienen elementos de unión al esterol en la región promotora (e. g., $A C A C A, F A S N$, LPL y SCD1; Harvatine y Bauman, 2006; Gervais et al., 2009). De forma similar, los descensos en la abundancia de los transcritos de SREBF1 se asociaron a la inhibición coordinada de la expresión de $A C A C A, F A S N, L P L, S C D$ y $A G P A T$ durante la MFD inducida por trans-10, cis-12 CLA en ovejas (Hussein et al., 2013). Sin embargo, en el ovino, la disminución del contenido de grasa en la leche en respuesta a las microalgas marinas no parece estar mediada por este isómero del CLA (Toral et al., 2010a; Bichi et al., 2013a), lo que podría explicar que la expresión de SREBF1 no cambie con esta estrategia nutricional (Bichi et al., 2013b). No obstante, algunos estudios han sugerido que, bajo ciertas condiciones, la acción de este factor de transcripción estaría determinada por la abundancia de su forma activada, que podría no reflejarse en la abundancia de su ARNm, de modo que los factores de transcripción ligados al proceso de activación de SREBF1 (e. g., LXR e INSIG1) 
también podrían jugar un papel relevante en la regulación de la lipogénesis mamaria (Bionaz y Loor, 2008; McFadden y Corl, 2010).

El receptor gamma activado por el proliferador de peroxisomas (PPARG) es el miembro de la familia de factores de transcripción PPAR que se ha relacionado en mayor medida con el metabolismo lipídico en la glándula mamaria de rumiantes (Bionaz y Loor, 2008; Kadegowda et al., 2009; Shi et al., 2013). A diferencia de SREBF1, PPARG codifica receptores nucleares que se activan por la unión con ligandos, como los AG poliinsaturados de cadena larga, los cuales provocan cambios en su expresión y, en consecuencia, afectan a la síntesis de grasa (Desvergne et al., 2006). Aunque los estudios al respecto aún son escasos, el cultivo de células epiteliales bovinas y caprinas mostró que PPARG parece activar la expresión de genes implicados en la síntesis y captación de AG y en su esterificación al glicerol (e. g., ACACA, FASN, LPL, FABP3, AGPAT y DGAT), así como la de otros factores de transcripción (e. g., SREBF1 e INSIG1; Kadegowda et al., 2009; Shi et al., 2013). Sin embargo, los resultados de los estudios in vivo en rumiantes alimentados con lipidos son a veces contradictorios (Invernizzi et al., 2010; Bichi et al., 2013b; Palin et al., 2014; Vahmani et al., 2014) y, aunque también parecen sugerir que $P P A R G$ juega un papel importante en el metabolismo mamario, ponen de relieve la complejidad de las redes de regulación génicas en relación a la lipogénesis y su interacción con la nutrición.

El estudio del síndrome de baja grasa en la leche también ha permitido sugerir la posible implicación de otros factores de transcripción en la síntesis de grasa láctea, pero la información al respecto es más escasa. Por ejemplo, el elemento de respuesta a la hormona tiroidea (THRSP) podría estar implicado en el efecto antilipogénico del trans-10, cis-12 CLA (Harvatine y Bauman, 2006; Bauman et al., 2011a), mientras que la chaperona SREBP (codificada por el gen SCAP) parece tener un papel importante en la respuesta de SREBF1 a dicho isómero del CLA (Eberlé et al., 2004; Bauman et al., 2011a). Sin embargo, el receptor hepático X alfa (codificado por el gen NR1H3), que actúa en forma de heterodímero con otros receptores, como el receptor $X$ alfa de los retinoides (RXRA; Lengqvist et al. 2004), 
parece estimular la lipogénesis en las células epiteliales mamarias de bovino, pero podría no tener un papel relevante en su regulación nutricional (Harvatine et al., 2014).

\subsection{TEJIDO ADIPOSO}

El tejido adiposo es un tipo especial de tejido conjuntivo caracterizado por su función de almacenamiento de energía en forma de triglicéridos (Vernon, 1980; Chilliard, 1993). En la deposición de los AG que forman estos triglicéridos están implicadas tres vías metabólicas principales. En primer lugar, una parte de los AG son sintetizados de novo en el propio adipocito, principalmente a partir de acetato y, en menor medida, de lactato (Vernon, 1980), en un proceso que implica la acción coordinada de enzimas como ACACA y FASN (Chakrabarty y Romans, 1972; Knowles et al., 1974). Como en el caso de las células secretoras mamarias, los adipocitos también puede captar AG circulantes en el plasma, utilizando preferentemente los triglicéridos transportados en los quilomicrones y las VLDL, cuyos enlaces éster rompen mediante la acción de la lipoproteinlipasa (LPL; Payne y Masters, 1971; Bonnet et al., 2000). Por último, ambos tipos de AG pueden ser elongados y desaturados (Deeth y Christie, 1979; Barber et al., 2000; Cherfaoui et al., 2012), siendo esterificados y almacenados finalmente en forma de triglicéridos (Vernon, 1980; Chilliard, 1993). Por otro lado, en situaciones de balance energético negativo, los lípidos almacenados en los tejidos adiposos pueden ser rápidamente movilizados por la acción de enzimas hidrolíticas que liberan AG no esterificados al plasma, disponibles para ser captados por otros órganos (Chilliard et al., 2000). Así pues, la cantidad de triglicéridos almacenados en los adipocitos dependerá del equilibrio entre la síntesis de AG de novo, su captación y la hidrólisis de los triglicéridos (lipólisis), en un proceso que, a nivel molecular, parece está regulado principalmente por el factor de transcripción PPARG (Rosen y MacDougald, 2006; Shingfield et al., 2010; Schmitt et al., 2011).

Debido a su implicación en la homeostasis energética, el tejido adiposo desempeña un papel fundamental durante la lactación en los rumiantes, aunque 
existen diferencias notables en la relevancia de los distintos depósitos grasos corporales en este proceso (Graham, 1964; Vernon, 1980). De forma general, durante las primeras etapas de la lactación y debido a las elevadas necesidades energéticas del tejido secretor mamario, los animales pueden experimentar un periodo de balance energético negativo durante el cual disminuye la actividad anabólica en el tejido adiposo y aumenta la movilización de las reservas (Flatt y Moe, 1974; Chilliard et al., 2000). En consecuencia, una parte importante de los AG captados por la glándula mamaria puede proceder de los depósitos grasos, lo que repercute en el perfil lipídico de la leche (Barber et al., 1997; Chilliard et al., 2003; Contreras et al., 2010). A medida que avanza la lactación, sin embargo, la capacidad lipogénica del tejido adiposo aumenta progresivamente con la finalidad de restablecer las reservas corporales, por lo que disminuye su contribución al conjunto de AG disponibles para la captación mamaria (Barber et al., 1997; Chilliard et al., 2003).

A pesar de la importante y conocida relación entre el metabolismo lipídico en los tejidos adiposos y mamario durante el ciclo de lactación, se dispone de poca información acerca de la participación del primero en la regulación nutricional de la lipogénesis mamaria y los mecanismos moleculares implicados (Thering et al., 2009a; Shingfield et al., 2013). En este sentido, se ha observado que los tratamientos que causan MFD en vacas lecheras promueven la deposición de grasa en el tejido adiposo, lo que se asoció al aumento de la transcripción de genes que codifican enzimas responsables de la adipogénesis (e. g., $L P L, S C D$ y FASN) y de sus posibles factores de transcripción (i. e., PPARG y SREBF1; Harvatine et al., 2009; Thering et al., 2009a). Esta respuesta parece explicarse por la desviación de los nutrientes no utilizados por la glándula mamaria hacia el tejido adiposo (Bauman y Griinari, 2001; Shingfield et al., 2010). En ausencia de MFD, sin embargo, la relación entre tejidos adiposo y mamario parece menos evidente, incluso cuando se producen ciertos cambios en la síntesis de grasa láctea. Así, en el caprino, los aumentos en la secreción de grasa en la leche tras la administración de lípidos vegetales no estuvieron relacionados con modificaciones relevantes en 
la expresión de los genes en el tejido adiposo (Bernard et al., 2005b, 2009a, 2009b). Además, aunque en cabras alimentadas con aceites de girasol y de pescado se observaron cambios en la abundancia del ARNm de FASN (reducción) y CD36, SREBF1 y LXRA (aumentos) en el tejido adiposo, estos no parecían relacionarse ni con su composición de AG ni con la respuesta del tejido secretor mamario a la dieta (Toral et al., 2013). En cuanto a las ovejas, la única información disponible (Bichi et al., 2013b) sugiere que, en esta especie, la MFD inducida por la ingestión de lípidos marinos no estaría asociada a cambios en la expresión génica en el tejido adiposo, pero sería necesaria más investigación al respecto para confirmar esta hipótesis.

\subsection{TÉCNICAS DE ESTUDIO DE LA EXPRESIÓN DE LOS GENES}

El análisis de las variaciones de los perfiles de expresión génica representa con frecuencia el primer paso en el estudio de los mecanismos moleculares implicados en la regulación nutricional del metabolismo. La identificación de genes o grupos de genes cuya abundancia varía en respuesta a la alimentación permite plantear hipótesis acerca de su participación en rutas metabólicas específicas (Müller y Kersten, 2003; García-Cañas et al., 2010). A partir de esta información, los estudios in vivo con modelos transgénicos (e. g., ratones knockout) en los que se inhibe la expresión de un determinado gen, han aportado información muy valiosa acerca de sus funciones biológicas (Müller y Kersten, 2003; Loor y Cohick, 2009). Sin embargo, debido al mayor coste y complejidad del trabajo con rumiantes, conseguir información equiparable en los mismos es sumamente difícil. Por ello, en el estudio de los mecanismos moleculares que intervienen en la lipogénesis mamaria se ha recurrido con frecuencia a la utilización de cultivos celulares (Bauman et al., 2008; Thering et al., 2009b; Bionaz et al., 2012).

Por otro lado, la reciente secuenciación de los genomas de especies domésticas, como la vaca y la oveja (Childers et al., 2011; Jian et al., 2014), está siendo clave en la aplicación más eficiente y fiable de las técnicas moleculares que permiten cuantificar las abundancias del ARNm in vivo, como la PCR cuantitativa 
con transcriptasa inversa o los microarrays de ADN. Por ello, la cantidad de información disponible en los rumiantes se ha multiplicado en los últimos años, ofreciendo una percepción más amplia de la relación causal entre los cambios en la dieta y en la expresión de los genes (Bauman et al., 2011a; Loor et al., 2013; Shingfield et al., 2013). Aunque la utilización de la técnica de secuenciación masiva del ARN (RNA-seq) podría suponer ventajas adicionales, como la detección de cualquier transcrito y no solo los de secuencia conocida (Wickramasinghe et al., 2014), su elevado coste y la necesidad de personal especializado suponen una limitación para su implantación. Por lo tanto, a continuación solo se describirán las técnicas moleculares más utilizadas hasta el momento en los estudios de nutrigenómica en rumiantes.

\subsubsection{PCR cuantitativa con transcriptasa inversa}

La PCR cuantitativa con transcriptasa inversa (RT-qPCR) es, probablemente, la técnica más utilizada para estudiar la expresión de los genes en los tejidos de los rumiantes (e. g., Piperova et al., 2000; Bionaz y Loor, 2008; Bichi et al., 2013b). Entre sus ventajas, cabe destacar su sensibilidad para la cuantificación del ARNm a partir de cantidades de muestra muy limitadas, a la que se une su alta especificidad y reproducibilidad, así como una relativa facilidad de aplicación (Bustin, 2000). De forma resumida, se trata de una variante de la PCR cuantitativa (ver apartado 2.3.2.3) que va precedida de una reacción de retrotranscripción, en la que el ARN extraído de la muestra se utiliza como molde para la síntesis de una cadena de ADN complementario, utilizando una enzima denominada transcriptasa inversa (Weiss et al., 1992; Bustin, 2000). A continuación, este ADN complementario se amplifica y cuantifica mediante una PCR cuantitativa convencional. Seguidamente, los resultados han de ser normalizados para tener en cuenta las variaciones en la integridad y cuantificación del ARN entre muestras, así como en la síntesis del ADN complementario (Vandesompele et al., 2002; Bonnet et al., 2013). 
A pesar de esta aparente sencillez, se trata de una técnica compleja y la relativamente baja estandarización en los protocolos de análisis y tratamiento de los resultados provoca cierta preocupación acerca de la fiabilidad de todos los resultados disponibles en la literatura científica (Vandesompele et al., 2002; Bustin et al., 2009). Por ello, y para facilitar la interpretación de los ensayos mediante RTqPCR, se ha propuesto una serie de directrices que promueven la homogeneidad entre laboratorios y la transparencia en la difusión de los resultados experimentales (Bustin et al., 2009). Algunos de los puntos clave son, por ejemplo, la medida de la integridad del ARN (i. e., valor RIN o RQI), la inclusión de controles adecuados o una normalización apropiada de los resultados (Bustin et al., 2009).

La selección de los genes de referencia es uno de los aspectos más críticos del análisis mediante RT-qPCR, recomendándose la utilización de varios genes cuya expresión sea lo más estable posible en el tipo de muestras analizadas y bajo las condiciones experimentales estudiadas (Vandesompele et al., 2002; Kadegowda et al., 2009; Bonnet et al., 2013). Por lo tanto, no existe un set de genes de referencia universal sino que ha de seleccionarse el conjunto más apropiado para cada ensayo, de ahí el número creciente de publicaciones dirigidas a proponer genes de referencia para los análisis mediante RT-qPCR (Finot et al., 2011; Modesto et al., 2013). No obstante, la información respecto a los más adecuados en los estudios de nutrigenómica es aún escasa (Bonnet et al., 2013; Paten et al., 2014) y, en el ovino, se ha tenido que recurrir con frecuencia al uso de genes de referencia propuestos en otro tipo de condiciones experimentales (Zang et al., 2011) o procedentes de publicaciones en vacuno y caprino.

\subsubsection{Microarrays de $A D N$}

En los últimos años, el estudio de la expresión de los genes mediantes microarrays o chips de ADN se ha convertido en uno de los métodos más utilizados en el campo de la transcriptómica (Loor y Cohick, 2009; García-Cañas et al., 2010). 
Un microarray de ADN típico está constituido por un conjunto de miles de oligonucleótidos o sondas fijados a un sustrato sólido, como por ejemplo una placa de vidrio, siguiendo un patrón predefinido (García-Cañas et al., 2010). Idealmente, el diseño de estas sondas está basado en la secuencia de un genoma conocido y, con frecuencia, se incluyen varias sondas para un mismo gen (Malone y Oliver, 2011). Como en el caso de la RT-qPCR, las muestras de ARN sirven de molde para la síntesis de ADN complementario, el cual se marca con fluorescencia y se utiliza para medir la expresión diferencial de los genes en las condiciones de estudio, a partir de la intensidad de la hibridación entre dicho ADN y el de las sondas incluidas en el chip (Brazma et al., 2001; Malone y Oliver, 2011). El análisis informático de las imágenes obtenidas mediante microscopía láser permite expresar dicha información en valores numéricos, lo que requiere la normalización de los datos obtenidos (Brazma et al., 2001). Por último, debido a la existencia de hibridaciones inespecíficas entre las sondas y el ADN, la mayoría de los trabajos publicados contrastan la información obtenida para los genes de mayor interés con el análisis mediante RT-qPCR (García-Cañas et al., 2010).

La identificación de genes expresados de forma diferencial en las condiciones de estudio permite establecer patrones globales de expresión para conjuntos de genes y plantear hipótesis acerca de su significado biológico (Loor y Cohick, 2009; García-Cañas et al., 2010). No obstante, hasta el momento ha sido muy poco utilizada para estudiar la regulación nutricional del metabolismo lipídico en los rumiantes domésticos (Loor et al., 2005; Ollier et al., 2007).

\section{REFERENCIAS}

Abe A and Sugiyama K 2005. Growth inhibition and apoptosis induction of human melanoma cells by $\omega$-hydroxy fatty acids. Anti-Cancer Drug. 16, 543-549.

Abecia L, Toral PG, Martín-García AI, Martínez G, Tomkins NW, Molina-Alcaide E, Newbold CJ and Yáñez-Ruiz DR 2012. Effect of bromochloromethane on methane emission, rumen fermentation pattern, milk yield, and fatty acid profile in lactating dairy goats. J. Dairy Sci. 95, 2027-2036.

Ahnadi CE, Beswick N, Delbecchi L, Kennelly JJ and Lacasse P 2002. Addition of fish oil to diets for dairy cows. II. Effects on milk fat and gene expression of mammary lipogenic enzymes. J. Dairy Res. 69, 521-531. 
Akers RM 2002. Lactation and the mammary gland (1st ed.). Iowa State University Press, Amens, IA, USA.

Amann RI 1995. In situ hybridization of micro-organisms by whole cell hybridization with rRNA-targeted nucleic acid probes. Pages 1-15 in Molecular microbial ecological manual, Akkermans ADL, van Elsas JD and de Bruijn FJ, eds. Kluwer Academic Publications, London, UK.

Angulo J, Mahecha L, Nuernberg K, Nuernberg G, Dannenberger D, Olivera M, Boutinaud M, Leroux C, Albrecht E and Bernard L 2012. Effects of polyunsaturated fatty acids from plant oils and algae on milk fat yield and composition are associated with mammary lipogenic and SREBF1 gene expression. Animal 6, 1961-1972.

Annison EF, Bickerstaffe R and Linzell JL 1974. Glucose and fatty acid metabolism in cows producing milk of low fat content. J. Agric. Sci. 82, 87-95.

Barber MC, Clegg RA, Travers MT and Vernon RG 1997. Lipid metabolism in the lactating mammary gland. Biochim. Biophys. Acta 1347, 101-126.

Barber MC, Ward RJ, Richards SE, Salter AM, Buttery PJ, Vernon RG and Travers MT 2000. Ovine adipose tissue monounsaturated fat content is correlated to depot-specific expression of the stearoyl-CoA desaturase gene. J. Anim. Sci. 78, 62-68.

Bauman DE and Griinari JM 2001. Regulation and nutritional manipulation of milk fat: low-fat milk syndrome. Livest. Prod. Sci. 70, 15-29.

Bauman DE and Griinari JM 2003. Nutritional regulation of milk fat synthesis. Ann. Rev. Nutr. 23, 203-227.

Bauman DE, Perfield J, Harvatine K and Baumgard L 2008. Regulation of fat synthesis by conjugated linoleic acid: lactation and the ruminant model. J. Nutr. 138, 403-409.

Bauman DE, Harvatine KJ and Lock AL 2011a. Nutrigenomics, rumen-derived bioactive fatty acids, and the regulation of milk fat synthesis. Pages 299-319 in Annual Review of Nutrition 31, Cousins RJ, Bier DM and Bowman BA, eds. Palo Alto, CA, USA.

Bauman DE, Mcguire MA and Harvatine KJ 2011b. Mammary gland, milk biosynthesis and secretion: milk fat. Pages 352-358 in Encyclopedia of Dairy Sciences, Fuquay JW, Fox PF and McSweeney PLH, eds. Academic Press, San Diego, CA, USA.

Belenguer A, Holtrop G, Duncan SH, Anderson SE, Calder AG, Flint HJ and Lobley GE 2011. Rates of production and utilisation of lactate by microbial communities from the human colon. FEMS Microbiol. Ecol. 77, 107-119.

Belenguer A, Toral PG, Frutos P and Hervás G 2010. Changes in the rumen bacterial community in response to sunflower oil and fish oil supplements in the diet of dairy sheep. J. Dairy Sci. $93,3275-3286$.

Benson DA, Karsch-Mizrachi I, Lipman DJ, Ostell J and Wheeler DL 2004. GenBank: update Nucleic Acids Res. 32, 23-26.

Béra-Maillet C, Mosoni P, Kwasiborski A, Suau F, Ribot Y and Forano E 2009. Development of a RT-qPCR method for the quantification of Fibrobacter succinogenes S85 glycoside hydrolase transcripts in the rumen content of gnotobiotic and conventional sheep. J. Microbiol. Meth. 77, 8-16.

Bergman EN 1990. Energy contributions of volatile fatty acids from the gastrointestinal tract in various species. Physiol Rev. 70, 567-590.

Bernard L, Leroux C and Chilliard Y 2008. Expression and nutritional regulation of lipogenic genes in the ruminant lactating mammary gland. Adv. Exp. Med. Biol. 606, 67-108. 
Bernard L, Leroux C and Chilliard Y 2013. Expression and nutritional regulation of stearoylCoA desaturase genes in the ruminant mammary gland: Relationship with milk fatty acid composition. Pages 161-193 in Stearoyl-CoA desaturase genes in lipid metabolism, Ntambi JM, ed. iSpringer Science+Business Media, New York, USA.

Bernard L, Leroux C, Bonnet M, Rouel J, Martin P and Chilliard Y 2005b. Expression and nutritional regulation of lipogenic genes in mammary gland and adipose tissues of lactating goats. J. Dairy Res. 72, 250-255.

Bernard L, Leroux C, Faulconnier Y, Durand D, Shingfield KJ and Chilliard Y 2009b. Effect of sunflower-seed oil or linseed oil on milk fatty acid secretion and lipogenic gene expression in goats fed hay-based diets. J. Dairy Res. 76, 241-248.

Bernard L, Leroux C, Rouel J, Bonnet M and Chilliard Y 2012. Effect of level and type of starchy concentrate on tissue lipid metabolism, gene expression, and milk fatty acid secretion in Alpine goats receiving a diet rich in sunflower oil. Brit. J. Nutr. 107, 1147-1159.

Bernard L, Mouriot J, Rouel J, Glasser F, Capitan P, Pujos-Guillot E, Chardigny JM and Chilliard Y 2010. Effects of fish oil and starch added to a diet containing sunflower-seed oil on dairy goat performance, milk fatty acid composition and in vivo delta-9 desaturation of $\left[{ }^{13} \mathrm{C}\right]$ vaccenic acid. Brit. J. Nutr. 104, 346-354.

Bernard L, Rouel J, Leroux C, Ferlay A, Faulconnier Y, Legrand P and Chilliard Y 2005a. Mammary lipid metabolism and milk fatty acid secretion in alpine goats fed vegetable lipids. J. Dairy Sci. 88, 1478-1489.

Bernard L, Shingfield KJ, Rouel J, Ferlay A and Chilliard Y 2009a. Effect of plant oils in the diet on performance and milk fatty acid composition in goats fed diets based on grass hay or maize silage. Brit. J. Nutr. 101, 213-224.

Biavanti B and Mattarelli P 1991. Bifidobacterium ruminantium sp. nov. and Bifidobacterium merycicum sp. nov. from the rumens of cattle. Int. J. Syst. Bacteriol. 41, 163-168.

Bichi E, Frutos P, Toral PG, Keisler D, Hervás G and Loor JJ 2013b. Dietary marine algae and its influence on tissue gene network expression during milk fat depression in dairy ewes. Anim. Feed Sci. Technol. 186, 36-44.

Bichi E, Hervás G, Toral PG, Loor JJ and Frutos P 2013a. Milk fat depression induced by dietary marine algae in dairy ewes: Persistency of milk fatty acid composition and animal performance responses. J. Dairy Sci. 96, 524-532.

Bichi E, Toral PG, Hervás G, Frutos P, Gómez-Cortés P, Juárez M and de la Fuente MA 2012. Inhibition of delta-9 desaturase activity with sterculic acid: Effect on the endogenous synthesis of cis-9 18:1 and cis-9, trans-11 18:2 in dairy sheep. J. Dairy Sci. 95, 5242-5252.

Bionaz M and Loor JJ 2008. Gene networks driving bovine milk fat synthesis during the lactation cycle. BMC Genomics 9, 366.

Bionaz M and Loor JJ 2012. Ruminant metabolic systems biology: reconstruction and integration of transcriptome dynamics underlying functional responses of tissues to nutrition and physiological state. Gene Regul. Syst. Bio. 6, 109-125.

Bionaz M, Thering BJ and Loor JJ 2012. Fine metabolic regulation in ruminants via nutrient-gene interactions: saturated long-chain fatty acids increase expression of genes involved in lipid metabolism and immune response partly through PPAR-a activation. Brit. J. Nutr. 107, 179191.

Boeckaert C, Vlaeminck B, Fievez V, Maignien L, Dijkstra J and Boon N 2008. Accumulation of trans C-18:1 fatty acids in the rumen after dietary algal supplementation is associated with changes in the Butyrivibrio community. Appl. Environ. Microbiol. 74, 6923-6930. 
Bonnet M, Bernard L, Bes S and Leroux C 2013. Selection of reference genes for quantitative realtime PCR normalisation in adipose tissue, muscle, liver and mammary gland from ruminants. Animal 7, 1344-1353.

Bonnet M, Leroux C, Faulconnier Y, Hocquette JF, Bocquier F, Martin P and Chilliard Y 2000. Lipoprotein lipase activity and mRNA are up-regulated by refeeding in adipose tissue and cardiac muscle of sheep. J. Nutr. 130, 749-756.

Brazma A, Hingamp P, Quackenbush J, Sherlock G, Spellman P, Stoecker C, Aach J, Ansorge, W, Ball CA, Causton HC, Gaasterland T, Glenisson P, Holstege FC, Kim IF, Markowitz V, Matese JC, Parkinson H, Robinson A, Sarkans U, Schulze-Kremer S, Stewart J, Taylor R, Vilo $\mathrm{J}$ and Vingron M 2001. Minimum information about a microarray experiment (MIAME)toward standards for microarray data. Nat. Genet. 29, 365-371.

Bryant MP 1972. Commentary on Hungate technique for culture of anaerobic bacteria. Am. J. Clin. Nutr. 25, 1324-1328.

Bryant MP and Robinson IM 1961. An improved nonseletive culture medium for ruminal bacteria and its use in determining non selective culture medium for ruminal bacteria and its use in determining diurnal variation in numbers of bacteria in rumen. J. Dairy Sci. 44, 14461456.

Bustin S 2000. Absolute quantification of mRNA using real-time reverse transcription polymerase chain reaction assays. J. Mol. Endocrinol. 25, 169-193.

Bustin SA, Benes V, Garson JA, Hellemans J, Huggett J, Kubista M, Mueller R, Nolan T, Pfaffl MW, Shipley GL, Vandesompele J and Wittwer CT 2009. The MIQE guidelines: minimum information for publication of quantitative real-time PCR experiments. Clin. Chem. 55, 611622.

Callaway TR, Dowd SE, Edrington TS, Anderson RC, Krueger N, Bauer N, Kononoff PJ and Nisbet DJ 2010. Evaluation of bacterial diversity in the rumen and feces of cattle fed different levels of dried distillers grains plus solubles using bacterial tag-encoded FLX amplicon pyrosequencing. J. Anim. Sci. 88, 3977-3983.

Canales RD, Luo Y, Willey JC, Austermiller B, Barbacioru CC, Boysen C, Hunkapiller K, Jensen RV, Knight CR, Lee KY, Ma Y, Maqsodi B, Papallo A, Peters EH, Poulter K, Ruppel PL, Samaha RR, Shi L, Yang W, Zhang L and Goodsaid FM 2006. Evaluation of DNA microarray results with quantitative gene expression platforms. Nat. Biotechnol. 24, 1115-1122.

Caporaso JG, Kuczynski J, Stombaugh J, Bittinger K, Bushman FD, Costello EK, Fierer N, Pena AG, Goodrich JK, Gordon JI, Huttley GA, Kelley ST, Knights D, Koenig JE, Ley RE, Lozupone CA, McDonald D, Muegge BD, Pirrung M, Reeder J, Sevinsky JR, Turnbaugh PJ, Walters WA, Widmann J, Yatsunenko T, Zaneveld J and Knight R 2010. QIIME allows analysis of high-throughput community sequencing data. Nat. Meth. 7, 335-336.

Castillo M, Skene G, Roca M, Anguita M, Badiola I, Duncan SH, Flint HJ and Martín-Orúe SM 2007. Application of $16 \mathrm{~S}$ rRNA gene-targetted fluorescence in situ hybridization and restriction fragment length polymorphism to study porcine microbiota along the gastrointestinal tract in response to different sources of dietary fibre. FEMS Microbiol. Ecol. 59, 138-146.

Czerkawski JW 1986. An introduction to rumen studies. Pergamon Press, Oxford, UK.

Chakrabarty K and Romans JR 1972. Lipogenesis in the adipose cells of the bovine (Bos taurus) as related to their intramuscular fat content. Comp. Biochem. Physiol. 41, 603-615.

Cherfaoui M, Durand D, Bonnet M, Cassar-Malek I, Bauchart D, Thomas A and Gruffat D 2012. Expression of enzymes and transcription factors involved in $n$-3 long chain PUFA 
biosynthesis in Limousin bull tissues. Lipids 47, 391-401.

Childers CP, Reese JT, Sundaram JP, Vile DC, Dickens CM, Childs KL, Salih H, Bennett AK, Hagen DE, Adelson DL and Elsik CG 2011. Bovine genome database: integrated tools for genome annotation and discovery. Nucleic Acids Res. 39, 830-834.

Chilliard Y 1993. Dietary fat and adipose tissue metabolism in ruminants, pigs, and rodents: A review. J. Dairy Sci. 76, 3897-3931.

Chilliard Y and Ferlay A 2004. Dietary lipids and forages interactions on cow and goat milk fatty acid composition and sensory properties. Repr. Nutr. Develop. 44, 467-492.

Chilliard Y, Ferlay A, Faulconnier Y, Bonnet M, Rouel J and Bocquier F 2000. Adipose tissue metabolism and its role in adaptations to undernutrition in ruminants. Proc. Nutr. Soc. 59, 129-134.

Chilliard Y, Ferlay A, Rouel J and Lamberett G 2003. A review of nutritional and physiological factors affecting goat milk lipid synthesis and lipolysis. J. Dairy Sci. 86, 1751-1770.

Chilliard Y, Glasser F, Ferlay A, Bernard L, Rouel J and Doreau M 2007. Diet, rumen biohydrogenation and nutritional quality of cow and goat milk fat. Eur. J. Lipid Sci. Technol. 109, 828-855.

Chilliard Y, Toral PG, Shingfield KJ, Rouel J, Leroux C and Bernard L 2014. Effects of diet and physiological factors on milk fat synthesis, milk fat composition and lipolysis in the goat: A short review. Small Ruminant Res. 122, 31-37.

Cole JR, Wang Q, Cardenas E, Fish J, Chai B, Farris RJ, Kulam-Syed-Mohideen AS, McGarrell DM, Marsh T, Garrity GM and Tiedje JM 2009. The ribosomal database project: improved alignments and new tools for rRNA analysis. Nucleic Acids Res. 37, 141-145.

Cole JR, Wang Q, Fish JA, Chai B, McGarrell DM, Sun Y, Brown CT, Porras-Alfaro A, Kuske CR and Tiedje JM 2014. Ribosomal Database Project: Data and tools for high throughput rRNA analysis. Nucleic Acids Res. 42, 633-642.

Contreras GA, O'Boyle NJ, Herdt TH and Sordillo LM 2010. Lipomobilization in periparturient dairy cows influences the composition of plasma nonesterified fatty acids and leukocyte phospholipid fatty acids. J. Dairy Sci. 93, 2508-2516.

de Menezes AB, Lewis E, O'Donovan M, O'Neill BF, Clipson N and Doyle EM. 2011. Microbiome analysis of dairy cows fed pasture or total mixed ration diets. FEMS Microbiol. Ecol. 78, 256-265.

Deeth H and Christie WW. 1979. Biosynthesis of triacylglycerols in ovine adipose tissue in vitro. Int. J. Biochem. 10, 577-582

Dehority BA 1969. Pectin-fermenting bacteria isolated from bovine rumen. J. Bacteriol. 99, 189196.

Dehority BA 1993. Laboratory manual for classification and morphology of rumen ciliate protozoa. CRC Press, Inc., Boca Raton, Florida, USA.

Dehority BA 2003. Rumen Microbiology. Nottingham University Press. Nottingham, UK.

Dehority BA, Tirabasso PA and Grifo AP 1989. Most-probable-number procedures for enumerating ruminal bacteria, including the simultaneous estimation of total and cellulolytic numbers in one medium. Appl. Environ. Microbiol. 55, 2789-2792.

Delbecchi L, Ahnadi CE, Kennelly JJ and Lacasse P 2001. Milk fatty acid composition and mammary lipid metabolism in Holstein cows fed protected or unprotected canola seeds. J. Dairy Sci. 84, 1375-1381. 
Deng W, Xi D, Mao H and Wanapat M 2008. The use of molecular techniques based on ribosomal RNA and DNA for rumen microbial ecosystem studies: a review. Mol. Biol. Rep. $35,265-274$.

Dervishi E, Joy M, Sanz A, Alvarez-Rodriguez J, Molino F and Calvo J 2012. Forage preservation (grazing vs. hay) fed to ewes affects the fatty acid profile of milk and CPT1B gene expression in the sheep mammary gland. BMC Vet. Res. 8, 106.

Desvergne B, Michalik L and Wahli W 2006. Transcriptional regulation of metabolism. Physiol. Rev. 86, 465-514.

Devillard E, McIntosh FM, Duncan SH and Wallace RJ 2007. Metabolism of linoleic acid by human gut bacteria: Different routes for biosynthesis of conjugated linoleic acid. J. Bacteriol. $189,2566-2570$.

Devillard E, McIntosh FM, Newbold CJ and Wallace RJ 2006. Rumen ciliate protozoa contain high concentrations of conjugated linoleic acids and vaccenic acid, yet do not hydrogenate linoleic acid or desaturate stearic acid. Brit. J. Nutr. 96, 697-704.

Dodds PF, Guadalupe M, Guzman F, Chalberg SC, Anderson GJ and Kumar S 1981. Acetoacetyl-CoA reductase activity of lactating bovine mammary fatty acid synthase. J. Biol. Chem. 256, 6282-6290.

Doege $\mathrm{H}$ and Stahl A 2006. Protein-mediated fatty acid uptake: novel insights from in vivo models. Physiology 21, 259-268.

Dowd S, Callaway T, Wallcott R, Sun Y, McKeehan T, Hagevoort R and Edrington T 2008. Evaluation of the bacterial diversity in the feces of cattle using $16 \mathrm{~S}$ rDNA bacterial tagencoded FLX amplicon pyrosequencing (bTEFAP). BMC Microbiol. 8, 125.

Dunbar J, Ticknor LO and Kuske CR 2001. Phylogenetic specificity and reproducibility and new method for analysis of terminal restriction fragment profiles of $16 \mathrm{~S}$ rRNA genes from bacterial communities. Appl. Environ. Microbiol. 67, 190-197.

Eberlé D, Hegarty B, Bossard P, Ferre P and Foufelle F 2004. SREBP transcription factors: Master regulators of lipid homeostasis. Biochimie 86, 839-848.

Edwards HD, Anderson RC, Taylor TM, Miller RK, Hardin MD, Nisbet DJ, Krueger NA and Smith SB 2013. Interactions between oil substrates and glucose on pure cultures of ruminal lipase-producing bacteria. Lipids 48, 749-755.

Edwards JE, McEwan NR., Travis AJ and Wallace RJ 2004. 16 SDNA library-based analysis of ruminal bacterial diversity. Anton. Leeuw. Int. J. G. 86, 263-281.

Eschenlauer SCP, McKain N, Walker ND, McEwan NR, Newbold CJ and Wallace RJ 2002. Ammonia production by ruminal microorganisms and enumeration, isolation, and characterization of bacteria capable of growth on peptides and amino acids from the sheep rumen. Appl. Environ. Microb. 68, 4925-4931.

Fievez V, Colman E, Castro-Montoya JM, Stefanov I and Vlaeminck B 2012. Milk odd- and branched-chain fatty acids as biomarkers of rumen function: An update. Anim. Feed Sci. Technol. 172, 51-65.

Finot L, Marnet PG and Dessauge F 2011. Reference gene selection for quantitative realtime PCR normalization: Application in the caprine mammary gland. Small Ruminant Res. 95, 20-26.

Flatt WP and Moe PW 1974. Nutritional requirements for lactation. Pages 311-347 in Lactation: A comprehensive treatise Vol. III, Larson BL and Smith VR, eds. Academic Press, New York, USA.

Fong BY, Norris CS and MacGibbon AKH 2007. Protein and lipid composition of bovine milk- 
fat-globule membrane. Int. Dairy J. 17, 275-288,

Fouts DE, Szpakowski S, Purushe J, Torralba M, Waterman RC, MacNeil MD, Alexander LJ and Nelson KE 2012. Next generation sequencing to define prokaryotic and fungal diversity in the bovine rumen. PLoS ONE 7, 11.

Frutos P, Toral PG, Ramos-Morales E, Shingfield KJ, Belenguer A and Hervás G 2014. Oral administration of cobalt acetate alters milk fatty acid composition, consistent with an inhibition of stearoyl-coenzyme A desaturase in lactating ewes. J. Dairy Sci. 97: 1036-1046.

Fuentes M, Calsamiglia S, Cardozo P and Vlaeminck B 2009. Effect of pH and level of concentrate in the diet on the production of biohydrogenation intermediates in a dual-flow continuous culture. J. Dairy Sci. 92, 4456-4466.

Fuentes MC, Calsamiglia S, Fievez V, Blanch M and Mercadal D 2011. Effect of pH on ruminal fermentation and biohydrogenation of diets rich in omega-3 or omega- 6 fatty acids in continuous culture of ruminal fluid. Anim. Feed Sci. Tech. 169, 35-45.

García-Cañas V, Simó C, León C and Cifuentes A 2010. Advances in nutrigenomics research: Novel and future analytical approaches to investigate the biological activity of natural compounds and food functions. J. Pharm. Biomed. Anal. 51, 290-304.

Gervais R, McFadden JW, Lengi AJ, Corl BA and Chouinard PY 2009. Effects of intravenous infusion of trans-10, cis-12 18:2 on mammary lipid metabolism in lactating dairy cows. J. Dairy Sci. 92, 5167-5177.

Glasser F, Ferlay A and Chilliard Y 2008. Oilseed lipid supplements and fatty acid composition of cow milk: A meta-analysis. J. Dairy Sci. 91, 4687-4703.

Gómez-Cortés P, de la Fuente MA, Toral PG, Frutos P, Juárez M and Hervás G 2011. Effects of different forage:concentrate ratios in dairy ewe diets supplemented with sunflower oil on animal performance and milk fatty acid profile. J. Dairy Sci. 94, 4578-4588.

Graham NMcC. 1964. Energy exchanges of pregnant and lactating ewes. Aust. J. Agric. Res. 15, 127-141.

Griinari JM, Corl BA, Lacy SH, Chouinard PY, Nurmela KVV and Bauman DE 2000. Conjugated linoleic acid is synthesized endogenously in lactating dairy cows by delta-9 desaturase. J. Nutr. 130, 2285-2291.

Gronow S, Munk C, Lapidus A, Nolan M, Lucas S, Hammon N, Deshpande S, Cheng J-F, Tapia R, Han C, Goodwin L, Pitluck S, Liolios K, Ivanova N, Mavromatis K, Mikhailova N, Pati A, Chen A, Palaniappan K, Land M, Hauser L, Chang Y-J, Jeffries C, Brambilla E, Rohde M, Göker M, Detter J, Woyke T, Bristow J, Eisen J, Markowitz V, Hugenholtz P, Kyrpides N and Klenk H-P 2011. Complete genome sequence of Paludibacter propionicigenes type strain (WB4T). Stand. Genom. Sci. 4, 36-44.

Gudla P, Ishlak A and AbuGhazaleh AA 2012. The effect of forage level and oil supplement on Butyrivibrio fibrisolvens and Anaerovibrio lipolytica in continuous culture fermenters. Asian Austral. J. Anim. Sci. 25, 234-239.

Guillou H, Zadravec D, Martin PGP and Jacobsson A 2010. The key roles of elongases and desaturases in mammalian fatty acid metabolism: Insights from transgenic mice. Prog. Lipid Res. 49, 186-199.

Halmemies-Beauchet-Filleau A, Kairenius P, Ahvenjärvi S, Crosley LK, Muetzel S, Huhtanen P, Vanhatalo A, Toivonen V, Wallace RJ and Shingfield KJ 2013. Effect of forage conservation method on ruminal lipid metabolism and microbial ecology in lactating cows fed diets containing a 60:40 forage-to-concentrate ratio. J. Dairy Sci. 96, 2428-2447. 
Halmemies-Beauchet-Filleau A, Kokkonen T, Lampi AM, Toivonen V, Shingfield KJ and Vanhatalo A 2011. Effect of plant oils and camelina expeller on milk fatty acid composition in lactating cows fed diets based on red clover silage. J. Dairy Sci. 94, 4413-4430.

Harfoot CG and Hazlewood GP 1997. Lipid metabolism in the rumen. Pages 382-346 in The rumen microbial ecosystem, Hobson PN and Stewart CS, eds. Chapman \& Hall, London, UK.

Harvatine KJ and Bauman DE 2006. SREBP1 and thyroid hormone responsive spot 14 (S14) are involved in the regulation of bovine mammary lipid synthesis during diet-induced milk fat depression and treatment with CLA. J. Nutr. 136, 2468-2474.

Harvatine KJ, Boisclair YR and Bauman DE 2014. Liver $x$ receptors stimulate lipogenesis in bovine mammary epithelial cell culture but do not appear to be involved in diet-induced milk fat depression in cows. Physiol. Rep. 2, e00266.

Harvatine KJ, Perfield JW and Bauman DE 2009. Expression of enzymes and key regulators of lipid synthesis is upregulated in adipose tissue during CLA-induced milk fat depression in dairy cows. J. Nutr. 139, 849-854.

Hawke TW and Taylor JC 1995. Influence of nutritional factors on the yield, composition and physical properties of milk fat. Pages 37-88 in Advanced dairy chemistry Vol. 2: Lipids, PF Fox, ed. Chapman \& Hall, London, UK.

Hazlewood G and Dawson RMC 1979. Characteristics of a lipolytic and fatty acid-requiring Butyrivibrio sp. isolated from the ovine rumen. J. Gen. Microbiol. 112, 15-27.

Hazlewood GP, Kemp P, Lander D and Dawson RMC 1976. C18-unsaturated fatty acid hydrogenation patterns of some rumen bacteria and their ability to hydrolyse exogenous phospholipid. Brit. J. Nutr. 35, 293-297.

Heid CA, Stevens J, Livak KJ and Williams PM 1996. Real time quantitative PCR. Genome Res. 6, 986-994.

Heid HW and Keenan TW 2005. Intracellular origin and secretion of milk fat globules. Eur. J. Cell Biol. 84, 245-258.

Hervás G, Luna P, Mantecón AR, Castañares N, de la Fuente MA, Juárez M and Frutos P 2008. Effect of diet supplementation with sunflower oil on milk production, fatty acid profile and ruminal fermentation in lactating dairy ewes. J. Dairy Res. 75, 399-405.

Ho YW and Barr DJS 1995. Classification of anaerobic gut fungi from herbivores with emphasis on rumen fungi from Malaysia. Pages 655-677 in Mycologia, McLaughlin D, ed. Mycological Society of America, Michigan, USA.

Hobson PN and Stewart CS 1997. The rumen microbial ecosystem. Hobson PN and Stewart CS, eds. Chapman \& Hall, London, UK.

Honkanen AM, Griinari JM, Vanhatalo A, Ahvenjärvi S, Toivonen V and Shingfield KJ 2012. Characterization of the disappearance and formation of biohydrogenation intermediates during incubations of linoleic acid with rumen fluid in vitro. J. Dairy Sci. 95, 1376-1394.

Hook SE, Wright A-DG and McBride BW 2010. Methanogens: methane producers of the rumen and mitigation strategies. Archaea 2010, 11.

Hudson JA, Cai Y, Corner RJ, Morvan B and Joblin KN 2000. Identification and enumeration of oleic acid and linoleic acid hydrating bacteria in the rumen of sheep and cows. J. Appl. Microbiol. 88, 286-292.

Hudson JA, MacKenzie CAM and Joblin KN 1995. Conversion of oleic acid to 10-hydroxystearic acid by two species of ruminal bacteria. Appl. Microbiol. Biot. 44, 1-6. 
Hudson JA, MacKenzie CAM and Joblin KN 1996. Factors affecting the formation of 10hydroxystearic acid from oleic acid by a ruminal strain of Enterococcus faecalis. Appl. Microbiol. Biot. 45, 404-407.

Hudson JA, Morvan B and Joblin KN 1998. Hydration of linoleic acid by bacteria isolated from ruminants. FEMS Microbiol. Lett. 169, 277-282.

Hungate RE 1944. Studies on cellulose fermentation I. The culture and physiology of an anaerobic cellulose digesting bacterium. J. Bacteriol. 48:499-513

Hungate RE 1969. A roll tube method for cultivation of strict anaerobes. Pages 117-132 en Methods in microbiology, Norris JR and Ribbons DW, eds. Academic Press, New York, USA.

Hurley WL 2010. Lactation biology website. Retrieved May 23, 2013, from http://classes.ansci.illinois.edu/ansc438/index.html

Hussein M, Harvatine KH, Weerasinghe WMPB, Sinclair LA and Bauman DE 2013. Conjugated linoleic acid-induced milk fat depression in lactating ewes is accompanied by reduced expression of mammary genes involved in lipid synthesis. J. Dairy Sci. 96, 3825-3834.

Huws SA, Kim EJ, Cameron SJS, Girdwood SE, Davies L, Tweed J, Vallin H and Scollan ND 2015. Characterization of the rumen lipidome and microbiome of steers fed a diet supplemented with flax and echium oil. Microbial Biotech. doi. 10.1111/1751-7915.12164

Huws SA, Kim EJ, Kingston-Smith AH, Lee MRF, Muetzel SM, Cookson AR, Newbold CJ, Wallace RJ and Scollan ND 2009. Rumen protozoa are rich in polyunsaturated fatty acids due to the ingestion of chloroplasts. FEMS Microbiol. Ecol. 69, 461-471.

Huws SA, Kim EJ, Lee MRF, Scott MB, Tweed JKS, Pinloche E, Wallace RJ and Scollan ND 2011. As yet uncultured bacteria phylogenetically classified as Prevotella, Lachnospiraceae incertae sedis and unclassified Bacteroidales, Clostridiales and Ruminococcaceae may play a predominant role in ruminal biohydrogenation. Environm. Microbiol. 13, 1500-1512.

Huws SA, Lee MRF, Muetzel SM, Scott TW, Wallace RJ and Scollan ND 2010. Forage type and fish oil cause shifts in rumen bacterial diversity. FEMS Microbiol. Ecol. 73, 396-407.

Invernizzi G, Thering BJ, McGuire MA, Savoini G and Loor JJ 2010. Sustained upregulation of stearoyl-CoA desaturase in bovine mammary tissue with contrasting changes in milk fat synthesis and lipogenic gene networks caused by lipid supplements. Funct. Integr. Genomics 10, 561-575.

Jacobs AAA, van Baal J, Smits MA, Taweel HZH, Hendriks WH, van Vuuren AM and Dijkstra J 2011. Effects of feeding rapeseed oil, soybean oil, or linseed oil on stearoyl-CoA desaturase expression in the mammary gland of dairy cows. J. Dairy Sci, 94, 874-887.

Jakobsson A, Westerberg R and Jacobsson A 2006. Fatty acid elongases in mammals: Their regulation and roles in metabolism. Prog. Lipid Res. 45, 237-249.

Jami E and Mizrahi I 2012. Composition and similarity of bovine rumen microbiota across individual animals. PLoS ONE 7, e33306.

Jarvis GN and Moore ERB 2010. Lipid metabolism and the rumen microbial ecosystem. Pages 2245-2257 in Handbook of hydrocarbon and lipid microbiology, Timmis KN, McGenity TJ, Meer JR and de Lorenzo V, eds. Springer-Verlag Berlin Heidelberg, New York, USA.

Jenkins TC, AbuGhazaleh AA, Freeman S and Thies EJ 2006. The production of 10hydroxystearic and 10-ketostearic acids is an alternative route of oleic acid transformation by the ruminal microbiota in cattle. J. Nutr. 136, 926-931.

Jenkins TC, Wallace RJ, Moate PJ and Mosley EE 2008. Recent advances in biohydrogenation of 
unsaturated fatty acids within the rumen microbial ecosystem. J. Anim. Sci. 86, 397-412.

Jensen RG 2002. The composition of bovine milk lipids: January 1995 to December 2000. J. Dairy Sci. 85, 295-350.

Jiang Y, Xie M, Chen W, Talbot R, Maddox JF, Faraut T, Wu C, Muzny DM, Li Y, Zhang W, Stanton JA, Brauning R, Barris WC, Hourlier T, Aken BL, Searle SMJ, Adelson DL, Bian C, Cam GR, Chen Y, Cheng S, DeSilva U, Dixen K, Dong Y, Fan G, Franklin IR, Fu S, FuentesUtrilla P, Guan R, Highland MA, Holder ME, Huang G, Ingham AB, Jhangiani SN, Kalra D, Kovar CL, Lee SL, Liu W, Liu X, Lu C, Lv T, Mathew T, McWilliam S, Menzies M, Pan S, Robelin D, Servin B, Townley D, Wang W, Wei B, White SN, Yang X, Ye C, Yue Y, Zeng P, Zhou Q, Hansen JB, Kristiansen K, Gibbs RA, Flicek P, Warkup CC, Jones HE, Oddy VH, Nicholas FW, McEwan JC, Kijas JW, Wang J, Worley KC, Archibald AL, Cockett N, Xu X, Wang W and Dalrymple BP 2014. The sheep genome illuminates biology of the rumen and lipid metabolism. Science 344, 1168-1173.

Kadegowda AKG, Bionaz M, Piperova LS, Erdman RA and Loor JJ 2009. Peroxisome proliferator-activated receptor-gamma activation and long-chain fatty acids alter lipogenic gene networks in bovine mammary epithelial cells to various extents. J. Dairy Sci. 92, 42764289.

Karlengen IJ, Harstad OM, Taugbol O, Berget I, Aastveit AH and Vage DI 2012. The effect of excess cobalt on milk fatty acid profiles and transcriptional regulation of $S C D, F A S N$, $D G A T 1$ and DGAT2 in the mammary gland of lactating dairy cows. J. Anim. Physiol. Anim. Nutr. 96, 1065-1073,

Katz I and Keeney M 1966. Occurrence of ketostearic acids in rumen. J. Dairy Sci. 49, 967.

Keenan TW and Mather IH 2006. Intracellular origin of milk fat globules and the nature of the milk fat globule membrane. Pages 137-171 in Advanced dairy chemistry Vol. 2: Lipids, Fox PF and McSweeney PLH, eds. Springer, New York, USA.

Keeney M 1970. Lipid metabolism in the rumen. Pages 489-503 in Physiology of digestion and metabolism in the ruminant, Phillipson AT, Annison EF, Armstrong DG, Balch CC, Comline RS, Hardy RN, Hobson PN and Keynes PD, eds. Oriel Press, Newcastle, UK.

Kemp P and Lander D 1984. Hydrogenation in vitro of alpha-linolenic acid to stearic acid by mixed cultures of pure strains of rumen bacteria. J. Gen. Microbiol. 130, 527-533.

Kemp P, White R and Lander D 1975. The hydrogenation of unsaturated fatty acids by five bacterial isolateds from the sheep rumen, including a new species. J. Gen. Microbiol. 90, 100114.

Kent AD, Smith DJ, Benson,BJ and Triplett EW 2003. Web-based phylogenetic assignment tool for analysis of terminal restriction fragment length polymorphism profiles of microbial communities. Appl. Environ. Microbiol. 69, 6768-6776.

Kenters N, Henderson G, Jeyanathan J, Kittelmann S and Janssen PH 2011. Isolation of previously uncultured rumen bacteria by dilution to extinction using a new liquid culture medium. J. Microbiol. Meth. 84, 52-60.

Kim EJ, Huws SA, Lee MRF, Wood JD, Muetzel SM, Wallace RJ and Scollan ND 2008. Fish oil increases the duodenal flow of long chain polyunsaturated fatty acids and trans-11 18:1 and decreases 18:0 in steers via changes in the rumen bacterial community. J. Nutr. 138, 889-896.

Kim M and Yu Z 2012. Quantitative comparisons of select cultured and uncultured microbial populations in the rumen of cattle fed different diets. J. Anim. Sci. Biotech. 3, 28.

Kim YJ, Liu RH, Rychlik JL and Russell JB 2002. The enrichment of a ruminal bacterium (Megasphaera elsdenii YJ-4) that produces the trans-10, cis-12 isomer of conjugated linoleic 
acid. J. Appl. Microbiol. 92, 976-982.

Knowles SE, Jarret IG, Filsell OH and Ballard FJ 1974. Production and utilization of acetate in mammals. Biochem. J. 142, 401-411.

Koenig KM, Newbold CJ, McIntosh FM and Rode LM 2000. Effects of protozoa on bacterial nitrogen recycling in the rumen. J. Anim. Sci. 78, 2431-2445.

Kong YH, He ML, McAlister TA, Seviour R and Forster R 2010. Quantitative fluorescence in situ hybridization of microbial communities in the rumen of cattle fed different diets. Appl. Environ. Microbiol. 76, 6933-6938.

Krause DO, Nagaraja TG, Wright ADG and Callaway TR 2013. Board-invited review: Rumen microbiology: Leading the way in microbial ecology. J. Anim. Sci. 91, 331-341.

Krumholz LR, Bryant MP, Brulla WJ, Vicini JL, Clark JH and Stahl DA 1993. Proposal of Quinella ovalis gen. nov., sp. nov., based on phylogenetic analysis. Int. J. Syst. Bacteriol. 43, 293-296.

Leahy SC, Kelly WJ, Ronimus RS, Wedlock N, Altermann E and Attwood GT 2013. Genome sequencing of rumen bacteria and archaea and its application to methane mitigation strategies. Animal 7, 235-243.

Leahy SC, Kelly WJ, Altermann E, Ronimus RS, Yeoman CJ, Pacheco DM, Li D, Kong Z, McTavish Z, Sang C, Lambie SC, Janssen PH, Dey D and Attwood GT 2010. The genome sequence of the rumen methanogen Methanobrevibacter ruminantium reveals new possibilities for controlling ruminant methane emissions. PLoS ONE 5, e8926.

Lee HJ, Jung JY, Oh YK, Lee SS, Madsen EL and Jeon CO 2012. Comparative survey of rumen microbial communities and metabolites across one caprine and three bovine groups, using bar-coded pyrosequencing and $1 \mathrm{H}$ nuclear magnetic resonance spectroscopy. Appl. Environ. Microbiol. 78, 5983-5993.

Lee MRF, Shingfield KJ, Tweed JKS, Toivonen V, Huws SA and Scollan ND 2008. Effect of fish oil on ruminal biohydrogenation of $\mathrm{C} 18$ unsaturated fatty acids in steers fed grass or red clover silages. Animal 2, 1859-1869.

Lengi A and Corl B 2007. Identification and characterization of a novel bovine stearoyl-CoA desaturase isoform with homology to human SCD5. Lipids 42, 499-508.

Lengqvist J, Mata De Urquiza A, Bergman AC, Willson TM, Sjovall J and Perlmann T 2004. Polyunsaturated fatty acids including docosahexaenoic and arachidonic acid bind to the retinoid X receptor alpha ligand-binding domain. Mol. Cell. Proteomics 3, 692-703.

Lennarz WJ 1966. Lipid metabolism in the bacteria. Adv. Lipid Res. 4, 175-225.

Li D, Wang J and Bu D 2012b. Ruminal microbe of biohydrogenation of trans-vaccenic acid to stearic acid in vitro. BMC Res. Notes 5, 97.

Li XZ, Yan CG, Lee HG, Choi CW and Song MK 2012a. Influence of dietary plant oils on mammary lipogenic enzymes and the conjugated linoleic acid content of plasma and milk fat of lactating goats. Anim. Feed Sci. Technol. 174, 26-35.

Li Z, Liu H, Li G, Bao K, Wang K, Xu C, Yang Y, Yang F and Wright A-D 2013. Molecular diversity of rumen bacterial communities from tannin-rich and fiber-rich forage fed domestic Sika deer (Cervus nippon) in China. BMC Microbiol. 13, 151.

Liavonchanka A, Hornung E, Feussner I and Rudolph MG 2006. Structure and mechanism of the Propionibacterium acnes polyunsaturated fatty acid isomerase. Proc. Natl. Acad. Sci. USA 103, 2576-2581.

Liggenstoffer AS, Youssef NH, Couger MB and Elshahed MS 2010. Phylogenetic diversity and 
community structure of anaerobic gut fungi (phylum Neocallimastigomycota) in ruminant and non-ruminant herbivores. ISME J. 4, 1225-1235.

Liu L, Li Y, Li S, Hu N, He Y, Pong R, Lin D, Lu L and Law N 2012. Comparison of nextgeneration sequencing systems. J. Biomed. Biotechnol. 2012: 251364.

Lock AL and Bauman DE 2004. Modifying milk fat composition of dairy cows to enhance fatty acids beneficial to human health. Lipids 39, 1197-1206.

Loor JJ, Bionaz M and Drackley JK 2013. Systems physiology in dairy cattle: nutritional genomics and beyond. Annu. Rev. Anim. Biosci. 1, 365-392.

Loor JJ and Cohick WS 2009. ASAS centennial paper: lactation biology for the twenty-first century. J. Anim. Sci. 87, 813-824.

Loor JJ, Piperova LS, Everts RE, Rodriguez-Zas SL, Drackley JK, Erdman RA and Lewin HA. 2005. Mammary gene expression profiling in cows fed a milk fat-depressing diet using a bovine 13,000 oligonucleotide microarray. J. Anim. Sci. 83 (Suppl 1), 120.

Lourenço M, Ramos-Morales E and Wallace RJ 2010. The role of microbes in rumen lipolysis and biohydrogenation and their manipulation. Animal 4, 1024-1036.

Ma L and Corl BA 2012. Transcriptional regulation of lipid synthesis in bovine mammary epithelial cells by sterol regulatory element binding protein-1. J. Dairy Sci. 95, 3743-3755.

Mackie RI, McSweeney CS and Klieve AV 2002. Microbial ecology of the ovine rumen. Pages 7194 in Sheep nutrition, Freer M and Dove H, eds. Oxon, New York, USA.

Maia MRG, Chaudhary LC, Figueres L and Wallace RJ 2007. Metabolism of polyunsaturated fatty acids and their toxicity to the microflora of the rumen. Anton. Leeuw. Int. J. G. 91, 303314.

Maia MRG, Chaudhary LC, Bestwick CS, Richardson AJ, McKain N, Larson TR, Graham IA and Wallace RJ 2010. Toxicity of unsaturated fatty acids to the biohydrogenating ruminal bacterium, Butyrivibrio fibrisolvens. BMC Microbiol. 10, 52-61.

Malone JH and Oliver B 2011. Microarrays, deep sequencing and the true measure of the transcriptome. BMC Biology 9, 34.

Mardis ER 2008. Next-generation DNA sequencing methods. Annu. Rev. Genomics Hum. Genet. 9, 387-402.

Martínez Marín AL, Gómez-Cortés P, Gómez Castro AG, Juárez M, Pérez Alba LM, Pérez Hernández M and de la Fuente MA 2011. Animal performance and milk fatty acid profile of dairy goats fed diets with different unsaturated plant oils. J. Dairy Sci. 94, 5359-5368.

Martini M, Salari F, Pesi R and Tozzi MG 2010. Relationship between activity of some fat globule membrane enzymes and the lipidic fraction in ewes' milk: Preliminary studies. Int. Dairy J. 20, 61-64.

Massart-Leën AM, Roets E, Peeters G and Verbeke R 1983. Propionate for fatty acid synthesis by the mammary gland of the lactating goat. J. Dairy Sci. 66, 1445-1454.

Mather IH 2000. A review and proposed nomenclature for major proteins of the milk-fat globule membrane. J. Dairy Sci. 83, 203-247.

McCann JC, Wickersham TA and Loor JJ 2014. High-throughput methods redefine the rumen microbiome and its relationship with nutrition and metabolism. Bioinform. Biol. Insights 8, 109-125.

McFadden JW and Corl BA 2010. Activation of liver X receptor (LXR) enhances de novo fatty acid synthesis in bovine mammary epithelial cells. J. Dairy Sci. 93, 4651-4658. 
McKain N, Shingfield KJ and Wallace RJ 2010. Metabolism of conjugated linoleic acids and 18:1 fatty acids by ruminal bacteria: products and mechanisms. Microbiol. 156, 579-588.

McManaman J, Russell T, Schaack J, Orlicky D and Robenek H 2007. Molecular determinants of milk lipid secretion. J. Mammary Gland Biol. 12, 259-268.

McSweeney C and Mackie R 2012. Microorganisms and ruminant digestion: State of knowledge, trends and future prospects. Commission on Genetic Resources for Food and Agriculture. Background study paper 61. Food and Agriculture Organisation, United Nations, Rome, Italy.

McSweeney C, Denman, SE, Wright ADG and Yu Z 2007. Application of recent DNA/RNAbased techniques in rumen ecology. Asian Aust. J. Anim. Sci. 20, 283-294.

Mele M, Sarra A, Buccioni A, Conte G, Pollicardo A and Secchiari P 2008. Effect of soybean oil supplementation on milk fatty acid composition from Saanen goats fed diets with different forage:concentrate ratios. Ital. J. Anim. Sci. 7, 297-311.

Metzker ML 2005. Emerging technologies in DNA sequencing. Genome Res. 15, 1767-1776.

Miller ME, Yeoman CJ, Chia N, Tringe SG, Angly FE, Edwards RA, Flint HJ, Lamed R, Bayer EA and White BA 2012. Phage-bacteria relationships and CRISPR elements revealed by a metagenomic survey of the rumen microbiome. Environ. Microbiol. 14, 207-227.

Modesto P, Peletto S, Pisoni G, Cremonesi P, Castiglioni B, Colussi S, Caramelli M, Bronzo V, Moroni P and Acutis PL 2013. Evaluation of internal reference genes for quantitative expression analysis by real-time reverse transcription-PCR in somatic cells from goat milk. J. Dairy Sci. 96, 7932-7944.

Moon C, Pacheco D, Kelly W, Leahy S, Li D and Kopecny J 2008. Reclassification of Clostridium proteoclasticum as Butyrivibrio proteoclasticus comb. nov., a butyrate producing ruminal bacterium. Int. J. Syst. Evol. Microbiol. 58, 2041-2045.

Moore JH and Christie WW 1981. Lipid metabolism in the mammary gland of ruminant animals. Pages 227-278 in Lipid metabolism in ruminant animals, Christie WW, ed. Pergamon Press Ltd, Oxford, UK

Morotomi M, Nagai F, Sakon H and Tanaka R 2009. Paraprevotella clara gen. nov., sp. nov. and Paraprevotella xylaniphila sp. nov., members of the family Prevotellaceae isolated from human faeces. Int. J. Syst. Evol. Micr. 59, 1895-1900.

Mosley EE and McGuire MA 2007. Methodology for the in vivo measurement of the delta-9 desaturation of myristic, palmitic, and stearic acids in lactating dairy cattle. Lipids 42, 939945.

Müller M and Kersten S 2003. Nutrigenomics: goals and strategies. Nat. Rev. Genet. 4, 315-322.

Murrieta CM, Hess BW, Scholljegerdes EJ, Engle TE, Hossner KL, Moss GE and Rule DC 2006. Evaluation of milk somatic cells as a source of mRNA for study of lipogenesis in the mammary gland of lactating beef cows supplemented with dietary high-linoleate safflower seeds. J. Anim. Sci. 84, 2399-2405,

Muyzer G 1999. DGGE/TGGE a method for identifying genes from natural ecosystems. Curr. Opin. Microbiol. 2, 317-322.

Myers RM, Fischer SG, Lerman LS and Maniatis T 1985. Nearly all single base substitutions in DNA fragments joined to a GC clamp can be detected by denaturing gradient gelelectrophoresis. Nucleic Acids Res. 13, 3131-3145.

Nam IS and Garnsworthy PC 2007. Biohydrogenation of linoleic acid by rumen fungi compared with rumen bacteria. J. App. Microbiol. 103, 551-556. 
Neefs JM, Van de Peer Y, Hendriks L and de Wachter R 1990. Compilation of small ribosomal subunit RNA sequences. Nucleic Acids. Res. 18, 2237-2330

Newbold CJ, Ushida K, Morvan B, Fonty G andy Jouany JP 1996. The role of ciliate protozoa in the lysis of methanogenic archaea in rumen fluid. Lett. Appl. Microbiol. 23, 421-425.

Nicholson M, Evans P and Joblin K 2007. Analysis of methanogen diversity in the rumen using temporal temperature gradient gel electrophoresis: identification of uncultured Methanogens. Microb. Ecol. 54, 141-150.

Nickerson SC and Akers RM, 2011. Mammary gland anatomy. Pages 328-337 in Encyclopedia of Dairy Sciences, Fuquay JW, Fox PF and McSweeney PLH, eds. Academic Press, San Diego, CA, USA.

Ogawa J, Matsumura K, Kishino S, Omura Y and Shimizu S 2001. Conjugated linoleic acid accumulation via 10-hydroxy-12 octadecaenoic acid during microaerobic transformation of linoleic acid by Lactobacillus acidophilus. Appl. Environ. Microb. 67, 1246-1252.

Ogg SL, Weldon AK, Dobbie L, Smith AJH and Mather IH 2004. Expression of butyrophilin (Btn1a1) in lactating mammary gland is essential for the regulated secretion of milk-lipid droplets. Proc. Natl. Acad. Sci. USA 101, 10084-10089.

Ogimoto K and Imain S 1981. Rumen bacteria, in Atlas of rumen microbiology. Japan Society Press, Japan.

Olivier-Bousquet M 2002. Milk lipid and protein traffic in mammary epithelial cells: joint and independent pathways. Reprod. Nutr. Develop. 42, 149-162.

Ollier S, Leroux C, de la Foye A, Bernard L, Rouel J and Chilliard Y 2009. Whole intact rapeseeds or sunflower oil in high-forage or high-concentrate diets affects milk yield, milk composition, and mammary gene expression profile in goats. J. Dairy Sci. 92, 5544-5560.

Ollier S, Robert-Granie C, Bernard L, Chilliard Y and Leroux C 2007. Mammary transcriptome analysis of food-deprived lactating goats highlights genes involved in milk secretion and programmed cell death. J. Nutr. 137, 560-567.

Orpin CG 1972. The culture in vitro of the rumen bacterium Quin's Oval. J. Gen. Microbiol. 73, 523-530.

Orpin CG and Joblin KN 1997. The rumen anaerobic fungi Pages 140-195 in The rumen microbial ecosystem, $2^{\text {nd }}$ Edition, Hobson PN and Stewart CS, eds. Blackie Academic \& Professional, London, UK.

Osborn AM, Moore ERB and Timmis KN 2000. An evaluation of terminal-restriction fragment length polymorphism (T-RFLP) analysis for the study of microbial community structure and dynamics. Environ. Microbiol. 2, 39-50.

Ovreas, L 2000. Population and community level approaches for analysing microbial diversity in natural environments. Ecol. Lett. 3, 236-251.

Paillard D, McKain N, Chaudhary LC, Walker ND, Pizette F, Koppova I, McEwan NR, Kopecny J, Vercoe PE, Louis P and Wallace RJ 2007. Relation between phylogenetic position, lipid metabolism and butyrate production by different Butyrivibrio-like bacteria from the rumen. Anton. Leeuw. Int. J. G. 91, 417-422.

Palin MF, Côrtes C, Benchaar C, Lacasse C and Petit HV 2014. mRNA Expression of lipogenic enzymes in mammary tissue and fatty acid profile in milk of dairy cows fed flax hulls and infused with flax oil in the abomasum. Brit. J. Nutr. 111, 1011-1020.

Palmquist DL 2006. Milk fat: origin of fatty acids and influence of nutritional factors thereon. Pages 43-92 in Advanced dairy chemistry Vol. 2: Lipids, Fox PF and McSweeney PL, eds. 


\section{Springer, New York, USA.}

Palmquist DL 1988. The feeding value of fats. Pages 293-311 in Feed Science, Ørskov ER, ed. Elsevier Science Publishers BV, New York, USA.

Papadopoulos G, Goulas C, Apostolaki E and Abril R 2002. Effects of dietary supplements of algae, containing polyunsaturated fatty acids, on milk yield and the composition of milk products in dairy ewes. J. Dairy Res. 69, 357-365.

Park YW, Juárez M, Ramos M and Haenlein GFW 2007. Physico-chemical characteristics of goat and sheep milk. Small Ruminant Res. 68, 88-113.

Patel TR, Jure KG and Jones GA 1981. Catabolism of phloroglucinol by the rumen anaerobe Coprococcus. Appl. Environ. Microb. 42, 1010-1017.

Paten AM, Pain SJ, Peterson SW, Blair HT, Kenyon PR, Dearden PK and Duncan EJ 2014. Identification of reference genes for RT-qPCR in ovine mammary tissue during late pregnancy and lactation and in response to maternal nutritional programming. Physiol. Genom. 46, 560-570.

Payne E and Masters C. 1971. The in vivo incorporation of fatty acids into ovine tissues during rumen development. J. Int. J. Biochem. 2, 349-367.

Peterson DG, Matitashvili EA and Bauman DE 2003. Diet-induced milk fat depression in dairy cows results in increased trans-10, cis-12 CLA in milk fat and coordinate suppression of mRNA abundance for mammary enzymes involved in milk fat synthesis. J. Nutr. 133, 30983102.

Peterson DG, Matitashvili EA and Bauman DE 2004. The inhibitory effect of trans-10, cis-12 CLA on lipid synthesis in bovine mammary epithelial cells involves reduced proteolytic activation of the transcription factor SREBP-1. J. Nutr. 134, 2523-2527.

Petersson A, Domig KJ, Schedle K, Windisch W and Kneifel W 2010. Comparison of three methods to enumerate gut microbiota of weanling piglets fed insoluble dietary fibre differing in lignin content. J. Agr. Sci. 148, 225-232.

Petri RM, Mapiye C, Dugan MER and McAllister TA 2014. Subcutaneous adipose fatty acid profiles and related rumen bacterial populations of steers fed red clover or grass hay diets containing flax or sunflower-seed. PLoS ONE 9, e104167.

Piknova M, Javorsky P, Guczynska W, Kasperowicz A, Michalowski T, Piknova M, Javorska P, Pristas P and Pristaa P 2006. New species of rumen treponemes. Folia Microbiol. 51, 303-305.

Piperova LS, Teter BB, Bruckental I, Sampugna J, Mills SE, Yurawecz MP, Fritsche J, Ku K and Erdman RA 2000. Mammary lipogenic enzyme activity, trans fatty acids and conjugated linoleic acids are altered in lactating dairy cows fed a milk fat-depressing diet. J. Nutr. 130, 2568-2574.

Privé F, Kaderbhai NN, Girdwood S, Worgan HJ, Pinloche E, Scollan ND, Huws SA and Newbold CJ 2013. Identification and characterization of three novel lipases belonging to families II and V from Anaerovibrio lipolyticus 5ST. PLoS ONE 8, e69076.

Raphael W, Halbert L, Contreras GA and Sordillo LM 2014. Association between polyunsaturated fatty acid-derived oxylipid biosynthesis and leukocyte inflammatory marker expression in periparturient dairy cows. J. Dairy Sci. 97, 3615-3625.

Regensbogenova M, Pristas P, Javorsky P, Moon-van der Staay SY, van der Staay GWM, Hackstein JHP, Newbold CJ and McEwan NR 2004. Assessment of ciliates in the sheep rumen by DGGE. Lett. Appl. Microbiol. 39, 144-147.

Ricard G, McEwan NR, Dutilh BE, Jouany JP, Macheboeuf D, Mitsumori M, McIntosh FM, 
Michalowski T, Nagamine T, Nelson N., Newbold CJ, Nsabimana E, Takenaka A, Thomas NA, Ushida K, Hackstein JHP and Huynen MA 2006. Horizontal gene transfer from bacteria to rumen ciliates indicates adaptation to their anaerobic carbohydrates rich environment. BMC Genom. 7, 22.

Rohwer F and Thurber RV 2009. Viruses manipulate the marine environment. Nature 459, 207212.

Rosen ED and MacDougald OA 2006. Adipocyte differentiation from the inside out. Nat. Rev. Mol. Cell Biol. 7, 885-896.

Rothberg JM and Leamon JH 2008. The development and impact of 454 sequencing. Nat. Biotech. 26, 1117-1124.

Rücker O, Dangel A and Klein H-G 2013. Developments and insights into the analysis of the human microbiome. J. Lab. Med. 37, 329-335.

Sanger F, Nicklen S and Coulson AR 1977. DNA sequencing with chain-terminating inhibitors. Proc. Natl. Acad. Sci. USA. 74, 5463-5467.

Saro C, Ranilla MJ, Cifuentes A, Rosselló-Mora R and Carro MD 2014a. Technical note: Comparison of automated ribosomal intergenic spacer analysis and denaturing gradient gel electrophoresis to assess bacterial diversity in the rumen of sheep. J. Anim. Sci. 92, 10831088.

Saro C, Ranilla MJ, Tejido ML and Carro MD 2014b. Influence of forage type in the diet of sheep on rumen microbiota and fermentation characteristics. Livest. Sci. 160, 52-59.

Schmitt E, Ballou MA, Correa MN, DePeters EJ, Drackley JK and Loor JJ 2011. Dietary lipid during the transition period to manipulate subcutaneous adipose tissue peroxisome proliferator-activated receptor- $\gamma$ co-regulator and target gene expression. J. Dairy Sci. 94, 5913-5925.

Schütte UE, Abdo Z, Bent S, Shyu C, Williams C, Pierson J and Forney L 2008. Advances in the use of terminal restriction fragment length polymorphism (T-RFLP) analysis of 16S rRNA genes to characterize microbial communities. Appl. Microbiol. Biot. 80, 365-380.

Shi H, Luo J, Zhu J, Li J, Sun Y, Lin X, Zhang L, Yao D and Shi H 2013. PPAR $\gamma$ regulates genes involved in triacylglycerol synthesis and secretion in mammary gland epithelial cells of dairy goats. PPAR Res. 2013, ID310948.

Shin EC, Cho KM, Lim WJ, Hong SY, An CL, Kim EJ, Kim YK, Choi BR, An JM, Kang JM, Kim H and Yun HD 2004. Phylogenetic analysis of protozoa in the rumen contents of cow based on the $18 \mathrm{~S}$ rDNA sequences. J. App. Microbiol. 97, 378-383.

Shingfield KJ, Arölä A, Ahvenjärvi S, Vanhatalo A, Toivonen V, Griinari JM and Huhtanen P 2008b. Ruminal infusions of cobalt-EDTA reduce mammary delta- 9 desaturase index and alter milk fatty acid composition in lactating cows. J. Nutr. 138, 710-717.

Shingfield KJ, Bernard L, Leroux C and Chilliard Y 2010. Role of trans fatty acids in the nutritional regulation of mammary lipogenesis in ruminants. Animal 4, 1140-1166

Shingfield KJ, Bonnet M and Scollan ND 2013. Recent developments in altering the fatty acid composition of ruminant-derived foods. Animal 7, 132-162.

Shingfield KJ, Chilliard Y, Toivonen V, Kairenius P and Givens DI 2008a. Trans fatty acids and bioactive lipids in ruminant milk. Adv. Exp. Med. Biol. 606, 3-65.

Shingfield KJ and Griinari JM 2007. Role of biohydrogenation intermediates in milk fat depression. Eur. J. Lipid Sci. Technol. 109, 799-816. 
Shingfield KJ, Kairenius P, Arölä A, Paillard D, Muetzel S, Ahvenjärvi S, Vanhatalo A, Huhtanen P, Toivonen V, Griinari JM and Wallace RJ 2012. Dietary fish oil supplements modify ruminal biohydrogenation, alter the flow of fatty acids at the omasum, and induce changes in the ruminal Butyrivibrio population in lactating cows. J. Nutr. 142, 1437-1448.

Shingfield KJ and Wallace RJ 2014. Synthesis of conjugated linoleic acid in ruminants and humans. Pages 1-65 in Conjugated linoleic acids and conjugated vegetable oils, Sels B and Philippaerts A, eds. The Royal Society of Chemistry, Oxford, UK.

Shyu C, Soule T, Bent S, Foster J and Forney L 2007. MiCA: A web-based tool for the analysis of microbial communities based on terminal-restriction fragment length polymorphisms of $16 \mathrm{~S}$ and $18 S$ rRNA genes. Microb. Ecol. 53, 562-570.

Sogin ML, Morrison HG, Huber JA, Welch DM, Huse SM, Neal PR, Arrieta JM and Herndl GJ 2006. Microbial diversity in the deep sea and the underexplored "rare biosphere". Proc. Natl. Acad. Sci. USA 103, 12115-12120.

Spiegelman D, Whissell G and Greer CW 2005. A survey of the methods for the characterization of microbial consortia and communities. Can. J. Microbiol. 51, 355-386.

Stevenson D and Weimer P 2007. Dominance of Prevotella and low abundance of classical ruminal bacterial species in the bovine rumen revealed by relative quantification real-time PCR. App. Microbiol. Biotechnol. 75, 165-174.

Stewart CS, Flint HJ and Bryant MP 1997. The rumen bacteria. Pages 10-72 in The rumen microbial ecosystem. 2nd ed. Hobson PS and Stewart CS, eds. Blackie Academic \& Professional, London, UK.

Strömpl C, Tindall BJ, Jarvis GN, Lünsdorf H, Moore ERB and Hippe H 1999. A re-evaluation of the taxonomy of the genus Anaerovibrio, with the reclassification of Anaerovibrio glycerini as Anaerosinus glycerini gen. nov., comb. nov., and Anaerovibrio burkinabensis as Anaeroarcus burkinensis [corrig.] gen. nov., comb. nov. Int. J. Syst. Evol. Micr. 49, 1861-1872.

Swain RA, Nolan JV and Klieve AV 1996. Natural variability and diurnal fluctuations within the bacteriophage population of the rumen. Appl. Environ. Microb. 62, 994-997.

Tajima K, Aminov RI, Nagamine T, Matsui H, Nakamura M and Benno Y 2001. Diet-dependent shifts in the bacterial population of the rumen revealed with real-time PCR. Appl. Environ. Microb. 67, 2766-2774.

Tajima K, Aminov RI, Nagamine T, Ogata K, Nakamura M, Matsui H and Benno Y 1999. Rumen bacterial diversity as determined by sequence analysis of $16 \mathrm{~S}$ rDNA libraries. FEMS Microbiol. Ecol. 29, 159-169.

Tajima K, Arai S, Ogata K, Nagamine T, Matsui H, Nakamura M, Aminov RI and Benno Y 2000. Rumen bacterial community transition during adaptation to high-grain diet. Anaerobe 6, 273-284.

Taylor MW and McGibbon AK 2011. Triacylglycerols. Pages 665-669 in Encyclopedia of Dairy Sciences, Fuquay JW, Fox PF and McSweeney PLH, eds. Academic Press, San Diego, CA, USA.

Thering BJ, Graugnard DE, Piantoni P and Loor JJ 2009a. Adipose tissue lipogenic gene networks due to lipid feeding and milk fat depression in lactating cows. J. Dairy Sci. 92, 4290-4300.

Thering BJ, Bionaz M, Loor JJ 2009b. Long-chain fatty acid effects on peroxisome proliferatoractivated receptor-alpha-regulated genes in Madin-Darby bovine kidney cells: Optimization of culture conditions using palmitate. J. Dairy Sci. 92, 2027-2037. 
Therion JJ, Kistner A and Kornelius JH 1982. Effect of pH on growth rates of rumen amylolytic and lactilytic bacteria. Appl. Environ. Microb. 44, 428-434.

Timmen H and Patton S 1988. Milk fat globules: fatty acid composition, size and in vivo regulation of fat liquidity. Lipids 23, 685-689.

Toral PG, Belenguer A, Shingfield KJ, Hervás G, Toivonen V and Frutos P 2012. Fatty acid composition and bacterial community changes in the rumen fluid of lactating sheep fed sunflower oil plus incremental levels of marine algae. J. Dairy Sci. 95, 794-806.

Toral PG, Bernard L, Delavaud C, Gruffat D, Leroux C and Chilliard Y 2013. Effects of fish oil and additional starch on tissue fatty acid profile and lipogenic gene mRNA abundance in lactating goats fed a diet containing sunflower-seed oil. Animal 7, 948-956.

Toral PG, Hervás G and Frutos P 2015. Reductions in milk delta-9 desturation to oral dosing of cobalt-acetate are accompained by the downregulation of SCD1 in lactating ewes. J. Dairy Sci. doi.10.3168/jds.2014-8731

Toral PG, Frutos P, Hervás G, Gómez-Cortés P, Juárez M and de la Fuente MA 2010b. Changes in milk fatty acid profile and animal performance in response to fish oil supplementation, alone or in combination with sunflower oil, in dairy ewes. J. Dairy Sci. 93, 1604-1615.

Toral PG, Hervás G, Gómez-Cortés P, Frutos P, Juárez M and de la Fuente MA 2010a. Milk fatty acid profile and dairy sheep performance in response to diet supplementation with sunflower oil plus incremental levels of marine algae. J. Dairy Sci. 93, 1655-1667.

Tringe SG and Hugenholtz P 2008. A renaissance for the pioneering 16S rRNA gene. Curr. Opin. Microbiol. 11, 442-446.

Turner CW 1952. The anatomy of the mammary gland of swine. Pages 279-314 in The mammary gland. I. The anatomy of the udder of cattle and domestic animals. CW Turner, ed. Lucas Brothers, Columbia, MO, USA.

Vahmani P, Glover KE and Fredeen AH 2014. Effects of pasture versus confinement and marine oil supplementation on the expression of genes involved in lipid metabolism in mammary, liver, and adipose tissues of lactating dairy cows. J. Dairy Sci. 97, 4174-4183.

Vandesompele J, De Preter K, Pattyn F, Poppe B, Van Roy N, de Paepe A and Speleman F 2002. Accurate normalization of real-time quantitative RT-PCR data by geometric averaging of multiple internal control genes. Genome Biol. 3, research0034.0031-research0034.0011.

van Gylswyk NO 1995. Succiniclasticum ruminis gen. nov., sp. nov., a ruminal bacterium converting succinate to propionate as the sole energy-yielding mechanism. Int. J. Syst. Bacteriol. 45, 297-300.

Van Soest PJ 1994. Nutritional Ecology of the Ruminant. Cornell University Press, Ithaca, NY, USA.

Vaughan EE, Heilig HG, Zoetendal EG, Satokari R, Collins JK, Akkermans ADL and de Vos WM 1999. Molecular approaches to study probiotic bacteria. Trends Food Sci. Tech. 10, 400-404.

Vernon RG 1980. Lipid metabolism in the adipose tissue of ruminant animals. Prog. Lipid Res. 19, 23-106.

Vilkki J, Viitala S, Leskinen H, Taponen J, Bernard L and Shingfield KJ 2012. Effect of ruminal cobalt-EDTA infusion on milk fat composition and mammary lipogenic gene expression. Page 238 in Book of Abstracts of the $63^{\text {rd }}$ Annual Meeteing of the European Federation of Animal Science. Bratislava, Slovakia.

Wagner M, Horn M and Daims H 2003. Fluorescence in situ hybridisation for the identification and characterisation of prokaryotes. Curr. Opin. Microbiol. 6, 302-309. 
Wallace RJ, Chaudhary LC, McKain N, McEwan NR, Richardson AJ, Vercoe PE, Walker ND and Paillard D 2006. Clostridium proteoclasticum: a ruminal bacterium that forms stearic acid from linoleic acid. FEMS Microbiol. Lett. 265, 195-201.

Wallace RJ, McKain N, Shingfield KJ and Devillard E 2007. Isomers of conjugated linoleic acids are synthesized via different mechanisms in ruminal digesta and bacteria. J. Lipid Res. 48, 2247-2254.

Wasowska I, Maia M, Niedźwiedzka KM, Czauderna M, Ribeiro J, Devillard E, Shingfield KJ and Wallace RJ 2006. Influence of fish oil on ruminal biohydrogenation of C18 unsaturated fatty acids. Brit. J. Nutr. 95, 1199-1211.

Weis JH, Tan SS, Martin BK and Wittwer CT 1992 Detection of rare mRNAs via quantitative RTPCR. Trends Genet. 8 263-264.

Whitford MF, Forster RJ, Beard CE, Gong J and Teather RM 1998. Phylogenetic analysis of rumen bacteria by comparative sequence analysis of cloned $16 \mathrm{~S}$ rRNA genes. Anaerobe 4, 153-163.

Wickramasinghe S, Cánovas A, Rincón G and Medrano JF 2014. RNA-Sequencing: A tool to explore new frontiers in animal genetics. Livest. Sci. 166, 206-216.

Williams AG and Coleman GS 1997. The rumen protozoa. Pages 73-139 in The rumen microbial ecosystem. $2^{\text {nd }}$ Edition. Hobson PN and Stewart CS, eds. Blackie Academic \& Professional, London. UK.

Wittwer CT, Mark G. Herrmann A, Moss A and Randy P. 2013 Rasmussen continuous fluorescence monitoring of rapid cycle DNA Amplification. USA Biotechniques, 54, 314-320.

Wittwer CT, Herrmann MG, Moss AA and Rasmussen RP 1997. Continuous fluorescence monitoring of rapid cycle DNA amplification. Biotechniques. 22, 130-131.

Woese CR 1987. Bacterial evolution. Microb. Rev. 51, 221-271.

Woese CR, Kandler O and Wheelis ML 1990. Towards a natural system of organism. Propossal for the domains Archaea, Bacteria, and Eucarya. Proc. Natl. Acad. Sci. USA 87, 4576-4579.

Wong ML and Medrano JF 2005. Real-time PCR for mRNA quantitation. Biotechniques 39, 7585.

Wright DE and Klieve AV 2011. Does the complexity of the rumen microbial ecology preclude methane mitigation? Anim. Feed Sci. Technol. 166-167, 248-253.

Wright DE. 1959. Hydrogenation of lipids by rumen protozoa. Nature 184, 875.

Wu S, Baldwin R, Li W, Li C, Connor E and Li R. 2012. The bacterial community composition of the bovine rumen detected using pyrosequencing of $16 \mathrm{~S}$ rRNA genes. Metagenomics 1, 11.

Yang SL, Bu DP, Wang JQ, Hu ZY, Li D, Wei HY, Zhou LY and Loor JJ 2009. Soybean oil and linseed oil supplementation affect profiles of ruminal microorganisms in dairy cows. Animal 3, 1562-1569.

Yang T, Espenshade PJ, Wright ME, Yabe D, Gong Y, Aebersold R, Goldstein JL and Brown MS 2002. Crucial step in cholesterol homeostasis: Sterols promote binding of SCAP to INSIG-1, a membrane protein that facilitates retention of SREBPS in ER. Cell 110, 489-500.

Yáñez-Ruiz DR, Macias B, Pinloche E and Newbold CJ 2010. The persistence of bacterial and methanogenic archaeal communities residing in the rumen of young lambs. FEMS Microbiol. Ecol. 72, 272-278.

Yáñez-Ruiz DR., Scollan ND, Merry RJ and Newbold CJ. 2006. Contribution of rumen protozoa to duodenal flow of nitrogen, conjugated linoleic acid and vaccenic acid in steers fed silages 
differing in their water-soluble carbohydrate content. Brit. J. Nutr. 96, 861-869.

Yokoyama MT and Davis CL 1971. Hydrogenation of unsaturated fatty acids by Treponema (Borrelia) strain B25, a rumen spirochete. J. Bacteriol. 107, 519-527.

Yoon KL, Modica-Napolitano JS, Ernst SG and Aprille JR 1991. Denaturing gradient gel method for mapping single base changes in human mitochondrial DNA. Anal. Biochem. 196, 427-32.

Yu Z and Morrison M 2004. Improved extraction of PCR-quality community DNA from digesta and fecal samples. Biotechniques 36, 808-812.

Zang R, Bai J, Xu H, Zhang L, Yang J, Yang L, Lu J and Wu J 2011. Selection of suitable reference genes for real-time quantitative PCR studies in Lanzhou fat-tailed sheep (Ovis aries). Asian J. Anim. Vet. Adv. 6, 789-804.

Zened A, Combes S, Cauquil L, Mariette J, Klopp C, Bouchez O, Troegeler-Meynadier A and Enjalbert F 2013. Microbial ecology of the rumen evaluated by 454 GS FLX pyrosequencing is affected by starch and oil supplementation of diets. FEMS Micorbiol. Ecol. 83, 504-514.

Zoetendal EG, Collier CT, Koike S, Mackie RI and Gaskins HR 2004. Molecular ecological analysis of the gastrointestinal microbiota: A review. J. Nutr. 134, 465-472. 
PLANTEAMIENTO DE LA TESIS 

En el marco general de la mejora de las propiedades saludables de la leche de oveja, un mayor conocimiento de los mecanismos implicados en la regulación nutricional del metabolismo lipídico ayudaría a modular, de forma más eficiente, la plasticidad de la grasa láctea. En este sentido, la información obtenida a partir de la aplicación de técnicas modernas de biología molecular resulta de incuestionable interés para avanzar en este campo, pero los estudios al respecto son aún muy escasos, sobre todo en el ovino. Así pues, tal y como se ha expuesto anteriormente, el objetivo general de esta tesis fue contribuir a esclarecer, en ovejas lecheras, qué microorganismos están implicados en el metabolismo ruminal de los AG, así como los mecanismos que intervienen en la regulación nutricional de la lipogénesis mamaria, al ser estos los principales puntos en los que sería necesario incidir para llegar a entender el efecto de la alimentación sobre el perfil lipídico de la leche.

A partir de este planteamiento, el trabajo de investigación se estructura en cuatro pruebas experimentales independientes. Las tres primeras están dirigidas al estudio de la microbiología del metabolismo lipídico en el rumen, mientras que en la cuarta se examina la expresión de los genes implicados en la lipogénesis en la glándula mamaria y el tejido adiposo en respuesta a cambios en la dieta de las ovejas.

La primera prueba se llevó a cabo con el objetivo de investigar, en ovejas lecheras, el efecto de la adición de microalgas marinas a una dieta rica en aceite de girasol sobre la población ruminal del grupo Butyrivibrio, utilizando una técnica molecular independiente de cultivo (T-RFLP). Aunque las bacterias cultivadas de este grupo parecen no ser clave en la biohidrogenación de los AG in vivo, especies relacionadas filogenéticamente pero que aún no han sido aisladas en cultivo podrían tener un papel relevante en dicho proceso. Además, como la adición de lípidos a la dieta puede provocar variaciones temporales en la microbiota ruminal, también se comparó la respuesta a las microalgas a medio y largo plazo (26 y 52 días, respectivamente). 
A partir de los resultados del primer estudio, que sugerían una baja relevancia también de las bacterias no cultivadas del grupo Butyrivibrio, en la segunda prueba se analizaron muestras del rumen de ovejas alimentadas con las mismas dietas utilizando la T-RFLP y una técnica de secuenciación masiva de nueva generación, la pirosecuenciación 454, que permite abarcar una mayor diversidad microbiana y alcanzar una resolución filogenética más alta. Su objetivo fue evaluar el efecto de la suplementación con microalgas marinas sobre la comunidad bacteriana total y comparar los resultados derivados de ambas metodologías. Además, como la implantación de cánulas ruminales en ovejas lecheras es poco factible y se suele recurrir a la recogida de muestras de fluido ruminal mediante el uso de sonda esofágica, un segundo objetivo fue investigar si las muestras de fluido ruminal podían ser una alternativa válida a las de contenido total para estudiar el impacto de la suplementación lipídica sobre la microbiota ruminal.

En la tercera prueba se intentó diseñar una estrategia de cultivo que permitiera examinar la posible implicación de bacterias identificadas como Quinella ovalis en el metabolismo ruminal de los AG. Debido a que no ha sido posible aislar este microorganismo en cultivos puros, se recurrió al empleo de una combinación de técnicas tradicionales de cultivo in vitro a partir de suspensiones enriquecidas en Q. ovalis, más herramientas de biología molecular (FISH) para su identificación y cuantificación.

Finalmente, en la cuarta prueba se planteó un estudio de nutrigenómica en ovejas lecheras alimentadas con aceite de girasol (i. e., con una dieta de la que se sabe que induce cambios en el perfil de AG de la leche) para examinar la respuesta de la glándula mamaria y los tejidos adiposos subcutáneo y perirrenal en términos de abundancia del ARNm de los principales genes candidatos relacionados con la síntesis de lípidos. 


\title{
PRUEBA I
}

\author{
CHANGES IN THE RUMEN BUTYRIVIBRIO GROUP \\ IN LACTATING EWES FED A DIET SUPPLEMENTED WITH \\ SUNFLOWER OIL WITH OR WITHOUT MARINE ALGAE
}
T. Castro-Carrera, P. G. Toral, G. Hervás, P. Frutos y A. Belenguer Instituto de Ganadería de Montaña, CSIC - Universidad de León Finca Marzanas s/n, 24346 Grulleros, León, España

Options Méditerranéennes A 107 (2013) 189-193

Presentado en el 14th International Seminar of the FAO-CHIEAM Sub-Network on Sheep and Goat Nutrition, 15-18 de mayo de 2012, Hammamet, Túnez 



\title{
CHANGES IN THE RUMEN BUTYRIVIBRIO GROUP IN LACTATING EWES FED A DIET SUPPLEMENTED WITH SUNFLOWER OIL WITH OR WITHOUT MARINE ALGAE
}

\author{
T. Castro-Carrera, P. G. Toral, G. Hervás, P. Frutos and A. Belenguer
}

\begin{abstract}
In ruminants, microbial biohydrogenation $(\mathrm{BH})$ of unsaturated fatty acids (FA) can be modulated by diet supplementation with lipids (e. g., sunflower oil -SO- or marine algae -MA-) to improve the fatty acid profile of the milk. The Butyrivibrio group contains the most active biohydrogenating bacteria isolated from the rumen and, for this reason, it has been extensively considered the main responsible for the $\mathrm{BH}$ process. With the aim of examining the effect of lipid addition on the Butyrivibrio population, as well as time dependent variations, thirty-six lactating ewes were divided in 6 lots (3 lots/treatment) and offered a diet supplemented with either $2.5 \%$ SO or $2.5 \%$ SO plus $0.8 \%$ MA. After 0, 26 and 52 days on treatments, individual samples of rumen fluid were collected through a stomach tube, composited for each lot, and analysed using the terminal restriction fragment length polymorphism (T-RFLP) molecular technique. Results showed no significant variations, due to either diet or time, in the Butyrivibrio T-RFLP profiles or in the relative abundances of the major terminal restriction fragments (T-RF) detected. However, some less abundant fragments (i. e., representing less than $4.3 \%$ of the total) varied significantly. For example, the frequency of a T-RF compatible with 18:0-producing bacteria increased on day 52 in the diet with only SO (from 0.4 to $4.3 \%$ ), whereas MA addition precluded this effect. The few changes caused in the Butyrivibrio group by a lipid supplementation that is known to alter rumen $\mathrm{BH}$ would indicate a low relevance of these bacteria in the ruminal FA metabolism in dairy sheep. Nevertheless, the effect on some small subpopulations would not allow to rule out their involvement in the process.
\end{abstract}

Key words: lipid supplementation, ruminal bacteria, biohydrogenation, T-RFLP 


\section{INTRODUCTION}

In ruminants, dietary lipid supplementation with sunflower oil (SO) in combination with marine lipids, such as marine algae (MA), has been reported to increase the milk concentration of potentially beneficial bioactive lipids (Shingfield et al., 2006; Toral et al., 2010). This effect has been related to diet-induced alterations in ruminal biohydrogenation $(\mathrm{BH})$ of unsaturated fatty acids (FA), which are mediated by rumen microorganisms. The Butyrivibrio group, which includes the genera Butyrivibrio and Pseudobutyrivibrio as well as phylogenetically related microbes, contains the most active biohydrogenating bacteria isolated from the rumen. For this reason, it has been extensively considered to be the main responsible for the $\mathrm{BH}$ process (Lourenço et al., 2010). However, studies using culture-independent molecular methods have suggested that identified biohydrogenating bacteria, such as the 18:0-producing B. proteoclasticus, may not play a major role in this process, whereas other yet-uncultured bacteria, within the Butyrivibrio group, might be more relevant (Boeckaert et al., 2008; Belenguer et al., 2010; Toral et al., 2012).

Results on the milk FA profile in lactating ewes supplemented with SO alone or in combination with marine lipids (Toral et al., 2010) suggest long-term variations in the rumen biohydrogenating bacteria. Despite that, information on the Butyrivibrio group is limited to a relatively short period (up to 28 days on supplemented diets; Belenguer et al., 2010; Toral et al., 2012). Therefore, the aim of this study was to investigate the effect of the addition of SO and MA to the diet of dairy ewes on the ruminal Butyrivibrio group, as well as time-dependent variations over an extended period, using a culture-independent molecular technique.

\section{MATERIALS AND METHODS}

Thirty-six Assaf ewes $(82.4 \pm 5.30 \mathrm{~kg}$ BW $)$ in mid lactation were randomly distributed in 6 lots (6 ewes/lot) and assigned to one of 2 dietary treatments (3 lots/treatment). Diets consisted of a total mixed ration (TMR) based on alfalfa hay 
and a concentrate (forage:concentrate ratio 40:60) and supplemented with either $2.5 \%$ SO (Control diet) or 2.5\% SO plus 0.8\% MA (SOMA diet; DHA Gold Animal Feed Ingredient, Martek Biosciences Corp., Columbia, MD, USA). All ewes were fed the control diet for a 20-day adaptation period before the start of the study. Fresh diets were offered daily ad libitum at 9:00 and 19:00 h and clean water was always available. After 0, 26 and 52 days on treatments, samples of ruminal fluid were individually collected $3 \mathrm{~h}$ after the morning feeding using a stomach tube. Samples were strained through 2 layers of muslin, composited for each lot, and immediately frozen at $-80^{\circ} \mathrm{C}$ for DNA extraction.

After thorough mixing, DNA was extracted from freeze-dried samples of rumen fluid as described in Belenguer et al. (2010). Duplicate DNA samples were used as templates for terminal restriction fragment length polymorphism (TRFLP) analysis, which was based on Butyrivibrio group-specific primers (Boeckaert et al., 2008) and one restriction enzyme (HhaI; Belenguer et al., 2010). The lengths of the fluorescently labelled terminal restriction fragments (T-RF) were determined using the size standard ET-550-R (GE Healthcare Life Sciences, Buckinghamshire, UK) with the GeneMarker Analysis software (SoftGenetics, State College, PA, USA).

To infer the potential phylogenetic bacterial assignment of the fragments, in silico restriction for the Butyrivibrio group bacteria with the primers and enzyme used in the analysis were obtained from the Ribosomal Database Project II (http://rdp.cme.msu.edu/; Cole et al., 2009).

Data from T-RFLP (size in base pairs -bp- and peak area for each T-RF) were analyzed as outlined by Abdo et al. (2006), and the number of T-RF and the relative abundances over the total peak area of each T-RF were calculated. Hierarchical clustering analysis with the Ward's method based on Jaccard distances was performed, using R-project software ( $R$ Development Core Team, 2011), to build a dendrogram.

For each T-RF, the relative abundance was analysed by repeated measures, using the MIXED procedure of the SAS software package, version 9.2 (SAS 
Institute Inc., Cary, NC, USA). The statistical model included the fixed effects of treatment, day of sampling and their interaction, and the lot as a random effect. Means were separated using the "pdiff" option of the "lsmeans" statement. Significant differences were declared at $P<0.05$ and tendencies at $P<0.10$.

\section{RESULTS AND DISCUSSION}

As plotted in the dendrogram (Figure 1), results showed no significant variations, due to either diet or time, in the bacterial profiles, which seems to indicate that the addition of MA to a SO containing diet did not alter noticeably the structure of the rumen Butyrivibrio group after 26 or 52 days on treatments. Although similar results were reported for lactating ewes fed fish oil (Belenguer et al., 2010), a certain separation of the Butyrivibrio group profiles was observed in sheep receiving the same diets as in this study, even though the effect was less clear on this group than on total bacteria (Toral et al., 2012).

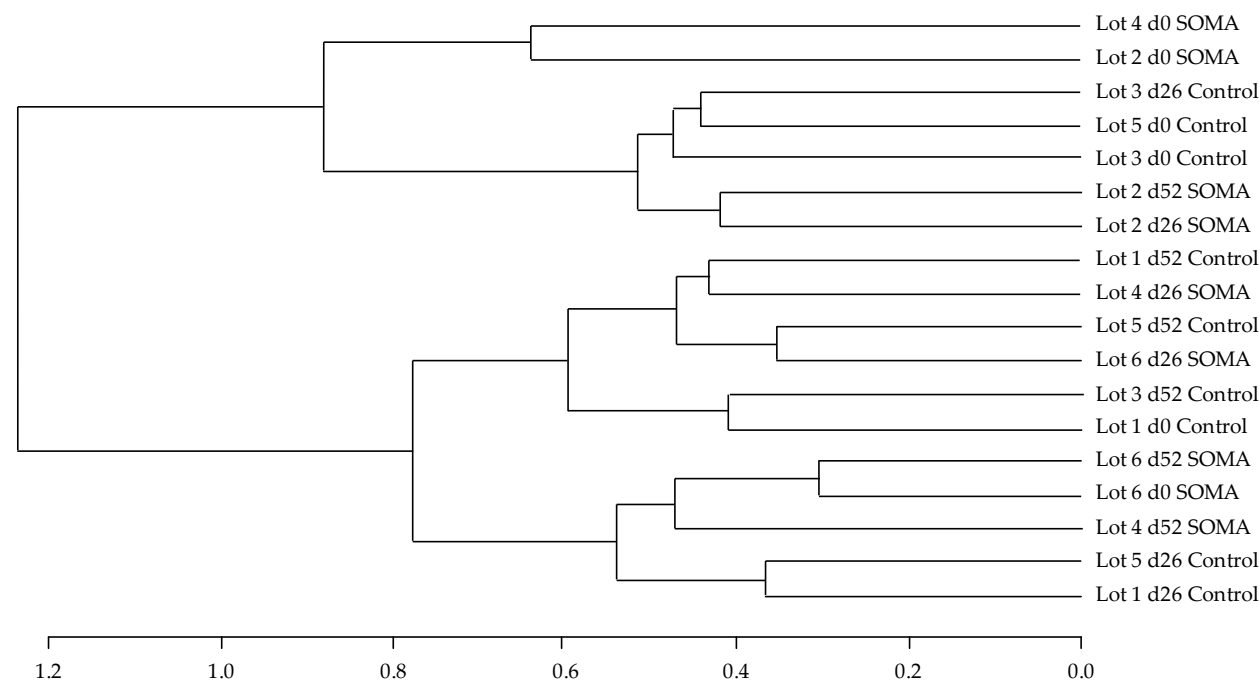

Figure 1. Terminal restriction fragment length polymorphism (T-RFLP) derived dendrogram showing the relationships among the profiles of the Butyrivibrio group. The DNA was extracted from rumen fluid of lactating ewes after 0 (d0), 26 (d26) and 52 (d52) days on a diet supplemented with $2.5 \%$ SO (Control) or $2.5 \%$ SO plus $0.8 \%$ MA (SOMA). 
The number of T-RF averaged $29.6 \pm 5.75$, which is in line with previous studies in sheep fed marine lipids (Belenguer et al., 2010; Toral et al., 2012), and was only reduced significantly after 52 days of MA supplementation $(P<0.05)$. This is consistent with the lack of effects of fish oil (Belenguer et al., 2010) or MA (Toral et al., 2012) supplementation on this parameter observed for shorter periods of time (up to 28 days).

Samples were composited per lot to reduce the high inter-animal variability described in the rumen bacterial composition ( $\mathrm{Li}$ et al., 2009) and favour the detection of significant effects. Nonetheless, the between-lot variation was still considerable, and there were no modifications, due to diet or time, in the relative abundance of the major T-RF detected (namely, those of 149, 162 and $405 \mathrm{bp}$ ). The 162-bp fragment may correspond to bacteria phylogenetically related to 18:0producers (Boeckaert et al., 2009) and the 405-bp T-RF is compatible with uncultured Lachnospiraceae bacteria potentially involved in BH (Boeckaert et al., 2009). The same lack of changes in the relative abundance was found for other fragments, such as the 164 and $300 \mathrm{bp}$ T-RF, which are compatible with potentially biohydrogenating Lachnospiraceae bacteria (Boeckaert et al., 2009). Although this seems to contrast with previous studies showing irregular variations in these fragments (Belenguer et al., 2010; Toral et al., 2012), it is probably noteworthy that apparently inconsistent changes may be accounted for by different bacteria, with different sensitivity to polyunsaturated FA (Maia et al., 2007), resulting in the same fragment size.

On the other hand, less abundant fragments (representing less than $4.3 \%$ of the total) varied significantly over time. For example, the frequency of the T-RF of $161 \mathrm{bp}$ increased on day 52 in the diet with only SO (from 0.4 to $4.3 \%$ ), whereas MA addition precluded this effect. This T-RF might be compatible with a strain of the 18:0-producing B. proteoclasticus, although in previous experiments with sheep (Belenguer et al., 2010; Toral et al., 2012) and cattle (Huws et al., 2011) no changes in this group, due to lipid supplementation, were observed using real time PCR. 
Nevertheless, as mentioned above, other unclassified bacteria of Lachnospiraceae might also match the same T-RF.

Table 1. Number of fragments (T-RF) and relative abundance over the total peak area (\%) of several T-RF obtained by T-RFLP in rumen fluid samples of lactating ewes fed a diet supplemented with $2.5 \%$ SO (Control) or $2.5 \%$ SO plus $0.8 \%$ MA (SOMA), on days 0,26 and 52.

\begin{tabular}{|c|c|c|c|c|c|c|c|c|c|c|}
\hline & \multicolumn{3}{|c|}{ Control } & \multicolumn{3}{|c|}{ SOMA } & \multirow[b]{2}{*}{$\mathrm{SED}^{2}$} & \multicolumn{3}{|c|}{$P^{11}$} \\
\hline & 0 & 26 & 52 & 0 & 26 & 52 & & $\mathrm{~T}$ & $\mathrm{D}$ & $\mathrm{T} \times \mathrm{D}$ \\
\hline $\begin{array}{l}\text { Number of T-RF } \\
\text { Length (bp) }\end{array}$ & 28.3 & 29.0 & 32.3 & $33.3^{\mathrm{a}}$ & $28.0^{\mathrm{ab}}$ & $26.3^{b}$ & 6.49 & 0.85 & 0.63 & 0.02 \\
\hline 149 & 31.16 & 30.16 & 32.31 & 30.66 & 24.88 & 29.45 & 7.430 & 0.32 & 0.54 & 0.79 \\
\hline 159 & $0.00^{\mathrm{b}}$ & $0.15^{b}$ & $0.66^{\mathrm{a}}$ & 0.10 & 0.28 & 0.11 & 0.160 & 0.45 & 0.01 & $<0.01$ \\
\hline 161 & $0.44^{b}$ & $0.32^{\mathrm{b}}$ & $4.26^{\mathrm{a}}$ & 1.40 & 1.88 & 2.02 & 1.024 & 0.92 & $<0.01$ & 0.01 \\
\hline 162 & 16.86 & 10.65 & 9.53 & 15.39 & 11.05 & 8.54 & 4.217 & 0.65 & 0.13 & 0.95 \\
\hline 164 & 3.17 & 3.06 & 3.90 & 4.41 & 1.90 & 2.43 & 1.369 & 0.57 & 0.43 & 0.34 \\
\hline 300 & 5.82 & 5.41 & 5.42 & 3.62 & 5.11 & 4.45 & 1.866 & 0.49 & 0.79 & 0.55 \\
\hline 405 & 19.57 & 22.09 & 20.16 & 20.62 & 16.39 & 27.51 & 5.185 & 0.77 & 0.44 & 0.25 \\
\hline
\end{tabular}

$a, b$ For each experiment, means within a row with different superscripts differ significantly $(P<0.05)$.

${ }^{1}$ Probability of significant effects due to experimental treatment (T) or day (D) and their interaction $(\mathrm{T} \times \mathrm{D})$.

${ }^{2} \mathrm{SED}=$ standard error of the difference.

\section{CONCLUSION}

Overall, the few changes caused in the Butyrivibrio group by a lipid supplementation (sunflower oil + marine algae) that is known to alter rumen $\mathrm{BH}$ would indicate a low relevance of these bacteria in the ruminal FA metabolism in dairy sheep. However, some small subpopulations were affected by the addition of MA, which would not allow to rule out their involvement in the process.

\section{REFERENCES}

Abdo Z, Schüette UME, Bent SJ, Williams CJ, Forney LJ and Joyce P 2006. Statistical methods for characterizing diversity of microbial communities by analysis of terminal restriction fragment length polymorphisms of $16 S$ rRNA genes. Environ. Microbiol. 8, 929-938.

Belenguer A, Toral PG, Frutos P and Hervás G 2010. Changes in the rumen bacterial community in response to sunflower oil and fish oil supplements in the diet of dairy sheep. J. Dairy Sci. 93, 3275-3286. 
Boeckaert C, Morgavi DP, Jouany JP, Maignien L, Boon N and Fievez V 2009. Role of the protozoan Isotricha prostoma, liquid-, and solid-associated bacteria in rumen biohydrogenation of linoleic acid. Animal 3, 961-971.

Boeckaert C, Vlaeminck B, Fievez V, Maignien L, Dijkstra J and Boon N 2008. Accumulation of trans $\mathrm{C} 18: 1$ fatty acids in the rumen after dietary algal supplementation is associated with changes in the Butyrivibrio community. Appl. Environ. Microbiol. 74, 6923-6930.

Cole JR, Wang Q, Cardenas E, Fish J, Chai B, Farris RJ, Kulam-Syed-Mohideen AS, McGarrell DM, Marsh T, Garrity GM and Tiedje JM 2009. The Ribosomal Database Project: improved alignments and new tools for rRNA analysis. Nucleic Acids Res. 37, 141-145.

Huws SA, Kim EJ, Lee MRF, Scott MB, Tweed JKS, Pinloche E, Wallace RJ and Scollan ND 2011. As yet uncultured bacteria phylogenetically classified as Prevotella, Lachnospiraceae incertae sedis and unclassified Bacteroidales, Clostridiales and Ruminococcaceae may play a predominant role in ruminal biohydrogenation. Environ. Microbiol. 13, 1500-1512.

Li M, Penner G, Hernandez-Sanabria E, Oba M and Guan LL 2009. Effects of sampling location and time, and host animal on assessment of bacterial diversity and fermentation parameters in the bovine rumen. J. App. Microbiol. 107, 1924-1934.

Lourenço M, Ramos-Morales E and Wallace RJ 2010. The role of microbes in rumen lipolysis and biohydrogenation and their manipulation. Animal 4, 1024-1036.

Maia MRG, Chaudhary LC, Figueres L and Wallace RJ 2007. Metabolism of polyunsaturated fatty acids and their toxicity to the microflora of the rumen. Anton. Leeuw. Int. J. G. 91, 303314.

R Development Core Team, 2011. R: A language and environment for statistical computing. R Foundation for Statistical Computing, Vienna, Austria http://www.R-project.org/.

Shingfield KJ, Reynolds CK, Hervás G, Griinari JM, Grandison AS and Beever DE 2006. Examination of the persistency of milk fatty acid composition responses to fish oil and sunflower oil in the diet of dairy cows. J. Dairy Sci. 89, 714-732.

Toral PG, Belenguer A, Shingfield KJ, Hervás G, Toivonen V and Frutos P 2012. Fatty acid composition and bacterial community changes in the rumen fluid of lactating sheep fed sunflower oil plus incremental levels of marine algae. J. Dairy Sci. 95, 794-806.

Toral PG, Hervás G, Gómez-Cortés P, Frutos P, Juárez M and de la Fuente MA 2010. Milk fatty acid profile and dairy sheep performance in response to diet supplementation with sunflower oil plus incremental levels of marine algae. J. Dairy Sci. 93, 1655-1667. 



\section{PRUEBA II}

\section{RUMEN BACTERIAL COMMUNITY EVALUATED BY 454 PYROSEQUENCING AND TERMINAL RESTRICTION FRAGMENT LENGTH POLYMORPHISM ANALYSES IN DAIRY SHEEP FED MARINE ALGAE}

T. Castro-Carrera ${ }^{1,2}$, P. G. Toral1 ${ }^{1}$, P. Frutos ${ }^{1}$, N. R. McEwan², G. Hervás ${ }^{1}$, L. Abecia ${ }^{3}$, E. Pinloche², S. E. Girdwood ${ }^{2}$ y A. Belenguer ${ }^{1}$ ${ }^{1}$ Instituto de Ganadería de Montaña, CSIC - Universidad de León Finca Marzanas s/n, 24346 Grulleros, León, España

2Institute of Biological, Environmental and Rural Sciences, Universidad de Aberystwyth, SY23 3DA, Aberystwyth, Reino Unido

${ }^{3}$ Instituto de Nutrición Animal, Estación Experimental del Zaidín, 18008, Granada, España

Journal of Dairy Science 97 (2014) 1661-1669

doi:10.3168/jds.2013-7243

Presentado en parte en el 8th Joint Symposium INRA-Rowett on Gut Microbiology. Gut microbiota: friend of foe?, 17-20 de junio de 2012, Clermont-Ferrand, Francia y en las XV Jornadas sobre Producción Animal AIDA, 14-15 de mayo de 2013, Zaragoza, España 



\title{
RUMEN BACTERIAL COMMUNITY EVALUATED BY 454 PYROSEQUENCING AND TERMINAL RESTRICTION FRAGMENT LENGTH POLYMORPHISM ANALYSES IN DAIRY SHEEP FED MARINE ALGAE
}

\author{
T. Castro-Carrera, P. G. Toral, P. Frutos, N. R. McEwan, G. Hervás, \\ L. Abecia, E. Pinloche, S. E. Girdwood and A. Belenguer
}

\begin{abstract}
Developing novel strategies to increase the content of bioactive unsaturated fatty acids (FA) in ruminant derived products requires a deeper understanding of rumen biohydrogenation and bacteria involved in this process. Although high-throughput pyrosequencing may allow for a great coverage of bacterial diversity, it has hardly been used to investigate the microbiology of ruminal FA metabolism. In this experiment, 454 pyrosequencing and a molecular fingerprinting technique (terminal restriction fragment length polymorphism; TRFLP) were used concurrently to assess the effect of diet supplementation with marine algae (MA) on the rumen bacterial community of dairy sheep. Eleven lactating ewes were divided in 2 lots and offered a total mixed ration (TMR) based on alfalfa hay and concentrate (40:60), supplemented with 0 (control) or 8 (MA) g of MA/kg of DM. After 54 days on treatments, animals were slaughtered and samples of rumen content and fluid were collected separately for microbial analysis. Pyrosequencing yielded a greater coverage of bacterial diversity than TRFLP and allowed the identification of low abundant populations. Conversely, both molecular approaches pointed to similar conclusions and showed that relevant changes due to MA addition were observed within the major ruminal phyla, namely Bacteroidetes, Firmicutes, and Proteobacteria. Decreases in the abundance of unclassified Bacteroidales, Porphyromonadaceae, and Ruminococcaceae and increases in as-yet uncultured species of the family Succinivibrionaceae, might be related to a potential role of these groups in different pathways of rumen FA metabolism. Diet supplementation with MA, however, had no effect on the
\end{abstract}


relative abundance of Butyrivibrio and Pseudobutyrivibrio genera. In addition, results from both 454 pyrosequencing and T-RFLP indicate that the effect of MA was rather consistent in rumen content or fluid samples, despite inherent differences between these fractions in their bacterial composition.

Key words: ewe, lipid, ruminal microbiota, $16 \mathrm{~S}$ rDNA

\section{INTRODUCTION}

Dietary PUFA are, in general, toxic for the rumen microbiota, although certain bacteria are able to metabolize and detoxify them through biohydrogenation $(\mathrm{BH}$; Maia et al., 2007, 2010). This process results in the formation of some intermediates with bioactive characteristics (e. g., conjugated linoleic acid) that will then appear in ruminant-derived products (Lourenço et al., 2010). Recent in vivo investigations question some results from earlier in vitro assays suggesting that FA biohydrogenation is achieved only by a small group of bacteria. In fact, it is now accepted that the rumen microbial ecology of FA metabolism is much more complex, and most aspects on the response to dietary lipids are still uncertain (Boeckaert et al., 2008; Huws et al., 2011; Toral et al., 2012).

Molecular fingerprinting techniques, such as terminal restriction fragment length polymorphism (T-RFLP) or denaturing gradient gel electrophoresis (DGGE), are very useful to compare the structure and diversity of ruminal ecosystems and have allowed the detection of groups of bacteria, some of them asyet uncultured or unclassified, with a potential predominant role in one or more metabolic pathways of $\mathrm{BH}$ in the rumen (Boeckaert et al., 2008; Belenguer et al., 2010; Huws et al., 2011). Nevertheless, they offer restricted information on less abundant taxa, which may bias the results. Thus, for instance, a previous study in dairy sheep fed marine lipids (i. e., $8 \mathrm{~g}$ of marine algae/kg of DM) showed marked changes in the concentration of $\mathrm{BH}$ intermediates that were only accompanied by little variations in the abundance of ruminal bacteria related to the $\mathrm{BH}$ process (Toral et al., 2012). 
This constraint might perhaps be overcome with next-generation techniques, such as high-throughput pyrosequencing (Hall, 2007). Yet, despite the much greater coverage of the microbial diversity allowed by this method, pyrosequencing has been little used in the study of rumen microbial ecology (Callaway et al., 2010; de Menezes et al., 2011; Pope et al., 2012); to our knowledge, only one article is available on ruminants fed lipids, with nonlactating cows (Zened et al., 2013). Pyrosequencing, conversely, is a high cost and not always available methodology.

Therefore, the first aim of the current study was to assess the effect of diet supplementation with marine algae (MA) on the rumen bacterial community structure of lactating sheep using T-RFLP and 454 pyrosequencing approaches. In addition, as ruminal cannulation is not really feasible in lactating sheep and stomach probe is often used to collect rumen samples, which rely solely on the liquid fraction (Belenguer et al., 2010; Toral et al., 2012), a second objective was to investigate if samples of rumen fluid may be an alternative to those of whole rumen content to examine the effect of lipid supplementation on the bacterial community.

\section{MATERIALS AND METHODS}

\subsection{Animals, diets and experimental design}

All experimental procedures were performed in accordance with Spanish Royal Decree 1201/2005 for the protection of animals used for experimental and other scientific purposes.

Twelve lactating Assaf ewes were recruited for the experiment, but due to health issues, 1 animal was withdrawn. Therefore, 11 sheep $(82.4 \pm 3.26 \mathrm{~kg} \mathrm{BW})$ were randomly distributed in 2 lots, which in turn were assigned to 1 of 2 dietary treatments. Diets were prepared weekly and consisted of a TMR based on alfalfa hay and a concentrate (40:60) supplemented with 0 (control diet; $\mathrm{n}=5$ ) or $8 \mathrm{~g}$ of marine algae (DHA Gold Animal Feed Ingredient, Martek Biosciences Corp., 
Columbia, MD, USA) per $\mathrm{kg}$ of DM (MA diet; $\mathrm{n}=6$ ). The concentrate was composed of corn grain, soybean meal, barley grain, beet pulp, a vitamin-mineral supplement, and molasses to reduce selection of dietary components. Diets also included $25 \mathrm{~g}$ of sunflower oil/kg of DM (Carrefour S.A., Madrid, Spain) and were offered daily ad libitum at 09:00 and 19:00 h throughout the 54-day experiment (for details, see Bichi et al., 2013).

\subsection{Measurements, sampling procedures, and analyses}

After 54 days of treatment, ewes were slaughtered humanely by an intravenous injection of a euthanasia drug (T-61; Intervet, Salamanca, Spain). The rumen was excised and carefully removed, then the rumen content (RC) was homogenized and sampled from each animal. After that, it was strained through 2 layers of muslin and an aliquot of the resulting supernatant, which represented the rumen fluid (RF), was taken. All samples were immediately frozen at $-80^{\circ} \mathrm{C}$, freeze-dried, and stored again at $-80^{\circ} \mathrm{C}$ until analysis.

\subsection{DNA extraction and quantification}

Freeze-dried rumen samples were thoroughly homogenized before DNA extraction, which was performed by physical disruption using a bead beater (Mini-bead Beater, BioSpec Products, Bartlesville, OK, USA) and subsequent DNA purification with the QIAamp DNA Stool Mini Kit (Qiagen Inc., Valencia, CA, USA), as reported in Belenguer et al. (2010). The DNA was extracted twice from each sample, and duplicates were combined and used as templates for T-RFLP and 454 pyrosequencing analyses. The DNA concentrations and purity were measured by spectrophotometry (NanoDrop ND-1000 Spectrophotometer; Nanodrop Technologies, Wilmington, DE, USA).

\subsection{T-RFLP analysis}

This analysis was performed as outlined previously (Belenguer et al., 2010), with a universal bacteria specific primer pair set $(27 \mathrm{f}$ = AGAGTTTGATCCTGGCTCAG; 
and 1389r = ACGGGCGGTGTGTACAAG; Hongoh et al., 2003) and 3 restriction enzymes (HhaI, MspI, and HaeIII). The lengths of the fluorescently labeled terminal restriction fragments (T-RF) were determined with the size standard ET-900-R (GE Healthcare Life Sciences, Buckinghamshire, UK) using the GeneMarker Analysis software (SoftGenetics, State College, PA, USA). To infer the potential bacterial composition in the samples, in silico restriction for the major rumen bacteria were obtained from the Ribosomal Database Project II website (http://rdp.cme.msu.edu/ index.jsp; Cole et al., 2009). Data from T-RFLP (size, bp, and peak area for each T$\mathrm{RF}$ ) were analyzed for peak filtering and binning, as outlined by Abdo et al. (2006), and used to determine the relative abundance of each fragment over the total peak area, as well as the diversity indices (number of T-RF or richness, Shannon and Shannon evenness indices; Hill et al., 2003).

\subsection{Pyrosequencing and sequence analysis}

Amplification of the bacterial V1-V2 regions of the 16S rRNA gene by PCR was performed using the primers pair 27f and 357r (CTGCTGCCTYCCGTA; Liu et al., 2007) appended with 454 sequencing adaptors at the $5^{\prime}$ end. Polymerase chain reaction for each sample was performed in triplicate in a total volume of $25 \mu \mathrm{L}$ containing $10 \times$ PCR buffer, $10 \mathrm{mM}$ deoxyribonucleotide triphosphate mix, 10 $\mathrm{pmol} / \mu \mathrm{L}$ of forward and reverse primers, $1 \mathrm{U}$ of FastStart Taq DNA Polymerase (Fast- Start High Fidelity PCR System; Roche, Brandford, CT, USA), and $1 \mu \mathrm{L}$ of DNA template. The amplification program consisted of an initial denaturation step at $95^{\circ} \mathrm{C}$ for $2 \mathrm{~min}, 25$ cycles of denaturation at $95^{\circ} \mathrm{C}$ for $30 \mathrm{~s}$, annealing at $60^{\circ} \mathrm{C}$ for $30 \mathrm{~s}$, elongation at $72^{\circ} \mathrm{C}$ for $45 \mathrm{~s}$, and a final extension step at $72^{\circ} \mathrm{C}$ for $7 \mathrm{~min}$. The size of the PCR product (330 bp) was then checked on 1\% agarose gel electrophoresis. Following this, triplicates were purified and normalized by quantitative DNA binding (SequalPrep kit; Invitrogen, Carlsbad, CA, USA), pooled together, cleaned up through ethanol precipitation, and finally purified with the short fragment removal method described by Roche using their GS FLX amplicon DNA preparation guide and AMPure beads. The purified PCR products 
were quantified by the Quant-iT PicoGreen dsDNA quantification kit (Invitrogen) and mixed in equimolar amounts to a $10^{7}$-molecules/ $\mu \mathrm{L}$ sample. The amplicon pooled libraries were pyrosequenced on a 454 FLX Titanium sequencer (454 Life Sciences; Roche).

Data of $16 \mathrm{~S}$ rRNA sequences generated by pyrosequencing were processed as follows. The flowgram files were converted to FASTA DNA and quality score files on the 454 cluster and transferred onto a Linuxbased workstation running quantitative insights into microbial ecology (QIIME) per scripted modules and workflow scripts (Caporaso et al., 2010). Sequences were filtered to exclude those that did not match the primer sequence, were less than 150 nucleotides in length, or contained either one or more ambiguous bases or a long homopolymer $(>6)$. Errors of amplicon pyrosequences were corrected through the Acacia software (Bragg et al., 2012).

Operational taxonomic units (OTU) were generated by aligning the reads to the GreenGenes database (DeSantis et al., 2006) and clustered at 97\% sequence identity using the PyNAST tool (Caporaso et al., 2010) and the UCLUST algorithm (Edgar, 2010), respectively. Taxonomic classification was assigned with the basic local alignment search tool (Altschul et al., 1990). Alpha diversity (i. e., diversity within a sample) indices (observed species, Chao, and Shannon) were generated with the QIIME pipeline, whereas $\beta$ diversity (i. e., diversity between groups of samples) was used to create principal coordinate analysis (PCoA) plots using unweighted and weighted UniFrac distances. The UniFrac phylogenetic method (Lozupone and Knight, 2005), which considers phylogenetic lineages and not just shared OTU, was used for community-level comparisons with the trees constructed during the OTU picking script.

\subsection{Statistical analysis}

Hierarchical clustering analysis with Ward's method based on Bray-Curtis distances was performed with R-project software (www.r-project.org, version 2.13.1) to build dendrograms with relative abundance data derived from T-RFLP 
(T-RF) and pyrosequencing (OTU at the genus level). Using the same software, multivariate ANOVA (MANOVA) of the same data was conducted to assess the effect of diet (control and MA), fraction ( $R C$ and $R F)$, and their interaction on the whole rumen bacterial structure.

In addition, relative abundances of each T-RF or OTU were analyzed by oneway ANOVA, employing the MIXED procedure of the SAS software package (version 9.3, SAS Institute Inc., Cary, NC, USA). As some results did not satisfy the assumptions of normality, data were transformed to $\log _{10}(\mathrm{n}+\mathrm{c}$; c being a constant of the same order of magnitude as the variable) before the analysis. The statistical model included the fixed effects of diet, fraction, and their interaction, plus the random effect of animal. Means were separated through "pdiff" option of the "lsmeans" statement of the MIXED procedure. Differences were declared significant at $P<0.05$ and considered a trend toward significance at $P<0.10$. Least squares means are reported.

\section{RESULTS}

\subsection{Bacterial community analysis by T-RFLP}

Rumen bacterial T-RFLP analysis generated, on average, $64.8 \pm 2.71,65.7 \pm 9.05$, and $152.9 \pm 7.42$ fragments with the enzymes Hhal, MspI, and HaeIII, respectively. Hierarchical clustering analysis grouped the bacterial structure of RC and RF samples derived from the same sheep (Figure 1a). In the dendrogram, most MA samples appeared in separate clusters, but the segregation by diet was not clear. According to MANOVA results, although the bacterial composition differed between rumen fractions $(P<0.05)$, the effect of MA was stronger $(P<0.001)$ and no significant interaction between diet and fraction was found $(P>0.10)$.

The diversity indices did not differ between diets in data derived from MspI and HaelII enzymes (Table $1 ; P>0.10$ ), whereas the HhaI digestion indicated a negative effect of the MA diet (i. e., Shannon and Shannon evenness; $P<0.10$ ) in 
both rumen fractions. All enzymes showed a greater bacterial diversity in RC compared with RF.

(a)

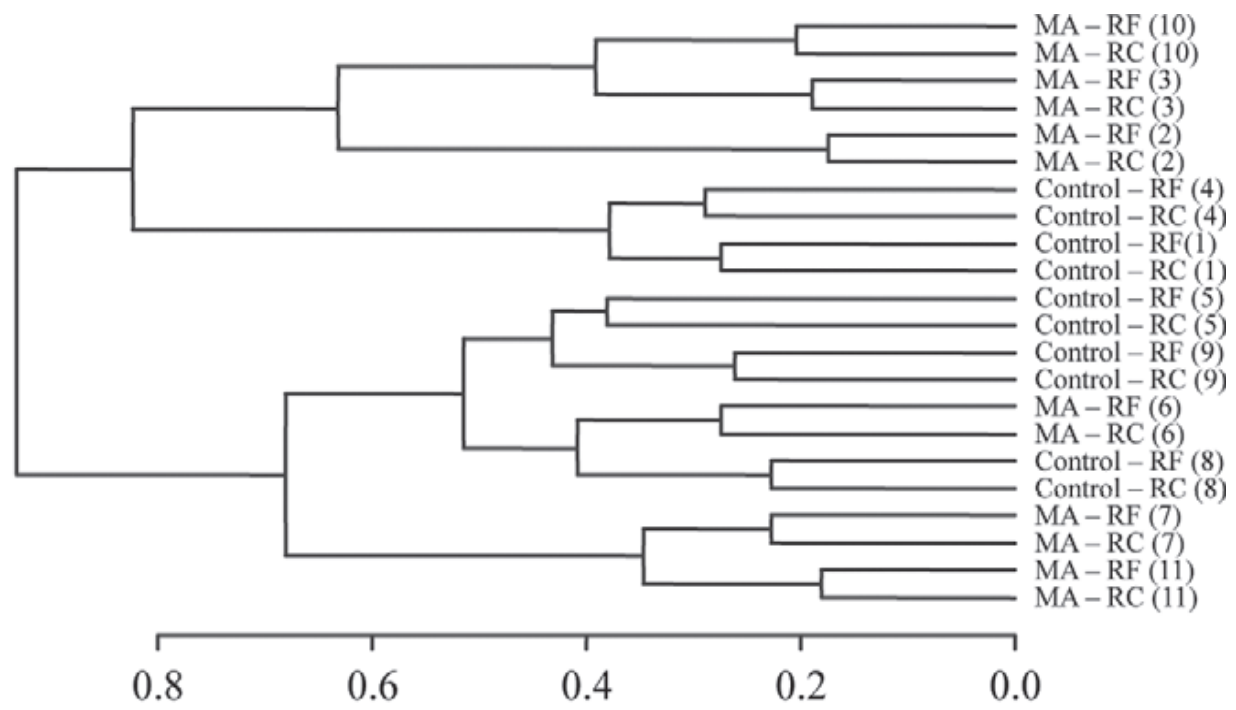

(b)

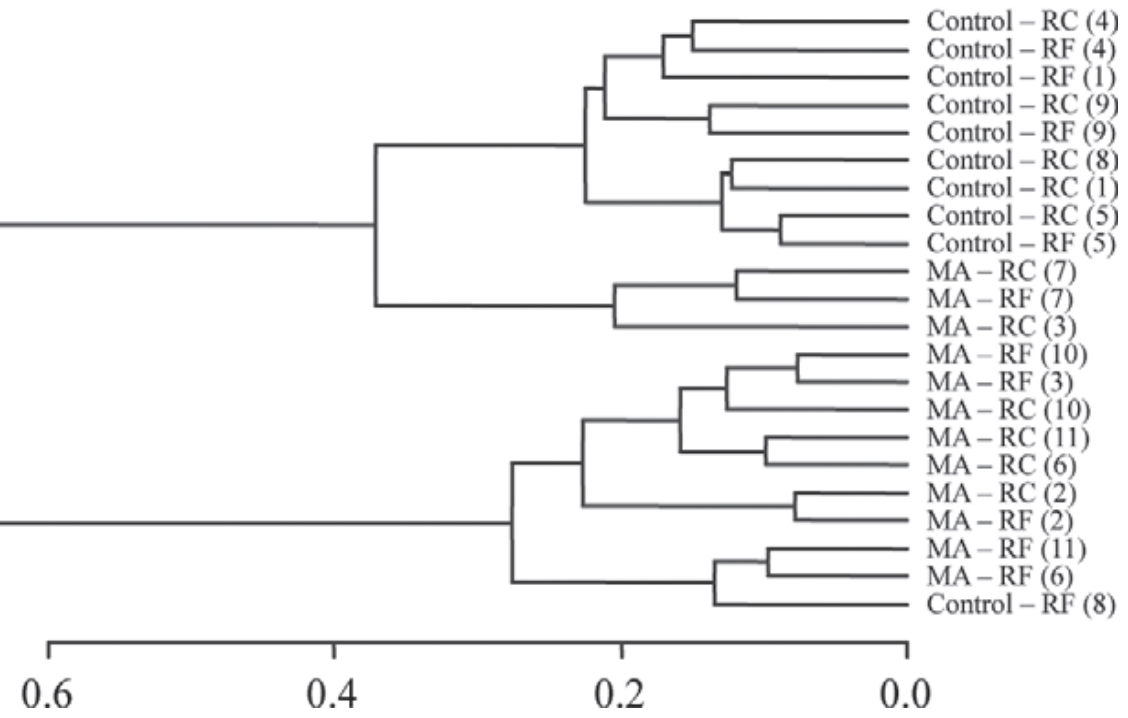

Figure 1. Cluster analysis of T-RFLP (a) or 454 pyrosequencing (b) profiles, based on Ward's method and the Bray-Curtis distances, of total bacteria in rumen content (RC) or fluid (RF) samples of ewes fed a diet with (marine algae $=M A$ ) or without (control) $8 \mathrm{~g}$ of marine algae/ $\mathrm{kg}$ of DM. Values in parentheses indicate the number of the animal. 
Putative taxonomic identification of major detected T-RF revealed that they were likely to be derived from bacteria of the phylum Bacteroidetes (Table 2). Some of these fragments and others that may correspond with Succinivibrionaceae were more prevalent $(P<0.05)$ in RF than $\mathrm{RC}$, but this did not preclude from attributing similar effects to MA addition. For instance, both fractions showed that MA decreased T-RF that would match Porphyromonadaceae $(P<0.01)$ and Ruminococcaceae $(P<0.10)$, and increased $(P<0.01)$ others that may correspond to Succinivibrionaceae. Inconsistencies between fractions, such as the reduction in a TRF putatively assigned to Bacteroidetes (98 bp with Hhal), which was only significant in RF samples, were rarely observed.

Table 1. Diversity indices ( $R=$ richness; $H=$ Shannon; $E=$ Shannon evenness; $O S=$ observed species; and Chao) of bacterial communities in rumen content (RC) or fluid (RF) samples of ewes fed the experimental diets ${ }^{1}$

\begin{tabular}{|c|c|c|c|c|c|c|c|c|c|}
\hline & \multicolumn{2}{|c|}{ RC } & \multicolumn{2}{|c|}{ RF } & \multirow[b]{2}{*}{ SED $^{2}$} & \multicolumn{3}{|c|}{$P^{3}$} \\
\hline & & Control & MA & Control & MA & & D & $\mathrm{F}$ & $D \times F$ \\
\hline \multicolumn{10}{|l|}{ T-RFLP } \\
\hline \multirow[t]{3}{*}{ HhaI } & $\mathrm{R}$ & 73.0 & 64.8 & 64.8 & 58.0 & 7.53 & 0.28 & 0.08 & 0.86 \\
\hline & $\mathrm{H}$ & 3.05 & 2.73 & 2.73 & 2.44 & 0.157 & 0.06 & $<0.01$ & 0.83 \\
\hline & $\mathrm{E}$ & 0.72 & 0.65 & 0.65 & 0.60 & 0.025 & 0.02 & $<0.001$ & 0.62 \\
\hline \multirow[t]{3}{*}{ MspI } & $\mathrm{R}$ & 81.0 & 75.3 & 59.2 & 48.7 & 26.39 & 0.75 & 0.02 & 0.79 \\
\hline & $\mathrm{H}$ & 3.23 & 2.97 & 2.60 & 2.32 & 0.522 & 0.58 & 0.01 & 0.98 \\
\hline & E & 0.78 & 0.71 & 0.66 & 0.62 & 0.053 & 0.33 & $<0.001$ & 0.42 \\
\hline \multirow[t]{3}{*}{ HaeIII } & $\mathrm{R}$ & 169.0 & 159.5 & 139.8 & 143.7 & 21.41 & 0.87 & 0.11 & 0.61 \\
\hline & $\mathrm{H}$ & 4.18 & 4.08 & 3.87 & 3.91 & 0.153 & 0.80 & 0.05 & 0.52 \\
\hline & E & 0.82 & 0.81 & 0.79 & 0.79 & 0.013 & 0.47 & 0.06 & 0.76 \\
\hline \multicolumn{10}{|c|}{454 Pyrosequencing } \\
\hline & OS & 756.8 & 711.8 & 635.8 & 631.8 & 62.34 & 0.68 & $<0.01$ & 0.39 \\
\hline & Chao & 1122.9 & 1138.3 & 1041.3 & 1022.6 & 109.20 & 0.99 & 0.08 & 0.74 \\
\hline & $\mathrm{H}$ & 7.94 & 7.30 & 7.46 & 7.01 & 0.331 & 0.13 & $<0.001$ & 0.16 \\
\hline
\end{tabular}

${ }^{1}$ Refers to a TMR containing 0 (control diet) or $8 \mathrm{~g}$ of marine algae (MA diet)/kg of DM. ${ }^{2} \mathrm{SED}=$ standard error of the difference.

3Probability of a significant effect due to diet (D), rumen fraction $(F)$, and their interaction $(\mathrm{D} \times \mathrm{F})$. 
Table 2. Relative frequencies [expressed as $\log 10(n+c)$ of percent over the total peak area, with original values in parentheses] of some terminal restriction fragments $(T-R F)$ and their putative taxonomic identification in rumen content (RC) or fluid (RF) samples of ewes fed the experimental diets ${ }^{1}$.

\begin{tabular}{|c|c|c|c|c|c|c|c|c|c|}
\hline \multirow[b]{2}{*}{ Taxonomic identification } & \multirow[b]{2}{*}{ T-RF (bp) } & \multicolumn{2}{|c|}{ RC } & \multicolumn{2}{|c|}{ RF } & \multirow[b]{2}{*}{ SED $^{2}$} & \multicolumn{3}{|c|}{$P^{3}$} \\
\hline & & Control & MA & Control & MA & & $\mathrm{D}$ & $\mathrm{F}$ & $\mathrm{D} \times \mathrm{F}$ \\
\hline \multirow[t]{9}{*}{ Bacteroidetes } & 98 (HhaI) & $0.64^{\mathrm{b}}(4.67)$ & $0.58^{\mathrm{b}}(3.83)$ & $0.77^{\mathrm{a}}(6.20)$ & $0.51^{\mathrm{b}}(3.26)$ & 0.074 & 0.03 & 0.44 & 0.02 \\
\hline & 100 (HhaI) & $1.54(35.01)$ & 1.59 (39.59) & $1.62(41.91)$ & $1.62(42.73)$ & 0.044 & 0.46 & 0.01 & 0.21 \\
\hline & 180 (HhaI) & $0.57(2.06)$ & $0.49(1.34)$ & $0.66(2.83)$ & $0.49(1.35)$ & 0.079 & 0.11 & 0.16 & 0.18 \\
\hline & $91(M s p I)$ & $0.80(3.22)$ & $0.74(2.66)$ & $0.84(3.96)$ & $0.73(2.69)$ & 0.077 & 0.27 & 0.57 & 0.31 \\
\hline & $93(M s p I)$ & $0.56(1.62)$ & $0.67(2.88)$ & $0.58(1.69)$ & $0.61(2.30)$ & 0.095 & 0.46 & 0.59 & 0.28 \\
\hline & $96(M s p I)$ & $1.43(28.80)$ & $1.48(31.56)$ & $1.61(43.66)$ & $1.54(37.46)$ & 0.104 & 0.90 & $<0.01$ & 0.12 \\
\hline & 156 (HaeIII) & $0.28(2.33)$ & $-0.39(0.44)$ & $0.48(4.67)$ & $-0.16(0.74)$ & 0.178 & $<0.01$ & 0.04 & 0.92 \\
\hline & $257+258($ HaeIII $)$ & $0.71(5.38)$ & $0.68(4.83)$ & $0.79(6.26)$ & $0.67(4.85)$ & 0.071 & 0.18 & 0.44 & 0.39 \\
\hline & $263+264($ HaeIII $)$ & 1.32 (20.95) & $1.36(23.63)$ & $1.38(24.15)$ & 1.42 (26.59) & 0.047 & 0.22 & 0.07 & 0.98 \\
\hline \multirow[t]{2}{*}{ Porphyromonadaceae } & $84(M s p I)$ & $0.33^{\mathrm{a}}(1.41)$ & $0.09^{\mathrm{b}}(0.40)$ & $0.36^{\mathrm{a}}(1.57)$ & $0.02^{\mathrm{c}}(0.24)$ & 0.078 & $<0.01$ & 0.39 & 0.04 \\
\hline & 257(HaeIII) & $0.52(3.30)$ & $0.42(2.74)$ & $0.54(3.54)$ & $0.45(2.96)$ & 0.071 & 0.17 & 0.40 & 0.94 \\
\hline \multirow[t]{3}{*}{ Ruminococcaceae } & 390 (HhaI) & $-0.53(0.27)$ & $-0.89(0.00)$ & $-0.56(0.30)$ & $-0.89(0.00)$ & 0.169 & 0.07 & 0.64 & 0.64 \\
\hline & $320(M s p I)$ & $0.76(4.04)$ & $0.41(0.84)$ & $0.64(2.65)$ & $0.36(0.47)$ & 0.078 & $<0.01$ & $<0.01$ & 0.22 \\
\hline & 280 (HaeIII) & 0.07 (1.19) & $-0.15(0.78)$ & $0.02(1.55)$ & $-0.22(0.66)$ & 0.145 & 0.09 & 0.50 & 0.91 \\
\hline \multirow[t]{2}{*}{ Succinivibrionaceae } & 201 (HhaI) & $0.24(1.84)$ & $0.90(8.95)$ & $0.33(2.73)$ & 1.07 (13.57) & 0.154 & $<0.01$ & $<0.01$ & 0.28 \\
\hline & $461(M s p I)$ & $1.03(1.07)$ & 1.32 (12.73) & $1.08(2.64)$ & 1.44 (19.77) & 0.085 & $<0.01$ & $<0.01$ & 0.15 \\
\hline
\end{tabular}

a-cWithin a row, different superscripts indicate significant differences $(P<0.05)$.

${ }^{1}$ Refers to a TMR containing 0 (control diet) or $8 \mathrm{~g}$ of marine algae (MA diet)/kg of DM.

2SED = standard error of the difference.

${ }^{3}$ Probability of a significant effect due to diet (D), rumen fraction $(F)$, and their interaction $(D \times F)$. 


\subsection{Bacterial community analysis by pyrosequencing}

An average of 5,688 sequences per sample were derived for bacterial diversity evaluation, with $4,945 \pm 253.5$ used for analysis after quality control. Hierarchical clustering (Figure 1b) showed a certain separation by diet, but not by rumen fraction. The MANOVA results indicated that, although bacterial communities differed between RF and RC $(P<0.01)$, the effect of MA addition was stronger $(P<$ $0.001)$, and no interaction was detected $(P>0.10)$. Similarly, PCoA showed no clear segregation due to the rumen fraction, whereas control samples were well separated from MA ones (Figure 2).

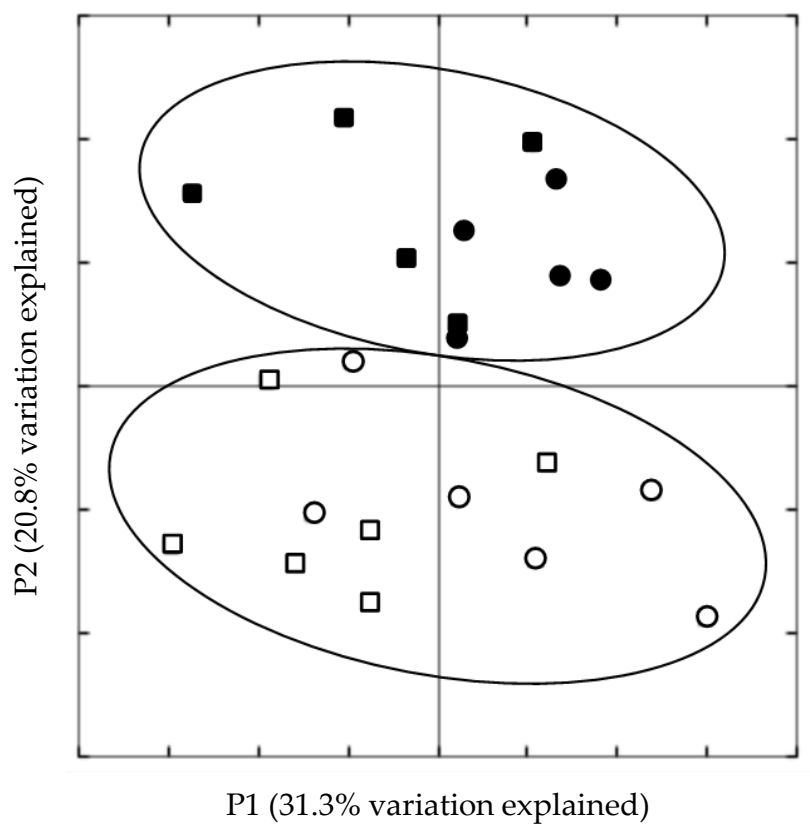

Figure 2. Principal coordinate analysis plot of bacterial $16 S r R N A$ gene sequences generated from 454 pyrosequencing run of DNA from rumen content (circles) or fluid (squares) samples of ewes fed a diet with (marine algae $=$ open symbols) or without (control = closed symbols) $8 \mathrm{~g}$ of marine algaelkg of DM. $P 1$ and $P 2=$ principal components 1 and 2, respectively.

In terms of diversity (Table 1$)$, the number of observed species was greater $(P$ $<0.01$ ) in RC samples and, consequently, some differences were also found in the Chao and Shannon diversity indices between RC and RF. Nonetheless, both fractions showed the same lack of significant effect of MA on diversity. 
Regarding the bacterial community composition, Bacteroidetes was the dominant phylum (69-77\%; Figure 3), followed by Firmicutes (13-26\%) and Proteobacteria (1$7 \%$ ), whereas the remaining detected phyla (Fibrobacteres, Tenericutes, Cyanobacteria, Spirochaetes, Synergistetes, TM7, Elusimicrobia, SR1, Verrucomicrobia, Fusobacteria, Chloroflexi, and Actinobacteria) appeared at percentages lower than 1.5 (Supplementary Table S1).

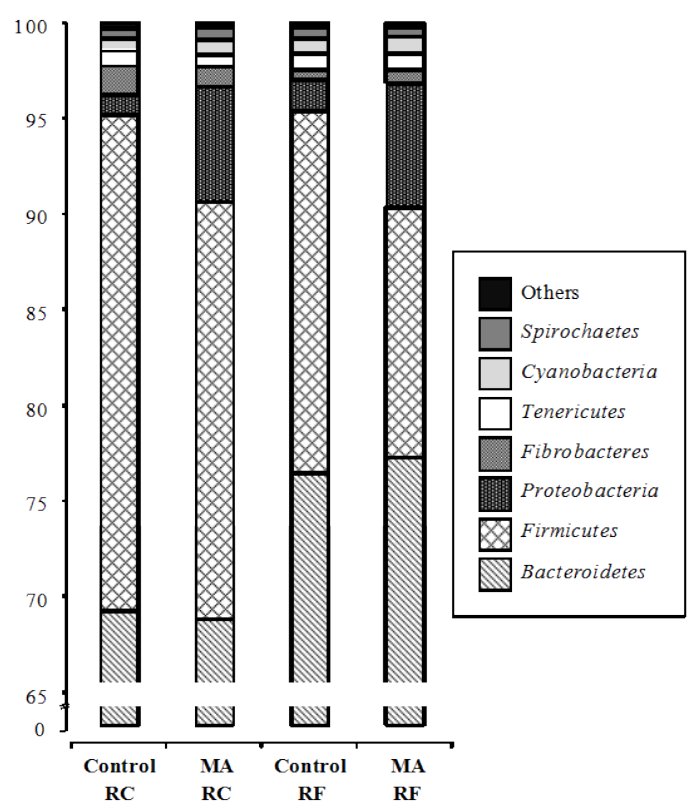

Figure 3. Relative abundances (\% of total sequences) of most abundant bacterial phyla identified by 454 pyrosequencing in rumen content $(R C)$ or fluid $(R F)$ samples of ewes fed a diet with (MA) or without (Control diet) $8 \mathrm{~g}$ of marine algae/kg DM.

Within Bacteroidetes, the abundance of Prevotellaceae, whose detected sequences belonged only to the genus Prevotella, represented 49 to 61\% (Table 3 and Supplementary Table S1). Despite the greater prevalence of this phylum in RF than in RC, similar effects of MA were observed in both rumen fractions for all identified subpopulations. Most relevant effects of MA included increases in the genus Bacteroides $(P<0.01)$ and the family S24-7 $(P<0.05)$, and decreases in Paraprevotellaceae $(P<0.10)$, Porphyromonadaceae $(P<0.001)$, and other unclassified members of the order Bacteroidales $(P<0.01$; Table 3$)$. 
Table 3. Relative abundances [expressed as $\log 10(n+c)$ of percent of total sequences, with original values in parentheses] of relevant orders, families, and genera identified by 454 pyrosequencing in rumen content $(R C)$ or fluid $(R F)$ samples of ewes fed the experimental diets ${ }^{1}$.

\begin{tabular}{|c|c|c|c|c|c|c|c|c|}
\hline \multirow[b]{2}{*}{ Taxonomy } & \multicolumn{2}{|c|}{$\mathrm{RC}$} & \multicolumn{2}{|c|}{ RF } & \multirow[b]{2}{*}{$\mathrm{SED}^{2}$} & \multicolumn{3}{|c|}{$P^{3}$} \\
\hline & Control & $\mathrm{MA}$ & Control & MA & & $\mathrm{D}$ & $\mathrm{F}$ & $\mathrm{D} \times \mathrm{F}$ \\
\hline \multicolumn{9}{|l|}{ Bacteroidetes } \\
\hline Bacteroidales & $1.84(69.2)$ & $1.83(68.8)$ & $1.88(76.4)$ & $1.89(77.2)$ & 0.029 & 0.98 & 0.02 & 0.74 \\
\hline Unclassified & $0.93(8.55)$ & $0.70(5.35)$ & $0.94(8.87)$ & $0.65(4.64)$ & 0.076 & $<0.01$ & 0.67 & 0.45 \\
\hline Bacteroidaceae & $-0.61(0.27)$ & $-0.34(0.50)$ & $-1.29(0.06)$ & $-0.69(0.25)$ & 0.159 & $<0.01$ & $<0.001$ & 0.13 \\
\hline Bacteroides & $-0.63(0.25)$ & $-0.34(0.50)$ & $-1.29(0.06)$ & $-0.70(0.25)$ & 0.157 & $<0.01$ & $<0.001$ & 0.15 \\
\hline Porphyromonadaceae & $0.41(2.66)$ & $-0.19(0.71)$ & $0.65(4.85)$ & $0.09(1.31)$ & 0.112 & $<0.001$ & $<0.001$ & 0.54 \\
\hline Paludibacter & $0.40(2.63)$ & $-0.19(0.71)$ & $0.64(4.75)$ & $0.08(1.28)$ & 0.114 & $<0.001$ & $<0.001$ & 0.59 \\
\hline Prevotellaceae (Prevotella) & $1.69(49.3)$ & $1.72(53.0)$ & $1.73(53.8)$ & $1.78(61.0)$ & 0.037 & 0.21 & 0.03 & 0.48 \\
\hline S24-7 & $0.29(2.00)$ & $0.59(4.73)$ & $0.01(1.12)$ & $0.53(4.21)$ & 0.146 & 0.02 & $<0.01$ & 0.06 \\
\hline Paraprevotellaceae & $0.80(6.42)$ & $0.64(4.47)$ & 0.89 (7.76) & $0.75(5.89)$ & 0.074 & 0.06 & $<0.01$ & 0.68 \\
\hline \multicolumn{9}{|l|}{ Firmicutes } \\
\hline Clostridiales & $1.35(22.6)$ & 1.25 (18.6) & $1.21(17.3)$ & $1.05(11.7)$ & 0.078 & 0.08 & $<0.01$ & 0.49 \\
\hline Clostridium & $-0.19(0.45)$ & $-0.36(0.23)$ & $-0.40(0.18)$ & $-0.60(0.04)$ & 0.065 & $<0.01$ & $<0.001$ & 0.75 \\
\hline Lachnospiraceae & $1.02(10.6)$ & $0.98(9.87)$ & $0.69(5.45)$ & $0.71(5.46)$ & 0.100 & 0.90 & $<0.01$ & 0.64 \\
\hline Unclassified & $0.70(5.07)$ & $0.59(4.50)$ & $0.47(3.16)$ & $0.44(3.07)$ & 0.126 & 0.53 & 0.01 & 0.54 \\
\hline Butyrivibrio & $0.41(2.72)$ & $0.43(2.74)$ & $-0.04(1.05)$ & $-0.05(0.98)$ & 0.123 & 0.96 & $<0.001$ & 0.86 \\
\hline Pseudobutyrivibrio & $-0.59(0.27)$ & $-0.45(0.40)$ & $-0.96(0.16)$ & $-0.87(0.18)$ & 0.216 & 0.41 & 0.02 & 0.88 \\
\hline Ruminococcaceae & $0.78(6.24)$ & $0.55(3.92)$ & $0.50(3.63)$ & $0.26(2.00)$ & 0.131 & 0.08 & $<0.001$ & 0.97 \\
\hline Unclassified & $0.34(2.32)$ & $0.04(1.26)$ & $0.24(2.00)$ & $-0.10(0.86)$ & 0.138 & 0.04 & 0.01 & 0.65 \\
\hline Ruminococcus & $0.50(3.35)$ & $0.32(2.38)$ & $-0.02(1.10)$ & $-0.12(0.83)$ & 0.139 & 0.27 & $<0.001$ & 0.59 \\
\hline
\end{tabular}


Table 3. (continued)

\begin{tabular}{|c|c|c|c|c|c|c|c|c|}
\hline \multirow[b]{2}{*}{ Taxonomy } & \multicolumn{2}{|c|}{$\mathrm{RC}$} & \multicolumn{2}{|c|}{$\mathrm{RF}$} & \multirow[b]{2}{*}{$\mathrm{SED}^{2}$} & \multicolumn{3}{|c|}{$P^{3}$} \\
\hline & Control & MA & Control & MA & & $\mathrm{D}$ & $\mathrm{F}$ & $\mathrm{D} \times \mathrm{F}$ \\
\hline Veillonellaceae & $0.57(3.94)^{\mathrm{b}}$ & $0.51(3.36)^{b}$ & $0.82(7.26)^{\mathrm{a}}$ & $0.50(3.54)^{\mathrm{b}}$ & 0.118 & 0.11 & 0.04 & 0.03 \\
\hline Unclassified & $0.55(3.76)^{b}$ & $0.46(2.97)^{b}$ & $0.79(6.87)^{\mathrm{a}}$ & $0.44(3.08)^{\mathrm{b}}$ & 0.120 & 0.07 & 0.07 & 0.04 \\
\hline Selenomonas & $-1.11(0.11)$ & $-0.58(0.28)$ & $-0.62(0.25)$ & $-0.62(0.34)$ & 0.204 & 0.13 & 0.11 & 0.07 \\
\hline \multicolumn{9}{|l|}{ Proteobacteria } \\
\hline Succinivibrionaceae & $-0.30(0.76)$ & $0.63(5.71)$ & $-0.02(1.28)$ & $0.76(6.19)$ & 0.216 & $<0.01$ & 0.03 & 0.38 \\
\hline Unclassified & $-0.46(0.58)$ & $0.61(5.57)$ & $-0.23(0.97)$ & $0.75(6.04)$ & 0.253 & $<0.01$ & 0.08 & 0.61 \\
\hline Succinivibrio & $-0.70(0.10)$ & $-0.67(0.10)$ & $-0.53(0.19)$ & $-0.67(0.11)$ & 0.114 & 0.55 & 0.25 & 0.25 \\
\hline
\end{tabular}

a,bWithin a row, different superscripts indicate significant differences $(P<0.05)$.

${ }^{1}$ Refers to a TMR containing 0 (control diet) or $8 \mathrm{~g}$ of marine algae (MA diet)/kg of DM.

${ }^{2} \mathrm{SED}=$ standard error of the difference.

3Probability of a significant effect due to diet $(D)$, rumen fraction $(F)$, and their interaction $(D \times F)$ 
Within Firmicutes, most sequences belonged to the order Clostridiales, and Lachnospiraceae, Ruminococcaceae, and Veillonellaceae were the most prevalent families. Again, although the relative abundance of Firmicutes was greater in RF, most changes due to MA addition were detected similarly in both fractions (e. g., the reduction of unclassified members of Ruminococcaceae and Clostridium; $P<$ 0.05). Only bacterial groups of the family Veillonellaceae were affected differently by MA in RC and RF, with unclassified species showing a decrease just in the latter, and Selenomonas an increase in the former $(P<0.05$ and $P<0.10$, respectively, for diet $\times$ fraction). Regarding the phylum Proteobacteria, MA supplementation promoted, similarly in RC and RF, at least a 4-fold increase in species of the family Succinivibrionaceae (Table 3 and Supplementary Table S1).

\section{DISCUSSION}

Developing novel strategies to increase the content of bioactive unsaturated FA in ruminant-derived products, such as milk and meat, requires a deeper understanding of ruminal $\mathrm{BH}$ and bacteria involved in this process (Boeckaert et al., 2009; Huws et al., 2011). Although pyrosequencing platforms may allow for a great coverage of bacterial diversity (Hall, 2007), they have hardly been used to investigate the microbiology of rumen FA metabolism. Conversely, several reports in the literature demonstrate, through molecular fingerprinting techniques such as T-RFLP or DGGE, the complexity of the rumen ecosystem response to dietary lipid supplementation and the potential predominant role of as-yet uncultured bacteria in ruminal BH (Boeckaert et al., 2008; Huws et al., 2011; Toral et al., 2012). The choice of the type of methodology will depend on several factors, one of the most important being the compromise between the accuracy and precision of the results and the cost of the approach.

In the current study, both 454 pyrosequencing and T-RFLP were used concurrently and the results pointed to similar conclusions, which may allow the usefulness of T-RFLP to be strengthened in this kind of study. Thus, hierarchical clustering, MANOVA, and PCoA analyses showed that, despite known variations 
in the bacterial composition of RC and RF (Pitta et al., 2010; de Menezes et al., 2011), dietary MA was stronger in shaping the bacterial community structure. This is in agreement with Pitta et al. (2010), who reported that the 2 rumen fractions studied (liquid and whole contents) were able to associate distinct bacterial communities with different forage diets. In the present study, samples were segregated in response to MA in spite of its low level of inclusion in the diet $(0.8 \%)$ and the small variations in the diversity indices estimated with either pyrosequencing or T-RFLP. These results are similar to those reported previously, using fingerprinting techniques, in sheep (Belenguer et al., 2010; Toral et al., 2012) and cattle (Boeckaert et al., 2007, 2008; Huws et al., 2011) fed marine lipids, and would underline the potent inhibitory effect of very long-chain PUFA on certain rumen bacteria (Maia et al., 2007, 2010).

The phylogenetic resolution of the 454 pyrosequencing allowed the identification at the phylum level of the entire set of sequences and up to the genus level of almost $75 \%$ (the remaining $25 \%$ was due to limitations in the available databases). Consistent with previous results in cattle, sheep, and goats (Stewart et al., 1997; Lee et al., 2012; Kittelmann et al., 2013), the phyla Bacteroidetes and Firmicutes were the most abundant in the rumen bacterial community, regardless of rumen fractions and effects of diet. Conversely, both RF and RC showed that the relative abundance of the phylum Proteobacteria was greater in ewes fed MA. These results agreed with detected T-RF, although pyrosequencing achieved the identification of 12 other phyla with much lower abundances $(<1.5 \%$ of total sequences; Supplementary Table S1), some of which may be significant at a functional level and therefore important for the study (Stewart et al., 1997). However, MA supplementation had almost no effect on the relative abundance of those minor groups, with the exception of a reduction in the candidate phylum TM7, and all relevant changes were observed in Bacteroidetes, Firmicutes, and Proteobacteria phyla, in line with concomitant variations in T-RF.

Regardless of the diet and rumen fraction, the relative abundance of Bacteroidetes sequences $(>68 \%)$ were on the highest range reported for ruminants 
using both traditional (van Gylswyk, 1990) and molecular techniques (Lee et al., 2012; Pope et al., 2012; Wu et al., 2012). Within this phylum, the genus Prevotella represented more than $50 \%$ of total sequences in most samples (particularly in RF), which may suggest a relevant function in the rumen ecosystem. Its predominance agrees with previous studies (Stevenson and Weimer, 2007; Jami and Mizrahi, 2012; Wu et al., 2012) and is probably explained by the basal diet composition, with relatively low fiber content and supplemented with sunflower oil. In this regard, it is known that Prevotella degrades readily metabolizable carbohydrates (Stewart et al., 1997) and is more abundant in low-fiber diets (Pitta et al., 2010). In addition, several Prevotella strains have shown a low sensitivity to linoleic acid, the major FA in sunflower oil, both in vitro (Maia et al., 2007) and in vivo (Zened et al., 2013), as well as to very long chain PUFA (Maia et al., 2007; Huws et al., 2010), which is consistent with the lack of variation in ewes fed MA. However, the treatment with marine lipids had contrasting effects on other subpopulations within this large and diverse phylum, which suggests either different roles of these groups in $\mathrm{BH}$ or distinct sensitivities to the toxic effect of very long-chain PUFA.

Changes within Bacteroidetes due to MA, observed both with T-RFLP and pyrosequencing, included reductions in Porphyromonadaceae and relatively abundant bacteria identified as unclassified Bacteroidales. In this respect, and despite the limited knowledge on the relationship between Bacteroidetes members and dietary lipids (Maia et al., 2007; Huws et al., 2010), putative taxonomic identifications have linked unclassified Bacteroidales and Porphyromonadaceae strains with 18:0, trans-11 18:1, and cis-9, trans-11 CLA concentrations in the rumen of cattle fed fish oils (Huws et al., 2011).

On the contrary, supplementing the dairy ewe diet with MA did not have an effect on the relative abundance of bacterial genera, including microorganisms that are by far the most active $\mathrm{BH}$ species isolated from the rumen, such as Butyrivibrio and Pseudobutyrivibrio (Paillard et al., 2007). These findings are in agreement with recent in vivo studies (Belenguer et al., 2010; Huws et al., 2011; 
Shingfield et al., 2012), which have suggested a lower relevance of those species in ruminal $\mathrm{BH}$ than initially thought. However, it must be considered that the functional activity of a microbial group may be affected without variations in its DNA abundance (Popova et al., 2011).

Other subpopulations of the phylum Firmicutes, such as unclassified Ruminococcaceae and Veillonellaceae strains and low abundant sequences corresponding to Selenomonas, were altered by MA. The increase in the relative abundance of the latter only tended to be significant in RC (Table 3) and, although it represented a very small fraction, the fact that it was present in all samples might indicate that Selenomonas occupies a special ecological niche in the rumen. In fact, and regarding rumen FA metabolism, the species Selenomonas ruminantium is known to be involved in FA hydration (Hudson et al., 1995), an alternative pathway that is enhanced in ewes fed marine lipids (Toral et al., 2012).

With regard to Ruminococcaceae, the relative abundance of unclassified species of this family was negatively affected by the treatment in both RF and RC, which is consistent with a potential link with decreased ruminal 18:0 concentrations in animals fed MA (Boeckaert et al., 2008; Huws et al., 2011; Toral et al., 2012). Another example of the similar effect of the treatment on RF and RC was the notable increase in the relative abundance of the phylum Proteobacteria, particularly in sequences corresponding to unclassified Succinivibrionaceae, which is also in agreement with increases in $2 \mathrm{~T}-\mathrm{RF}$ assigned phylogenetically to this family. Although Tokoyama and Davis (1970) showed a putative ability of Succinivibrio dextrinosolvens to biohydrogenate, and Li et al. (2012) pointed out a potential involvement of Proteobacteria in lipid metabolism, the role of these bacteria in $\mathrm{BH}$ is still uncertain. Despite the known differences in the bacterial composition of RC and RF, which should serve as a note of caution when interpreting the effect of fat supplementation on the ruminal microbial community, the consistent effect of feeding MA on both fractions would suggest that, when rumen cannulation is not really feasible, fluid samples might be a valid alternative to infer the effect of dietary lipids on bacterial structure and diversity. 


\section{CONCLUSIONS}

Pyrosequencing yielded a greater coverage of rumen bacterial diversity than TRFLP and allowed the identification of low abundant populations. However, both molecular techniques show that the main changes due to MA addition are observed within the major ruminal groups, namely Bacteroidetes, Firmicutes, and Proteobacteria, and correspond in most cases to as-yet uncultured or unclassified bacteria. These results underline the complexity of the rumen ecosystem response to dietary lipid supplementation and the need for further research. In addition, both 454 pyrosequencing and TRFLP indicate that the effect of MA supplementation on bacterial diversity and structure is rather consistent in rumen content or fluid samples, despite inherent differences between these fractions in their microbial composition.

\section{REFERENCES}

Abdo Z, Schüette UME, Bent SJ, Williams CJ, Forney LJ and Joyce P 2006. Statistical methods for characterizing diversity of microbial communities by analysis of terminal restriction fragment length polymorphisms of $16 \mathrm{~S}$ rRNA genes. Environ. Microbiol. 8, 929-938.

Altschul SF, Gish W, Miller W, Myers EW and Lipman DJ 1990. Basic local alignment search tool. J. Mol. Biol. 215, 403-410.

Belenguer A, Toral PG, Frutos P and Hervás G 2010. Changes in the rumen bacterial community in response to sunflower oil and fish oil supplements in the diet of dairy sheep. J. Dairy Sci. 93, 3275-3286.

Bichi E, Hervás G, Toral PG, Loor JJ and Frutos P 2013. Milk fat depression induced by dietary marine algae in dairy ewes: Persistency of milk fatty acid composition and animal performance responses. J. Dairy Sci. 96, 524-532.

Boeckaert C, Fievez V, Van Hecke D, Verstraete W and Boon N 2007. Changes in rumen biohydrogenation intermediates and ciliate protozoa diversity after algae supplementation to dairy cattle. Eur. J. Lipid Sci. Technol. 109, 767-777.

Boeckaert C, Morgavi DP, Jouany JP, Maignien L, Boon N and Fievez V 2009. Role of the protozoan Isotricha prostoma, liquid-, and solid-associated bacteria in rumen biohydrogenation of linoleic acid. Animal 3, 961-971.

Boeckaert C, Vlaeminck B, Fievez V, Maignien L, Dijkstra J and Boon N 2008. Accumulation of trans C18:1 fatty acids in the rumen after dietary algal supplementation is associated with changes in the Butyrivibrio community. Appl. Environ. Microbiol. 74, 6923-6930.

Bragg L, Stone G, Imelfort M, Hugenholtz M and Tyson GW 2012. Fast, accurate error-correction of amplicon pyrosequences using Acacia. Nat. Methods 9, 425-426. 
Callaway TR, Dowd SE, Edrington TS, Anderson RC, Krueger N, Bauer N, Kononoff PJ and Nisbet DJ 2010. Evaluation of bacterial diversity in the rumen and feces of cattle fed different levels of dried distillers grains plus solubles using bacterial tag-encoded FLX amplicon pyrosequencing. J. Anim. Sci. 88, 3977-3983.

Caporaso JG, Kuczynski J, Stombaugh J, Bittinger K, Bushman FD, Costello EK, Fierer N, Peña AG, Goodrich JK, Gordon JI, Huttley GA, Kelley ST, Knights D, Koening JE, Ley RE, Lozupone CA, McDonald D, Muegge BD, Pirrung M, ReederJ, Sevinsky JR, Turnbaugh PJ, Walters WA, Widmann J, Yatsunenko T, Zaneveld J and Y Knight R 2010. QIIME allows analysis of high throughput community sequencing data. Nat. Methods 7, 335-336.

Cole JR, Wang Q, Cardenas E, Fish J, Chai B, Farris RJ, Kulam-Syed-Mohideen AS, McGarrell DM, Marsh T, Garrity GM and Tiedje JM 2009. The Ribosomal Database Project: Improved alignments and new tools for rRNA analysis. Nucleic Acids Res. 37, 141-145.

de Menezes AB, Lewis E, O'Donovan M, O'Neill BF, Clipson N and Doyle EM 2011. Microbiome analysis of dairy cows fed pasture or total mixed ration diets. FEMS Microbiol. Ecol. 78, 256265.

DeSantis TZ, Hugenholtz P, Larsen N, Rojas M, Brodie EL, Keller K and Huber T 2006. Greengenes, a chimera-checked 16S rRNA gene database and workbench compatible with ARB. Appl. Environ. Microbiol. 72, 5069-5072.

Edgar RC 2010. Search and clustering orders of magnitude faster than BLAST. Bioinformatics 26, 2460-2461.

Hall N 2007. Advanced sequencing technologies and their wider impact in microbiology. J. Exp. Biol. 210, 1518-1525.

Hill TCJ, Walsh KA, Harris JA and Moffett BF 2003. Using ecological diversity measures with bacterial communities. FEMS Microbiol. Ecol. 43, 1-11.

Hongoh Y, Yuzawa H, Ohkuma M and Kudo T 2003. Evaluation of primers and PCR conditions for the analysis of 16S rRNA genes from a natural environment. FEMS Microbiol. Lett. 221, 299-304.

Hudson JA, MacKenzie CAM and Joblin KN 1995. Conversion of oleic acid to 10-hydroxystearic acid by two species of ruminal bacteria. App. Microbiol. Biotechnol. 44, 1-6.

Huws SA, Kim EJ, Lee MRF, Scott MB, Tweed JKS, Pinloche E, Wallace RJ and Scollan ND 2011. As yet uncultured bacteria phylogenetically classified as Prevotella, Lachnospiraceae incertae sedis and unclassified Bacteroidales, Clostridiales and Ruminococcaceae may play a predominant role in ruminal biohydrogenation. Environ. Microbiol. 13, 1500-1512.

Huws SA, Lee MRF, Muetzel SM, Scott TW, Wallace RJ and Scollan ND 2010. Forage type and fish oil cause shifts in rumen bacterial diversity. FEMS Microbiol. Ecol. 73, 396-407.

Jami E and Mizrahi I 2012. Composition and similarity of bovine rumen microbiota across individual animals. PLoS ONE 7, e33306.

Kittelmann S, Seedorf H, Walters WA, Clemente JC, Knight R, Gordon JI and Janssen PH 2013. Simultaneous amplicon sequencing to explore co-occurrence patterns of bacterial, archaeal and eukaryotic microorganisms in rumen microbial communities. PLoS ONE 8, e47879.

Lee HJ, Jung JY, Oh YK, Lee S-S, Madsen EL and Jeon CO 2012. Comparative survey of rumen microbial communities and metabolites across one caprine and three bovine groups, using bar-coded pyrosequencing and $1 \mathrm{H}$ nuclear magnetic resonance spectroscopy. Appl. Environ. Microbiol. 78, 5983-5993. 
Li D, Wang J and Bu D 2012. Ruminal microbe of biohydrogenation of trans-vaccenic acid to stearic acid in vitro. BMC Res. Notes 5, 97.

Liu Z, Lozupone C, Hamady M, Bushman FD and Knight R 2007. Short pyrosequencing reads suffice for accurate microbial community analysis. Nucleic Acids Res. 35, e120.

Lourenço M, Ramos-Morales E and Wallace RJ 2010. The role of microbes in rumen lipolysis and biohydrogenation and their manipulation. Animal 4, 1024-1036.

Lozupone C and Knight R 2005. UniFrac: A new phylogenetic method for comparing microbial communities. Appl. Environ. Microbiol. 71, 8228-8235.

Maia MRG, Chaudhary LC, Bestwick CS, Richardson AJ, McKain N, Larson TR, Graham IA and Wallace RJ 2010. Toxicity of unsaturated fatty acids to the biohydrogenating ruminal bacterium, Butyrivibrio fibrisolvens. BMC Microbiol. 10, 52-61.

Maia MRG, Chaudhary LC, Figueres L and Wallace RJ 2007. Metabolism of polyunsaturated fatty acids and their toxicity to the microflora of the rumen. Anton. Leeuw. Int. J. G. 91, 303314.

Paillard D, McKain N, Chaudhary LC, Walker ND, Pizette F, Koppova I, McEwan NR, Kopecny J, Vercoe PE, Louis P and Wallace RJ 2007. Relation between phylogenetic position, lipid metabolism and butyrate production by different Butyrivibrio-like bacteria from the rumen. Anton. Leeuw. Int. J. G. 91, 417-422.

Pitta D, Pinchak W, Dowd S, Osterstock J, Gontcharova V, Youn E, Dorton K, Yoon I, Min B, Fulford JD, Wickersham T and Malinowski D 2010. Rumen bacterial diversity dynamics associatedwith changing from bermudagrass hay to grazed winter wheat diets. Microb. Ecol. 59, 511-522.

Pope PB, Mackenzie AK, Gregor I, Smith W, Sundset MA, McHardy AC, Morrison M and Eijsink VGH 2012. Metagenomics of the Svalbard reindeer rumen microbiome reveals abundance of polysaccharide utilization loci. PLoS ONE 7:e38571.

Popova M, Martin C, Eugène M, Mialon MM, Doreau M and Morgavi DP 2011. Effect of fibreand starch-rich finishing diets on methanogenic Archaea diversity and activity in the rumen of feedlot bulls. Anim. Feed Sci. Technol. 167, 113-121.

Shingfield KJ, Kairenius P, Arölä A, Paillard D, Muetzel S, Ahvenjärvi S, Vanhatalo A, Huhtanen P, Toivonen V, Griinari JM and Wallace RJ 2012. Dietary fish oil supplements modify ruminal biohydrogenation, alter the flow of fatty acids at the omasum, and induce changes in the ruminal Butyrivibrio population in lactating cows. J. Nutr. 142, 1437-1448.

Stevenson D and Weimer P 2007. Dominance of Prevotella and low abundance of classical ruminal bacterial species in the bovine rumen revealed by relative quantification real-time PCR. Appl. Microbiol. Biotechnol. 75, 165-174.

Stewart CS, Flint HJ and Bryant MP 1997. The rumen bacteria. Pages 10-72 in The Rumen Microbial Ecosystem. Hobson PN and Stewart CS, eds. Chapman \& Hall, London, UK.

Tokoyama MT and Davis CL 1970. Hydrogenation of linoleic acid by Borrelia B25 and Succinivibrio dextrinosolvens. Fed. Proc. 29, A691.

Toral PG, Belenguer A, Shingfield KJ, Hervás G, Toivonen V and Frutos P 2012. Fatty acid composition and bacterial community changes in the rumen fluid of lactating sheep fed sunflower oil plus incremental levels of marine algae. J. Dairy Sci. 95, 794-806.

van Gylswyk NO 1990. Enumeration and presumptive identification of some functional groups of bacteria in the rumen of dairy cows fed grass silage-based diets. FEMS Microbiol. Lett. 73, 243-261. 
Wu S, Baldwin RL, Li W, Li C, Connor EE and Li RW 2012. The bacterial community composition of the bovine rumen detected using pyrosequencing of 16s rRNA genes. Metagenomics $1: 235571$.

Zened A, Combes S, Cauquil L, Mariette J, Klopp C, Bouchez O, Troegeler-Meynadier A and Enjalbert F 2013. Microbial ecology of the rumen evaluated by 454 GS FLX pyrosequencing is affected by starch and oil supplementation of diets. FEMS Microbiol. Ecol. 83, 504-514.

\section{SUPPLEMENTARY MATERIAL}

Supplementary Table S1. Relative abundances [expressed as $\log _{10}(n+c)$ of $\%$ of total sequences, with original values in parentheses] of selected taxa identified by 454 pyrosequencing in rumen content $(R C)$ or fluid $(R F)$ samples of ewes fed the experimental diets. 
Supplementary Table S1. Relative abundances [expressed as $\log _{10}(n+c)$ of percent of total sequences, with original values in parentheses] of selected taxa ${ }^{1}$ identified by 454 pyrosequencing in rumen content $(R C)$ or fluid $(R F)$ samples of ewes fed the experimental diets ${ }^{2}$.

\begin{tabular}{|c|c|c|c|c|c|c|c|c|}
\hline \multirow[b]{2}{*}{ Taxonomy } & \multicolumn{2}{|c|}{$\mathrm{RC}$} & \multicolumn{2}{|c|}{ RF } & \multirow[b]{2}{*}{$\mathrm{SED}^{3}$} & \multicolumn{3}{|c|}{$P^{4}$} \\
\hline & Control & MA & Control & MA & & $\mathrm{D}$ & $\mathrm{F}$ & $\mathrm{D} \times \mathrm{F}$ \\
\hline Bacteroidetes & $1.84(69.2)$ & $1.83(68.8)$ & $1.88(76.4)$ & $1.89(77.2)$ & 0.029 & 0.98 & 0.02 & 0.74 \\
\hline Bacteroidales & $1.84(69.2)$ & $1.83(68.8)$ & $1.88(76.4)$ & $1.89(77.2)$ & 0.029 & 0.98 & 0.02 & 0.74 \\
\hline Unclassified & $0.93(8.55)$ & $0.70(5.35)$ & $0.94(8.87)$ & $0.65(4.64)$ & 0.076 & $<0.01$ & 0.67 & 0.45 \\
\hline Bacteroidaceae & $-0.61(0.27)$ & $-0.34(0.50)$ & $-1.29(0.06)$ & $-0.69(0.25)$ & 0.159 & $<0.01$ & $<0.01$ & 0.13 \\
\hline Bacteroides & $-0.63(0.25)$ & $-0.34(0.50)$ & $-1.28(0.06)$ & $-0.70(0.25)$ & 0.157 & $<0.01$ & $<0.001$ & 0.15 \\
\hline Porphyromonadaceae & $0.41(2.66)$ & $-0.19(0.71)$ & $0.65(4.85)$ & $0.09(1.31)$ & 0.112 & $<0.01$ & $<0.001$ & 0.54 \\
\hline Paludibacter & $0.40(2.63)$ & $-0.19(0.71)$ & $0.64(4.75)$ & $0.08(1.27)$ & 0.114 & $<0.001$ & $<0.001$ & 0.59 \\
\hline Prevotellaceae (Prevotella) & $1.69(49.3)$ & $1.72(53.0)$ & $1.73(53.8)$ & $1.78(60.9)$ & 0.037 & 0.21 & 0.03 & 0.48 \\
\hline S24-7 (Unclassified) & $0.29(2.00)$ & $0.59(4.73)$ & $0.01(1.12)$ & $0.53(4.21)$ & 0.146 & 0.02 & $<0.01$ & 0.06 \\
\hline Paraprevotellaceae & $0.80(6.42)$ & $0.64(4.47)$ & $0.89(7.76)$ & $0.75(5.89)$ & 0.074 & 0.06 & $<0.01$ & 0.68 \\
\hline Unclassified & $-0.02(1.30)$ & $-0.24(0.63)$ & $-0.06(1.19)$ & $-0.19(0.77)$ & 0.187 & 0.35 & 0.98 & 0.40 \\
\hline$C F 231$ & $0.13(1.67)^{\mathrm{ab}}$ & $0.13(1.51)^{\mathrm{b}}$ & $0.11(2.01)^{\mathrm{ab}}$ & $0.31(2.23)^{\mathrm{a}}$ & 0.195 & 0.62 & 0.08 & 0.04 \\
\hline$Y R C 22$ & $0.48(3.21)$ & $0.31(2.18)$ & $0.59(4.34)$ & $0.33(2.72)$ & 0.144 & 0.13 & 0.32 & 0.48 \\
\hline Cyanobacteria & $0.13(0.60)$ & $0.14(0.72)$ & $0.14(0.79)$ & $0.19(0.85)$ & 0.089 & 0.66 & 0.55 & 0.74 \\
\hline YS2 (Unclassified) & $0.04(0.45)$ & $0.10(0.67)$ & $0.12(0.78)$ & $0.16(0.81)$ & 0.097 & 0.56 & 0.17 & 0.84 \\
\hline Fibrobacteres (Fibrobacter) & $0.04(1.48)$ & $-0.06(1.05)$ & $-0.42(0.49)$ & $-0.45(0.68)$ & 0.238 & 0.76 & $<0.01$ & 0.78 \\
\hline Firmicutes & $1.41(25.9)$ & $1.32(21.8)$ & $1.25(18.9)$ & $1.10(13.1)$ & 0.078 & 0.10 & $<0.01$ & 0.49 \\
\hline Unclassified & $-0.13(0.77)$ & $-0.31(0.53)$ & $-0.80(0.24)$ & $-0.68(0.24)$ & 0.157 & 0.79 & $<0.001$ & 0.10 \\
\hline Clostridiales & 1.35 (22.6) & $1.25(18.6)$ & $1.21(17.3)$ & $1.05(11.7)$ & 0.078 & 0.08 & $<0.01$ & 0.49 \\
\hline Unclassified & $0.08(0.72)$ & $-0.01(0.54)$ & $-0.06(0.41)$ & $-0.09(0.35)$ & 0.082 & 0.43 & 0.01 & 0.40 \\
\hline Clostridiaceae & $0.03(1.08)$ & $-0.10(0.84)$ & $-0.36(0.45)$ & $-0.56(0.32)$ & 0.114 & 0.13 & $<0.001$ & 0.60 \\
\hline Clostridium & $-0.19(0.45)$ & $-0.36(0.23)$ & $-0.40(0.18)$ & $-0.60(0.04)$ & 0.065 & $<0.01$ & $<0.001$ & 0.75 \\
\hline Lachnospiraceae & $1.02(10.6)$ & $0.98(9.87)$ & $0.69(5.45)$ & $0.71(5.46)$ & 0.100 & 0.90 & $<0.01$ & 0.64 \\
\hline Unclassified & $0.70(5.07)$ & $0.59(4.50)$ & $0.47(3.16)$ & $0.44(3.07)$ & 0.126 & 0.53 & 0.01 & 0.54 \\
\hline Butyrivibrio & $0.41(2.72)$ & $0.43(2.74)$ & $-0.04(1.05)$ & $-0.05(0.98)$ & 0.123 & 0.96 & $<0.001$ & 0.86 \\
\hline Coprococcus & $0.16(1.48)$ & $0.14(1.42)$ & $-0.40(0.54)$ & $-0.13(0.81)$ & 0.141 & 0.29 & $<0.001$ & 0.13 \\
\hline
\end{tabular}


Supplementary Table S1. (continued)

\begin{tabular}{|c|c|c|c|c|c|c|c|c|}
\hline \multirow[b]{2}{*}{ Taxonomy } & \multicolumn{2}{|c|}{$\mathrm{RC}$} & \multicolumn{2}{|c|}{ RF } & \multirow[b]{2}{*}{$\mathrm{SED}^{3}$} & \multicolumn{3}{|c|}{$P^{4}$} \\
\hline & Control & MA & Control & $\mathrm{MA}$ & & $\mathrm{D}$ & $\mathrm{F}$ & $\mathrm{D} \times \mathrm{H}$ \\
\hline Pseudobutyrivibrio & $-0.59(0.27)$ & $-0.45(0.40)$ & $-0.96(0.16)$ & $-0.87(0.18)$ & 0.216 & 0.41 & 0.02 & 0.88 \\
\hline Ruminococcaceae & $0.78(6.24)$ & $0.55(3.92)$ & $0.50(3.63)$ & $0.26(2.00)$ & 0.131 & 0.08 & $<0.001$ & 0.97 \\
\hline Unclassified & $0.34(2.32)$ & $0.04(1.26)$ & $0.24(2.00)$ & $-0.10(0.86)$ & 0.138 & 0.04 & 0.01 & 0.65 \\
\hline Ruminococcus & $0.50(3.35)$ & $0.32(2.38)$ & $-0.02(1.10)$ & $-0.12(0.83)$ & 0.139 & 0.27 & $<0.001$ & 0.59 \\
\hline Oscillospora & $-0.04(0.56)$ & $-0.19(0.27)$ & $-0.06(0.53)$ & $-0.16(0.31)$ & 0.093 & 0.18 & 0.78 & 0.49 \\
\hline Veillonellaceae & $0.57(3.94)^{\mathrm{b}}$ & $0.51(3.36)^{b}$ & $0.82(7.26)^{\mathrm{a}}$ & $0.50(3.54)^{\mathrm{b}}$ & 0.118 & 0.11 & 0.04 & 0.03 \\
\hline Unclassified & $0.55(3.76)^{\mathrm{b}}$ & $0.46(2.98)^{b}$ & $0.79(6.87)^{\mathrm{a}}$ & $0.44(3.08)^{\mathrm{b}}$ & 0.120 & 0.07 & 0.07 & 0.04 \\
\hline Anaerovibrio & $-1.37(0.01)^{\mathrm{b}}$ & $-1.22(0.04)^{\mathrm{ab}}$ & $-1.12(0.06)^{a}$ & $-1.34(0.02)^{\mathrm{ab}}$ & 0.120 & 0.76 & 0.41 & 0.03 \\
\hline Mitsuokella & $-1.56(0.02)$ & $-1.50(0.02)$ & $-1.27(0.04)$ & $-1.49(0.01)$ & 0.149 & 0.56 & 0.08 & 0.11 \\
\hline Selenomonas & $-1.11(0.11)$ & $-0.58(0.28)$ & $-0.62(0.25)$ & $-0.62(0.34)$ & 0.204 & 0.13 & 0.11 & 0.07 \\
\hline Coriobacteriales & $0.21(1.64)$ & $0.25(2.05)$ & $-0.09(1.03)$ & $-0.12(0.80)$ & 0.146 & 0.97 & $<0.01$ & 0.67 \\
\hline Unclassified & $0.18(1.53)$ & $0.21(1.93)$ & $-0.11(0.97)$ & $-0.13(0.79)$ & 0.148 & 0.93 & $<0.01$ & 0.77 \\
\hline \multicolumn{9}{|l|}{ Erysipelotrichales } \\
\hline Erysipelotrichaceae & $-0.12(0.87)$ & $-0.31(0.59)$ & $-0.51(0.34)$ & $-0.64(0.26)$ & 0.161 & 0.26 & $<0.01$ & 0.76 \\
\hline Bulleidia & $-0.29(0.63)$ & $-0.47(0.42)$ & $-0.79(0.23)$ & $-0.77(0.20)$ & 0.221 & 0.69 & 0.01 & 0.43 \\
\hline Proteobacteria & $-0.09(1.06)$ & $0.68(6.02)$ & $0.11(1.65)$ & $0.79(6.51)$ & 0.186 & $<0.01$ & 0.04 & 0.52 \\
\hline Succinivibrionaceae & $-0.30(0.76)$ & $0.63(5.71)$ & $0.02(1.28)$ & $0.76(6.19)$ & 0.216 & $<0.01$ & 0.03 & 0.38 \\
\hline Unclassified & $-0.46(0.58)$ & $0.61(5.57)$ & $-0.23(0.97)$ & $0.75(6.04)$ & 0.253 & $<0.01$ & 0.08 & 0.61 \\
\hline Succinivibrio & $-0.70(0.10)$ & $-0.67(0.10)$ & $-0.53(0.19)$ & $-0.67(0.11)$ & 0.114 & 0.55 & 0.25 & 0.25 \\
\hline Spirochaetes & $-0.39(0.53)$ & $-0.19(0.71)$ & $-0.55(0.57)$ & $-0.34(0.52)$ & 0.230 & 0.32 & 0.26 & 0.98 \\
\hline Treponema & $0.00(0.51)$ & $0.09(0.69)$ & $-0.01(0.55)$ & $0.03(0.51)$ & 0.100 & 0.50 & 0.48 & 0.61 \\
\hline Tenericutes & $-0.13(0.82)$ & $-0.49(0.67)$ & $-0.07(0.86)$ & $-0.25(0.86)$ & 0.222 & 0.23 & 0.09 & 0.29 \\
\hline Anaeroplasmataceae & $-0.17(0.75)$ & $-0.54(0.66)$ & $-0.15(0.73)$ & $-0.26(0.83)$ & 0.235 & 0.31 & 0.12 & 0.16 \\
\hline RFN20 & $-0.62(0.28)$ & $-0.67(0.54)$ & $-0.54(0.34)$ & $-0.43(0.65)$ & 0.251 & 0.90 & 0.08 & 0.37 \\
\hline Synergistetes & $-0.92(0.15)$ & $-0.86(0.21)$ & $-0.82(0.18)$ & $-0.78(0.22)$ & 0.232 & 0.81 & 0.44 & 0.92 \\
\hline TM7 & $-0.73(0.14)$ & $-1.03(0.03)$ & $-0.83(0.09)$ & $-1.01(0.04)$ & 0.122 & 0.02 & 0.66 & 0.47 \\
\hline Elusimicrobia & $-2.55(0.03)$ & $-2.99(0.00)$ & $-2.38(0.01)$ & $-2.48(0.01)$ & 0.446 & 0.50 & 0.17 & 0.34 \\
\hline
\end{tabular}


Supplementary Table S1. (continued)

\begin{tabular}{|c|c|c|c|c|c|c|c|c|}
\hline \multirow[b]{2}{*}{ Taxonomy } & \multicolumn{2}{|c|}{$\mathrm{RC}$} & \multicolumn{2}{|c|}{ RF } & \multirow[b]{2}{*}{$\mathrm{SED}^{3}$} & \multicolumn{3}{|c|}{$P^{4}$} \\
\hline & Control & MA & Control & MA & & $\mathrm{D}$ & $\mathrm{F}$ & $\mathrm{D} \times \mathrm{F}$ \\
\hline SR1 & $-2.12(0.02)$ & $-2.78(0.003)$ & $-2.41(0.01)$ & $-2.53(0.01)$ & 0.448 & 0.21 & 0.96 & 0.39 \\
\hline Actinobacteria & $-2.72(0.005)$ & $-2.99(0.00)$ & $-2.99(0.00)$ & $-2.99(0.00)$ & 0.182 & 0.30 & 0.30 & 0.30 \\
\hline Chloroflexi & $-2.99(0.00)$ & $-2.99(0.00)$ & $-2.99(0.00)$ & $-2.80(0.002)$ & 0.146 & 0.39 & 0.39 & 0.39 \\
\hline Fusobacteria & $-2.99(0.00)$ & $-2.77(0.004)$ & $-2.99(0.00)$ & $-2.77(0.003)$ & 0.253 & 0.22 & 0.98 & 0.98 \\
\hline Verrumicrobia & $-2.73(0.004)$ & $-2.99(0.00)$ & $-2.99(0.00)$ & $-2.77(0.003)$ & 0.235 & 0.91 & 0.91 & 0.19 \\
\hline
\end{tabular}

${ }^{1}$ All phyla and other taxa related to lipid metabolism or contributing $>0.5 \%$ in at least one treatment in either RC or RF were included.

${ }^{2}$ Refers to TMR containing 0 (Control diet) or $8 \mathrm{~g}$ of marine algae (MA diet) $/ \mathrm{kg}$ of DM.

${ }^{3} \mathrm{SED}=$ standard error of the difference.

${ }^{4}$ Probability of significant effect due to diet $(\mathrm{D})$, rumen fraction $(\mathrm{F})$, and their interaction $(\mathrm{D} \times \mathrm{F})$.

${ }^{\mathrm{a}-\mathrm{b}}$ Within a row, different superscripts indicate significant differences $(P<0.05)$. 



\section{PRUEBA III}

ENRIQUECIMIENTO EN QUINELLA OVALIS DE SUSPENSIONES

DE MICROORGANISMOS RUMINALES

Y SU CULTIVO IN VITRO

\section{ENRICHMENT OF SUSPENSIONS OF RUMINAL \\ MICROORGANISMS IN QUINELLA OVALIS AND THEIR IN VITRO \\ CULTURE}

Instituto de Ganadería de Montaña, CSIC - Universidad de León

Finca Marzanas s/n, 24346 Grulleros, León, España 



\title{
ENRICHMENT OF SUSPENSIONS OF RUMINAL MICROORGANISMS IN QUINELLA OVALIS AND THEIR IN VITRO CULTURE
}

\begin{abstract}
Biohydrogenation is the major process by which some rumen bacteria are able to metabolize unsaturated FA as a detoxification mechanism that prevents the inhibition of microbial growth. Alternatively, some bacteria may also hydrate FA, but it is unclear which populations are responsible for this metabolic pathway. In this regard, previous studies in ewes fed marine lipids have suggested the implication of large oval-shaped bacteria, belonging to the clostridial cluster IX and identified as Quinella ovalis-like bacteria (QO), in FA hydration. Although QO has not yet been maintained in axenic cultures, a number of its metabolic features have been determined by obtaining cell suspensions highly enriched in this species. Nevertheless, its involvement in ruminal lipid metabolism remains unknown. Therefore, this study was aimed at designing a strategy to examine the ability of QO to metabolize unsaturated FA.
\end{abstract}

Four in vitro assays were conducted using 4 cannulated ewes as rumen fluid donors. Animals received a high concentrate diet supplemented with $1.8 \%$ of fish oil (FO; to favour the presence of QO) and rumen fluid was employed to obtain QO-enriched cell suspensions (ES) by successive differential centrifugations and washings with a solution of inorganic salts and beta-mercaptoethanol (a reducing agent). Total bacteria and QO were counted by fluorescence in situ hybridization (FISH). Due to the preliminary nature of this study, only descriptive statistics were employed and results must then be interpreted as a rough approximation.

The objective of the first three assays was to obtain suspensions highly enriched in QO and viable for in vitro culture. In the first one, the 4 sheep received the diet supplemented with FO for 7 days before rumen fluid collection. The protocol of enrichment, which included 4 washings, increased the proportion of QO over total bacteria from $2.6 \%$ in the initial fluid to $12.6 \%$ in the ES, a result that seemed unsufficient for a metabolic study. Thus, in the second assay, the same 
animals received FO for 7 further days and the preparation of the ES included 2 more washings to remove as many contaminating bacteria as possible, followed by selective cultures with mannitol ( $2 \mathrm{~g} / \mathrm{L})$ as the sole substrate. Accordingly, the protocol of enrichment appeared to be improved, given that the relative abundance of QO increased from $1.2 \%$ to $12.2 \%$ in the ES. Furthermore, QO reached values of up to $35.3 \%$ of total bacteria after $6 \mathrm{~h}$ of incubation but, surprisingly, decreased to $0.9 \%$ at $24 \mathrm{~h}$. The third assay was then conducted to examine if the higher number of washings for further concentrating $\mathrm{QO}$ could have affected their viability in vitro and to optimize culture conditions that may favour their growth. To prevent the adaptation of rumen microbiota to lipid supplements, which might explain the low abundance of QO in the rumen fluid in the second assay, FO feeding was preceded by a 7-day wash-out period in which ewes were offered the non-supplemented diet. The ES was prepared with either 4 or 6 washings (ES4 and ES6, respectively), but this change in the protocol resulted only in moderate differences in the percentage of QO (25.5 vs. 30.8\%, respectively). Afterwards, both treatments were cultivated for 4, 6, 8 and $10 \mathrm{~h}$, with half the amount of mannitol $(1 \mathrm{~g} / \mathrm{L})$ than in the second assay to increase the selective pressure. The cell suspensions obtained after 6 and $8 \mathrm{~h}$ of incubation of ES6 were then reinoculated under the same conditions, and incubated for 6 more hours. However, the greater manipulation in ES6 could have probably affected QO viability, because reinoculation of 6 and 8 h cultures (containing up to 32.8\% of QO) decreased its relative abundance to very low values ( $<8 \%$ of total bacteria). The maximum enrichment in QO was obtained for ES4 at $6 \mathrm{~h}(42.4 \%)$, consistent with a greater viability with less manipulation, but dramatic reductions were observed at longer times $(<10 \%$ at $10 \mathrm{~h})$.

Since we failed to obtain a suspension highly concentrated in QO, an alternative strategy was proposed in the fourth assay, consisting of the comparison of two cell suspensions with similar microbial structure but rich or depleted in QO through selective cultures with substrates that may favour (mannitol) or minimize (cellobiose and starch, 1:1) its growth. Rumen fluid was 
collected from 2 ewes fed FO and the ES was incubated for 3 and $6 \mathrm{~h}$ with the substrates at 2 concentrations ( 0.2 and $0.5 \mathrm{~g} / \mathrm{L})$. However, these selective cultures did not lead either to major differences in the percentage of QO over total bacteria.

Overall, these results emphasize the great difficulty of designing culturebased strategies to examine the metabolic features of QO. Further research would be necessary to improve culturing conditions or to implement alternative approaches of study, such as using micromanipulation procedures to isolate QO cells or searching their genome for functional genes involved in lipid metabolism.

Key words: ewe, FISH, lipid metabolism, rumen bacteria, selective culture

\section{INTRODUCCIÓN}

Para paliar el efecto tóxico de los ácidos grasos (AG) insaturados de la dieta sobre el crecimiento microbiano, determinadas bacterias ruminales han desarrollado la capacidad de metabolizarlos (Maia et al., 2007, 2010). El principal mecanismo de destoxificación es la biohidrogenación (Lourenço et al., 2010), aunque existen especies capaces de hidratar algunos AG insaturados (Hudson et al., 2000; Jenkins et al., 2006), probablemente con el mismo fin. Sin embargo, aún persiste un gran desconocimiento sobre los microorganismos que podrían estar involucrados en estos procesos, y muy especialmente en el caso de la hidratación (Hudson et al., 2000; Jenkins et al., 2008; Huws et al., 2011).

Estudios recientes en ovejas alimentadas con lípidos marinos (Belenguer et al., 2010; Toral et al., 2012) han sugerido la implicación de bacterias grandes y ovaladas, presumiblemente pertenecientes a la especie Quinella ovalis, en la formación de 10-oxo-18:0, producto de la hidratación y posterior oxidación de ciertos AG insaturados en el rumen (Jenkins et al., 2006; McKain et al., 2010). Su proximidad filogenética con Selenomonas ruminantium, capaz de hidratar el cis-9 18:1 (Hudson et al., 1995), apoyaría esta hipótesis.

Q. ovalis es una bacteria gram negativa, de forma ovalada y gran tamaño (3-4 $\times 5-8 \mu \mathrm{m})$, presente en el rumen en concentraciones variables comprendidas 
habitualmente entre $1,9 \times 10^{5}$ y 3,0 $\times 10^{8}$ células/mL (Orpin, 1972), aunque excepcionalmente se han observado valores de hasta $10^{11}$ células/mL $(>50 \%$ de las bacterias totales) en presencia de grandes cantidades de azúcares fácilmente fermentables (Vicini et al., 1987; Tolosa, 2006). Al encuadrarse dentro del grupo IX de los Clostridiales (Selenomonas-Megasphaera-Sporomusa; Krumholz et al., 1993) y dadas sus características morfológicas diferenciales, se puede cuantificar de forma fiable en el fluido ruminal mediante hibridación fluorescente in situ (FISH) con sondas específicas (Belenguer et al., 2010). Sin embargo, el estudio de sus características metabólicas se ha visto obstaculizado por la imposibilidad de aislarla en cultivo puro. A pesar de ello, la obtención de suspensiones celulares formadas casi exclusivamente por Q. ovalis (Wicken y Howard, 1967; Brough et al., 1970), así como el cultivo de la misma en presencia de otras bacterias (Orpin, 1972), ha permitido descubrir que solo metaboliza un rango estrecho de carbohidratos (e. g., manitol y glucosa), entre los que no se encuentran algunos de los comúnmente presentes en el medio ruminal (e. g., almidón y celobiosa). Sin embargo, aún se desconoce su posible función en el metabolismo lipídico ruminal.

Por todo ello, se llevó a cabo este estudio con el objetivo de diseñar una estrategia experimental que permitiera examinar la implicación de las bacterias presumiblemente pertenecientes a la especie $Q$. ovalis detectadas en ovejas alimentadas con lípidos marinos, en el metabolismo ruminal de los AG insaturados. A pesar de no haber sido clasificadas a nivel de especie, las características morfológicas y filogenéticas de estos microorganismos permiten asumir que pertenecen a la especie $Q$. ovalis, por lo que serán denominadas $Q O$ en el resto del texto.

\section{MATERIAL Y MÉTODOS}

El presente estudio incluye una serie de cuatro ensayos in vitro que se fueron diseñando de forma sucesiva en función de los resultados que se iban obteniendo. En este apartado se describe la metodología común a todas ellas. 


\subsection{Animales y dietas}

Para la realización de este experimento se utilizaron como donantes de fluido ruminal 4 ovejas adultas $(76,7 \pm 4,33 \mathrm{~kg} \mathrm{PV})$ canuladas (40 mm de diámetro interno) en el rumen y alojadas en jaulas individuales. Las dietas consistieron en una ración completa mezclada, basada en heno de alfalfa (tamaño medio de partícula $>4 \mathrm{~cm}$ ) y concentrado (relación forraje:concentrado 40:60), suplementada con 0 o $18 \mathrm{~g}$ de aceite de pescado/kg MS, para favorecer el crecimiento de QO. Los ingredientes y la composición química de las dietas experimentales se muestran en la Tabla 1. Estas se ofertaron en una sola toma diaria (a las 9:00 h) y de forma restringida, a razón de $38 \mathrm{~g} / \mathrm{kg} \mathrm{PV}^{0,75}$ y día, para asegurar que las ovejas lo ingerían todo y se cubrían sus necesidades energéticas de mantenimiento (estimadas de acuerdo con INRA, 2007). La incorporación del aceite de pescado a la dieta se realizó semanalmente para evitar problemas de rancidez. Las ovejas dispusieron en todo momento de agua limpia y de un bloque corrector vitamínico-mineral.

Todos los procedimientos experimentales fueron realizados de acuerdo con el Real Decreto 53/2013 para la protección de animales utilizados para experimentación y otros fines científicos.

\subsection{Obtención de la fracción enriquecida en $Q O$}

El protocolo de separación para obtener la fracción enriquecida en QO (FE) se llevó a cabo siguiendo el procedimiento descrito por Orpin (1972). Para cada uno de los ensayos, antes de la comida de la mañana, se tomó contenido ruminal de las ovejas a través de la cánula. Una vez recolectado, se filtró a través de 4 capas de gasa y se transportó inmediatamente al laboratorio en termos, procurando conservar en lo posible sus condiciones de anaerobiosis y temperatura. Los líquidos ruminales (LR) se mezclaron y se diluyeron (1:1) con una solución que contenía sales inorgánicas y beta-mercaptoetanol en las concentraciones que se describen en la Tabla 2. Este último compuesto sustituyó a otros utilizados más habitualmente como agentes reductores (e. g., cisteína) para evitar la adición de 
Tabla 1. Ingredientes y composición química de las dietas experimentales ${ }^{1}$.

\begin{tabular}{lcc}
\hline \hline & SIN & PES \\
\hline Ingredientes (g/kg MF) & 400 & 394 \\
Heno de alfalfa & 187 & 184 \\
Maíz en grano entero & 150 & 148 \\
Torta de soja & 113 & 111 \\
Cebada en grano entero & 67 & 66 \\
Pulpa de remolacha & 49 & 48 \\
Melazas & 30 & 30 \\
Sales $^{2}$ & 4 & 4 \\
Minerales y vitaminas $^{3}$ & 0 & 15 \\
Aceite de pescado & & \\
Composición química (g/kg MS) & 889 & 878 \\
Materia orgánica & 145 & 165 \\
Proteína bruta & 319 & 300 \\
Fibra neutro detergente & 203 & 202 \\
Fibra ácido detergente & 29 & 42 \\
Extracto etéreo &
\end{tabular}

${ }^{1}$ Ración completa mezclada a la que se añadieron 0 (dieta SIN) o $15 \mathrm{~g}$ de aceite de pescado/kg MF (dieta PES).

${ }^{2}$ Contiene (g/kg): $\mathrm{NaHCO}_{3}(375), \mathrm{CaCO}_{3}(350), \mathrm{Ca}_{2} \mathrm{HPO}_{4}(150)$ y $\mathrm{NaCl}(125)$.

${ }^{3}$ VITAFAC Ovino 0,2\% AC (DSM Nutritional Products S.A., Madrid, España).

${ }^{4}$ Aceite semirrefinado de atún y sardina (AFAMPES 121 DHA, AFAMSA, Vigo, España).

fuentes de nitrógeno que pudieran favorecer el crecimiento de otras bacterias (e. g., S. ruminantium; Prins et al., 1971). La mezcla de los LR con la solución de sales se dejó decantar en un embudo cónico durante 15 min para permitir la sedimentación de las partículas groseras de alimento y los protozoos (Figura 1). A continuación, se recogió la fase superior, que se centrifugó durante 5 min a $500 \times g$ para eliminar el resto de las partículas groseras no sedimentadas en el paso anterior. El sobrenadante obtenido se centrifugó a $1000 \times g$ durante 10 min para permitir la precipitación de las bacterias de mayor tamaño, entre las que se encontraría QO. Este precipitado se sometió a una serie de lavados (4 o 6), resuspendiéndolo en la solución de sales inorgánicas y beta-mercaptoetanol mencionada anteriormente y centrifugando una vez a $1000 \times g$ y el resto a menor velocidad $(800 \times g)$, durante $10 \mathrm{~min}$. Al final del proceso, el precipitado bacteriano resultante se resuspendió en LR autoclavado hasta alcanzar el mismo volumen de LR de partida, obteniéndose así la fracción enriquecida (FE). 
Tabla 2. Composición del medio utilizado para los cultivos discontinuos de microorganismos ruminales (Orpin, 1972).

\begin{tabular}{ll}
\hline \hline Ingredientes & $\mathrm{g} / \mathrm{L}$ \\
\hline Sales inorgánicas & \\
$\mathrm{KH}_{2} \mathrm{PO}_{4}$ & 4,90 \\
$\mathrm{~K}_{2} \mathrm{HPO}_{4}$ & 2,80 \\
$\mathrm{NaCl}$ & 1,27 \\
$\mathrm{CaCl}_{2}$ & 0,35 \\
$\mathrm{MgSO}_{4} \times 7 \mathrm{H}_{2} \mathrm{O}$ & 0,07 \\
$\quad \mathrm{NaHCO}_{3}$ & 6,50 \\
Compuestos orgánicos & \\
$\quad$ Beta-mercaptoetanol & 0,20 \\
$\quad$ Lactato sódico & 0,10 \\
$\quad$ Ácido valérico & 0,09 \\
$\quad$ Ácido isovalérico & 0,09 \\
Ácido 2-metilbutírico & 0,09 \\
Sustrato & $0,2-2$ \\
Líquido ruminal clarificado $(\mathrm{mL} / \mathrm{L})^{2}$ & 100 \\
\hline \hline
\end{tabular}

${ }^{1}$ Manitol (0,2-2 g/L) o mezcla de celobiosa y almidón (0,2-0,5 g/L).

${ }^{2}$ El líquido ruminal se clarificó mediante centrifugación a $1000 \times g$ durante $10 \mathrm{~min}$.

Siempre que fue posible, los procedimientos se desarrollaron bajo un flujo continuo de $\mathrm{CO}_{2}$ para intentar conservar las condiciones de anaerobiosis del LR, procurando también mantenerlo a una temperatura adecuada $\left(40^{\circ} \mathrm{C}\right)$, para minimizar así los posibles efectos negativos de la manipulación de los microorganismos sobre su viabilidad en cultivo.

\subsection{Cultivos discontinuos de microorganismos ruminales}

Para la realización de los cultivos discontinuos de microorganismos ruminales, se utilizó el medio descrito por Orpin (1972; Tabla 2), incluyendo un sustrato selectivo que potencialmente favoreciera (manitol) o minimizara (mezcla de celobiosa y almidón) el crecimiento de QO. Previamente, todos sus componentes fueron esterilizados, bien mediante autoclavado $\left(120^{\circ} \mathrm{C}\right.$ durante $\left.20 \mathrm{~min}\right)$ en el caso del líquido ruminal clarificado, o bien mediante filtrado $(0,22 \mu \mathrm{m}$ de tamaño de poro; Millex ${ }^{\circledR} G P$, Millipore, Carrightwohill, Irlanda) en el caso de las sales inorgánicas, los compuestos orgánicos y los sustratos (todos ellos en solución 


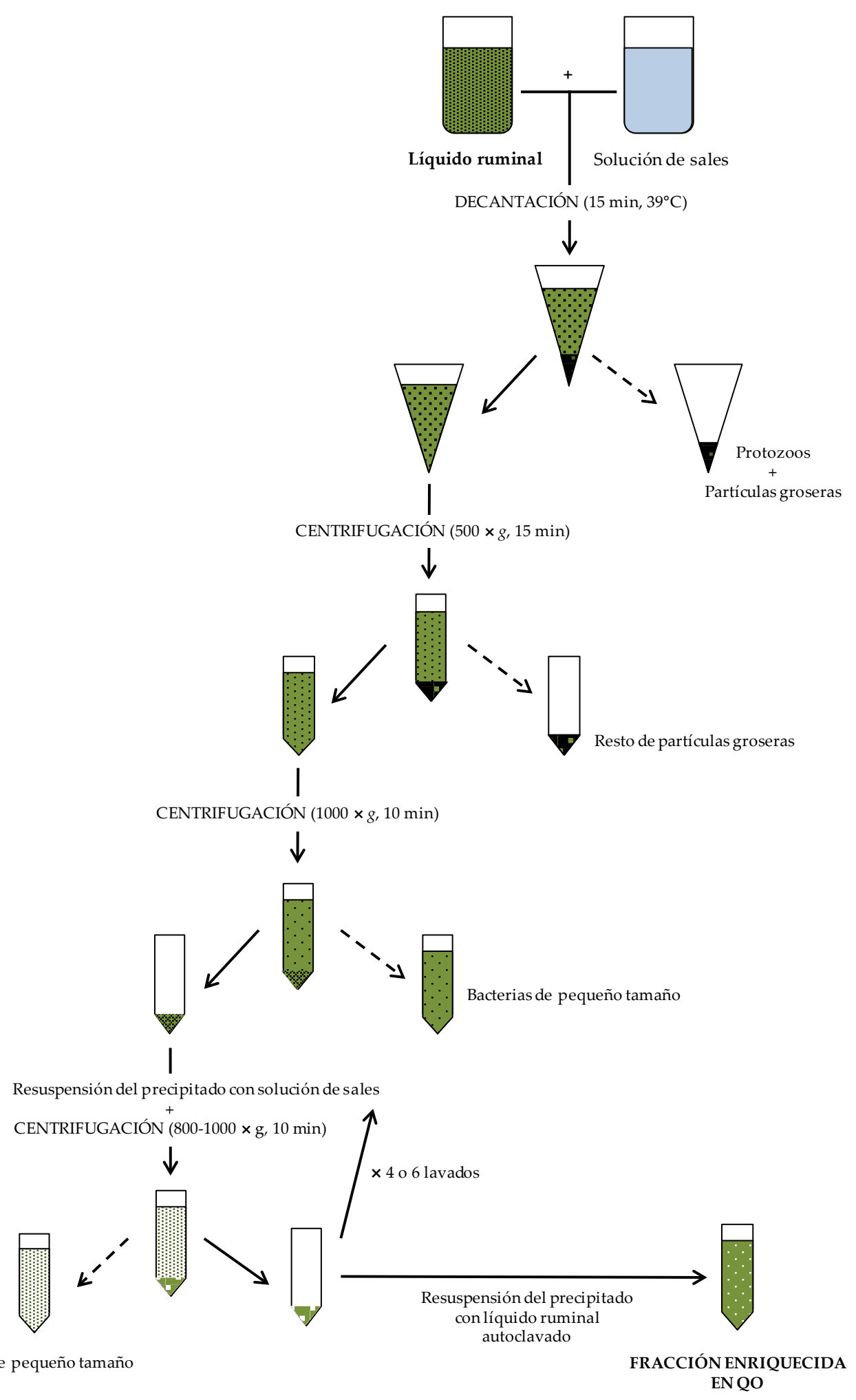

Figura 1. Protocolo de obtención de la fracción enriquecida en QO. 
acuosa). La mezcla se gaseó con $\mathrm{CO}_{2}$ para asegurar su reducción y se vertieron 9 $\mathrm{mL}$ en tubos de ensayo Hungate de $16 \mathrm{~mL}$, que se conservaron a temperatura ambiente hasta su utilización. Todos los procedimientos se realizaron en condiciones de esterilidad.

La inoculación de la suspensión de microorganismos ruminales en el medio de cultivo se llevó a cabo al menos por triplicado, en condiciones asépticas y bajo un flujo continuo de $\mathrm{CO}_{2}$. Los tubos se introdujeron en un incubador (UFP 500, Memmert, Alemania) a $39 \pm 1^{\circ} \mathrm{C}$ y, transcurrido el tiempo de incubación (3-24 h), esta se interrumpió sumergiéndolos en agua helada.

\subsection{Toma de muestras}

Para el recuento de las bacterias totales (BT) y QO mediante FISH, se tomaron muestras de la mezcla de LR de partida y se diluyeron (1:4) con una solución salina con tampón fosfato $(8,18 \mathrm{~g} / \mathrm{L}$ de $\mathrm{NaCl}, 0,20 \mathrm{~g} / \mathrm{L}$ de $\mathrm{KCl}, 1,15 \mathrm{~g} / \mathrm{L}$ de $\mathrm{Na}_{2} \mathrm{HPO}_{4}$ y 0,24 g/L de $\mathrm{KH}_{2} \mathrm{PO}_{4} ; \mathrm{pH}=7,4$ ) esterilizada por filtración. También se recogieron muestras de la FE y de los cultivos bacterianos (una única muestra para cada tipo de cultivo y tiempo de incubación, correspondiente a la mezcla de todos los tubos incubados en las mismas condiciones). Para fijar las células, las muestras se mezclaron (1:3) con paraformaldehído al $4 \%$ y se mantuvieron a $4^{\circ} \mathrm{C}$ durante 16 $\mathrm{h}$, almacenándose después a $-20^{\circ} \mathrm{C}$ hasta ser analizadas.

\subsection{Análisis mediante FISH}

Las suspensiones celulares diluidas y fijadas se aplicaron sobre portaobjetos cubiertos de gelatina, procesándose a continuación según el procedimiento descrito por Belenguer et al. (2007) y utilizando la sonda universal Eub338 (GCTGCCTCCCGTAGGAGT; Amann et al., 1990) para cuantificar el número de BT, y la sonda Prop853 (ATTGCGTTAACTCCGGCAC; Walker et al., 2005) para detectar aquellas pertenecientes al grupo IX de los Clostridiales (en el que se encuentra Q. ovalis). Las imágenes para recuento celular (Figura 2) se tomaron con un microscopio de epifluorescencia equipado con una cámara digital (Nikon 
Eclipse TE2000-E, Nikon Instruments, Melville, EE.UU.), usando el programa Metamorph Imaging (versión 7.1; Universal Imaging, Downington, EE.UU.). Para cada muestra, se llevó a cabo el recuento en 25 campos de microscopio con la ayuda del programa NIS-Elements AR (Nikon Instruments, Badhoeverdorp, Holanda), salvo en el caso de QO, en el que se contabilizaron de forma manual.
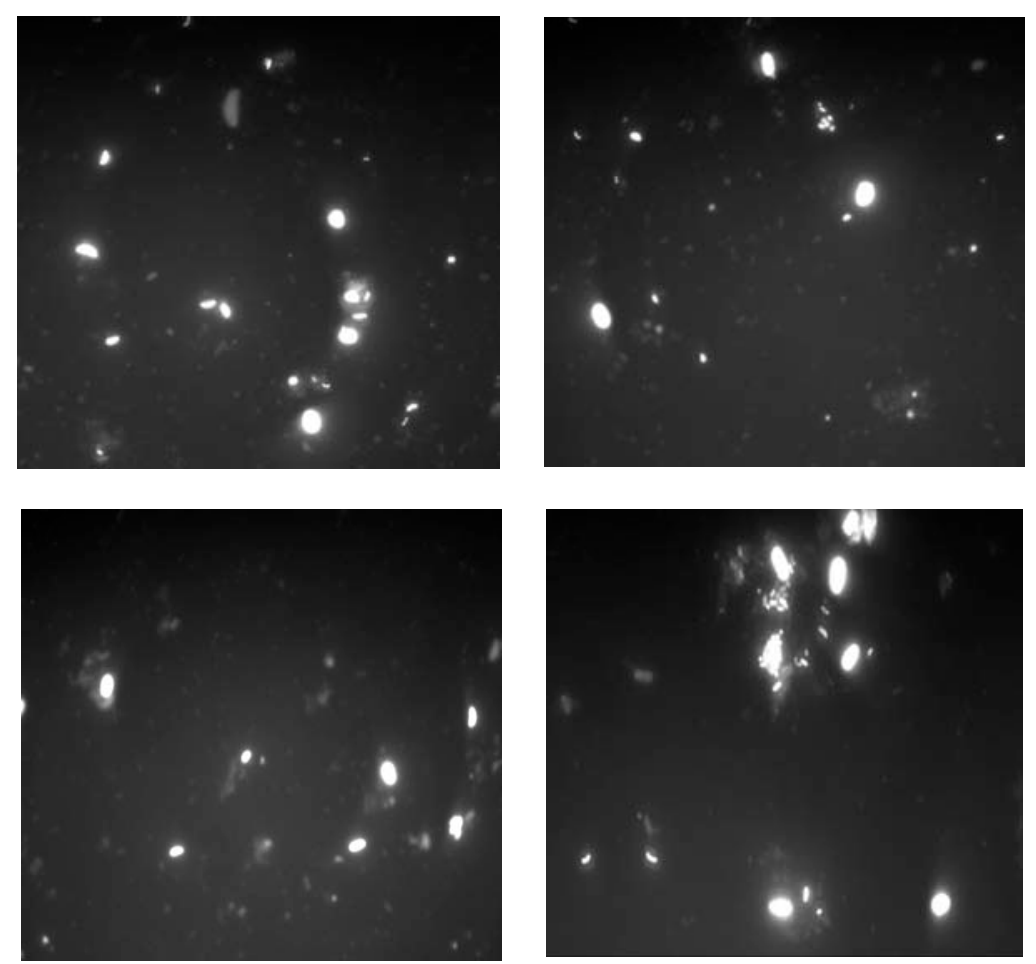

Figura 2. Imágenes tomadas mediante un microscopio de epifluorescencia en las que se observan las bacterias ruminales marcadas con la sonda Prop853.

\subsection{Análisis químicos}

Las dietas experimentales se analizaron para determinar su contenido de MS (ISO 6496:1999), cenizas (ISO 5984:2002) y proteína bruta (ISO 5983-2:2005). Los contenidos de fibra neutro y ácido detergente se determinaron utilizando la tecnología Ankom (Ankom, 2006a, 2006b) añadiendo sulfito de sodio y alfaamilasa a la solución neutro detergente, y se expresaron incluyendo las cenizas residuales. El contenido de extracto etéreo de las dietas se analizó mediante la 
técnica de las bolsas de filtro Ankom (procedimiento oficial Am 5-04 de la AOCS; AOCS, 2008).

\section{ENSAYOS}

La especie bacteriana $Q$. ovalis no ha podido ser conservada en cultivos puros debido a que, con los medios de cultivo utilizados hasta el momento, la presencia de otras bacterias ha sido de algún modo esencial para su crecimiento (Orpin, 1972). Esto ha provocado la necesidad de recurrir a técnicas alternativas para estudiar las características fisiológicas de esta especie (Brough et al., 1970; Orpin, 1972). Por ello, en el presente estudio se llevó a cabo una serie de ensayos destinados a evaluar la eficacia de algunos de estos métodos alternativos, de cara a examinar la implicación de QO en el metabolismo ruminal de los AG. Convendría señalar que, debido al carácter preliminar de este trabajo, no se realizaron réplicas experimentales que permitieran efectuar ningún tipo de análisis de varianza y, por lo tanto, solo se presenta un análisis descriptivo y las comparaciones entre los resultados que se exponen a continuación son aproximativas.

Los primeros tres ensayos se diseñaron con el objetivo de obtener una suspensión celular con el máximo enriquecimiento posible en QO que además fueran viables para su cultivo in vitro. También se realizó un cuarto experimento dirigido a estudiar de forma indirecta las características metabólicas de QO, mediante la obtención simultánea de fracciones enriquecidas y libres de esta bacteria.

\subsection{Ensayo 1}

\subsubsection{Objetivo y desarrollo experimental}

El objetivo de este primer ensayo fue examinar el enriquecimiento en QO obtenido mediante el protocolo de separación descrito por Orpin (1972) cuando se partía de LR de ovejas alimentadas con una dieta suplementada con lípidos de origen marino. 
Para su realización, 4 ovejas canuladas recibieron la dieta con aceite de pescado durante 7 días, tras los cuales se tomó LR y se realizó el protocolo de separación de QO descrito en el apartado 2.2. El proceso de lavado del precipitado bacteriano se repitió 4 veces (ver Figura 1).

\subsubsection{Resultados y discusión}

El protocolo de separación de QO permitió incrementar el porcentaje de dichos microorganismos respecto al total de bacterias desde el 2,6\% en el LR recogido de las ovejas hasta el $12,6 \%$ en la FE. Este enriquecimiento relativamente bajo, insuficiente para poder emplear la FE en una prueba de metabolismo, podría explicarse en parte por la escasa abundancia de QO en el LR de partida. Así, aunque la utilización de procedimientos de separación similares había permitido la obtención de suspensiones celulares con porcentajes de Q. ovalis superiores al 90\% (Wicken y Howard, 1967; Krumholz et al., 1993), en esos casos se partía de LR con una elevada abundancia de dicha especie ( $>50 \%$ ) debido a la inclusión de cantidades considerables de melazas en la dieta (hasta un $87 \%$ de la MF). A pesar de que la adición de estas, o de otros productos ricos en azúcares fácilmente fermentables, podría favorecer más el crecimiento de Q. ovalis en el rumen de lo que parecen hacerlo los lípidos marinos (Vicini et al., 1987; Tolosa, 2006; Belenguer et al., 2010), en el presente estudio se utilizó la suplementación lipídica puesto que, durante una prueba preliminar, la inclusión de dosis relativamente altas de melazas en la dieta de las ovejas provocó una caída importante en su ingestión.

Por otra parte, en los trabajos de Wicken y Howard (1967) y Krumholz et al. (1993) no se especifica el número de veces que se lavó el precipitado bacteriano en el que se encuentra $Q$. ovalis y podría haber sido superior al utilizado en este primer ensayo. Aunque la decisión de hacer únicamente 4 lavados se tomó siguiendo la metodología de Orpin (1972) y con el objetivo de minimizar la manipulación de los microorganismos y el impacto sobre su viabilidad, incrementar ligeramente el número de lavados podría mejorar los resultados de enriquecimiento en QO. Sin embargo, en ese caso sería necesario cultivar in vitro 
la FE, para comprobar si las bacterias obtenidas son viables para la realización del experimento de metabolismo lipídico. Además, si el cultivo de la FE se realizara en un medio selectivo que favoreciera el crecimiento de QO, quizás se podría incrementar aún más el porcentaje de esta bacteria, acercándose así al objetivo final del estudio.

\subsection{Ensayo 2}

\subsubsection{Objetivo y desarrollo experimental}

Este segundo ensayo se planteó con el objetivo de mejorar la efectividad del protocolo de separación de QO (aumentando el número de lavados de 4 a 6) y comprobar la viabilidad de la FE mediante su cultivo in vitro. Este se realizó en un medio selectivo, con manitol como sustrato, con el fin de aumentar todo lo posible el porcentaje de QO en relación al total de bacterias.

Para su desarrollo, se utilizaron los mismos animales que en el ensayo 1, que continuaron recibiendo la dieta suplementada con aceite de pescado durante 7 días más. A continuación, se recogió LR de dichas ovejas y se realizó el protocolo de separación de QO, repitiendo 6 veces el proceso de lavado con la solución de sales inorgánicas y beta-mercaptoetanol. Una vez finalizado el protocolo de separación, la FE (1 mL) se empleó como inóculo en un medio de cultivo selectivo $(9 \mathrm{~mL})$ con manitol como único sustrato $(2 \mathrm{~g} / \mathrm{L})$ y se incubó por triplicado durante 6 y $24 \mathrm{~h}$.

\subsubsection{Resultados y discusión}

El protocolo de separación de QO permitió aumentar su porcentaje respecto al total de bacterias desde el 1,2\% en el LR hasta el 12,2\% en la FE. Aunque este último valor es similar al que se obtuvo en el ensayo 1, cabe destacar que, en este caso, se partió de un LR con una menor abundancia de QO. Por lo tanto, el incremento del número de lavados podría haber supuesto cierta mejora en la eficacia del protocolo de obtención de la FE. En cualquier caso, al haber partido de 
un LR diferente del utilizado en el ensayo anterior, estos resultados no pueden considerarse concluyentes al respecto y sería necesario comparar de forma directa la eficacia del protocolo de separación con 4 o 6 lavados.

La disminución del porcentaje de QO en el LR de las ovejas entre los días 7 (2,6\%, ensayo 1) y $14(1,2 \%$, ensayo 2$)$ de ingestión de la dieta suplementada con aceite de pescado se debió a un incremento del número de BT (de 2,6 a 7,0 × $10^{9}$ células $/ \mathrm{mL}$ ) proporcionalmente superior al de QO (de 6,8 a 8,6 × 107 células $/ \mathrm{mL}$ ). Ello pudo ser el reflejo de una adaptación de la comunidad microbiana ruminal al consumo de lípidos, con el desarrollo de tolerancia a los AG potencialmente tóxicos del aceite de pescado, tal y como se había sugerido en un estudio previo (Belenguer et al., 2010). Por lo tanto, un periodo de wash-out durante el cual los animales no recibieran ningún tipo de suplementación lipídica podría permitir que la comunidad microbiana ruminal recuperase una composición similar a la inicial, facilitando la obtención de un LR más enriquecido en $\mathrm{QO}$ al recomenzar la suplementación con aceite de pescado.

Tal y como se había planteado, el cultivo de la FE en un medio selectivo con manitol provocó un incremento del porcentaje de QO en la suspensión celular desde el 12,2 al 35,3\% de las BT tras 6 h de incubación, como consecuencia del aumento de la abundancia de QO (de 0,2 a 1,5 × 107 células/mL). Sin embargo, esta bacteria solo representaba un $0,9 \%$ de las BT tras 24 h de incubación, debido tanto al descenso de su concentración (hasta $0,5 \times 10^{7}$ células $/ \mathrm{mL}$ ) como al marcado aumento del número de BT (de 4,2 hasta 52,4 × $10^{7}$ células/mL). Paradójicamente, el descenso del porcentaje de $\mathrm{QO}$ al prolongar el tiempo de incubación podría haberse debido a un exceso de manitol en el medio, ya que cuando el sustrato no es un factor limitante, $Q$. ovalis puede no metabolizarlo completamente y producir ácido láctico (Brough et al., 1970; Krumholz et al., 1993), el cual se liberaría al medio y sería utilizado por otras bacterias en un fenómeno de alimentación cruzada (Fondevila y Dehority, 1996; Dehority, 2003). Por otro lado, al ser el manitol el único sustrato y estar presente en concentraciones elevadas, tampoco fue posible descartar que otras bacterias que normalmente no metabolizan este 
compuesto, o que lo hacen con una eficiencia muy baja, pudieran haberlo utilizado como fuente de energía. En cualquier caso, de cara a la realización de un tercer ensayo, parecía razonable plantear que la disminución de la concentración de manitol en el medio de cultivo minimizaría el crecimiento de otras bacterias. Además, y puesto que el mayor crecimiento de QO pareció producirse durante las primeras horas de cultivo in vitro, la realización de dos incubaciones en medio selectivo consecutivas, utilizando como inóculo de la segunda la suspensión celular resultante de la primera (con una proporción de QO potencialmente mayor que la de la FE), podría permitir aumentar aún más el porcentaje de esta bacteria.

\subsection{Ensayo 3}

\subsubsection{Objetivo y desarrollo experimental}

Este tercer ensayo se planteó para dar respuesta a los interrogantes surgidos en el ensayo 2. Contó por ello con tres objetivos específicos. En primer lugar, se evaluó el efecto de la inclusión de un periodo de wash-out (en el que las ovejas recibieran la dieta sin suplementar) previo a la administración del aceite de pescado sobre el porcentaje de QO en el LR. En segundo lugar, se buscó confirmar si el incremento del número de lavados en el protocolo de separación tenía un impacto sobre la abundancia y viabilidad de QO en la FE. Por último, se planteó llevar a cabo dos cultivos selectivos consecutivos, inoculando la suspensión obtenida en el primero en un medio de cultivo fresco, para intentar incrementar aún más el porcentaje de QO. Además, se disminuyó la cantidad de sustrato en el medio para aumentar la presión selectiva y se incluyeron varios tiempos cortos de incubación, para determinar el momento de máximo crecimiento de QO.

En este caso se utilizaron 2 ovejas canuladas como donantes del fluido ruminal. Inmediatamente después de la realización del ensayo 2, los animales recibieron la dieta sin suplementación lipídica durante un periodo de 7 días, tras el cual se administró la dosis diaria de aceite de pescado (i. e., 0,57 g/kg PV0,75) durante otros 7 días, infundiéndola directamente en el rumen a través de la 
cánula. Pasado este tiempo, se recogió el LR de las ovejas y, una vez filtrado y mezclado, se dividió en dos alícuotas para realizar de forma simultánea el protocolo de separación de QO con 4 o 6 lavados, obteniéndose así dos fracciones enriquecidas ( $\mathrm{FE}_{4}$ y $\mathrm{FE}_{6}$, respectivamente). Estas se cultivaron in vitro tal y como se describió en el ensayo 2 ( $1 \mathrm{~mL}$ de inóculo $+9 \mathrm{~mL}$ de medio de cultivo), pero reduciendo a la mitad la concentración de manitol en el medio $(1 \mathrm{~g} / \mathrm{L})$ y durante tiempos más cortos (4, 6, 8 y 10 h). Además, $1 \mathrm{~mL}$ de las suspensiones celulares resultantes del cultivo de la $\mathrm{FE}_{6}$ durante 6 y 8 h (FE6-6 y FE6-8, respectivamente) se reinoculó en las mismas condiciones y se incubó durante otras $6 \mathrm{~h}$.

\subsubsection{Resultados y discusión}

La interrupción temporal de la administración de aceite de pescado pudo haber favorecido el incremento del porcentaje de QO en el rumen al retomar de nuevo el tratamiento, cuando llegaron a representar un 5,7\% de las BT en el LR. Dicho valor supera a los obtenidos en el ensayo 2 y en los experimentos previos con ovejas que recibían una dosis similar de aceite de pescado (1\% de la dieta; Belenguer et al., 2010) aunque durante periodos relativamente más largos, lo que podría conllevar una adaptación de la microbiota al consumo de los lípidos marinos (Toral et al., 2010). Por otro lado, el porcentaje de QO también fue mayor que el obtenido en el LR del ensayo 1, luego no puede descartarse que las diferencias sean debidas a la elevada variabilidad individual en la composición de la comunidad microbiana del rumen (Firkins y Yu, 2006), ya que en este caso se utilizó un número menor de animales.

En cuanto al protocolo de separación de QO, cada lavado eliminó proporcionalmente un mayor número de BT que de QO, por lo que la abundancia relativa de esta bacteria fue ligeramente superior en la $\mathrm{FE}_{6}$ que en la $\mathrm{FE}_{4}$ (30,8 y 25,5\% de las BT, respectivamente), aunque ello podría haber afectado a su viabilidad en cultivo en el primer caso. Así, aunque la evolución del número de BT y de QO durante el cultivo selectivo siguió el mismo patrón en ambas fracciones (Figura 3) y las mayores abundancias relativas de QO se alcanzaron siempre a las 
$6 \mathrm{~h}$ de incubación (Figura 3c), los porcentajes fueron superiores en la FE4 (42,4\%) que en la $\mathrm{FE}_{6}(32,8 \%)$. A partir de este momento, aunque el número de QO siguió aumentando ligeramente hasta las $8 \mathrm{~h}$ de incubación (Figura 3a), el gran incremento del de BT (Figura 3b) provocó una caída drástica del porcentaje de QO, alcanzándose en ambas fracciones valores inferiores al 10\% tras $10 \mathrm{~h}$ de incubación (Figura 3c). Estos resultados podrían indicar que las QO solo son capaces de competir bien durante las primeras horas de cultivo, lo que coincide con lo observado por otros autores (Brough et al., 1970).

(a) Recuento QO

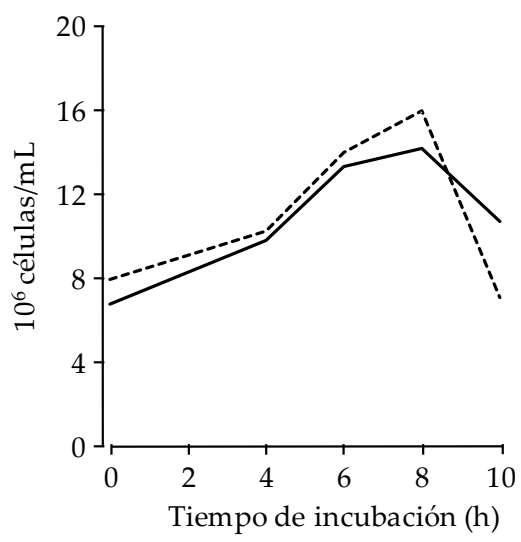

(c) Porcentaje QO

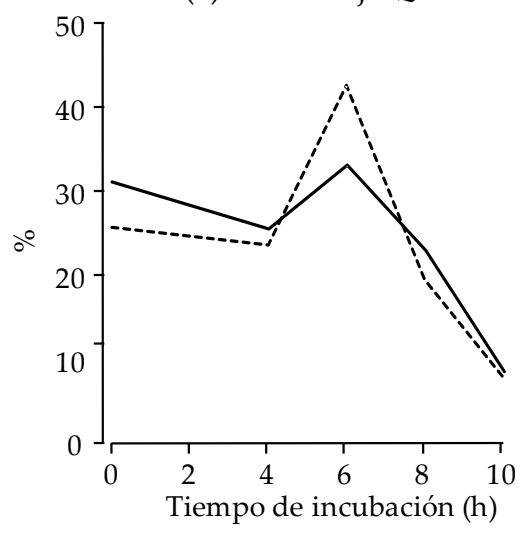

(b) Recuento bacterias totales

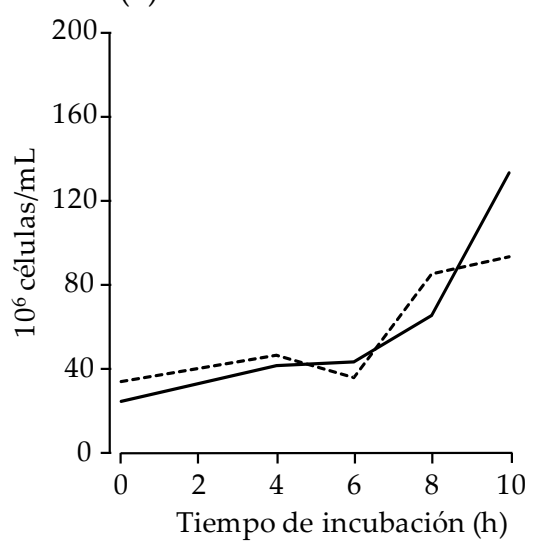

--.-- 4 lavados - 6 lavados

Figura 3. Recuento $\left(\times 10^{6}\right.$ células $\left./ m L\right)$ de $\mathrm{Q}$. ovalis (QO; a) y de bacterias totales $(B T ; \boldsymbol{b})$ y porcentaje de $Q O$ respecto a $B T(c)$, durante el cultivo de las fracciones enriquecidas en QO obtenidas mediante el protocolo de separación con 4 o 6 lavados a partir del fluido ruminal de ovejas canuladas que recibían aceite de pescado (ensayo 3). 
En el segundo cultivo selectivo se optó por utilizar como inóculo la FE6 incubada durante 6 y 8 h (FE6-6 y FE6-8), al no poder disponer de los resultados de la primera parte del experimento y haber asumido (a partir de los resultados del ensayo 2) que el grado de enriquecimiento en QO sería el más elevado. De forma inesperada, esta segunda incubación produjo una caída brusca de la abundancia relativa de QO a las $6 \mathrm{~h}$ (desde 32,8 a 7,6\% en la FE6-6, y de 22,7 a 1,7\% en la FE68), a pesar de que su número había aumentado ligeramente en este periodo (de 1,3 a 3,4 $\times 10^{6}$ células/mL en la FE6-6 y de 1,4 a $1,7 \times 10^{6}$ células/mL en la FE6-8). El descenso de la proporción de QO se debió, por lo tanto, a la proliferación de BT (de 0,4 a 4,5 × $10^{7}$ células/mL en FE6-6 y de 0,6 a 10,3 × $10^{7}$ células/mL en FE6-8), lo que lleva a especular que la presión selectiva del primer cultivo podría haber favorecido no solo al crecimiento de QO, sino también al de otras bacterias capaces de utilizar manitol o alguno de los productos de su metabolismo.

En conclusión, ni el protocolo de separación empleado para concentrar QO, ni el cultivo selectivo de las suspensiones celulares enriquecidas en esta bacteria, permitió obtener una fracción con un porcentaje de QO lo suficientemente alto para poder estudiar su implicación en el metabolismo de los AG insaturados. Así pues, se planteó un cuarto ensayo para estudiar la efectividad de una estrategia alternativa sin recurrir a la obtención de una fracción muy enriquecida en esta bacteria.

\subsection{Ensayo 4}

\subsubsection{Objetivo y desarrollo experimental}

Debido a la dificultad de obtener una suspensión de microorganismos ruminales suficientemente enriquecida en QO mediante las técnicas utilizadas en estudios previos (Wicken y Howard, 1967; Orpin, 1972; Krumholz et al., 1993), el objetivo de este ensayo fue conseguir simultáneamente una suspensión celular con un porcentaje relativamente elevado de QO y otra lo más similar posible pero libre de 
esta bacteria. La comparación entre ambas en una prueba de metabolismo permitiría atribuir a QO los cambios que no ocurran en su ausencia.

Para ello se planteó la utilización de dos tipos de cultivos selectivos, utilizando por un lado manitol como sustrato, para favorecer el crecimiento de QO, y por el otro celobiosa y almidón (dos compuestos que Q. ovalis no es capaz de metabolizar, pero sí la mayoría de las bacterias ruminales; Brough et al., 1970; Orpin, 1972; Dehority, 2003), para minimizar su crecimiento. Ambos sustratos se añadieron a dos concentraciones menores que las incubadas en los ensayos anteriores, para incrementar aún más la presión selectiva del cultivo.

En este ensayo se utilizaron 2 ovejas que fueron alimentadas con la dieta $\sin$ suplementación lipídica durante un periodo de adaptación de 7 días. A continuación, se les administró el mismo tratamiento que en la prueba anterior

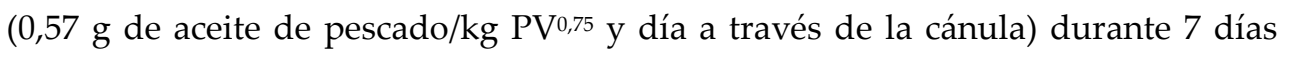
más. Una vez recogido el LR, se obtuvo la FE mediante el protocolo de separación de QO con 4 lavados y se utilizó como inóculo para las incubaciones in vitro, que se realizaron tal y como se describe en el ensayo 2, pero incluyendo 2 sustratos selectivos: manitol o una combinación 1:1 de celobiosa y almidón, a 2 concentraciones (0,2 y 0,5 g/L de medio de cultivo). Las incubaciones se prolongaron durante 3 y $6 \mathrm{~h}$.

\subsubsection{Resultados y discusión}

El LR recogido presentaba una abundancia de QO menor que el del ensayo 3 (2,8 vs 5,7\%), aunque su porcentaje en la FE fue muy similar al que se obtuvo entonces realizando también 4 lavados (25,5 y 27,8\% en los ensayos 3 y 4, respectivamente; Tabla 3). Puesto que el manejo de las ovejas fue muy similar en ambos experimentos, las diferencias en la proporción de QO en el LR de partida podrían quizás deberse a variaciones temporales en la comunidad bacteriana del rumen (Michelland et al., 2009). Podría también especularse que estas diferencias en la composición del LR expliquen las distintas eficacias del protocolo de separación de QO, ya que al tratarse de un método de separación mecánico, los resultados 
dependerían tanto de la proporción de la bacteria de interés como de la abundancia, la forma y el tamaño del resto de microorganismos presentes.

Tabla 3. Recuento ( $n^{\circ}$ de células $/ m L$ ) de Q. ovalis $(Q O)$ y de bacterias totales (BT) y porcentaje de $Q O$ respecto a $B T(\% Q O)$, en el fluido ruminal de ovejas canuladas que recibían aceite de pescado y en la fracción enriquecida obtenida mediante el protocolo de separación de QO en los distintas ensayos.

\begin{tabular}{|c|c|c|c|c|c|c|c|}
\hline \multirow[b]{2}{*}{ Ensayo } & \multicolumn{3}{|c|}{ Fluido ruminal } & \multirow[b]{2}{*}{ Lavados $^{1}$} & \multicolumn{3}{|c|}{ Fracción enriquecida } \\
\hline & $\begin{array}{c}\mathrm{QO} \\
\left(\times 10^{8}\right) \\
\end{array}$ & $\begin{array}{c}\text { BT } \\
\left(\times 10^{8}\right) \\
\end{array}$ & $\% \mathrm{QO}$ & & $\begin{array}{c}\text { QO } \\
\left(\times 10^{8}\right) \\
\end{array}$ & $\begin{array}{c}\text { BT } \\
\left(\times 10^{8}\right) \\
\end{array}$ & $\% \mathrm{QO}$ \\
\hline 1 & 0,68 & 25,6 & 2,6 & 4 & 0,42 & 3,29 & 12,6 \\
\hline 2 & 0,86 & 69,9 & 1,2 & 6 & 0,23 & 1,92 & 12,2 \\
\hline \multirow[t]{2}{*}{3} & 1,45 & 25,8 & 5,7 & 4 & 0,79 & 3,10 & 25,5 \\
\hline & & & & 6 & 0,68 & 2,21 & 30,8 \\
\hline 4 & 1,14 & 40,4 & 2,8 & 4 & 0,51 & 1,85 & 27,8 \\
\hline
\end{tabular}

${ }^{1}$ Número de repeticiones del proceso de lavado durante el protocolo de separación de QO.

Tal y como se muestra en la Figura 4a, la incubación de la FE con la concentración alta de manitol $(0,5 \mathrm{~g} / \mathrm{L})$ permitió un pequeño aumento del recuento de QO a las $6 \mathrm{~h}$ de cultivo, mientras que la concentración menor $(0,2 \mathrm{~g} / \mathrm{L})$ indujo cambios menos evidentes. Por otro lado, el número de BT apenas varió durante las primeras $3 \mathrm{~h}$ de incubación con manitol, pero aumentó de forma importante a las 6 h (Figura 4b), provocando una caída drástica del porcentaje de QO con ambas concentraciones de sustrato (Figura 4c). Por lo tanto, el potencial aumento de la presión selectiva al reducir la cantidad de manitol en el cultivo no tuvo el efecto esperado. Aunque en un estudio previo en condiciones similares $(0,2 \mathrm{~g} / \mathrm{L}$ de manitol en el medio; Orpin, 1972) se habían mantenido suspensiones celulares muy enriquecidas en $Q$. ovalis durante tiempos de incubación relativamente largos, en ese caso se había partido de inóculos formados casi exclusivamente por esta especie, gracias a su aislamiento mediante laboriosas técnicas de micromanipulación, lo que podría explicar sus resultados.

La incubación de la FE con otros carbohidratos que no pueden ser metabolizados por Q. ovalis (Brough et al., 1970; Orpin, 1972) tampoco indujo la respuesta esperada (i. e., la desaparición de QO). Así, aunque el número de BT 
aumentó progresivamente durante la incubación, el número de QO se mantuvo bajo pero no lo suficiente como para poder considerar estas suspensiones libres de QO. En este sentido, cabría esperar que la realización de un cultivo selectivo a partir del LR hubiera permitido obtener porcentajes de QO más bajos, pero los efectos atribuibles a la ausencia de este microorganismo (en comparación con la suspensión celular rica en QO) estarían confundidos con los resultantes de otras

(a) Recuento QO

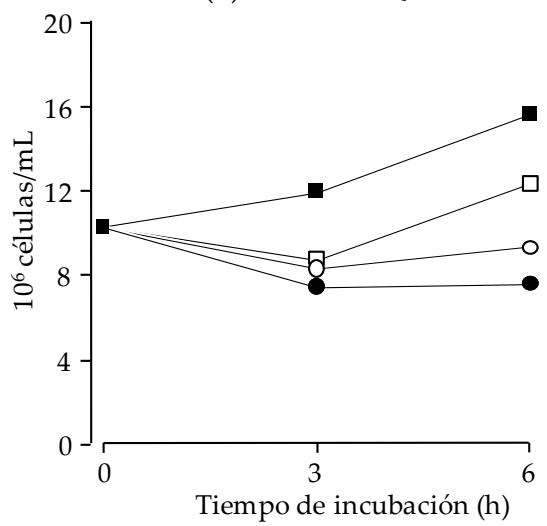

(c) Porcentaje QO

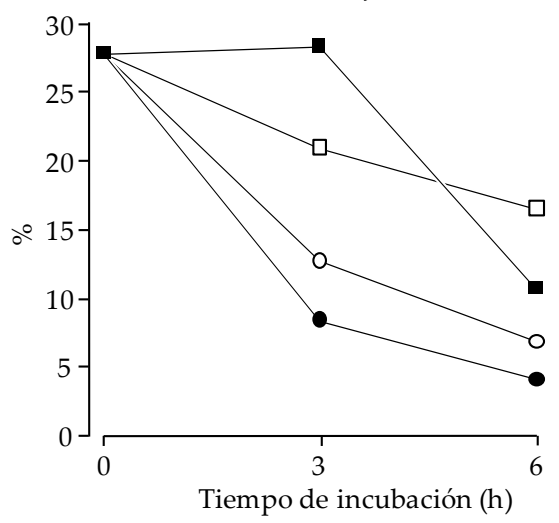

(b) Recuento bacterias totales

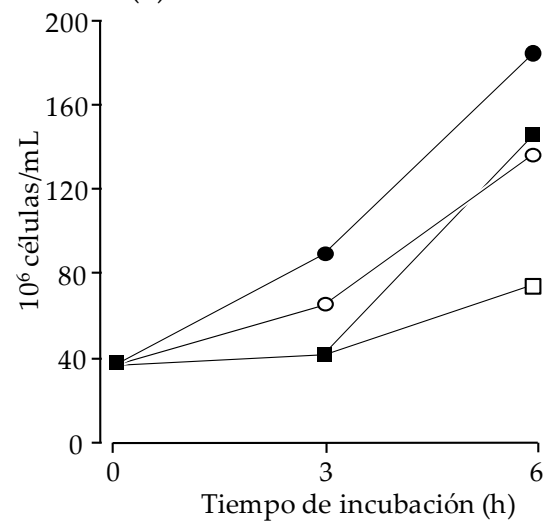

$\longrightarrow$ - Manitol 0,2 g/L

$\rightarrow-$ Manitol 0,5 g/L

-

$\longrightarrow$ Celobiosa y almidón $0,5 \mathrm{~g} / \mathrm{L}$

Figura 4. Recuento (células $\left./ m L \times 10^{6}\right)$ de Q. ovalis $(Q O ; \boldsymbol{a})$ y de bacterias totales $(B T ; \boldsymbol{b})$ y porcentaje de QO respecto a BT (c) durante el cultivo de la fracción enriquecida en $Q O$ obtenida mediante el protocolo de separación con 4 lavados a partir del fluido ruminal de ovejas canuladas que recibían aceite de pescado (ensayo 4). Se presentan 4 tipos de cultivo con 2 sustratos (manitol, o celobiosa más almidón en proporción 1:1) a 2 concentraciones (0,2 y 0,5 g/L de medio de cultivo). 
diferencias en las comunidades microbianas ligadas a la ausencia de lavados previos. En cualquier caso, los resultados de la incubación con celobiosa y almidón parecen indicar que, a pesar de la ausencia de un sustrato adecuado para el crecimiento de $Q$. ovalis, estas bacterias podrían ser capaces de utilizar algún metabolito intermedio liberado por otros microorganismos presentes en la suspensión celular (Fondevila y Dehority, 1996; Dehority, 2003). Ello concuerda con la necesidad de que haya otras bacterias en el medio de cultivo para que $Q$. ovalis pueda sobrevivir durante periodos largos de incubación (Orpin, 1972). En cualquier caso, cabe recordar una vez más que, a pesar de que las bacterias grandes y ovaladas denominadas QO pertenecen al mismo grupo taxonómico que Q. ovalis y comparten características morfológicas, no es posible asegurar de forma inequívoca que sean la misma especie $\mathrm{y}$, por lo tanto, tengan las mismas características fisiológicas.

\section{CONCLUSIONES}

Cuando se parte de líquido ruminal procedente de ovejas que reciben aceite de pescado (1,8\% MS de la dieta), ni concentrar QO mediante el protocolo de obtención de la fracción enriquecida ni los cultivos con un sustrato selectivo para favorecer el crecimiento de este microorganismo permiten aumentar suficientemente su porcentaje para llevar a cabo el estudio directo de su implicación en el metabolismo de los AG. La estrategia alternativa, consistente en el cultivo de suspensiones ricas en QO con sustratos selectivos que favorezcan o impidan su crecimiento, tampoco ofrece resultados satisfactorios, lo que pone de manifiesto la complejidad para desarrollar un método que permita examinar sus características metabólicas, tanto de forma directa como indirecta. Sería pues necesaria la búsqueda de otras alternativas, bien que incluyan una mejora de las condiciones de cultivo que permitan obtener suspensiones muy enriquecidas en QO o que estén implementadas con técnicas de aislamiento mucho más laboriosas, como la micromanipulación. Otra posibilidad sería estudiar el genoma de este microorganismo, lo cual no solo podría aportar información sobre sus 
requerimientos nutricionales, sino que permitiría la búsqueda de genes

funcionales relacionados con el metabolismo de los AG insaturados.

\section{REFERENCIAS}

Amann RI, Binder BJ, Olson RJ, Chisholm SW, Devereux R and Stahl DA 1990. Combination of $16 \mathrm{~S}$ rRNA-targeted oligonucleotide probes with flow cytometry for analyzing mixed microbial populations. Appl. Environ. Microbiol. 56, 1919-1925.

Ankom 2006a. Acid detergent fiber in feeds. Filter bag technique (para A2000, A2000I). Ankom Technology Method 8. En: Ankom Technology Corp., Macedon, EE.UU.

Ankom 2006b. Neutral detergent fiber in feeds. Filter bag technique (para A2000, A2000I). Ankom Technology Method 8. En: Ankom Technology Corp., Macedon, EE.UU.

AOCS, 2008. Official methods and recommended practices of the American oil chemist's society. $5^{\mathrm{a}}$ Edición. AOCS, Urbana, IL, EE.UU.

Belenguer A, Duncan SH, Holtrop G, Anderson SE, Lobley GE and Flint HJ 2007. Impact of pH on lactate formation and utilization by uuman fecal microbial communities. Appl. Environ. Microbiol. 73, 6526-6533.

Belenguer A, Toral PG, Frutos P and Hervás G 2010. Changes in the rumen bacterial community in response to sunflower oil and fish oil supplements in the diet of dairy sheep. J. Dairy Sci. 93, 3275-3286.

Brough BE, Howard BH and College L 1970. The biochemistry of the rumen bacterium "Quin's Oval": The carbohydrase enzymes. Lincoln College (Canterbury University), Canterbury, Reino Unido.

Dehority BA 2003. Rumen Microbiology. Nottingham University Press. Nottingham, Reino Unido.

Firkins JL and Yu Z. 2006. Characterization and quantification of the microbial populations in the rumen. Páginas 19-54 en Ruminant physiology, digestion, metabolism and impact of nutrition on gene expression, immunology and stress. Sejrsen K, Hvelplund, T, Nielsen, MO, eds. Wageningen Academic Publishers. Wageningen, Holanda.

Fondevila M and Dehority BA 1996. Interactions between Fibrobacter succinogenes, Prevotella ruminicola, and Ruminococcus flavefaciens in the digestion of cellulose from forages. J. Anim. Sci. 74, 678-684.

Hudson JA, MacKenzie CAM and Joblin KN 1995. Conversion of oleic acid to 10-hydroxystearic acid by two species of ruminal bacteria. Appl. Microbiol. Biotechnol. 44, 1-6.

Hudson JA, Cai Y, Corner RJ, Morvan B and Joblin KN 2000. Identification and enumeration of oleic acid and linoleic acid hydrating bacteria in the rumen of sheep and cows. J. Appl. Microbiol. 88, 286-292.

Huws SA, Kim EJ, Lee MRF, Scott MB, Tweed JKS, Pinloche E, Wallace RJ and Scollan ND 2011. As yet uncultured bacteria phylogenetically classified as Prevotella, Lachnospiraceae incertae sedis and unclassified Bacteroidales, Clostridiales and Ruminococcaceae may play a predominant role in ruminal biohydrogenation. Environm. Microbiol. 13, 1500-1512.

INRA 2007. Alimentation des bovins, ovins et caprins. Besoins des animaux: Valeur des aliments. Tables INRA 2007. INRA, Versailles, Francia. 
Jenkins TC, AbuGhazaleh AA, Freeman S and Thies EJ 2006. The production of 10hydroxystearic and 10-ketostearic acids is an alternative route of oleic acid transformation by the ruminal microbiota in cattle. J. Nutr. 136, 926-931.

Jenkins TC, Wallace RJ, Moate PJ and Mosley EE 2008. Recent advances in biohydrogenation of unsaturated fatty acids within the rumen microbial ecosystem. J. Anim. Sci. 86, 397-412.

Krumholz LR, Bryant MP, Brulla WJ, Vicini JL, Clark JH and Stahl DA 1993. Proposal of Quinella ovalis gen. nov., sp. nov., based on phylogenetic analysis. Int. J. Syst. Bacteriol. 43, 293-296.

Lourenço M, Ramos-Morales E and Wallace RJ 2010. The role of microbes in rumen lipolysis and biohydrogenation and their manipulation. Animal 4, 1024-1036.

Maia MRG, Chaudhary LC, Figueres L and Wallace RJ 2007. Metabolism of polyunsaturated fatty acids and their toxicity to the microflora of the rumen. Anton. Leeuw. Int. J. G. 91, 303314.

Maia MRG, Chaudhary LC, Bestwick CS, Richardson AJ, McKain N, Larson TR, Graham IA and Wallace RJ 2010. Toxicity of unsaturated fatty acids to the biohydrogenating ruminal bacterium, Butyrivibrio fibrisolvens. BMC Microbiol. 10, 52-61.

McKain N, Shingfield KJ and Wallace RJ 2010. Metabolism of conjugated linoleic acids and 18:1 fatty acids by ruminal bacteria: products and mechanisms. Microbiology 156, 579-588.

Michelland RJ, Monteils V, Zened A, Combes S, Cauquil L, Gidenne T, Hamelin J and FortunLamothe L 2009. Spatial and temporal variations of the bacterial community in the bovine digestive tract. J. Appl. Microbiol. 107, 1642-1650.

Orpin CG 1972. The culture in vitro of the rumen bacterium Quin's Oval. J. Gen. Microbiol. 73, 523-530.

Prins RA 1971. Isolation, culture and fermentation characteristics of Selenomonas ruminantium var. bryanti var. n. from the rumen of sheep. J. Bacteriol. 105, 820-825.

Tolosa MX. 2006. Molecular ecology of rumen bacterial populations in steers fed molasses diets. Tesis doctoral. Universidad de Queensland, Australia.

Toral PG, Hervás G, Gómez-Cortés P, Frutos P, Juárez M and de la Fuente MA 2010. Milk fatty acid profile and dairy sheep performance in response to diet supplementation with sunflower oil plus incremental levels of marine algae. J. Dairy Sci. 93, 1655-1667.

Toral PG, Belenguer A, Shingfield KJ, Hervás G, Toivonen V and Frutos P 2012. Fatty acid composition and bacterial community changes in the rumen fluid of lactating sheep fed sunflower oil plus incremental levels of marine algae. J. Dairy Sci. 95, 794-806.

Vicini JL, Brulla WJ, Davis CL and Bryant MP 1987. Quin's oval and other microbiota in the rumens of molasses-fed sheep. Appl. Environ. Microbiol. 53, 1273-1276.

Walker AW, Duncan SH, McWilliam Leitch EC, Child MW and Flint HJ 2005. pH and peptide supply can radically alter bacterial populations and short-chain fatty acid ratios within microbial communities from the human colon. Appl. Environ. Microbiol. 71, 3692-3700.

Wicken AJ and Howard BH 1967. On the taxonomic status of Quin's Oval organisms. J. Gen. Microbiol. 47, 207-2011. 


\section{PRUEBA IV}

\section{DIETARY SUNFLOWER OIL MODULATES MILK FATTY ACID COMPOSITION WITHOUT MAJOR CHANGES IN ADIPOSE AND MAMMARY TISSUE FATTY ACID PROFILE OR RELATED GENE mRNA ABUNDANCE IN SHEEP}

T. Castro-Carrera ${ }^{1,2,3}$, P. Frutos ${ }^{1}$, C. Leroux ${ }^{2,3}$, Y. Chilliard ${ }^{2,3}$, G. Hervás', A. Belenguer ${ }^{1}$, L. Bernard ${ }^{2,3}$ y P. G. Toral ${ }^{2,3}$ ${ }^{1}$ Instituto de Ganadería de Montaña, CSIC - Universidad de León Finca Marzanas s/n, 24346 Grulleros, León, España 2INRA, UMR 1213 Herbivores, Equipe Alimentation Génomique Lactation, Site de Theix, F-63122 Saint-Genès-Champanelle, Francia ${ }^{3}$ Clermont Université, VetAgro Sup, BP 10448, F-63000, Clermont-Ferrand, Francia

Animal 9 (2015, en prensa) doi:10.1017/S1751731114002882

Presentado en parte en las XV Jornadas sobre Producción Animal AIDA, 14-15 de mayo de 2013, Zaragoza, España 



\title{
DIETARY SUNFLOWER OIL MODULATES MILK FATTY ACID COMPOSITION WITHOUT MAJOR CHANGES IN ADIPOSE AND MAMMARY TISSUE FATTY ACID PROFILE OR RELATED GENE mRNA ABUNDANCE IN SHEEP
}

\author{
T. Castro-Carrera, P. Frutos, C. Leroux, Y. Chilliard, G. Hervás, \\ A. Belenguer, L. Bernard and P. G. Toral
}

\begin{abstract}
There are very few studies in ruminants characterizing mammary and adipose tissue (AT) expression of genes and gene networks for diets causing variations in milk fatty acid (FA) composition without altering milk fat secretion, and even less complementing this information with data on tissue FA profiles. This work was conducted in sheep in order to investigate the response of the mammary gland and the subcutaneous and perirenal AT, in terms of FA profile and mRNA abundance of genes involved in lipid metabolism, to a diet known to modify milk FA composition. Ten lactating Assaf ewes were randomly assigned to 2 treatments consisting of a total mixed ration based on alfalfa hay and a concentrate (60:40) supplemented with 0 (control diet) or 25 (SO diet) g of sunflower oil/kg of diet DM for 7 weeks. Milk composition, including FA profile, was analysed after 48 days on treatments. On day 49 , the animals were euthanized and tissue samples were collected to analyse FA and mRNA abundance of 16 candidate genes. Feeding SO did not affect animal performance but modified milk FA composition. Major changes included decreases in the concentration of FA derived from de novo synthesis (e. g., 12:0, 14:0 and 16:0) and increases in that of long chain FA (e. g., 18:0, cis-9 18:1, trans-18:1 isomers and cis-9, trans-11 CLA); however, they were not accompanied by significant variations in the mRNA abundance of the studied lipogenic genes (i. e., ACACA, FASN, LPL, CD36, FABP3, $S C D 1$ and SCD5) and transcription factors (SREBF1 and PPARG), or in the constituent FA of mammary tissue. Regarding the FA composition of AT, the little influence of SO did not appear to be linked to changes in gene mRNA abundance
\end{abstract}


(decreases of GPAM and SREBF1 in both tissues, and of PPARG in the subcutaneous depot). Similarly, the great variation between AT (higher contents of saturated FA and trans-18:1 isomers in the perirenal, and of cis-18:1, cis-9, trans-11 CLA and n-3 PUFA in the subcutaneous AT) could not be related to differences in gene mRNA abundance due to tissue site (higher LPL and CD36, and lower SREBF1 in perirenal than in subcutaneous AT). Overall, these results suggest a marginal contribution of gene expression to the nutritional regulation of lipid metabolism in these tissues, at least with the examined diets and after 7 weeks on treatments. It cannot be ruled out, however, that the response to SO is mediated by other genes or post-transcriptional mechanisms.

Key words: fatty acid composition, lactating ewe, lipogenic gene expression, plant oil, tissue

\section{INTRODUCTION}

The addition of a moderate amount of sunflower oil (SO) to a forage-rich diet has proved in dairy ewes to modulate milk fat composition without negatively affecting its production (Toral et al., 2010; Gómez-Cortés et al., 2011). However, mechanisms explaining changes in milk fatty acids (FA), including mediation via coordinated downregulation and upregulation of genes involved in lipid metabolism, are still poorly understood. In addition, there are very few studies characterizing mammary expression of genes and gene networks for diets causing variations in milk FA composition without altering milk fat secretion (Shingfield et al., 2010). The available information is almost limited to cows suffering from milk fat depression (MFD; Piperova et al., 2000; Peterson et al., 2003) or to goats (Bernard et al., 2005a, 2005b, 2009a), a species in which this syndrome is not often observed, but little work has been published yet on ewes (Dervishi et al., 2012; Bichi et al., 2013).

Althoug the physiological adaptations of the mammary gland or adipose tissues (AT) occurring during lactation have been well described in ruminants 
(Vernon, 1980; Chilliard, 1999; Bauman, 2000), the possible contribution of AT to the regulation of mammary lipogenesis still needs to be documented (Shingfield et al., 2010). Studies on diet-induced MFD in cows report an increase in the mRNA abundance of lipogenic genes in AT related to the preferential partitioning of nutrients towards non-mammary tissues (Harvatine et al., 2009; Thering et al., 2009; Schmitt et al., 2011). On the contrary, lipid supplementation inducing no changes or increases in milk fat yield in goats is not accompanied by alterations of the mRNA abundance or activity of lipogenic enzymes in AT (Bernard et al., 2005a, 2009a). Although it is complicated to discern whether these differences are linked to the diet, its interaction with species or other factors, there is no information at all in sheep.

Furthermore, most works relied on the study of subcutaneous AT (Harvatine et al., 2009; Thering et al., 2009; Bichi et al., 2013), despite the fact that differences among AT in FA composition, lipogenic gene expression or enzyme activity have been described (Chilliard et al., 1981; Bas et al., 1987; Barber et al., 2000). Data on the FA profile of AT could complement results on gene mRNA abundance to improve our understanding of lipid metabolism, but simultaneous measurements are seldom reported (Toral et al., 2013). Similarly, most studies last for up to only 4 weeks (Piperova et al., 2000; Bernard et al., 2009b; Jacobs et al., 2011) and mechanisms involved in a longer term response are not considered. On the other hand, according to previous results in dairy ewes (e. g., Toral et al., 2010; GómezCortés et al., 2011), the longer the time on lipid-supplemented diets, the greater the differences in milk fat composition. Therefore, it may be expected that changes in the mRNA abundance of genes involved in lipid metabolism would also be more easily observed after relatively long periods on lipid-treatments.

Thus, an assay with lactating ewes receiving SO for 7 weeks was conducted based on the hypothesis that SO-induced changes in milk FA profile would be mediated by variations in mammary lipogenic gene expression, this response also being putatively related to changes in AT. 


\section{MATERIALS AND METHODS}

\subsection{Animals, experimental diets and management}

A total of 10 multiparous Assaf ewes $(84.1 \mathrm{~kg} \mathrm{BW,} \mathrm{s.d.} \mathrm{8.35;} 75$ days in milk, s.d. 3.7) were divided into two groups $(n=5)$, balanced for milk yield, BW, days in milk, and number of lactation, and were assigned to one of the following 2 experimental treatments (diets): control and supplemented with SO. Diets, prepared weekly, consisted of a TMR based on dehydrated alfalfa hay (particle size $>4 \mathrm{~cm}$ ) and a concentrate (60:40) supplemented with 0 (control diet) or 25 (SO diet) $\mathrm{g}$ of $\mathrm{SO} / \mathrm{kg}$ of $\mathrm{DM}$. The ingredients and chemical composition of the experimental diets, which included molasses to reduce selection of dietary components, are given in Table 1. Clean water was always available and fresh diets were offered daily ad libitum at 9:00 and 19:00 h. Ewes were milked twice daily at approximately 8:30 and $18: 30 \mathrm{~h}$ in a $1 \times 10$ stall milking parlour (DeLaval, Madrid, Spain). The experiment lasted for 7 weeks and was carried out in accordance with the Spanish Royal Decree 1201/2005 for the protection of animals used for experimental purposes.

\subsection{Measurements and sampling procedures}

Representative samples of offered and refused diets were collected weekly, stored at $-20^{\circ} \mathrm{C}$ and then freeze-dried. Diet samples were analysed for DM, ash, crude protein, NDF, ADF and ether extract as outlined in Toral et al. (2010).

On day 48 of the experiment, individual milk yield was recorded both at morning and evening sessions of milking, and milk samples were collected from each animal and stored at $4^{\circ} \mathrm{C}$ with a preservative (bronopol) until analysed for fat, crude protein, lactose and total solids by infrared spectrophotometry as described in Toral et al. (2010). Milk fat composition was determined in unpreserved samples stored at $-30^{\circ} \mathrm{C}$.

At the end of the experiment (day 49), the ewes were slaughtered humanely by an intravenous injection of a euthanasia drug (T-61, Intervet, Salamanca, Spain; 
$0.1 \mathrm{~mL} / \mathrm{kg} \mathrm{BW}$ ) and samples of the mammary secretory tissue, and subcutaneous (abdomen) and perirenal AT were collected under sterile conditions. The samples were immediately frozen in liquid $\mathrm{N}_{2}$ and stored at $-80^{\circ} \mathrm{C}$ until lipid and RNA extraction.

Table 1. Ingredients and chemical composition of the experimental diets.

\begin{tabular}{lcccc}
\hline \hline & \multicolumn{2}{c}{ Diet } & & \\
\cline { 2 - 3 } & Control & SO & SED $^{1}$ & $P^{2}$ \\
\hline Ingredient (g/kg of fresh matter) & & & & \\
Dehydrated alfalfa hay & 600 & 587 & - & - \\
Whole maize grain & 125 & 123 & - & - \\
$\quad$ Soybean meal solvent 44\% CP & 100 & 98 & - & - \\
Whole barley grain & 81 & 80 & - & - \\
Beet pulp, pellets & 45 & 44 & - & - \\
Molasses, liquid & 33 & 32 & - & - \\
Mineral-vitamin mix ${ }^{3}$ & 16 & 16 & - & - \\
Sunflower oil ${ }^{4}$ & 0 & 22 & - & - \\
Chemical composition (g/kg of DM) & & & & \\
Organic matter & 902 & 899 & 2.7 & $\mathrm{~ns}$ \\
Crude protein & 154 & 154 & 6.4 & $\mathrm{~ns}$ \\
NDF & 390 & 395 & 37.6 & $\mathrm{~ns}$ \\
ADF & 349 & 351 & 32.8 & $\mathrm{~ns}$ \\
Ether extract & 23 & 49 & 2.1 & $* * *$ \\
Fatty acid composition (g/100 g fatty acids) & & & & \\
14:0 & 0.96 & 0.42 & 0.114 & $* * *$ \\
16:0 & 21.68 & 12.15 & 0.489 & $* * *$ \\
cis-9 16:1 & 0.53 & 0.40 & 0.063 & + \\
18:0 & 4.48 & 3.81 & 0.027 & $* * *$ \\
cis-9 18:1 & 10.31 & 24.26 & 0.563 & $* * *$ \\
cis-11 18:1 & 0.58 & 0.71 & 0.014 & $* * *$ \\
cis-9, cis-12 18:2 & 29.93 & 44.85 & 0.928 & $* * *$ \\
18:3n-3 & 17.89 & 6.96 & 0.532 & $* * *$ \\
20:0 & 0.94 & 0.52 & 0.025 & $* * *$ \\
22:0 & 1.23 & 0.90 & 0.043 & $* * *$ \\
\hline \hline
\end{tabular}

${ }^{1} \mathrm{SED}=$ standard error of the difference.

${ }^{2}$ Probability of significant effects due to experimental diet. $\mathrm{ns}=$ non-significant $(P>0.10) ;+P$ $<0.10$; ${ }^{* * *} P<0.001$.

${ }^{3}$ Contained (g/kg): salts $\left[\mathrm{NaHCO}_{3}\right.$ (458.3), $\mathrm{CaCO}_{3}$ (250.0), $\mathrm{NaCl}$ (125.0)], minerals and vitamins (104.2), and wheat bran (62.5).

${ }^{4}$ Carrefour S.A. (Madrid, Spain). Contained (g/100 g fatty acids): 16:0 (5.5), 18:0 (4.4), cis-9 18:1 (36.4), and cis-9, cis-12 18:2 (50.3). 


\subsection{Lipid analysis}

Fatty acid methyl esters (FAME) of lipid in TMR and milk were prepared in a onestep extraction-transesterification procedure, as outlined previously by Shingfield et al. (2003). Total lipids in $500 \mathrm{mg}$ of mammary secretory tissue and in $30 \mathrm{mg}$ of subcutaneous and perirenal AT were extracted (Folch et al., 1957) and converted to FAME using a base-acid catalysed transesterification procedure (Glass, 1971). Methyl esters were separated and quantified by gas chromatography using a temperature gradient programme, and isomers of 18:1 were further resolved in a separate analysis under isothermal conditions (Shingfield et al., 2003). Peaks were identified based on retention time comparisons with authentic standards (from Nu-Chek Prep., Elysian, MN, USA; Sigma-Aldrich, Madrid, Spain; and Larodan Fine Chemicals $A B$, Malmö, Sweden) and milk samples for which the FA composition was determined based on gas chromatography analysis of FAME and GC-MS analysis of corresponding 4,4-dimethyloxazoline derivatives (Shingfield et al., 2006).

\section{4. $R N A$ isolation and quantitative PCR}

Total RNA from each tissue was isolated and purified further as described in Bernard et al. (2005b). Concentration and purity of RNA were determined by spectrophotometry using a Nano-Drop ND-1000 spectrophotometer (Nano-Drop Technologies, Wilmington, DE, USA). The RNA integrity was evaluated using the Agilent Bioanalyzer system (Agilent Technologies, Santa Clara, CA, USA), the RIN value for all the samples being 7.2 \pm 0.14 . Reverse-transcription qPCR was carried out (Bernard et al., 2005b) using specific primers and probes (Supplementary Table S1) for the following genes: acetyl-CoA carboxylase alpha (ACACA) and fatty acid synthase $(F A S N)$, involved in de novo FA synthesis; lipoprotein lipase $(L P L), \mathrm{CD} 36$ molecule (thrombospondin receptor) (CD36) and fatty acid-binding proteins $3(F A B P 3)$ and $4(F A B P 4)$, involved in the uptake and intracellular transport of FA; stearoyl-CoA desaturase (SCD1 and SCD5), involved in delta-9 
desaturation of FA; glycerol-3-phosphate acyltransferase mitochondrial (GPAM), involved in the esterification of FA to glycerol; carnitine palmitoyltransferase 2 (CPT2), involved in the mitochondrial oxidation of FA; fatty acid elongases 5 and 6 (ELOVL5 and ELOVL6), involved in the elongation to very long-chain and longchain FA, respectively; milk fat globule-EGF factor 8 (MFGE8) and xanthine dehydrogenase $(X D H)$, encoding two of the major proteins of the milk fat globule membrane; and the transcription factors: sterol regulatory element binding transcription factor 1 (SREBF1) and peroxisome proliferator-activated receptor gamma (PPARG). To account for variations in RNA integrity, RNA quantification and cDNA synthesis, mRNA abundance was normalized using the geometric mean of three housekeeping genes: peptidylprolyl isomerase A (PPIA), ubiquitiously-expressed prefoldin-like chaperone (UXT) and eukaryotic translation initiation factor 3 subunit $\mathrm{K}$ (EIF3K), which were identified as suitable internal controls among several tested (Bonnet et al., 2013). Abundance of gene transcripts was expressed as the log value of mRNA copy number relative to the geometric mean of the three housekeeping genes.

\subsection{Statistical analysis}

All statistical analyses were performed using the MIXED procedure of the SAS software package (version 9.3, SAS Institute Inc., Cary, NC, USA). Data of diet composition, animal performance, milk and mammary FA profiles, as well as mammary mRNA abundances of candidate genes were analysed by a one-way ANOVA with a statistical model that included the fixed effect of the diet. Twoway ANOVA was applied to data of FA composition and gene mRNA abundance of AT, the statistical model including the fixed effects of the diet, the adipose site and their interaction. In both cases, animals were nested within the treatment and used as the error term to contrast the effect of SO supplementation. Differences between means were evaluated using the "pdiff" option of the "lsmeans" statement of the MIXED procedure. They were declared significant at $P<0.05$ and 
considered as tendencies towards significance at $P<0.10$. Least square means are reported throughout.

\section{RESULTS}

\subsection{Animal performance and milk FA composition and secretion}

The inclusion of SO did not affect any of the animal performance parameters studied (i. e., DM intake, calculated energy balance, milk yield and milk fat, protein, lactose and total solid composition and yields; Table 2; $P>0.10$ ).

Table 2. Milk yield and composition in ewes fed a total mixed ration plus 0 (control diet) or $25 \mathrm{~g}$ of sunflower oil/kg of DM (SO diet).

\begin{tabular}{lccccc}
\hline \hline & \multicolumn{3}{c}{ Diet } & & \\
\cline { 2 - 3 } & Control & SO & & SED & $P^{2}$ \\
\hline DM intake (kg/day) & 2.73 & 2.74 & 0.095 & $\mathrm{~ns}$ \\
Energy balance (MJ/day) & 5.18 & 5.48 & & 0.698 & $\mathrm{~ns}$ \\
Yield (g/day) & & & & \\
$\quad$ Milk & 1280 & 1364 & 116.7 & $\mathrm{~ns}$ \\
Fat & 72 & 75 & 8.1 & $\mathrm{~ns}$ \\
$\quad$ Crude protein & 62 & 67 & 7.2 & $\mathrm{~ns}$ \\
$\quad$ Lactose & 63 & 66 & 6.1 & $\mathrm{~ns}$ \\
$\quad$ Total solids & 209 & 223 & & 20.5 & $\mathrm{~ns}$ \\
Composition (g/100 g) & & & & \\
$\quad$ Fat & 5.60 & 5.54 & 0.062 & $\mathrm{~ns}$ \\
$\quad$ Crude protein & 4.82 & 4.94 & & 0.296 & $\mathrm{~ns}$ \\
$\quad$ Lactose & 4.93 & 4.87 & 0.051 & $\mathrm{~ns}$ \\
$\quad$ Total solids & 16.32 & 16.43 & 0.657 & $\mathrm{~ns}$ \\
\hline \hline
\end{tabular}

${ }^{1} \mathrm{SED}=$ standard error of the difference.

${ }^{2}$ Probability of significant effects due to experimental diet. ns $=$ non-significant $(P>0.10)$.

${ }^{3}$ Calculated according to INRA (2007).

In contrast, as shown in Table 3 and Supplementary Table S2, milk FA profile changed noticeably. The dietary addition of SO decreased milk concentrations of $<16$ and 16-carbon FA and increased those of $>16$-carbon FA $(P<0.01)$. The proportions of 18:0, some 18:1 intermediates, such as cis-9 18:1, trans-11 18:1 and trans-10 18:1, and some conjugated linoleic acid (CLA) isomers (e. g., cis-9, trans-11 CLA) were augmented in response to dietary SO $(P<0.05)$. Lipid supplementation 
Table 3. FA composition of milk and mammary tissue from ewes fed a total mixed ration plus 0 (control diet) or $25 \mathrm{~g}$ of sunflower oil/kg of DM (SO diet).

\begin{tabular}{|c|c|c|c|c|c|c|c|c|}
\hline \multirow[b]{2}{*}{$\mathrm{FA}(\mathrm{g} / 100 \mathrm{~g}$ FA) } & \multicolumn{4}{|c|}{ Milk } & \multicolumn{4}{|c|}{ Mammary tissue } \\
\hline & Control & $\mathrm{SO}$ & $\mathrm{SED}^{1}$ & $P^{2}$ & Control & $\mathrm{SO}$ & $\mathrm{SED}^{1}$ & $P^{2}$ \\
\hline \multicolumn{9}{|l|}{ Saturated FA } \\
\hline 4:0 & 2.71 & 2.97 & 0.195 & ns & $\mathrm{nd}^{3}$ & nd & - & - \\
\hline $6: 0$ & 2.38 & 1.95 & 0.178 & * & nd & nd & - & - \\
\hline 8:0 & 2.51 & 1.74 & 0.182 & $* *$ & 0.06 & 0.05 & 0.016 & ns \\
\hline 10:0 & 8.49 & 4.99 & 0.579 & $* * *$ & 2.61 & 1.57 & 1.139 & ns \\
\hline 12:0 & 5.03 & 3.16 & 0.348 & $* *$ & 2.70 & 1.79 & 0.937 & ns \\
\hline 14:0 & 11.58 & 9.43 & 0.614 & $* *$ & 8.16 & 6.33 & 1.739 & ns \\
\hline $15: 0$ & 1.11 & 0.89 & 0.070 & * & 0.97 & 0.84 & 0.125 & ns \\
\hline $16: 0$ & 25.73 & 21.53 & 1.178 & $* *$ & 25.90 & 22.97 & 1.796 & ns \\
\hline $17: 0$ & 0.71 & 0.56 & 0.057 & $*$ & 1.10 & 0.93 & 0.087 & t \\
\hline anteiso-17:0 & 0.65 & 0.51 & 0.063 & * & 0.70 & 0.58 & 0.058 & t \\
\hline 18:0 & 7.64 & 11.90 & 0.778 & $* *$ & 12.01 & 14.95 & 1.859 & ns \\
\hline iso-18:0 & 0.09 & 0.06 & 0.008 & $* *$ & 0.12 & 0.10 & 0.012 & $\dagger$ \\
\hline \multicolumn{9}{|c|}{ Monounsaturated FA } \\
\hline cis-9 14:1 & 0.20 & 0.18 & 0.029 & ns & 0.19 & 0.16 & 0.035 & ns \\
\hline cis-9 16:1 & 0.78 & 0.67 & 0.078 & ns & 1.01 & 0.99 & 0.111 & ns \\
\hline cis-9 18:14 & 15.35 & 21.58 & 1.134 & $* *$ & 23.67 & 26.33 & 2.590 & $\mathrm{~ns}$ \\
\hline cis-12 18:1 & 0.35 & 0.71 & 0.046 & $* * *$ & 0.61 & 0.86 & 0.156 & ns \\
\hline trans-9 18:1 & 0.20 & 0.48 & 0.027 & $* * *$ & 0.31 & 0.47 & 0.084 & t \\
\hline trans-10 18:1 & 0.26 & 0.53 & 0.040 & $* * *$ & 0.42 & 0.49 & 0.101 & ns \\
\hline trans-11 18:1 & 1.32 & 2.36 & 0.422 & * & 1.73 & 2.46 & 0.506 & ns \\
\hline trans-12 18:1 & 0.32 & 0.81 & 0.059 & $* * *$ & 0.47 & 0.71 & 0.146 & ns \\
\hline
\end{tabular}


Table 3 (continued)

\begin{tabular}{|c|c|c|c|c|c|c|c|c|}
\hline \multirow[b]{2}{*}{$\mathrm{FA}(\mathrm{g} / 100 \mathrm{~g} \mathrm{FA})$} & \multicolumn{4}{|c|}{ Milk } & \multicolumn{4}{|c|}{ Mammary tissue } \\
\hline & Control & $\mathrm{SO}$ & $\mathrm{SED}^{1}$ & $P^{2}$ & Control & SO & SED $^{1}$ & $P^{2}$ \\
\hline \multicolumn{9}{|l|}{ Polyunsaturated FA } \\
\hline cis-9, cis-12 18:2 & 2.81 & 2.79 & 0.340 & ns & 4.40 & 4.34 & 0.555 & ns \\
\hline cis-9, trans-12 18:2 & 0.11 & 0.20 & 0.015 & $* * *$ & 0.11 & 0.15 & 0.029 & ns \\
\hline trans-9, cis-12 18:2 & 0.03 & 0.09 & 0.006 & $* * *$ & 0.05 & 0.08 & 0.016 & + \\
\hline trans -11 , cis-15 18:2 & 0.13 & 0.10 & 0.011 & * & 0.11 & 0.10 & 0.013 & ns \\
\hline cis-9, trans-11 CLA ${ }^{5}$ & 0.69 & 1.18 & 0.150 & * & 0.94 & 1.30 & 0.311 & ns \\
\hline Total CLA & 0.80 & 1.30 & 0.157 & * & 1.06 & 1.41 & 0.317 & ns \\
\hline $18: 3 n-3$ & 1.06 & 0.75 & 0.104 & * & 1.08 & 0.82 & 0.131 & + \\
\hline \multicolumn{9}{|l|}{ Summary } \\
\hline Saturated FA & 71.80 & 62.43 & 2.027 & $* *$ & 57.11 & 52.63 & 4.494 & ns \\
\hline Odd- and branched-chain FA & 5.64 & 4.48 & 0.377 & * & 5.17 & 4.47 & 0.512 & ns \\
\hline Monounsaturated FA & 21.96 & 30.88 & 1.511 & $* * *$ & 33.45 & 37.67 & 3.435 & ns \\
\hline PUFA $n-3$ & 1.58 & 1.17 & 0.126 & $* *$ & 2.15 & 1.84 & 0.245 & ns \\
\hline PUFA $n-6$ & 3.32 & 3.38 & 0.357 & ns & 6.57 & 6.71 & 0.972 & ns \\
\hline$<16$-carbon FA & 36.19 & 26.92 & 1.524 & $* * *$ & 16.08 & 11.89 & 4.143 & ns \\
\hline 16-carbon FA & 27.52 & 23.12 & 1.100 & $* *$ & 27.46 & 24.50 & 1.809 & ns \\
\hline$>16$-carbon FA & 36.29 & 49.97 & 2.429 & $* *$ & 56.46 & 63.62 & 1.645 & ns \\
\hline
\end{tabular}

${ }^{1} \mathrm{SED}=$ standard error of the difference.

${ }^{2}$ Probability of significant effects due to experimental diet. ns = non-significant $(P>0.10) ;+P<0.10 ;{ }^{*} P<0.05 ;{ }^{* *} P<0.01 ;{ }^{* * *} P<0.001$.

${ }^{3}$ Non-determined.

${ }^{4}$ In milk, contains cis-10, trans-13, trans-14, and trans-15 18:1 as minor components. In mammary tissue, contains trans-13, and trans-14 18:1 as minor components.

${ }^{5}$ In milk, contains trans-7, cis-9 CLA and trans-8, cis-10 CLA as minor components. 
also caused significant variations in other milk FA, such as decreases in 12:0, 14:0, 16:0, cis-9 17:1, trans-11, cis-15 18:2 and 18:3n-3, and increases in most minor 18:2 isomers.

The effect of dietary treatment on milk FA secretion is presented in Table 4 . The inclusion of SO significantly augmented the yield of $>16$-carbon FA, whereas no effect was detected on 16-carbon, and $<16$-carbon FA tended to be reduced $(P<$ 0.10). Reflecting the effects reported for milk FA concentrations, the secretion of 18:0, some 18:1 isomers, and total CLA (particularly cis-9, trans-11 CLA) was higher with the SO diet. On the other hand, SO supplementation did not affect saturates, odd- and branched-chain FA and PUFA $n-6$ secretion $(P>0.10)$.

Table 4. Milk FA yield in ewes fed a total mixed ration plus 0 (control diet) or $25 \mathrm{~g}$ of sunflower oil/kg of DM (SO diet).

\begin{tabular}{lcccc}
\hline \hline FA yield (g/day) & Control & SO & SED $^{1}$ & $P^{2}$ \\
\hline $4: 0+6: 0+8: 0$ & 5.02 & 4.71 & 0.613 & $\mathrm{~ns}$ \\
$10: 0+12: 0+14: 0$ & 16.86 & 12.34 & 2.031 & $\dagger$ \\
$16: 0$ & 17.21 & 15.09 & 1.953 & $\mathrm{~ns}$ \\
$18: 0$ & 5.13 & 8.35 & 0.957 & $*$ \\
cis-9 $18: 1^{3}$ & 10.32 & 15.07 & 1.457 & $*$ \\
trans-10 18:1 & 0.18 & 0.37 & 0.044 & $* *$ \\
trans-11 18:1 & 0.88 & 1.62 & 0.247 & $*$ \\
cis-9, cis-12 18:2 & 1.86 & 1.95 & 0.252 & $\mathrm{~ns}$ \\
cis-9, trans-11 CLA ${ }^{4}$ & 0.46 & 0.81 & 0.092 & $* *$ \\
Total CLA & 0.54 & 0.89 & 0.100 & $* *$ \\
$18: 3 n-3$ & 0.70 & 0.52 & 0.074 & $*$ \\
Saturated FA & 48.09 & 43.82 & 5.574 & $\mathrm{~ns}$ \\
Odd- and branched-chain FA & 3.81 & 3.13 & 0.513 & $\mathrm{~ns}$ \\
Monounsaturated FA & 14.77 & 21.52 & 1.939 & $* *$ \\
PUFA $n-3$ & 1.04 & 0.82 & 0.100 & $\dagger$ \\
PUFA $n$-6 & 2.19 & 2.36 & 0.283 & $\mathrm{~ns}$ \\
$<16-$ carbon FA & 24.25 & 18.92 & 2.801 & $\dagger$ \\
16-carbon FA & 18.42 & 16.20 & 2.087 & $\mathrm{~ns}$ \\
$>16-$ carbon FA & 24.34 & 34.88 & 3.170 & $*$ \\
cis-9 14:1/(14:0 + cis-9 14:1) & 0.02 & 0.02 & 0.002 & $\mathrm{~ns}$ \\
cis-9 16:1/(16:0 + cis-9 16:1) & 0.03 & 0.03 & 0.004 & $\mathrm{~ns}$ \\
cis-9, trans-11 CLA/(trans-11 18:1 + & & & & \\
cis-9, trans-11 CLA) & 0.35 & 0.34 & 0.022 & $\mathrm{~ns}$ \\
\hline \hline
\end{tabular}

${ }^{1} \mathrm{SED}=$ standard error of the difference.

${ }^{2}$ Probability of significant effects due to experimental diet. ns = non-significant $(P>0.10) ;+P$ $<0.10$; ${ }^{*} P<0.05$; ${ }^{* *} P<0.01$.

${ }^{3}$ Contains cis-10, trans-13, trans-14, and trans-15 18:1 as minor components.

${ }^{4}$ Contains trans-7, cis-9 CLA and trans-8, cis-10 CLA as minor components. 


\subsection{Mammary and adipose tissue FA composition}

Most of the diet-induced differences observed in milk FA composition were not detected in the mammary secretory tissue (Table 3 and Supplementary Table S3), where changes due to SO were limited to a tendency $(P<0.10)$ to a reduction of some OBCFA (17:0, anteiso-17:0 and iso-18:0) and a rise in some trans isomers (trans-5 to trans-9 18:1 and trans-9, cis-12 18:2). Major differences in the FA composition of AT were related to the effect of tissue site rather than to dietary treatment (Table 5 and Supplementary Table S4). The subcutaneous AT was richer in OBCFA, unsaturated FA, especially delta-9 desaturase products, other cis-18:1 and CLA isomers, and 20- and 22-carbon PUFA $n-3$ and $n-6(P<0.05)$, whereas the perirenal AT showed a higher content of 18:0 and trans-18:1 $(P<0.01)$. Some of the few differences in FA profile due to dietary treatments $(P<0.05)$ were in line with those mentioned for the mammary tissue (e. g., the decrease in 17:0 and 18:3n-3). Significant interactions between the effects of tissue site and diet were only observed for minor FA (namely trans-9, cis-12, cis-15 18:3 and iso-16:0; Table 5).

\section{3. $m R N A$ abundances of candidate genes in mammary and adipose tissues}

The mRNA abundance of some candidate genes (Tables 6 and 7 and Supplementary Table S5) was tissue specific: MFEG8, XDH and FABP3 were higher in the mammary tissue and FABP4 and ELOVL6 in AT. The consumption of SO did not significantly affect the mRNA abundance of the analysed genes in the mammary tissue but caused a decrease of GPAM and SREBF1 in both AT $(P<$ $0.05)$ and of PPARG in the subcutaneous depot (interaction diet $\times \mathrm{AT}, P<0.05$ ). There were also differences between AT, with SREBF1 being more abundant in the subcutaneous $(P<0.01)$ and $L P L(P<0.05)$ and CD36 $(P<0.10)$ in the perirenal AT. The mRNA abundance of MFGE8 $(P<0.001)$ and FABP3 $(P<0.05)$ also varied between depots but their levels were always very low. 
Table 5. FA composition of subcutaneous and perirenal AT from ewes fed a total mixed ration plus 0 (control diet) or $25 \mathrm{~g}$ of sunflower oil/kg of DM (SO diet).

\begin{tabular}{|c|c|c|c|c|c|c|c|c|}
\hline \multirow[b]{2}{*}{ FA (g/100 g FA) } & \multicolumn{2}{|c|}{ Subcutaneous AT } & \multicolumn{2}{|c|}{ Perirenal AT } & \multirow[b]{2}{*}{$\mathrm{SED}^{2}$} & \multicolumn{3}{|c|}{$P P^{1}$} \\
\hline & Control & $\mathrm{SO}$ & Control & $\mathrm{SO}$ & & $\mathrm{D}$ & $\mathrm{T}$ & $\mathrm{D} \times \mathrm{T}$ \\
\hline \multicolumn{9}{|l|}{ Saturated FA } \\
\hline $14: 0$ & 2.20 & 2.50 & 2.38 & 2.45 & 0.229 & ns & ns & ns \\
\hline 15:0 & 0.63 & 0.57 & 0.45 & 0.41 & 0.055 & ns & $* * *$ & ns \\
\hline $16: 0$ & 20.09 & 21.09 & 21.45 & 21.27 & 1.050 & ns & ns & ns \\
\hline iso- $16: 0$ & $0.17^{\mathrm{b}}$ & $0.20^{\mathrm{ab}}$ & $0.21^{\mathrm{a}}$ & $0.21^{\mathrm{a}}$ & 0.017 & ns & $* *$ & * \\
\hline $17: 0$ & 2.50 & 2.03 & 2.09 & 1.80 & 0.214 & + & $* *$ & ns \\
\hline anteiso-17:0 & 1.03 & 0.95 & 0.82 & 0.77 & 0.054 & ns & $* * *$ & ns \\
\hline $18: 0$ & 16.82 & 19.02 & 34.36 & 35.72 & 2.551 & ns & $* * *$ & ns \\
\hline iso-18:0 & 0.26 & 0.25 & 0.23 & 0.21 & 0.019 & ns & $* *$ & ns \\
\hline \multicolumn{9}{|l|}{ Monounsaturated FA } \\
\hline cis-9 14:1 & 0.09 & 0.08 & 0.02 & 0.03 & 0.014 & ns & $* * *$ & ns \\
\hline cis-9 16:1 & 1.15 & 1.07 & 0.47 & 0.48 & 0.148 & ns & $* * *$ & ns \\
\hline cis-9 17:1 & 1.33 & 0.88 & 0.39 & 0.33 & 0.223 & ns & $* * *$ & ns \\
\hline cis-9 18:1 & 35.68 & 34.24 & 22.15 & 22.46 & 2.046 & ns & $* * *$ & ns \\
\hline cis-10 18:133 & 2.62 & 2.58 & 1.46 & 1.75 & 0.234 & ns & $* * *$ & ns \\
\hline cis-11 18:1 & 1.54 & 1.30 & 0.91 & 0.83 & 0.137 & ns & $* * *$ & ns \\
\hline trans-10 18:1 & 0.51 & 0.55 & 0.50 & 0.43 & 0.187 & ns & ns & ns \\
\hline trans-11 18:1 & 1.78 & 1.95 & 2.54 & 2.27 & 0.267 & ns & $* *$ & ns \\
\hline trans-12 18:1 & 0.35 & 0.39 & 0.49 & 0.47 & 0.055 & ns & $* *$ & ns \\
\hline \multicolumn{9}{|l|}{ Polyunsaturated FA } \\
\hline cis-9, cis-12 18:2 & 1.88 & 1.90 & 2.02 & 1.85 & 0.154 & ns & ns & ns \\
\hline cis-9, trans-11 CLA & 0.64 & 0.57 & 0.35 & 0.31 & 0.076 & ns & $* * *$ & ns \\
\hline Total CLA & 0.73 & 0.64 & 0.44 & 0.37 & 0.087 & ns & $* * *$ & ns \\
\hline $18: 3 n-3$ & 0.83 & 0.70 & 0.83 & 0.59 & 0.080 & $*$ & $t$ & ns \\
\hline
\end{tabular}


Table 5. (continued)

\begin{tabular}{|c|c|c|c|c|c|c|c|c|}
\hline \multirow[b]{2}{*}{ FA (g/100 g FA) } & \multicolumn{2}{|c|}{ Subcutaneous AT } & \multicolumn{2}{|c|}{ Perirenal AT } & \multirow[b]{2}{*}{ SED $^{2}$} & \multicolumn{3}{|c|}{$P^{1}$} \\
\hline & Control & $\mathrm{SO}$ & Control & $\mathrm{SO}$ & & $\mathrm{D}$ & $\mathrm{T}$ & $\mathrm{D} \times \mathrm{T}$ \\
\hline trans -9, trans- 12, cis- $15-18: 3$ & $0.012^{\mathrm{b}}$ & $0.012^{\mathrm{bc}}$ & $0.014^{\mathrm{a}}$ & $0.010^{c}$ & 0.0011 & + & ns & * \\
\hline cis- 5, cis- 8, cis- 11, cis- $14-20: 4$ & 0.06 & 0.07 & 0.04 & 0.03 & 0.014 & ns & $* * *$ & ns \\
\hline cis-8, cis-11, cis-14, cis-17 20:4 & 0.01 & 0.02 & 0.01 & 0.01 & 0.003 & ns & ** & ns \\
\hline cis-7, cis-10, cis-13, cis-16, cis-19 22:5 & 0.09 & 0.10 & 0.05 & 0.04 & 0.023 & ns & $* * *$ & ns \\
\hline \multicolumn{9}{|l|}{ Summary } \\
\hline Saturated FA & 44.93 & 47.98 & 63.44 & 64.39 & 2.718 & ns & $* * *$ & ns \\
\hline Odd- and branched-chain FA & 5.22 & 4.69 & 4.63 & 4.21 & 0.321 & ns & ** & ns \\
\hline Monounsaturated FA & 49.56 & 46.99 & 31.95 & 31.70 & 2.492 & ns & $* * *$ & ns \\
\hline PUFA $n-3$ & 1.65 & 1.43 & 1.39 & 1.03 & 0.143 & + & $* * *$ & ns \\
\hline PUFA $n-6$ & 2.09 & 2.13 & 2.21 & 1.99 & 0.164 & ns & ns & + \\
\hline$<16$-carbon FA & 4.19 & 4.33 & 3.47 & 3.64 & 0.309 & ns & $* * *$ & ns \\
\hline 16-carbon FA & 22.93 & 23.50 & 22.85 & 22.58 & 1.058 & ns & ns & $\mathrm{ns}$ \\
\hline$>16$-carbon FA & 72.28 & 71.63 & 72.59 & 72.77 & 1.318 & ns & $\mathrm{ns}$ & ns \\
\hline
\end{tabular}

a,b,cMeans within a row with different superscripts differ significantly $(P<0.05)$.

${ }^{1}$ Probability of significant effects due to experimental diet $(\mathrm{D})$, tissue $(\mathrm{T})$, and their interaction $(\mathrm{D} \times \mathrm{T})$. ns $=$ non-significant $(P>0.10)$; $+P<0.10$; ${ }^{*} P<0.05$; ${ }^{* *} P<0.01 ;{ }^{* * *} P<0.001$.

${ }^{2} \mathrm{SED}=$ standard error of the difference.

${ }^{3}$ Contains trans-15 18:1 as a minor component. 
Table 6. mRNA relative abundance (log transformed data) of genes of the mammary tissue involved in lipid metabolism in ewes fed a total mixed ration plus 0 (control diet) or $25 \mathrm{~g}$ of sunflower oil/kg of $D M$ (SO diet). mRNA levels are expressed in arbitrary units determined as the abundance relative to the geometric mean of PPIA, UXT and EIF3K $m R N A$.

\begin{tabular}{lcccc}
\hline & \multicolumn{2}{c}{ Mammary tissue } & & \\
\cline { 2 - 3 } & Control & SO & SED $^{1}$ & $P^{2}$ \\
\hline Lipogenic genes & & & & \\
ACACA & 1.31 & 1.32 & 0.085 & $\mathrm{~ns}$ \\
FASN & 1.88 & 1.79 & 0.103 & $\mathrm{~ns}$ \\
LPL & 1.75 & 1.66 & 0.084 & $\mathrm{~ns}$ \\
CD36 & 1.86 & 1.92 & 0.056 & $\mathrm{~ns}$ \\
FABP3 & 1.63 & 1.59 & 0.138 & $\mathrm{~ns}$ \\
FABP4 & 0.54 & 0.55 & 0.064 & $\mathrm{~ns}$ \\
SCD1 & 1.63 & 1.63 & 0.076 & $\mathrm{~ns}$ \\
SCD5 & 1.73 & 1.78 & 0.077 & $\mathrm{~ns}$ \\
GPAM & 1.72 & 1.83 & 0.080 & $\mathrm{~ns}$ \\
CPT2 & 1.62 & 1.66 & 0.029 & $\mathrm{~ns}$ \\
ELOVL5 & 0.90 & 0.83 & 0.141 & $\mathrm{~ns}$ \\
ELOVL6 & -0.10 & -0.28 & 0.127 & $\mathrm{~ns}$ \\
MFGE8 & 1.72 & 1.73 & 0.108 & $\mathrm{~ns}$ \\
XDH & 1.81 & 1.82 & 0.079 & $\mathrm{~ns}$ \\
Transcription factors & & & & \\
SREBF1 & 1.79 & 1.76 & 0.102 & $\mathrm{~ns}$ \\
PPARG & 0.95 & 0.95 & 0.049 & $\mathrm{~ns}$ \\
\hline \hline
\end{tabular}

${ }^{1} \mathrm{SED}=$ standard error of the difference.

${ }^{2}$ Probability of significant effects due to experimental diet. $\mathrm{ns}=$ non-significant $(P>0.10)$.

\section{DISCUSSION}

\subsection{Animal performance and milk FA composition and secretion}

The present results provide further support that feeding a moderate amount $(2.5 \%$ $\mathrm{DM}$ ) of SO modulates milk FA composition in the absence of negative effects on ewe performance (Toral et al., 2010; Gómez-Cortés et al., 2011). The observed variations in milk FA composition and secretion (lower levels of medium-chain saturated FA, and greater of cis-9, trans-11 CLA and trans-11 18:1) are related to potentially beneficial effects for human health (Shingfield et al., 2008). Nevertheless, and in contrast to what was expected from previous experiments in ewes fed similar diets (e. g., Toral et al., 2010; Gómez-Cortés et al., 2011), the addition of SO increased the content of trans-10 18:1, together with that of trans-9 
and trans-12 18:1, which might be potentially detrimental to consumers (Shingfield et al., 2008). Their concentrations, however, were kept relatively low (less than $0.48,0.53$ and $0.81 \%$ of total FA, respectively).

Table 7. $m R N A$ relative abundance (log transformed data) of genes of subcutaneous and perirenal AT involved in lipid metabolism in ewes fed a total mixed ration plus 0 (control diet) or $25 \mathrm{~g}$ of sunflower oil/kg of DM (SO diet). mRNA levels are expressed in arbitrary units determined as the abundance relative to the geometric mean of PPIA, UXT and EIF3K $m R N A$.

\begin{tabular}{|c|c|c|c|c|c|c|c|c|}
\hline & \multicolumn{2}{|c|}{ Subcutaneous AT } & \multicolumn{2}{|c|}{ Perirenal AT } & \multirow[b]{2}{*}{ SED $^{2}$} & \multicolumn{3}{|c|}{$P^{11}$} \\
\hline & Control & $\mathrm{SO}$ & Control & $\mathrm{SO}$ & & $\mathrm{D}$ & $\mathrm{T}$ & $\mathrm{D} \times \mathrm{T}$ \\
\hline \multicolumn{9}{|c|}{ Lipogenic genes } \\
\hline$A C A C A$ & 1.82 & 1.58 & 1.60 & 1.58 & 0.183 & ns & ns & ns \\
\hline FASN & 1.38 & 1.14 & 1.19 & 1.14 & 0.245 & ns & ns & ns \\
\hline$L P L$ & 1.70 & 1.66 & 1.83 & 1.82 & 0.121 & ns & $*$ & ns \\
\hline CD36 & 1.82 & 1.81 & 1.88 & 1.90 & 0.063 & ns & + & ns \\
\hline FABP3 & -2.84 & -2.61 & -3.08 & -2.94 & 0.090 & ns & * & ns \\
\hline$F A B P 4$ & 1.87 & 1.83 & 1.87 & 1.91 & 0.075 & ns & ns & ns \\
\hline SCD1 & 1.69 & 1.71 & 1.67 & 1.56 & 0.164 & ns & ns & ns \\
\hline SCD5 & 1.00 & 1.02 & 1.19 & 1.17 & 0.166 & ns & ns & ns \\
\hline GPAM & 1.42 & 1.09 & 1.39 & 1.28 & 0.122 & $*$ & ns & ns \\
\hline CPT2 & 1.89 & 1.83 & 1.83 & 1.82 & 0.080 & ns & ns & ns \\
\hline ELOVL5 & 1.62 & 1.73 & 1.68 & 1.78 & 0.126 & ns & ns & ns \\
\hline ELOVL6 & 1.79 & 1.61 & 1.77 & 1.74 & 0.168 & ns & ns & ns \\
\hline MFGE8 & 0.202 & 0.231 & -0.002 & -0.052 & 0.1085 & ns & $* * *$ & ns \\
\hline$X D H$ & -2.74 & -2.83 & -2.82 & -2.82 & 0.196 & ns & ns & ns \\
\hline \multicolumn{9}{|c|}{ Transcription factors } \\
\hline SREBF1 & 1.60 & 1.40 & 1.39 & 1.10 & 0.106 & $*$ & $* *$ & ns \\
\hline PPARG & $1.92^{\mathrm{a}}$ & $1.77^{\mathrm{b}}$ & $1.87^{\mathrm{ab}}$ & $1.86^{\mathrm{a}}$ & 0.056 & ns & ns & * \\
\hline
\end{tabular}

a,bMeans within a row with different superscripts differ significantly $(P<0.05)$.

${ }^{1}$ Probability of significant effects due to experimental diet $(D)$, tissue $(T)$, and their interaction $(\mathrm{D} \times \mathrm{T}) . \mathrm{ns}=$ non-significant $(P>0.10) ;{ }^{\dagger} P<0.10 ;{ }^{*} P<0.05 ;{ }^{* *} P<0.01 ;{ }^{* * *} P<0.001$. ${ }^{2} \mathrm{SED}=$ standard error of the difference.

\subsection{Mammary lipid metabolism}

The tendency to a reduction in the secretion of $<16$-carbon FA and the lower milk percentages of $<16$ and 16-carbon FA in response to $\mathrm{SO}$ were not associated with changes in the mRNA abundance in the mammary secretory tissue of the candidate genes involved in de novo synthesis (i. e., ACACA and FASN). These results are consistent with data on gene expression and enzymatic activities reported in goats (Bernard et al., 2005b, 2008) and beef cows (Murrieta et al., 2006) 
fed high forage diets supplemented with plant oils and showing no reductions in milk fat synthesis.

The SO treatment also increased the proportion and secretion of milk longchain FA with no evidences of significant changes in the mRNA abundances of genes related with the uptake, transport and trafficking of long-chain FA in the mammary epithelial cells (i. e., LPL, CD36 and FABP3). These findings are consistent with previous research in dairy goats fed plant oils (Bernard et al., 2009a, 2009b; Ollier et al., 2009), suggesting that, in the absence of MFD, dietinduced changes in the content of milk long-chain FA might not be mediated by changes in the mRNA abundance of these particular candidate genes. They would also suggest that other regulatory mechanisms, such as post-transcriptional events linked to higher availability of 18-carbon FA, may be involved (Bernard et al., 2008). Nonetheless, given the high inter individual variation in gene expression and the low statistical power of the experiment, it cannot be ruled out that changes are also mediated by modifications in the candidate genes occurring below the level of detection.

With regard to delta-9 desaturation, despite the fact that SO modified the milk content of several substrates for (14:0, 16:0, 18:0 and trans-11 18:1) and products of (cis-9 18:1 and cis-9, trans-11 CLA) mammary SCD, no variation in the milk delta-9 desaturase indices (used as a proxy for the SCD activity) was observed, indicating that the SO treatment did not affect the activity of this enzyme. In the same way, no changes in the mRNA abundance of SCD1 and SCD5 were detected, suggesting that variations in the availability of substrates did not have a significant effect on the transcription of these genes.

This weak relationship between mammary SCD mRNA abundance and delta9 desaturase activity suggests a greater relevance of post-transcriptional regulatory events, such as mRNA stability, initiation of translation or turnover and activity regulation of the enzymatic protein, as observed in rodents (Ntambi, 1999) and ruminants (Bernard et al., 2013). 
Concerning the FA profile of the mammary tissue, there is very little literature reporting this data in ruminants (Christie, 1981; Toral et al., 2013) and no information is available in lactating ewes. In the present study, the virtual absence of shorter chain FA (4 to 9 carbons, which are present in the milk) would suggest not only that residual milk was well removed but also a minor contribution of unsecreted cytosolic lipid droplets to extracted lipids. Nevertheless, the few changes detected in the longer-chain FA in response to SO treatment suggest that variations in milk FA profile and secretion had no significant reflect in mammary FA composition, as previously observed in goats (Toral et al., 2013).

\subsection{Adipose tissue lipid metabolism}

Few changes were observed in lipogenic gene expression in subcutaneous and perirenal AT in response to SO treatment, which agrees with the lack of variation in energy balance and milk fat secretion and with data reported in cows and goats (Shingfield et al., 2010). However, the mRNA abundance of SREBF1 (which might have a central role in lipid synthesis; Harvatine et al., 2009) was decreased in response to SO in both $\mathrm{AT}$ (Table 7), and that of PPARG in the subcutaneous depot. Although changes in these transcription factors have been related with the upregulationup or downregulation of several lipogenic genes (Harvatine et al., 2009; Schmitt et al., 2011), no effect of SO on the mRNA abundance of genes related to lipogenesis was detected in the present study, and only GPAM mRNA showed a coordinated downregulation. Yet, since GPAM is involved in the esterification of FA to glycerol, this can hardly be related with the few effects of dietary SO on the FA composition of AT (reductions in 18:3n-3 and 17:0), which were probably caused by potential reductions in their availability for tissue uptake, as a result of the negative impact of $\mathrm{SO}$ on their ruminal concentration (Toral et al., 2012). Putative effects of SO on the availability of other long-chain FA, as inferred from their changes in milk fat or in the rumen fluid of ewes fed similar diets (Toral et al., 2012), had no substantial consequences on AT composition. Previous data in cows showed that a high availability of exogenous FA (through 
duodenal infusion of rapeseed oil) had no effect on AT lipogenic activities during early lactation, but caused a reduction after the lactation peak, when the activity was observed to increase in cows receiving the control diet because of variation in the energy balance (Chilliard et al., 1991). The few changes observed in the present study in mid-lactation ewes in positive energy balance are likely a result of the relatively low amount of supplemental SO.

When comparing AT, the greater content of saturated FA (mainly 18:0) and trans- 18:1 isomers (trans-11 and trans-12 18:1) in the perirenal AT, and of cis-18:1, cis-9, trans-11 CLA and n-3 PUFA in the subcutaneous AT, are in line with previous data in ruminants (Christie, 1981; Bas et al., 1987). These specificities due to tissue site have also been correlated with a depot-specific expression of lipogenic genes (Barber et al., 2000; Bernard et al., 2005a). However, the higher proportion of delta-9 desaturase products (mainly cis-9 14:1, cis-9 16:1, cis-9 17:1, cis-9 18:1 and cis-9, trans-11 CLA) and the lower proportion of delta-9 desaturase substrates (mainly 18:0 and trans-11 18:1) observed in subcutaneous compared with perirenal AT were not associated with differences in tissue mRNA abundance of SCD1, which is consistent with previous research in non-lactating sheep (Barber et al., 2000) but not in goats (Bernard et al., 2005b).

Subcutaneous and perirenal AT exhibited different levels of LPL and CD36 mRNA, suggesting potential divergences in FA uptake. The higher abundance of LPL transcripts in the perirenal AT is in line with results of the corresponding enzyme activity in lactating goats (Chilliard et al., 1981; Bernard et al., 2005a) and cows (Chilliard and Robelin, 1985). The lack of significant variation due to SO is also consistent with previous data in goats fed soyabeans (Bernard et al., 2005a).

Altogether, these results show only marginal changes in the mRNA abundance of the candidate genes and related transcription factors in AT. Although it cannot be dismissed that the lack of more significant differences is due to statistical power limitations of the experiment, they agree with previous observations in goats fed plant lipids (Bernard et al., 2005a, 2009a) and in sheep 
fed marine algae (Bichi et al., 2013) for which, respectively, an increase and a decrease of milk fat yield were observed.

\section{CONCLUSIONS}

This study provides novel and complementary information on the response to diet supplementation with SO in terms of milk FA composition and secretion, and FA profile and lipogenic gene expression of mammary and AT in lactating ewes. Dietary inclusion of a moderate amount $(2.5 \% \mathrm{DM})$ of SO for 7 weeks modifies the FA profile of the milk but has only slight effects on that of mammary and adipose tissues. No relationship is detected between these changes and results on mammary mRNA abundance of the candidate genes and transcription factors involved in lipid metabolism. Neither the marginal repercussion of SO feeding on the gene expression in subcutaneous and perirenal AT, after 7 weeks on the diet, is related with differences in FA profile between adipose sites or with milk fat secretion. Nevertheless, it cannot be ruled out that the response to linoleic-rich diets is mediated by other genes, post-transcriptional mechanisms, or particularly the availability of FA of dietary origin, which would support the need for further studies.

\section{REFERENCES}

Barber MC, Ward RJ, Richards SE, Salter AM, Buttery PJ, Vernon RG and Travers MT 2000. Ovine adipose tissue monounsaturated fat content is correlated to depot-specific expression of the stearoyl-CoA desaturase gene. J. Anim. Sci. 78, 62-68.

Bas P, Chilliard Y, Morand-Fehr P, Rouzeau A and Mandran N 1987. Composition des principaux tissus adipeux de la chèvre Alpine en fin de lactation. Ann. Zootech. 36, 361-374.

Bauman DE 2000. Regulation of nutrient partitioning during lactation: Homeostasis and homeorhesis revisited. Pages 311-328 in Ruminant physiology: digestion, metabolism, growth and reproduction, Cronje PB, ed. CABI Publishing, Wallingford, UK.

Bernard L, Bonnet M, Leroux C, Shingfield KJ and Chilliard Y 2009a. Effect of sunflower seed oil and linseed oil on tissue lipid metabolism, gene expression, and milk fatty acid secretion in Alpine goats fed maize silage-based diets. J. Dairy Sci. 92,385 6083-6094. 
Bernard L, Leroux C, Bonnet M, Rouel J, Martin P and Chilliard Y 2005a. Expression and nutritional regulation of lipogenic genes in mammary gland and adipose tissues of lactating goats. J. Dairy Res. 72, 250-255.

Bernard L, Leroux C and Chilliard Y 2008. Expression and nutritional regulation of lipogenic genes in the ruminant lactating mammary gland. Adv. Exp. Med. Biol. 606, 67-108.

Bernard L, Leroux C, Faulconnier Y, Durand D, Shingfield KJ and Chilliard Y 2009b. Effect of sunflower-seed oil or linseed oil on milk fatty acid secretion and lipogenic gene expression in goats fed hay-based diets. J. Dairy Res. 76, 241-248.

Bernard L, Leroux C and Chilliard Y 2013. Expression and nutritional regulation of stearoylCoA desaturase genes in the ruminant mammary gland: Relationship with milk fatty acid composition. Pages 161-193 in Stearoyl-CoA desaturase genes in lipid metabolism, Ntambi JM, ed. iSpringer Science+Business Media, New York, USA.

Bernard L, Rouel J, Leroux C, Ferlay A, Faulconnier Y, Legrand P and Chilliard Y 2005b. Mammary lipid metabolism and milk fatty acid secretion in alpine goats fed vegetable lipids. J. Dairy Sci. 88, 1478-1489.

Bichi E, Frutos P, Toral PG, Keisler D, Hervás G and Loor JJ 2013. Dietary marine algae and its influence on tissue gene network expression during milk fat depression in dairy ewes. Anim. Feed Sci. Tech. 186, 36-44.

Bonnet M, Bernard L, Bes S and Leroux C 2013. Selection of reference genes for quantitative realtime PCR normalisation in adipose tissue, muscle, liver and mammary gland from ruminants. Animal 7, 1344-1353.

Chilliard Y 1999. Metabolic adaptations and nutrient partitioning in the lactating animal. Pages 503-552 en Biology of lactation, Martinet J, Houdebine LM and Head H, eds. INRA Publishing, Paris, France.

Chilliard Y, Sauvant D, Bas P, Pascal G and Morand-Fehr P 1981. Importance relative et activités métaboliques des différents tissus adipeux de la chèvre laitière. Pages 80-89 in Nutrition et systèmes d'alimentation de la chèvre, Tome I, Morand-Fehr P, Borbouze A and de Simiane M, eds. INRA-ITOVIC, Tours, France.

Chilliard Y, Gagliostro G, Flechet J, Lefaivre J and Sebastian I 1991. Duodenal rapeseed oil infusion in early and midlactation cows. 5. Milk fatty-acids and adipose-tissue lipogenic activities. J. Dairy Sci. 74, 1844-1854.

Chilliard Y and Robelin J 1985. Activité lipoprotéine-lipasique de différents dépôts adipeux, et ses relations avec la taille des adipocytes chez la vache tarie en cours d'engraissement, ou en début de lactation. Reprod. Nutr. Dev. 25, 287-293.

Christie WW 1981. Lipid metabolism in ruminant animals. Pergamon Press Ltd., Oxford, UK.

Dervishi E, Joy M, Sanz A, Álvarez-Rodríguez J, Molino F and Calvo JH 2012. Forage preservation (grazing vs. hay) fed to ewes affects the fatty acid profile of milk and CPT1B gene expression in the sheep mammary gland. BMC Vet. Res. 8, 106.

Folch J, Lees M and Sloane-Stanley GH 1957. A simple method for the isolation and purification of total lipides from animal tissues. J. Biolog. Chem. 226, 497-509.

Glass RL 1971. Alcoholysis, saponification and the preparation of fatty acid methyl esters. Lipids 6, 919-925.

Gómez-Cortés P, de la Fuente MA, Toral PG, Frutos P, Juárez M and Hervás G 2011. Effects of different forage:concentrate ratios in dairy ewe diets supplemented with sunflower oil on animal performance and milk fatty acid profile. J. Dairy Sci. 94, 4578-4588. 
Harvatine KJ, Perfield JW and Bauman DE 2009. Expression of enzymes and key regulators of lipid synthesis is upregulated in adipose tissue during CLA-induced milk fat depression in dairy cows. J. Nutr. 139, 849-854.

INRA 2007. Alimentation des bovins, ovins et caprins. Besoins des Animaux: Valeur des aliments. Tables INRA 2007. INRA, Versailles, France.

Jacobs AAA, van Baal J, Smits MA, Taweel HZH, Hendriks WH, van Vuuren AM and Dijkstra J 2011. Effects of feeding rapeseed oil, soybean oil, or linseed oil on stearoyl-CoA desaturase expression in the mammary gland of dairy cows. J. Dairy Sci. 94, 874-887.

Murrieta CM, Hess BW, Scholljegerdes EJ, Engle TE, Hossner KL, Moss GE and Rule DC 2006. Evaluation of milk somatic cells as a source of mRNA for study of lipogenesis in the mammary gland of lactating beef cows supplemented with dietary high-linoleate safflower seeds. J. Anim. Sci. 84, 2399-2405.

Ntambi JM 1999. Regulation of stearoyl-CoA desaturase by polyunsaturated fatty acids and cholesterol. J. Lipid Res. 40, 1549-1558.

Ollier S, Leroux C, de la Foye A, Bernard L, Rouel J and Chilliard Y 2009. Whole intact rapeseeds or sunflower oil in high-forage or high-concentrate diets affects milk yield, milk composition, and mammary gene expression profile in goats. J. Dairy Sci. 92, 5544-5560.

Peterson DG, Matitashvili EA and Bauman DE 2003. Diet-induced milk fat depression in dairy cows results in increased trans-10, cis-12 CLA in milk fat and coordinate suppression of mRNA abundance for mammary enzymes involved in milk fat synthesis. J. Nutr. 133, 30983102.

Piperova LS, Teter BB, Bruckental I, Sampugna J, Mills SE, Yurawecz MP, Fritsche J, Ku K and Erdman RA 2000. Mammary lipogenic enzyme activity, trans fatty acids and conjugated linoleic acids are altered in lactating dairy cows fed a milk fat-depressing diet. J. Nutr. 130, 2568-2574.

Schmitt E, Ballou MA, Correa MN, DePeters EJ, Drackley JK and Loor JJ 2011. Dietary lipid during the transition period to manipulate subcutaneous adipose tissue peroxisome proliferator-activated receptor- $\gamma$ co-regulator and target gene expression. J. Dairy Sci. 94, 5913-5925.

Shingfield KJ, Ahvenjärvi S, Toivonen V, Äröla A, Nurmela KVV, Huhtanen P and Griinari JM 2003. Effect of dietary fish oil on biohydrogenation of fatty acids and milk fatty acid content in cows. Anim. Sci. 77, 165-179.

Shingfield KJ, Bernard L, Leroux C and Chilliard Y 2010. Role of trans fatty acids in the nutritional regulation of mammary lipogenesis in ruminants. Animal 4, 1140-1166.

Shingfield KJ, Chilliard Y, Toivonen V, Kairenius P and Givens DI 2008. Trans fatty acids and bioactive lipids in ruminant milk. Adv. Exp. Med. Biol. 606, 3-65.

Shingfield KJ, Reynolds CK, Hervás G, Griinari JM, Grandison AS and Beever DE 2006. Examination of the persistency of milk fatty acid composition responses to fish oil and sunflower oil in the diet of dairy cows. J. Dairy Sci. 89, 714-732.

Thering BJ, Graugnard DE, Piantoni P and Loor JJ. 2009. Adipose tissue lipogenic gene networks due to lipid feeding and milk fat depression in lactating cows. J. Dairy Sci. 92, 4290-4300.

Toral PG, Belenguer A, Shingfield KJ, Hervás G, Toivonen V and Frutos P 2012. Fatty acid composition and bacterial community changes in the rumen fluid of lactating sheep fed sunflower oil plus incremental levels of marine algae. J. Dairy Sci. 95, 794-806. 
Toral PG, Bernard L, Delavaud C, Gruffat D, Leroux C and Chilliard Y 2013. Effects of fish oil and additional starch on tissue fatty acid profile and lipogenic gene mRNA abundance in lactating goats fed a diet containing sunflower-seed oil. Animal 7, 948-956.

Toral PG, Hervás G, Gómez-Cortés P, Frutos P, Juárez M and de la Fuente MA 2010. Milk fatty acid profile and dairy sheep performance in response to diet supplementation with sunflower oil plus incremental levels of marine algae. J. Dairy Sci. 93, 1655-1667.

Vernon RG 1980. Lipid metabolism in the adipose tissue of ruminant animals. Prog. Lipid Res.19, 23-106.

\section{SUPPLEMENTARY MATERIAL}

Supplementary Table S1. Primer and probe sequences and conditions used for real-time reverse transcription-PCR.

Supplementary Table S2. Other fatty acids (FA) of milk from ewes fed a total mixed ration plus 0 (control diet) or $25 \mathrm{~g}$ of sunflower oil/kg of DM (SO diet).

(to complete the FA profile shown in Table 3)

Supplementary Table S3. Other fatty acids (FA) of mammary tissue from ewes fed a total mixed ration plus 0 (control diet) or $25 \mathrm{~g}$ of sunflower oil/kg of DM (SO diet).

(to complete the FA profile shown in Table 3)

Supplementary Table S4. Other fatty acids (FA) of subcutaneous and perirenal adipose tissues (AT) from ewes fed a total mixed ration plus 0 (control diet) or $25 \mathrm{~g}$ of sunflower oil/kg of DM (SO diet).

(to complete the FA profile shown in Table 5)

Supplementary Table S5. Real-time reverse transcription PCR performance of lipogenic genes, transcription factors and reference genes. 
Supplementary Table S1. Primer and probe sequences and conditions used for real-time reverse transcription-PCR.

\begin{tabular}{|c|c|c|c|c|c|}
\hline Gene & Encoded protein & Accession no. & Nucleotide sequence $\left(5^{\prime} \rightarrow 3^{\prime}\right)^{1}$ & $\mathrm{~T}^{2}$ & Source \\
\hline$A C A C A$ & Acetyl-CoA carboxylase alpha & NM_001009256 & $\begin{array}{l}\text { F: CAT GGA AAT GTA CGCGGA CC } \\
\text { R: GGT GGT AGA TGG GAA GGA GG } \\
\text { P: CGA GCG GAA GGA GCT GGA GAG CA }\end{array}$ & 58 & Bernard et al., 2005 \\
\hline FASN & Fatty acid synthase & DQ223929 & $\begin{array}{l}\text { F: ACA GCC TCT TCC TGT TTG ACG } \\
\text { R: CTC TGC ACG ATC AGC TCG AC } \\
\text { P: ATC TGG AGG CGC GTG TGG CAG CC }\end{array}$ & 60 & Bernard et al., 2005 \\
\hline$L P L$ & Lipoprotein lipase & AF228667 & $\begin{array}{l}\text { F: TTC AGA GGC TAT TAC TGG AAA TCC } \\
\text { R: ATG TCA ATC ACA GCA TTC ATT CTA CT } \\
\text { P: TTC CAG TGG TGC CGG AAC ACT CCT TC }\end{array}$ & 60 & Bernard et al., 2005 \\
\hline CD36 & CD36 molecule (thombospondin receptor) & X91503 & $\begin{array}{l}\text { F: ACA GAT GTG GCT TGA GCG TG } \\
\text { R: ACT GGG TCT GTG TTT TGC AGG }\end{array}$ & 58 & Bernard et al., 2012 \\
\hline FABP3 & Fatty acid-binding protein 3 , muscle and heart & ВT021486 & $\begin{array}{l}\text { F: CCT CTC CTT CCA CTG ACT GC } \\
\text { R: TTG ACC TCA GAG CAC CCT TT }\end{array}$ & 58 & Jurie et al., 2007 \\
\hline FABP4 & Fatty acid-binding protein 4 , adipocyte & NM_174314 & $\begin{array}{l}\text { F: GGT ACC TGG AAA CTT GTC TCC } \\
\text { R: CTG ATT TAA TGG TGA CCA CAC }\end{array}$ & 58 & Jurie et al., 2007 \\
\hline SCD1 & Stearoyl-CoA desaturase 1 & AF325499 & $\begin{array}{l}\text { F: TGC TGA CAA CTT ATC TGG ATG C } \\
\text { R: AAG GAA TCC TGC AAA CAG CTA } \\
\text { P: CCA GAG CCT GCA GAA GTG GCT GGT ATA }\end{array}$ & 60 & Bernard et al., 2005 \\
\hline SCD5 & Stearoyl-CoA desaturase 5 & NM_001112815 & $\begin{array}{l}\text { F: AGA AGG GGA GGA AGC TTG AC } \\
\text { R: GGA GGC CAG GAA GTA GGA GT }\end{array}$ & 58 & Lengi and Corl, 2007 \\
\hline GPAM & Glycerol-3-phosphate acyltransferase, mitochondrial & NM_001012282 & $\begin{array}{l}\text { F: ACC AGC AGT TCA TCA CCT TC } \\
\text { R: GTA CAC GGC AAC CCT CCT CT }\end{array}$ & 58 & Faulconnier et al., 2011 \\
\hline CPT2 & Carnitine palmitoyl transferase $1 \mathrm{~B}$ & NM_001045889 & $\begin{array}{l}\text { F: GCC TCT GTT TCA CCA GCA TAA } \\
\text { R: GGT GCT CAG GCA CCT CAT A }\end{array}$ & 60 & This study \\
\hline ELOVL5 & Fatty acid elongase 5 & NM_001046597 & $\begin{array}{l}\text { F: CTG AAT ACC TTC TCC ACT GGA GGA } \\
\text { R: GCT CCC TGT AAT ATG AAT GTG CAA }\end{array}$ & 60 & Faulconnier et al., 2011 \\
\hline ELOVL6 & Fatty acid elongase 6 & NP_001095625 & $\begin{array}{l}\text { F: CAA TAT TTT CCC AGG GTT } \\
\text { R: AGC TGC CCT TTC AAG AGT TG }\end{array}$ & 62 & This study \\
\hline
\end{tabular}


Supplementary Table S1. (continued)

\begin{tabular}{|c|c|c|c|c|c|}
\hline Gene & Encoded protein & Accession no. & Nucleotide sequence $\left(5^{\prime} \rightarrow 3^{\prime}\right)^{1}$ & $\mathrm{~T}^{2}$ & Source \\
\hline $\mathrm{XDH}$ & Xanthine dehydrogenase oxidase & X83508 & $\begin{array}{l}\text { F: GCC CTG CAG AAC ATG AAT CT } \\
\text { R: GCA CAA ATA CTT CCT ACA CCT }\end{array}$ & 60 & Ollier et al., 2009 \\
\hline PPARG & Peroxisome proliferator-activated receptor gamma & NM_177945 & $\begin{array}{l}\text { F: CAG GTT TGA AAG AAG CCA CA } \\
\text { R: TTA CGG AAA CGT CCC TCT TG }\end{array}$ & 60 & Bonnet et al., 2007 \\
\hline UXT & Ubiquitously-expressed transcript & BQ676558 & $\begin{array}{l}\text { F: TGT GGC CCT TGG ATA TGG TT } \\
\text { R: GGT TGT CGC TGA GCT CTG TG }\end{array}$ & 60 & Kadegowda et al., 2009 \\
\hline EIF3K & Eukaryotic translation initiation factor 3 subunit $\mathrm{K}$ & NM_001034489 & $\begin{array}{l}\text { F: CCA GGC CCA CCA AGA AGA A } \\
\text { R: TTA TAC CTT CCA GGA GGT CCA TGT }\end{array}$ & 60 & Kadegowda et al., 2009 \\
\hline
\end{tabular}

${ }^{1}$ Sequences: $\mathrm{F}=$ forward primer; $\mathrm{R}=$ reverse primer; $\mathrm{P}=$ Taqman probe.

${ }^{2} \mathrm{~T}=\mathrm{PCR}$ annealing temperature $\left({ }^{\circ} \mathrm{C}\right)$. 
Supplementary Table S2. Other fatty acids (FA) of milk from ewes fed a total mixed ration plus 0 (control diet) or $25 \mathrm{~g}$ of sunflower oil/kg of DM (SO diet).

(to complete the FA profile shown in Table 3)

\begin{tabular}{|c|c|c|c|c|}
\hline \multirow[b]{2}{*}{$\mathrm{FA}(\mathrm{g} / 100 \mathrm{~g} \mathrm{FA})$} & \multicolumn{2}{|c|}{ Milk } & \multirow[b]{2}{*}{$\mathrm{SED}^{1}$} & \multirow[b]{2}{*}{$P^{2}$} \\
\hline & Control & $\mathrm{SO}$ & & \\
\hline $5: 0$ & 0.02 & 0.01 & 0.002 & ns \\
\hline $7: 0$ & 0.03 & 0.02 & 0.003 & $* *$ \\
\hline 9:0 & 0.06 & 0.03 & 0.007 & $* *$ \\
\hline cis-9 10:1 & 0.30 & 0.18 & 0.024 & $* *$ \\
\hline 11:0 & 0.09 & 0.04 & 0.013 & $* *$ \\
\hline cis-9 12:1 & 0.09 & 0.04 & 0.010 & $* *$ \\
\hline trans-9 12:1 & 0.05 & 0.03 & 0.005 & $* *$ \\
\hline iso-13:0 & 0.03 & 0.02 & 0.002 & ns \\
\hline anteiso-13:0 & 0.010 & 0.007 & 0.0008 & $*$ \\
\hline 4,8,12-trimethyl-13:0 & 0.24 & 0.23 & 0.012 & ns \\
\hline iso-14:0 & 0.14 & 0.10 & 0.020 & $*$ \\
\hline cis-7 14:1 & 0.01 & 0.01 & 0.001 & ns \\
\hline cis-12 14:1 & 0.09 & 0.04 & 0.010 & $* *$ \\
\hline trans-5 14:1 & 0.02 & 0.02 & 0.003 & ns \\
\hline iso-15:0 & 0.28 & 0.26 & 0.021 & ns \\
\hline anteiso-15:0 & 0.52 & 0.42 & 0.047 & $*$ \\
\hline trans-5 15:1 & 0.18 & 0.13 & 0.019 & $*$ \\
\hline trans-6,-7 15:1 & 0.03 & 0.02 & 0.003 & $*$ \\
\hline iso- $16: 0$ & 0.04 & 0.04 & 0.004 & ns \\
\hline 3,7,11,15-tetramethyl-16:0 & 0.35 & 0.27 & 0.045 & ns \\
\hline cis-7 16:1 & 0.29 & 0.32 & 0.033 & ns \\
\hline cis-14 16:1 & 0.16 & 0.07 & 0.019 & $* *$ \\
\hline trans-5 16:1 & 0.03 & 0.02 & 0.004 & $*$ \\
\hline trans-6,-8 16:1 & 0.08 & 0.10 & 0.012 & ns \\
\hline trans-9 16:1 & 0.09 & 0.14 & 0.024 & $*$ \\
\hline iso-17:0 & 0.40 & 0.34 & 0.038 & ns \\
\hline cis-9 17:1 & 0.27 & 0.20 & 0.025 & $*$ \\
\hline trans-7 17:1 & 0.02 & 0.02 & 0.006 & ns \\
\hline 10-охо-18:0 & 0.03 & 0.03 & 0.005 & ns \\
\hline 13-охо-18:0 & 0.03 & 0.02 & 0.003 & $* *$ \\
\hline cis-11 18:1 & 0.55 & 0.53 & 0.037 & $\mathrm{~ns}$ \\
\hline cis-13 18:1 & 0.07 & 0.11 & 0.018 & $*$ \\
\hline cis-15 18:1 & 0.09 & 0.17 & 0.011 & $* * *$ \\
\hline cis-16 18:1 & 0.08 & 0.14 & 0.008 & $* * *$ \\
\hline trans-4 18:1 & 0.02 & 0.04 & 0.004 & $* *$ \\
\hline trans-5 18:1 & 0.02 & 0.04 & 0.004 & $* *$ \\
\hline trans-6,-7,-8 18:1 & 0.19 & 0.43 & 0.035 & $* *$ \\
\hline trans-16 18:13 & 0.35 & 0.66 & 0.046 & $* * *$ \\
\hline cis-9, cis-15 18:2 & 0.15 & 0.10 & 0.011 & $* *$ \\
\hline cis-9, trans-13 18:2 & 0.24 & 0.50 & 0.053 & $* *$ \\
\hline
\end{tabular}


Supplementary Table S2. (continued)

\begin{tabular}{|c|c|c|c|c|}
\hline \multirow[b]{2}{*}{ FA (g/100 g FA) } & \multicolumn{2}{|c|}{ Milk } & \multirow[b]{2}{*}{ SED $^{1}$} & \multirow[b]{2}{*}{$P^{2}$} \\
\hline & Control & SO & & \\
\hline $9,1418: 2$ & 0.07 & 0.15 & 0.014 & ** \\
\hline trans -9, trans -12 18:2 & 0.006 & 0.012 & 0.0015 & $* *$ \\
\hline trans-9, cis-11 CLA & 0.02 & 0.03 & 0.003 & * \\
\hline trans-10, cis-12 CLA & 0.005 & 0.007 & 0.0008 & * \\
\hline trans-11, trans-13 CLA & 0.01 & 0.01 & 0.002 & ns \\
\hline other trans, trans $\mathrm{CLA}^{4}$ & 0.08 & 0.07 & 0.008 & * \\
\hline cis-6, cis-9, cis-12 18:3 & 0.09 & 0.04 & 0.008 & $* *$ \\
\hline cis-9, trans- 11 , cis-15 18:3 & 0.02 & 0.02 & 0.008 & ns \\
\hline trans -9 , trans -12 , cis-15 18:3 & 0.02 & 0.01 & 0.001 & $* * *$ \\
\hline trans -9 , trans -12 , trans -15 18:3 & 0.04 & 0.04 & 0.009 & ns \\
\hline 19:0 $0^{5}$ & 0.12 & 0.11 & 0.011 & ns \\
\hline 20:0 & 0.26 & 0.29 & 0.014 & * \\
\hline cis-5 20:1 & 0.08 & 0.09 & 0.010 & $\mathrm{~ns}$ \\
\hline cis-11 20:1 & 0.07 & 0.07 & 0.009 & ns \\
\hline cis-11, cis-14 20:2 & 0.03 & 0.02 & 0.003 & * \\
\hline cis- 11 , cis- 14, cis-17 20:3 & 0.03 & 0.03 & 0.006 & ns \\
\hline cis-5, cis-8, cis-11, cis-14 20:4 & 0.20 & 0.18 & 0.016 & ns \\
\hline cis-8, cis-11, cis-14, cis-17 20:4 & 0.02 & 0.01 & 0.004 & * \\
\hline cis-5, cis-8, cis-11, cis-14, cis-17 20:5 & 0.06 & 0.05 & 0.003 & $* * *$ \\
\hline 21:0 & 0.11 & 0.09 & 0.007 & * \\
\hline 22:0 & 0.21 & 0.25 & 0.025 & ns \\
\hline cis-7, cis-10, cis-13, cis $1622: 4$ & 0.04 & 0.03 & 0.006 & ns \\
\hline cis-7, cis-10, cis-13, cis-16 , cis-19 22:5 & 0.15 & 0.12 & 0.018 & ns \\
\hline cis-4, cis-7, cis-10, cis-13, cis-16, cis-19 22:6 & 0.05 & 0.05 & 0.012 & ns \\
\hline 23:0 & 0.15 & 0.10 & 0.016 & * \\
\hline 24:0 & 0.07 & 0.06 & 0.004 & ns \\
\hline cis-15 24:1 & 0.03 & 0.03 & 0.007 & ns \\
\hline
\end{tabular}

${ }^{1}$ Standard error of the difference.

${ }^{2}$ Probability of significant effects due to experimental diet. ns $=$ non-significant $(P>0.10) ;{ }^{*} P$ $<0.05 ;{ }^{* *} P<0.01 ;{ }^{* * *} P<0.001$.

${ }^{3}$ Coelutes with 10,14 18:2.

${ }^{4}$ Sum of trans-7, trans-9 CLA + trans-8, trans-10 CLA + trans-9, trans-11 CLA + trans-10, trans12 CLA.

${ }^{5}$ Contains trans-11, trans-15 18:2 as a minor component. 
Supplementary Table S3. Other fatty acids (FA) of mammary tissue from ewes fed a total mixed ration plus 0 (control diet) or $25 \mathrm{~g}$ of sunflower oil/kg of DM (SO diet).

(to complete the FA profile shown in Table 3)

\begin{tabular}{|c|c|c|c|c|}
\hline \multirow[b]{2}{*}{$\mathrm{FA}(\mathrm{g} / 100 \mathrm{~g}$ FA) } & \multicolumn{2}{|c|}{ Mammary tissue } & \multirow[b]{2}{*}{ SED $^{1}$} & \multirow[b]{2}{*}{$P^{2}$} \\
\hline & Control & $\mathrm{SO}$ & & \\
\hline cis-9 12:1 & 0.06 & 0.04 & 0.025 & ns \\
\hline iso-15:0 & 0.19 & 0.21 & 0.040 & ns \\
\hline anteiso-15:0 & 0.42 & 0.35 & 0.078 & ns \\
\hline trans-9 14:1 & 0.06 & 0.01 & 0.043 & ns \\
\hline iso-16:0 & 0.33 & 0.29 & 0.056 & ns \\
\hline trans-9 16:1 & 0.08 & 0.11 & 0.026 & ns \\
\hline iso- $17: 0^{3}$ & 0.72 & 0.70 & 0.037 & ns \\
\hline cis-9 17:1 & 0.48 & 0.39 & 0.052 & ns \\
\hline cis-10 18:14 & 1.55 & 1.62 & 0.157 & ns \\
\hline cis-11 18:1 & 1.14 & 1.13 & 0.108 & ns \\
\hline cis-13 18:1 & 0.13 & 0.14 & 0.021 & ns \\
\hline cis-15 18:1 & 0.15 & 0.17 & 0.019 & ns \\
\hline cis-16 18:1 & 0.06 & 0.07 & 0.011 & ns \\
\hline trans-4 18:1 & 0.03 & 0.04 & 0.009 & ns \\
\hline trans-5 18:1 & 0.01 & 0.02 & 0.005 & $t$ \\
\hline trans-6,-7,-8 18:1 & 0.21 & 0.34 & 0.067 & + \\
\hline trans-16 18:1 & 0.34 & 0.42 & 0.056 & ns \\
\hline cis-9, cis-15 18:2 & 0.24 & 0.21 & 0.019 & ns \\
\hline cis-9, trans-13 18:2 & 0.36 & 0.43 & 0.074 & ns \\
\hline 9,14 18:2 & 0.16 & 0.20 & 0.026 & ns \\
\hline 10,14 18:2 & 0.12 & 0.16 & 0.030 & ns \\
\hline trans-9, cis-11 CLA & 0.05 & 0.06 & 0.012 & ns \\
\hline trans-10, cis-12 CLA & 0.02 & 0.02 & 0.007 & ns \\
\hline trans- 11 , trans-13 CLA & 0.05 & 0.03 & 0.012 & + \\
\hline other trans, trans CLA ${ }^{5}$ & 0.05 & 0.06 & 0.012 & ns \\
\hline cis-6, cis-9, cis-12 18:3 & 0.03 & 0.02 & 0.002 & $t$ \\
\hline 19:06 & 0.12 & 0.11 & 0.010 & ns \\
\hline 20:0 & 0.29 & 0.28 & 0.027 & ns \\
\hline cis-11 20:1 & 0.14 & 0.14 & 0.018 & ns \\
\hline cis-11, cis-14 20:2 & 0.09 & 0.07 & 0.024 & ns \\
\hline cis-8, cis-11, cis-14 20:3 & 0.08 & 0.09 & 0.018 & ns \\
\hline cis-11, cis-14, cis-17 20:3 & 0.03 & 0.02 & 0.018 & ns \\
\hline cis-5, cis- 8 , cis- 11, cis- 14 20:4 & 0.57 & 0.61 & 0.128 & ns \\
\hline cis-5, cis-8, cis-11, cis-14, cis-17 20:5 & 0.13 & 0.13 & 0.011 & ns \\
\hline 21:0 & 0.09 & 0.07 & 0.023 & ns \\
\hline 22:0 & 0.15 & 0.15 & 0.022 & ns \\
\hline
\end{tabular}


Supplementary Table S3. (continued)

\begin{tabular}{|c|c|c|c|c|}
\hline \multirow[b]{2}{*}{ FA (g/100 g FA) } & \multicolumn{2}{|c|}{ Mammary tissue } & \multirow[b]{2}{*}{ SED $^{1}$} & \multirow[b]{2}{*}{$P^{2}$} \\
\hline & Control & $\mathrm{SO}$ & & \\
\hline cis-7, cis-10, cis-13, cis-16 22:4 & 0.11 & 0.11 & 0.128 & ns \\
\hline cis-7, cis-10, cis-13, cis-16, cis-19 22:5 & 0.44 & 0.43 & 0.011 & ns \\
\hline cis-4, cis-7, cis-10, cis-13, cis-16, cis-19 22:6 & 0.13 & 0.13 & 0.031 & ns \\
\hline 23:0 & 0.09 & 0.07 & 0.019 & ns \\
\hline
\end{tabular}

${ }^{1}$ Standard error of the difference.

2Probability of significant effects due to experimental diet. ns = non-significant $(P>0.10)$; $\dagger$ $P<0.10$.

${ }^{3}$ Coelutes with cis-7 16:1

${ }^{4}$ Contains trans-15 18:1 as minor component.

${ }^{5}$ Sum of trans-7, trans-9 CLA + trans-8, trans-10 CLA + trans-9, trans-11 CLA + trans-10, trans12 CLA.

${ }^{6}$ Contains trans-11, trans-15-18:2 as minor component. 
Supplementary Table S4. Other fatty acids (FA) of subcutaneous and perirenal adipose tissues (AT) from ewes fed a total mixed ration plus 0 (control diet) or $25 \mathrm{~g}$ of sunflower oil/kg of DM (SO diet).

\begin{tabular}{|c|c|c|c|c|c|c|c|c|}
\hline \multirow[b]{2}{*}{ FA (g/100 g FA) } & \multicolumn{2}{|c|}{ Subcutaneous AT } & \multicolumn{2}{|c|}{ Perirenal AT } & \multirow[b]{2}{*}{$\mathrm{SED}^{2}$} & \multicolumn{3}{|c|}{$P^{1}$} \\
\hline & Control & $\mathrm{SO}$ & Control & $\mathrm{SO}$ & & $\mathrm{D}$ & $\mathrm{T}$ & $\mathrm{D} \times \mathrm{T}$ \\
\hline 10:0 & 0.06 & 0.09 & 0.08 & 0.11 & 0.010 & * & $*$ & $\mathrm{~ns}$ \\
\hline 12:0 & 0.06 & 0.07 & 0.05 & 0.06 & 0.005 & $\mathrm{~ns}$ & $* *$ & ns \\
\hline trans-9 14:1 & 0.05 & 0.03 & 0.01 & 0.01 & 0.008 & ns & $* *$ & $\mathrm{~ns}$ \\
\hline cis-13 18:1 & 0.15 & 0.13 & 0.10 & 0.08 & 0.013 & t & $* * *$ & ns \\
\hline iso-15:0 & 0.12 & 0.15 & 0.15 & 0.17 & 0.019 & $\mathrm{~ns}$ & $* * *$ & t \\
\hline anteiso-15:0 & 0.17 & 0.18 & 0.20 & 0.20 & 0.016 & ns & * & ns \\
\hline 3,7,11,15-tetramethyl-16:0 & 0.03 & 0.04 & 0.05 & 0.04 & 0.003 & ns & $* * *$ & + \\
\hline trans-9 16:1 & 0.04 & 0.03 & 0.03 & 0.03 & 0.003 & * & $* *$ & $\mathrm{~ns}$ \\
\hline iso-17:0 & 0.37 & 0.38 & 0.37 & 0.35 & 0.020 & ns & $t$ & ns \\
\hline iso-18:0 & 0.26 & 0.25 & 0.23 & 0.21 & 0.019 & ns & $* *$ & ns \\
\hline cis-12 18:1 & 0.53 & 0.54 & 0.49 & 0.47 & 0.039 & ns & * & ns \\
\hline cis-15 18:1 & 0.19 & 0.19 & 0.18 & 0.16 & 0.018 & ns & * & ns \\
\hline cis-16 18:1 & 0.08 & 0.08 & 0.09 & 0.08 & 0.008 & ns & $*$ & $\mathrm{~ns}$ \\
\hline trans-5 18:1 & 0.01 & 0.01 & 0.01 & 0.01 & 0.001 & ns & ns & ns \\
\hline trans- $6,-7,-818: 1$ & 0.26 & 0.23 & 0.32 & 0.25 & 0.052 & ns & ns & ns \\
\hline trans-9 18:1 & 0.25 & 0.25 & 0.25 & 0.25 & 0.023 & $\mathrm{~ns}$ & ns & $\mathrm{ns}$ \\
\hline trans-16 18:1 & 0.29 & 0.30 & 0.45 & 0.37 & 0.086 & ns & ns & ns \\
\hline cis-9, cis-15 18:2 & 0.36 & 0.33 & 0.21 & 0.18 & 0.030 & ns & $* * *$ & ns \\
\hline cis- 9 , trans -12 18:2 & 0.01 & 0.03 & 0.04 & $<0.01$ & 0.019 & ns & ns & 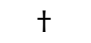 \\
\hline cis-9, trans-13 18:2 & 0.38 & 0.31 & 0.20 & 0.16 & 0.038 & ns & $* * *$ & ns \\
\hline 9,14 18:2 & 0.16 & 0.13 & 0.03 & 0.07 & 0.028 & $\mathrm{~ns}$ & $* * *$ & 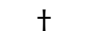 \\
\hline 10,14 18:2 & 0.10 & 0.09 & 0.10 & 0.08 & 0.013 & ns & ns & ns \\
\hline
\end{tabular}


Supplementary Table S4. (continued)

\begin{tabular}{|c|c|c|c|c|c|c|c|c|}
\hline \multirow[b]{2}{*}{ FA $(g / 100 \mathrm{~g} \mathrm{FA})$} & \multicolumn{2}{|c|}{ Subcutaneous AT } & \multicolumn{2}{|c|}{ Perirenal AT } & \multirow[b]{2}{*}{$\mathrm{SED}^{2}$} & \multicolumn{3}{|c|}{$P^{1}$} \\
\hline & Control & $\mathrm{SO}$ & Control & $\mathrm{SO}$ & & $\mathrm{D}$ & $\mathrm{T}$ & $\mathrm{D} \times \mathrm{T}$ \\
\hline trans-9, cis-12 18:2 & 0.03 & 0.03 & 0.03 & 0.03 & 0.003 & ns & ns & ns \\
\hline trans-11, cis-15 18:2 & 0.27 & 0.23 & 0.25 & 0.18 & 0.039 & ns & $t$ & ns \\
\hline trans-9, cis-11 CLA & 0.04 & 0.03 & 0.02 & 0.02 & 0.008 & ns & $* *$ & ns \\
\hline trans-10, cis-12 CLA & 0.011 & 0.011 & 0.013 & 0.012 & 0.0109 & ns & + & ns \\
\hline trans-11, trans-13 CLA & 0.03 & 0.03 & 0.06 & 0.04 & 0.012 & ns & $*$ & ns \\
\hline other trans, trans CLA ${ }^{3}$ & 0.04 & 0.05 & 0.04 & 0.04 & 0.003 & ns & ns & ns \\
\hline cis-6, cis-9, cis-12 18:3 & 0.02 & 0.02 & 0.02 & 0.02 & 0.004 & ns & ns & ns \\
\hline $19: 0^{4}$ & 0.21 & 0.22 & 0.31 & 0.28 & 0.019 & ns & $* * *$ & ns \\
\hline 20:0 & 0.08 & 0.10 & 0.16 & 0.18 & 0.015 & ns & $* * *$ & ns \\
\hline cis-11 20:1 & 0.14 & 0.15 & 0.15 & 0.13 & 0.030 & ns & ns & ns \\
\hline cis-11, cis-14 20:2 & 0.03 & 0.02 & 0.02 & 0.02 & 0.007 & ns & ns & ns \\
\hline cis-8, cis-11, cis-14 20:3 & 0.02 & 0.02 & 0.01 & 0.01 & 0.005 & ns & $*$ & ns \\
\hline cis-11, cis-14, cis-17 20:3 & 0.02 & 0.02 & 0.01 & 0.01 & 0.005 & ns & $*$ & ns \\
\hline cis-8, cis-11, cis-14, cis-17 20:4 & 0.01 & 0.02 & 0.01 & 0.01 & 0.003 & ns & $* *$ & ns \\
\hline 21:0 & $0.008^{c}$ & $0.012^{\mathrm{b}}$ & $0.021^{\mathrm{a}}$ & $0.021^{\mathrm{a}}$ & 0.0097 & ns & $* * *$ & $*$ \\
\hline 22:0 & 0.01 & 0.01 & 0.02 & 0.02 & 0.005 & ns & * & ns \\
\hline cis-7, cis-10, cis-13, cis-16 22:4 & 0.014 & 0.014 & 0.008 & 0.007 & 0.0050 & ns & $* *$ & ns \\
\hline cis-4, cis-7, cis-10, cis-13, cis-16, cis-19 22:6 & 0.02 & 0.02 & 0.01 & $<0.01$ & 0.009 & ns & * & ns \\
\hline 23:0 & 0.01 & 0.02 & 0.02 & 0.02 & 0.004 & ns & ns & ns \\
\hline
\end{tabular}

$\mathrm{a}, \mathrm{b}, \mathrm{c}$ Means within a row with different differ significantly $(P<0.05)$.

${ }^{1}$ Probability of significant effects due to experimental diet $(\mathrm{D})$, tissue $(\mathrm{T})$, and their interaction $(\mathrm{D} \times \mathrm{T})$. ns $=$ non-significant $(P>0.10)$; $+P<0.10$; ${ }^{*} P<0.05$; ${ }^{* *} P<0.01 ;{ }^{* * *} P<0.001$.

2Standard error of the difference.

${ }^{3}$ Sum of trans-7, trans-9 CLA + trans-8, trans-10-CLA + trans-9, trans-11 CLA + trans-10, trans-12 CLA.

${ }^{4}$ Contains trans-11, trans-15 18:2 as minor component. 
Supplementary Table S5. Real-time reverse transcription-PCR performance of lipogenic genes, transcription factors and reference genes.

\begin{tabular}{|c|c|c|c|c|c|}
\hline & \multicolumn{3}{|c|}{$\mathrm{Ct}^{1}$} & \multirow[b]{2}{*}{$\mathrm{R}^{2}$ statistic ${ }^{2}$} & \multirow[b]{2}{*}{ Efficiency $^{3}$} \\
\hline & Mammary tissue & Subcutaneous AT & Perirenal AT & & \\
\hline \multicolumn{6}{|c|}{ Lipogenic genes } \\
\hline$A C A C A$ & $32-33$ & $27-32$ & $28-32$ & 0.974 & 1.85 \\
\hline FASN & $27-29$ & $26-32$ & $27-31$ & 0.999 & 1.80 \\
\hline$L P L$ & $26-28$ & $23-29$ & $23-27$ & 0.998 & 1.54 \\
\hline CD36 & $18-19$ & $17-18$ & $16-17$ & 0.998 & 1.60 \\
\hline FABP3 & $15-17$ & $25-28$ & $26-28$ & 0.913 & 1.91 \\
\hline FABP4 & $27-28$ & $21-23$ & $21-23$ & 0.912 & 1.90 \\
\hline SCD1 & $25-26$ & $22-24$ & $21-25$ & 0.997 & 1.73 \\
\hline SCD5 & $31-33$ & $31-35$ & $31-33$ & 0.975 & 2.10 \\
\hline GPAM & $20-22$ & $19-22$ & $19-22$ & 0.996 & 1.76 \\
\hline СРT2 & $30-31$ & $26-28$ & $26-29$ & 0.995 & 1.78 \\
\hline ELOVL5 & $31-33$ & $26-30$ & $26-29$ & 0.984 & 1.92 \\
\hline ELOVL6 & $32-35$ & $23-27$ & $23-27$ & 0.999 & 1.72 \\
\hline MFGE8 & $21-23$ & $25-28$ & $26-28$ & 0.998 & 1.60 \\
\hline$X D H$ & $19-20$ & $34-35$ & $33-36$ & 0.965 & 1.81 \\
\hline \multicolumn{6}{|c|}{ Transcription factors } \\
\hline SREBF1 & $28-29$ & $27-29$ & $27-30$ & 0.996 & 2.02 \\
\hline PPARG & $28-29$ & $23-25$ & $23-25$ & 0.993 & 1.85 \\
\hline \multicolumn{6}{|c|}{ Reference genes } \\
\hline PPIA & $26-27$ & $24-26$ & $24-26$ & 0.979 & 1.83 \\
\hline UXT & $27-28$ & $26-27$ & $25-27$ & 0.998 & 1.94 \\
\hline EIF3K & $25-27$ & $23-26$ & $22-25$ & 0.997 & 1.74 \\
\hline
\end{tabular}

${ }^{1}$ Cycle threshold.

${ }^{2}$ Coefficient of determination $\left(\mathrm{R}^{2}\right)$ of the standard curve.

${ }^{3}$ The efficiency was calculated as $\left[10^{(-1 / \text { Slope })}\right]$. 


\section{Supplementary Material S1. References used in Supplementary Table S1.}

Bernard L, Leroux C, Rouel J, Bonnet M and Chilliard Y 2012. Effect of level and type of starchy concentrate on tissue lipid metabolism, gene expression, and milk fatty acid secretion in Alpine goats receiving a diet rich in sunflower oil. Brit. J. Nutr. 107, 1147-1159.

Bernard L, Rouel J, Leroux C, Ferlay A, Faulconnier Y, Legrand P and Chilliard Y 2005. Mammary lipid metabolism and milk fatty acid secretion in alpine goats fed vegetable lipids. J. Anim. Sci. 88, 1478-1489.

Bonnet M, Faulconnier Y, Leroux C, Jurie C, Cassar-Malek I, Bauchart D, Boulesteix P, Pethick D, Hocquette JF and Chilliard Y 2007. Glucose-6-phosphate dehydrogenase and leptin are related to marbling differences among Limousin and Angus or Japanese Black $\times$ Angus steers. J. Anim. Sci 85, 2882-2894.

Bonnet M, Leroux C, Faulconnier Y, Hocquette JF, Bocquier F, Martin P and Chilliard Y 2000. Lipoprotein lipase activity and mRNA are up-regulated by refeeding in adipose tissue and cardiac muscle of sheep. J. Nutr. 130, 749-756.

Faulconnier Y, Chilliard Y, Montazer Torbati MB and Leroux C 2011. The transcriptomic profiles of adipose tissues are modified by feed deprivation in lactating goats. Comp. Biochem. Phys. D 6, 139-149.

Harvatine KJ and Bauman DE 2006. SREBP1 and thyroid hormone responsive spot 14 (S14) are involved in the regulation of bovine mammary lipid synthesis during diet-induced milk fat depression and treatment with CLA. J. Nutr. 136, 2468-2474.

Jurie C, Cassar-Malek I, Bonnet M, Leroux C, Bauchart D, Boulesteix P, Pethick DW and Hocquette JF 2007. Adipocyte fatty acid-binding protein and mitochondrial enzyme activities in muscles as relevant indicators of marbling in cattle. J. Anim. Sci 85, 2660-2669.

Kadegowda AKG, Bionaz M, Thering B, Piperova LS, Erdman RA and Loor JJ 2009. Identification of internal control genes for quantitative polymerase chain reaction in mammary tissue of lactating cows receiving lipid supplements. J. Dairy Sci. 92, 2007-2019.

Lengi A and Corl B 2007. Identification and characterization of a novel bovine stearoyl-CoA desaturase isoform with homology to human SCD5. Lipids 42, 499-508.

Ollier S, Leroux C, de la Foye A, Bernard L, Rouel J and Chilliard Y 2009. Whole intact rapeseeds or sunflower oil in high-forage or high-concentrate diets affects milk yield, milk composition, and mammary gene expression profile in goats. J. Dairy Sci. 92, 5544-5560.

Ollier S, Robert-Granie C, Bernard L, Chilliard Y and Leroux C 2007. Mammary transcriptome analysis of food-deprived lactating goats highlights genes involved in milk secretion and programmed cell death. J. Nutr. 137, 560-567. 

CONCLUSIONES 

Primera. Según los resultados obtenidos mediante T-RFLP y pirosecuenciación 454, la adición de 0,8\% MS de microalgas marinas a la dieta de ovejas lecheras, de la cual se sabe que altera la biohidrogenación en el rumen, provoca pocos cambios en las bacterias filogenéticamente próximas al grupo Butyrivibrio. Esto sugiere una baja relevancia de dichas bacterias en el metabolismo lipídico ruminal en el ovino, aunque las variaciones observadas en algunas subpoblaciones poco abundantes no permiten descartar por completo su implicación en el proceso.

Segunda. Aunque la tecnología de pirosecuenciación 454 de alto rendimiento permite abarcar una mayor diversidad microbiana que la T-RFLP, los principales cambios en la comunidad bacteriana del rumen de ovejas alimentadas con microalgas marinas se detectan de forma similar con ambas técnicas moleculares. Dichas variaciones se observan fundamentalmente en los filos mayoritarios (es decir, Bacteroidetes, Firmicutes y Proteobacteria) y corresponden en su mayor parte a bacterias que aún no han sido cultivadas o clasificadas, lo que pone de manifiesto la complejidad de la microbiología ruminal del metabolismo lipídico.

Tercera. A pesar de las diferencias en la composición microbiana del contenido y el fluido ruminal, cuando el impacto de la suplementación con microalgas marinas sobre la diversidad y la estructura bacterianas se estudia mediante pirosecuenciación 454 o T-RFLP, los resultados son semejantes en ambas fracciones. Por lo tanto, en los casos en los que la canulación ruminal no es factible, las muestras de fluido pueden ser una alternativa válida para inferir el efecto de los lípidos sobre la estructura y la diversidad de la comunidad bacteriana.

Cuarta. Cuando se parte de fluido ruminal de ovejas que reciben aceite de pescado, ni la centrifugación diferencial para concentrar las bacterias filogenéticamente próximas a Quinella ovalis, ni el cultivo in vitro con un sustrato selectivo (manitol), permiten aumentar suficientemente su porcentaje para examinar su posible implicación en el metabolismo de los ácidos grasos. La 
estrategia alternativa, consistente en la comparación de suspensiones celulares con una estructura microbiana similar pero enriquecidas en este microorganismo o libres de él, tampoco resulta satisfactoria.

Quinta. En ovejas lecheras, la respuesta del perfil de ácidos grasos de la leche a la adición de aceite de girasol a la dieta $(2,5 \%$ MS) no se acompaña de cambios en la abundancia del ARNm de los genes de la lipogénesis (e. g., ACACA, FASN, LPL, CD36, FABP3, SCD1 y SCD5) o de los factores de transcripción (SREBF1 y PPARG) estudiados en el tejido mamario. Así mismo, la escasa influencia de la suplementación con aceite de girasol sobre la composición de los ácidos grasos de los tejidos adiposos perirrenal y subcutáneo parece no estar relacionada con las variaciones en la abundancia del ARNm de los genes analizados. Sin embargo, a pesar de la contribución aparentemente marginal de la expresión génica a la regulación nutricional del metabolismo lipídico en las condiciones estudiadas, no se puede descartar que los efectos del aceite de girasol estén mediados por cambios en otros genes o por mecanismos postranscripcionales. 
CONCLUSIONS 

First. The addition of $0.8 \% \mathrm{DM}$ of marine algae to the diet of dairy ewes, which is known to alter ruminal biohydrogenation, causes only few changes in bacteria phylogenetically close to the Butyrivibrio group, as determined by both T-RFLP and 454 pyrosequencing. The results suggest a low relevance of these bacteria in ruminal lipid metabolism in dairy sheep, although variations in some minor subpopulations within this group would not allow to completely rule out their involvement in the process.

Second. Although the high-throughput 454 pyrosequencing technique yields a greater coverage of rumen bacterial diversity than T-RFLP, the main marine algaeinduced changes in the bacterial community of sheep are detected similarly with both molecular approaches. These variations, observed especially in the major ruminal groups (namely Bacteroidetes, Firmicutes and Proteobacteria), correspond in most cases to as-yet uncultured or unclassified bacteria, which underlines the complexity of the rumen microbial ecology of fatty acid metabolism.

Third. Despite inherent differences between rumen content and fluid samples in their microbial composition, the impact of marine algae supplementation on bacterial diversity and structure is rather consistent in both types of samples when examined with either 454 pyrosequencing or T-RFLP. Therefore, when rumen cannulation is not feasible, fluid samples may be a valid alternative to infer the effect of dietary lipids on bacterial structure and diversity.

Fourth. Neither concentrating Quinella ovalis-like bacteria by differential centrifugation of rumen fluid from ewes fed fish oil, nor subsequent in vitro cultures with a selective substrate (mannitol), increase sufficiently the relative abundance of this group to examine its potential involvement in fatty acid metabolism. An alternative strategy, based on the comparison of two cell suspensions similar in microbial structure but rich in $Q$. ovalis or free of this microorganism, is not satisfactory either. 
Fifth. In dairy ewes, the response in milk fatty acid composition to dietary sunflower oil $(2.5 \% \mathrm{DM})$ is not accompanied by significant changes in the mammary mRNA abundance of the studied lipogenic genes (e. g., ACACA, FASN, $L P L, C D 36, F A B P 3, S C D 1$ and SCD5) and transcription factors (SREBF1 and PPARG). Similarly, the little influence of sunflower oil supplementation on the fatty acid profile of perirenal and subcutaneous adipose tissues does not appear to be related with observed variations in gene mRNA abundance. However, despite the apparent marginal contribution of gene expression to the nutritional regulation of lipid metabolism in the studied conditions, it cannot be ruled out that the effects of sunflower oil are mediated by other genes or posttranscriptional mechanisms. 